\title{
New Chemical and Stereochemical Applications of Organoiron Complexes
}

\author{
Alexander J. Fatiadi \\ National Institute of Standards \\ and Technology, \\ Gaithersburg, MD 20899
}

The objective of this review is to provide a current overview of the rapidly developing chemistry of organometallic complexes and particularly organoiron complexes useful in asymmetric and stereoselective reactions. Also covered are stereoselective reactions of $\alpha, \beta$-unsaturated acyl ligands bound to the chiral auxiliary $\left[\left(\eta^{5}-\right.\right.$ $\left.\left.\mathrm{C}_{5} \mathrm{H}_{5}\right) \mathrm{Fe}(\mathrm{CO})\left(\mathrm{PPh}_{3}\right)\right]$ and new applications of organoiron complexes in the synthesis of natural products. The mechanistic aspects and stabilizing effects of the $\mathrm{Fe}(\mathrm{CO})_{3}$ group for alkenes or conjugated dienes are discussed. A brief summary of recent work on the special role of iron in biological reactions is also included.

Key words: applications; asymmctric synthesis; chemistry; chiral auxiliaries; enantiomers; iron-carbene complexes; organoiron complexes; overview; iron in biological systems; stereoselective reactions.

Accepted: August 6, 1990

\section{Contents}

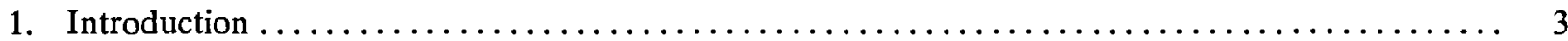

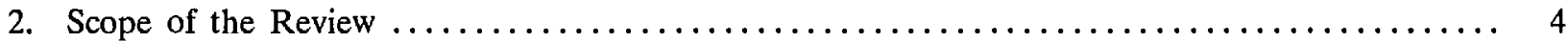

3. Tricarbonyliron $\mathrm{Fe}(\mathrm{CO})_{3}$ Group Stabilization of Diene Systems................... 5

3.1 Iron-Stabilized Cyclic Dienes in Regio- and Stereocontrolled Synthesis ............. 6

4. Iron-Stabilized Carbenes in Organic Synthesis $\ldots \ldots \ldots \ldots \ldots \ldots \ldots \ldots \ldots \ldots \ldots \ldots \ldots \ldots, 8$

4.1 Preparation and Some Reactions of Iron-Carbene Complexes.................... 10

4.2 Reactions of Electrophilic Iron-Carbene Complexes $\ldots \ldots \ldots \ldots \ldots \ldots \ldots \ldots \ldots \ldots \ldots \ldots$

4.3 Additional Reactions of Iron-Carbene Complexes $\ldots \ldots \ldots \ldots \ldots \ldots \ldots \ldots \ldots \ldots \ldots \ldots . \ldots \ldots$

4.4 New Iron-Nitrene Complexes for Synthesis $\ldots \ldots \ldots \ldots \ldots \ldots \ldots \ldots \ldots \ldots \ldots \ldots \ldots \ldots \ldots \ldots$

5. Iron-Catalyzed Synthesis and Some Reactions of Cyclopropanes. Cyclopropanation Reaction. ... 13

5.1 Synthesis of Cyclopropanes via Carbene-Transfer Reaction $\ldots \ldots \ldots \ldots \ldots \ldots \ldots \ldots \ldots \ldots 14$

5.2 Stereoselective Synthesis of Cyclopropanes. $\ldots \ldots \ldots \ldots \ldots \ldots \ldots \ldots \ldots \ldots \ldots \ldots \ldots \ldots \ldots$

5.3 Metal-Induced Rearrangements of Cyclopropyl Alkenes $\ldots \ldots \ldots \ldots \ldots \ldots \ldots \ldots \ldots \ldots \ldots, 18$

5.4 A New Class of $\sigma$-Cyclopropenyliron Complexes $\ldots \ldots \ldots \ldots \ldots \ldots \ldots \ldots \ldots \ldots \ldots \ldots \ldots$

6. Stereochemical Control of Organic Reactions by Use of Chiral Organoiron Reagents ......... 21

6.1 Stereoselective Synthesis via Chiral Auxiliary $\left[\left(\eta^{5}-\mathrm{C}_{5} \mathrm{H}_{5}\right) \mathrm{Fe}(\mathrm{CO})\left(\mathrm{PPh}_{3}\right)\right]$.

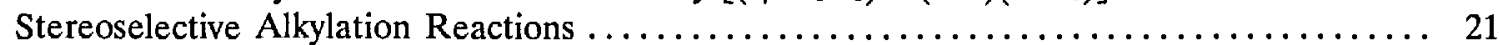

6.2 Diastereocontrol of Aldol Reactions via Chiral Iron Acyl Complexes.

Stereochemical Effect of Metal Counterions ............................ 22

6.3 Stereoselective Synthesis of $\beta$-Lactams via Chiral Iron Acyl Complexes ............. 25 
6.4 Stereoselective Michael Addition via Chiral Iron Acyl Complexes $\ldots \ldots \ldots \ldots \ldots \ldots \ldots \ldots 28$

6.5 Tricarbonyliron Complexes in Synthesis of 1,4-Diketones....................... 29

6.6 Davies' Chiral Auxiliary Reagent for Synthesis of Unsaturated Iron Acyls ............ 30

6.7 Asymmetric Diels-Alder Reactions via Chiral Iron Acyl Complexes................. 33

$6.8 \quad\left[\left(\eta^{5}-\mathrm{C}_{5} \mathrm{H}_{5}\right) \mathrm{Fe}(\mathrm{CO})_{2}\left(\eta^{1}-\mathrm{C}_{5} \mathrm{H}_{5}\right)\right]$ a Useful Synthetic Equivalent of Substituted

1,3-Cyclopentadienes in Cycloadditions Reactions ............................ 35

6.9 Stereoselective Syntheses of Coordinated Phosphines $\ldots \ldots \ldots \ldots \ldots \ldots \ldots \ldots \ldots \ldots \ldots, 36$

7. Synthesis of Natural Products via Iron Carbonyls ............................. 36

7.1 Synthesis of Alkaloid ( \pm )-Limaspermine. The Pearson Synthetic Approach via

Cyclohexadienyliron Complexes.................................... 36

7.2 Synthesis of Alkaloid $( \pm)-O$-Methyljoubertiamine and Other Natural Products via

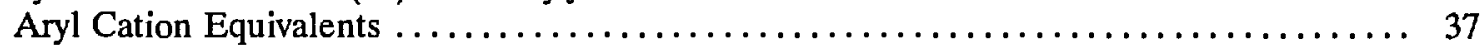

7.3 Synthetic Applications of Cycloheptadienyliron Complexes to Natural Products .......... 39

7.4 Natural-Product Synthesis via Polybromo Ketone-Iron Carbonyl Reaction. The

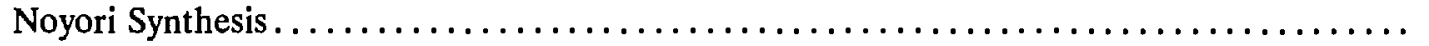

7.4.1 Reaction of the Noyori Intermediate with Alkenes and Dienes ............. 40

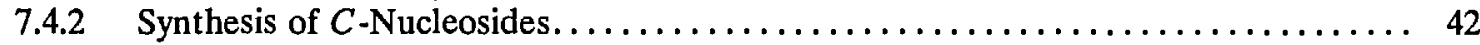

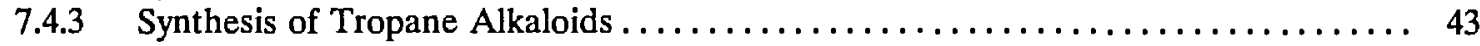

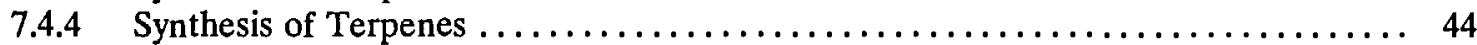

7.4.5 Other Related Syntheses.................................... 44

7.5 Synthesis of $\beta$-Lactam Antibiotic ( + -Thienamycin via an Intermediate

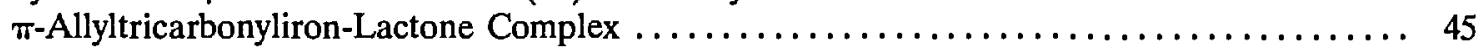

7.6 Highly Enantioselective Synthesis of Leucotriene $B_{4}$ and Its 14,15-Didehydro

Derivative by the Use of Butadiene Tricarbonyl-Iron Complex................ 45

7.7 Synthesis of Natural Products and Drugs via Chiral Organoiron Enolates. Use of

Enolate from the Davies' Chiral Auxiliary $\left[\left(\eta^{5}-\mathrm{C}_{5} \mathrm{H}_{5}\right) \mathrm{Fe}(\mathrm{CO})\left(\mathrm{PPh}_{3}\right)\right] \ldots \ldots \ldots \ldots \ldots \ldots .48$

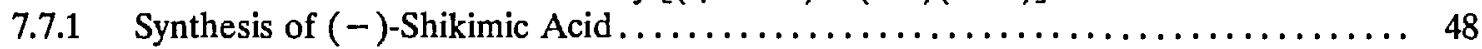

7.7.2 Synthesis of the Bark Beetle Sex Pheromone $\ldots \ldots \ldots \ldots \ldots \ldots \ldots \ldots \ldots \ldots \ldots \ldots \ldots$

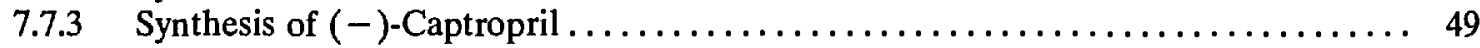

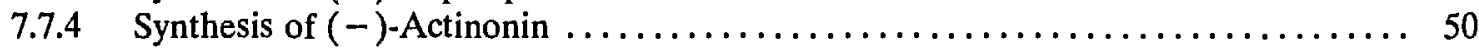

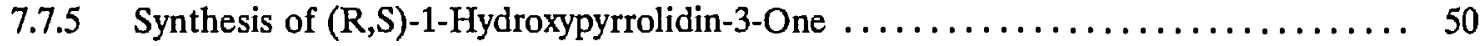

7.8 Asymmetric Synthesis with Chiral Ferrocenylamine Ligands: The Importance

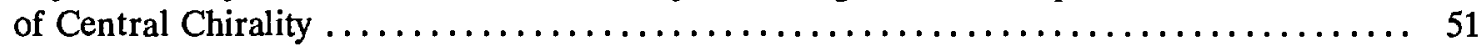

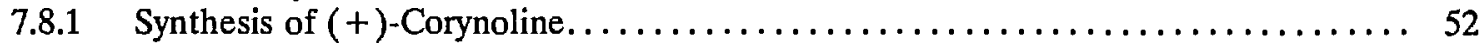

8. Miscellaneous Recent Results....................................... 53

8.1 Organoiron Complexes in Carbon-Carbon Bond-Formation Reactions ............. 53

8.1.1 Enantioselectivity in $\mathrm{Bu}_{4} \mathrm{~N}\left[\mathrm{Fe}(\mathrm{CO})_{3} \mathrm{NO}\right]$-Catalyzed Nucleophilic Substitution

of Optically Active Allylic Carbonates with Malonate................. 53

8.1.2 Regioselective Addition of Nucleophiles to Cationic Diiron

$\mu$-Vinylcarbyne Complexes ................................ 53

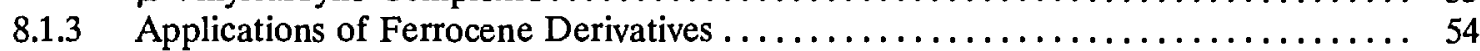

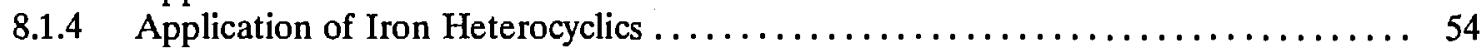

8.1.5 Use of Optically Active Iron-Alkene Complexes $\ldots \ldots \ldots \ldots \ldots \ldots \ldots \ldots \ldots \ldots$

8.2 New Reactions of Bridged Organoiron Complexes ......................... 55

8.3 Enzymatic Resolution of Chiral Butadiene Tricarbonyliron Complexes by

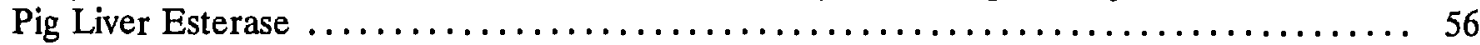

8.4 The Stereoselective Reaction of Norbornyl Aldehydes with Diiron

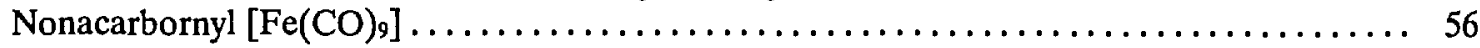

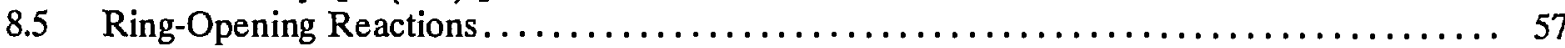

8.5.1 Novel Ring-Opening Reaction of Norbornadiene (Tricarbonyl)Iron.......... 57

8.5.2 Step-Wise Cleavage of 1,1-Bis(Diphenylphosphino)Ethylene Iron Complex ....... 57

8.6 Reaction of Organosulfur Ligands in Bridged Ironcarbonyls $\ldots \ldots \ldots \ldots \ldots \ldots \ldots \ldots \ldots \ldots$

8.7 Photoinduced Reactions Involving Ironcarbonyl Complexes. . . . . . . . . . . . . . . . 59

8.8 Other Recent Results ......................................... 62 
8.8.1 Novel Phosphorous-Bridging Iron Carbonyl Complexes $\ldots \ldots \ldots \ldots \ldots \ldots \ldots \ldots \ldots 2$

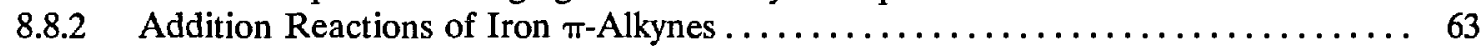

8.8.3 Some Recent Work on the Chemistry of Ferrocenes and Porphyrins........... 63

8.8.4 Some Recent Pertinent References .............................. 64

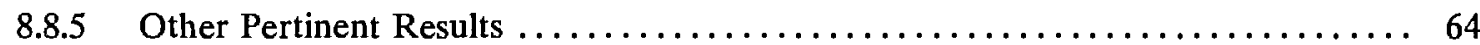

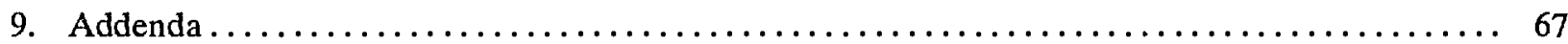

9.1 Mononuclear Iron Complexes. Iron Carbene Complexes $\ldots \ldots \ldots \ldots \ldots \ldots \ldots \ldots \ldots \ldots . \ldots 6$

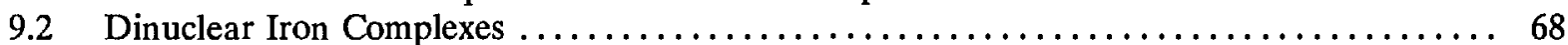

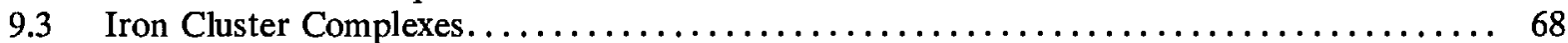

9.4 Iron-Main Group Element Complexes.................................... 69

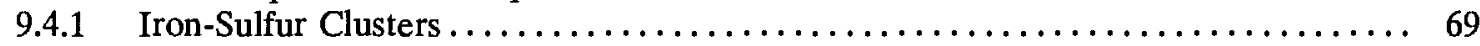

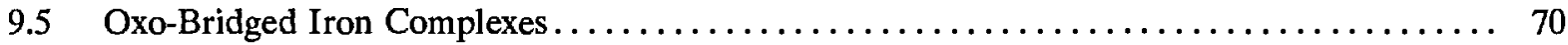

9.5.1 Novel Iron-Based Catalyst for Dioxygenation $\ldots \ldots \ldots \ldots \ldots \ldots \ldots \ldots \ldots \ldots \ldots$

9.5.2 Biological and Enzymatic Application of Oxo-Bridged Iron Clusters . . . . . . . . 70

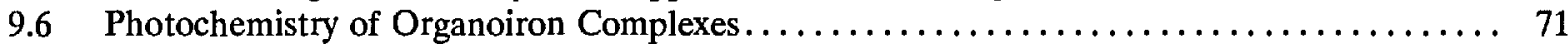

9.7 Gas-Phase Reaction of Organoiron Complexes and Iron Ions $\ldots \ldots \ldots \ldots \ldots \ldots \ldots \ldots \ldots \ldots$

9.8 New Ferrocene Chemistry. Novel Multiple-Decker Ferrocenes. . . . . . . . . . . . . . . . 71

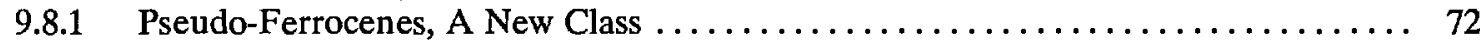

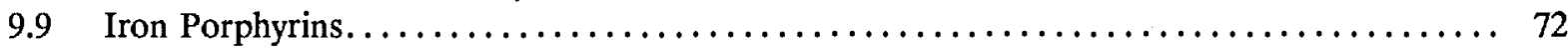

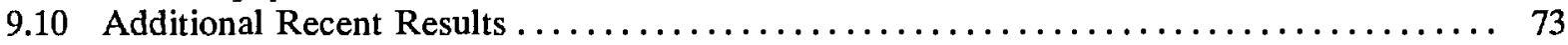

9.10.1 New Carbon-Carbon Bond-Forming Reactions. New Seven-Membered

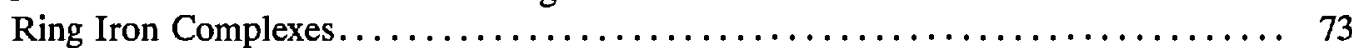

9.10.2 Tripodal Polyphosphine Metal Complexes.......................... 74

9.10.3 Novel Charge-Transfer Complexes and Ferromagnets.................. 74

9.10.4 Recent Physical, Spectral, and Catalytic Studies of Organoiron Complexes ....... 75

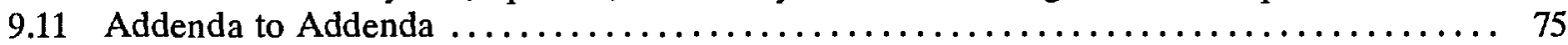

9.11.1 New Carbon-Carbon Bond-Forming Reactions......................... 75

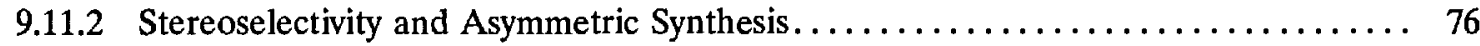

9.11.3 Ferrocene and Ferrocene Derivatives.............................. 77

9.11 .4 Porphyrins and Cytochrome Enzymes............................... 77

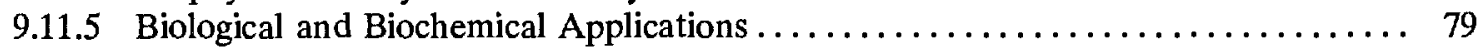

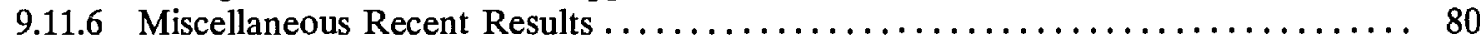

9.11.7 Additional Miscellaneous Results $\ldots \ldots \ldots \ldots \ldots \ldots \ldots \ldots \ldots \ldots \ldots \ldots \ldots \ldots \ldots \ldots$

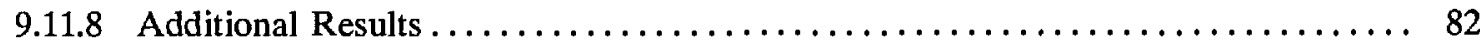

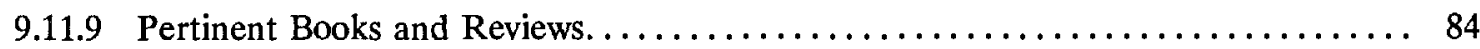

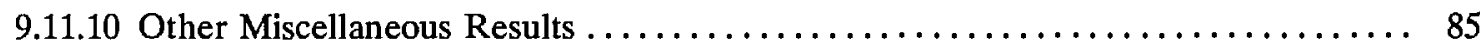

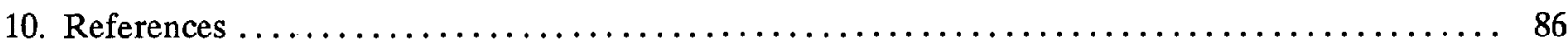

\section{Introduction}

Transition-metal organometallic chemistry has been one of the most active areas of chemical research for the past 35 years. A significant part of this research has been concerned with the use of transition-metal organometallics in organic synthesis [1].

Transition metals play an important role in both organic and inorganic chemistry. Transition-metalmediated organic synthesis [1,2], catalysis [3-5], biomolecular synthesis [6], and organometallic conductors [7] are all current subjects of intense interest. Of particular note are the applications of organotransitionmetal chemistry to the problems of constructing carbocyclic rings [8-9].

This review is primarily concerned with recent synthetic applications of organoiron complexes, with only brief comparison to their strong competitors namely, organochromium complexes. Metal carbonyl complexes are readily available, and serve as starting materials for the preparation of many other organometallic compounds. In the case of organoiron complexes, the synthesis begins with the use of such stable iron carbonyl reagents as pentacarbonyliron $\mathrm{Fe}(\mathrm{CO})_{5}$ (b.p. $103{ }^{\circ} \mathrm{C} / 760$ Torr), the dimer $\mathrm{Fe}_{2}(\mathrm{CO})_{9}$ or the solid trimer $\mathrm{Fe}_{3}(\mathrm{CO})_{12}$ [9] in their reactions with alkenes, dienes, or aromatic compounds. The nitrogen 
(or argon)-protected reaction is conducted either by heating an unsaturated substrate with the reagent, e.g., $\mathrm{Fe}(\mathrm{CO})_{5}$ without solvent, or using the high-boiling dibutyl ether, tetrahydrofuran or hydrocarbons as the solvent. The carbonyl reagents are regarded as highly toxic materials and all operations should be handled with care in a hood having an efficient exhaust. A vast number of tricarbonyliron complexes (comprising the $\mathrm{Fe}(\mathrm{CO})_{3}$ group) have been prepared and studied, and basic aspects of pentacarbonyliron reactions with a large number of organic functional groups have been reviewed [10-14].

Generally, iron carbonyls obey the 18-electron rule configuration in the formation of their organoiron complexes. For example, the mechanism by which $\mathrm{Fe}(\mathrm{CO})_{s}$ reacts with alkene is by initial dissociation of a molecule of $\mathrm{CO}$, to give, at first, the 16-electron (coordinatively unsaturated) $\mathrm{Fe}(\mathrm{CO})_{4}$ complex, which then coordinates with the alkene to give an 18-electron complex, i.e., (alkene) $\mathrm{Fe}(\mathrm{CO})_{4}$; all these are $\pi$-bonded complexes with $\mathrm{Fe}$ (zero-valent). In such $\sigma$-bonded complexes as $\left[\left(\eta^{5}-\mathrm{C}_{5} \mathrm{H}_{5}\right) \mathrm{Fe}(\mathrm{CO})_{2} \mathrm{C}_{2} \mathrm{H}_{5}\right]$, the iron is probably best regarded as $\mathrm{Fe}$ (II) with a 6-electron $\left(\eta^{5}-\mathrm{C}_{5} \mathrm{H}_{5}\right)^{-}$donor, a 2-electron ethyl $\left(\mathrm{C}_{2} \mathrm{H}_{5}\right)$ anion donor, and 2-electron $\mathrm{CO}$ donors $[14,15]$. However, existence of a 19-electron intermediate $\left[\left(\eta^{5}-\mathrm{C}_{5} \mathrm{H}_{5}\right) \mathrm{Fe}(\mathrm{CO})\left(\mathrm{PPh}_{3}\right)\right.$ $(\mathrm{Nu}) \mathrm{CH}_{3}{ }^{+}$] (where $\mathrm{Nu}$ is a pyridine nucleophile) has recently been reported [16].

The $\pi$-acid nature of carbonyl ligands makes anionic carbonyl complexes quite common, and the bonding capabilities of transition-metal clusters, including anions $\left[\mathrm{Fe}(\mathrm{CO})_{4}\right]^{2-}$ or $\left[\mathrm{Fe}_{2}(\mathrm{CO})_{8}\right]^{2-}$, are reasonably well understood [17]. Substitution by tertiary phosphine (i.e., the $\mathrm{PR}_{3}$ groups) frequently converts unbridged polynuclear carbonyls into bridged structures, because bridging carbonyls are better $\pi$ acids and are better able to handle the increased electron density. The physical and chemical properties of ironcarbonyl reagents, and their handling and use in synthesis of a variety of organoiron complexes (especially $\mathrm{Fe}(\mathrm{CO})_{3-}$ substituted complexes), have been thoroughly reviewed and discussed [10-15], and the reader is referred to these comprehensive treatises.

In contrast to the electron-withdrawing effect of tricarbonylchromium, e.g., $\mathrm{Cr}(\mathrm{CO})_{3}$ in (arene) $\mathrm{Cr}(\mathrm{CO})_{3}$ complexes [18,19], tricarbonyliron, e.g., $\mathrm{Fe}(\mathrm{CO})_{3}$ in (diene) $\mathrm{Fe}(\mathrm{CO})_{3}$ complexes behaves as a net inductive electron donor [15-20]. Metal stabilization of intermediates [21,22] and fluxionality in polyeneiron complexes [23] have recently been discussed [24]. In regard to double bonds, a metal can activate, deactivate, or protect the double bonds for electrophilic or nucleophilic attack; also, it can resolve geometric and optical isomers, direct attack stereospecifically, and aromatize or dearomatize appropriate systems, and these achievements are often difficult or impossible to reach by standard organic-type reaction alone [14]. Some examples of metal action on double bonds that includes metal $\sigma$-bonds will be presented in this review.

Removal of the $\mathrm{Fe}(\mathrm{CO})_{3}$ group $[14,20]$ is normally achieved by treating the complex with an oxidizing agent such as ceric ammonium nitrate $\left(\mathrm{CH}_{3} \mathrm{OH}, 0^{\circ} \mathrm{C}\right)$ [25], ferric chloride, cupric chloride, or hydrogen peroxide usually between $0^{\circ} \mathrm{C}$ and room temperature, in a solvent such as aqueous acetone or ethanol, or dilute acetic acid. The $\mathrm{Fe}(\mathrm{CO})_{3}$ group can also be removed by treatment with bromine or iodine in dichloromethane at low temperature $\left(-40\right.$ to $\left.-78^{\circ} \mathrm{C}\right)$, or treatment with trimethylamine $N$-oxide $\left[\left(\mathrm{CH}_{3}\right)_{3} \mathrm{~N} \rightarrow \mathrm{O}\right]$ in $\mathrm{N}, \mathrm{N}$-dimethylacetamide at $0^{\circ}$, or in acetone at room temperature [26]. Although trimethylamine $N$-oxide is a mild oxidant and extensively used for the cleavage of $\mathrm{Fe}(\mathrm{CO})_{3}$ groups without disturbing the stereochemistry, in certain cases the reagent is not specific, because it will also oxidize primary alcohols to aldehydes [27]. A recently introduced active manganese dioxide as a selective oxidant for removal of the $\mathrm{Fe}(\mathrm{CO})_{3}$ group and oxidative cyclization in one step could be an important reagent in the natural products synthesis [28]. The $\mathrm{Fe}(\mathrm{CO})_{3}$ protecting group may also influence the chemistry at sites remote from those of coordination.

\section{Scope of the Review}

Reactions of ironcarbonyl-coordinated alkenes and alkynes with tetracyanoethylene (TCNE) have recently been reviewed [29]; among the topics covered were reactions of main group metal complexes with TCNE, reactions of metallocenes with TCNE, and reactions of transition-metal complexes, including platinum-family complexes with TCNE. The objective of this review is to provide a current overview of the rapidly developing chemistry of organometallic complexes and particularly organoiron complexes useful in stereoselective synthesis. Several important topics in applications of organoiron complexes, to effect the 
regio- and stereospecific construction of organic molecules are covered and discussed in this review. The first involves diastereoselective reactions involving a complex in which a chiral auxiliary has been incorporated. Here the chiral auxiliary may either be the organic ligand of interest or other ligands on the metal (e.g., a chiral phosphine). The next topic involves the enantioselective addition of a nucleophile to an organoiron complex where the alkene, by having the metal complexed to one face of the $\pi$ system, becomes the center of chirality. And in a new addition to this series, a chiral nucleophile can be added diastereoselectively to an achiral organometallic complex. Alternatively, the iron itself may be considered chiral by virtue of having different ligands attached. Thus, optically active metal-alkene and -alkenyl complexes, in which the coordinated ligand is the center of asymmetry, constitute reagents with significant potential in asymmetric synthesis, since nucleophilic addition to such ligands provides a means for creating one or more asymmetric saturated carbon centers, with high enantioselectivity. Also covered are new applications of iron carbenes in synthesis, applications of organometallics in the synthesis of natural products, and the $\mathrm{Fe}(\mathrm{CO})_{3}$ - complexes from cyclic derivatives such as cyclopenta-, hexa- or heptadienes. Ferrocenes, bridged ferrocenes, iron porphyrins, capped iron porphyrins, iron pyrroles, and related organoiron compounds, and the unique role of iron in biological reactions will not be covered herein; however, a brief summary of work discussed in the recent literature on these subjects will be included. The application of acyclic butadiene iron-tricarbonyl complexes in organic synthesis has recently been reviewed at length by Grée [30]; also synthetic applications of enantioselective organo-transition metal mediated reactions have recently been surveyed by Blystone [31]. Because of space limitations, the literature cited and the topics discussed are highly selective. The literature from Chemical Abstracts covers approximately the period from 1970 through October 1990.

The credit for the development and application of organoiron complexes in organic and organometallic chemistry can be ascribed to brilliant contributions by Fischer [32,33], Pettit [34], Müller [35], Alper [10], King [36], Rosenblum [37-40], Brunner [41], Birch [14], Collman [42], Gompper [43], Sarel [44], Noyori [45,46], Pearson [20,21], Casey [47], Hegedus [13], Wojcicki [48], Reger [49], Helquist [50], Gladysz [51], Kerber [52], Wulff [53], Ojima [54], Negishi [55], Backvall [56], Herndon [57], von Gustorf [58], Grée [30], Seyferth [59], Davies [60-63], Liebeskind [64], Semmelhack [65], Brookhart [66], and others [31,67-73]. Credit is also due Fischer [24], Dötz [74], Jaouen [18], Semmelhack [19], Wulff [53,75] Hegedus [76], Yamashita [77], and others [77a,77b] for their studies and synthetic evaluations of the related organochromium complexes. A number of excellent, recent books and monographs covering general synthesis that are pertinent to this review of organometallic chemistry have been published [20,22,24,53,78-85].

New catalytic transition-metal-mediated carbon-carbon bond-forming reactions have found exceptional utility in organic synthesis $[1,5,31,46,79,84-87]$ and numerous examples are illustrative of the recent synthetic usefulness of organoiron complexes $[20,30,31,39,60,64,88-93]$.

\section{Tricarbonyliron $\mathrm{Fe}(\mathrm{CO})_{3}$ Group Stabilization of Diene Systems}

The incorporation of organometallic moieties into biologically important, unsaturated molecules is a field of increasing interest. Among many transition-metal carbonyls, the tricarbonyliron group $\left[\mathrm{Fe}(\mathrm{CO})_{3}\right]$ has been found useful as a stabilizing group for alkenes, dienes, and related unsaturated systems, and the topic has been exhaustively studied and reviewed $[14,20-22]$. The $\mathrm{Fe}(\mathrm{CO})_{3}$ group attached to an organic ligand possesses a number of useful properties that may be exploited for synthetic transformations $[14,20,21,65]$.

However, one of the important properties of the $\mathrm{Fe}(\mathrm{CO})_{3}$ group is protection of an alkenic (or dienyl) function during synthetic interconversions. The $\mathrm{Fe}(\mathrm{CO})_{3}$ group has been used to protect a $\mathrm{B}$ ring $\Delta^{5,6}$ diene during hydrogenation of a side chain $\Delta^{22}$ double bond in a steroid [94], and to protect a diene group during osmylation ( $\mathrm{OsO}_{4}$-pyridine, $20^{\circ} \mathrm{C}, 24 \mathrm{~h}$ ) of a sesquiterpene intermediate [95]; the use of steroidal hormones labelled with metal carbonyls to assay receptor sites has also been described [96]. A recent use of the $\mathrm{Fe}(\mathrm{CO})_{3}$ group was in protection of stereochemistry of the $(2 E, 4 E)$-dienoate unit of a polyene during homogeneous tritiation [97], regioselective reduction of allylic alcohols [98], or in stabilization of bicyclotetraenes [99]; also regio- and stereoselectivity of $\mathrm{Bu}{ }_{4} \mathrm{~N}\left[\mathrm{Fe}(\mathrm{CO})_{3} \mathrm{NO}\right.$-catalyzed allylic alkylation has been described [100]. Other examples illustrating the potential use of the $\mathrm{Fe}(\mathrm{CO})_{3}$ group as a diene protector during interconversion of the alkenic group have been reported [101-104]. Activation of alkane $\mathrm{C}-\mathrm{H}$ bonds by organometallics (including organoiron complexes) has been reviewed $[105,106]$ and bonding in metal-CO 
chemisorption, e.g., ironcarbonyls has been discussed [107]; also the electron affinity of ( $\eta^{4}-1,3$-butadiene) irontricarbonyl, e.g., $\eta^{4}-\mathrm{Bd} \cdot \mathrm{Fe}(\mathrm{CO})_{3}$ has recently been determined [108].

\subsection{Iron-Stabilized Cyclic Dienes in Regio- and Stereocontrolled Synthesis}

Synthetic application of organometallic complexes is both an exciting and a challenging area of research: exciting because of the enormous areas of chemistry still awaiting exploration, and challenging because, to a large extent, the behavior of such complexes has still to be put on a firm, mechanistic basis $[1,20,79,85]$. Attachment of a transition-metal moiety (e.g., $\mathrm{Fe}(\mathrm{CO})_{3}$ group) to an alkenic ligand presents the organic chemist with unequalled opportunities to control the regio- and stereoselectivity of bond formation. The iron-carbonyl unit may direct the regio- and stereochemistry of nucleophilic addition, important in the synthesis of natural products.

Reaction of 1,4-cyclohexanediene (readily available from the Birch reduction of benzene or its derivatives) [109] or 1,3-cyclohexanediene with pentacarbonyliron $\left[\mathrm{Fe}(\mathrm{CO})_{5}\right]$ gives tricarbonyl $(1,4$ - or 1,3 -cyclohexanediene) iron complexes [14,20,109-112]. These complexes readily undergo hydride abstraction by treatment with triphenylmethyl (trityl) hexafluorophosphate $\left(\mathrm{Ph}_{3} \mathrm{C}^{+} \mathrm{PF}_{6}^{-}\right)$or tetrafluoroborate $\left(\mathrm{Ph}_{3} \mathrm{C}^{+} \mathrm{BF}_{4}^{-}\right)$ in dichloromethane, to give tricarbonylcyclohexadienyliron hexafluorophosphate (or tetrafluoroborate) as stable, dull-yellow salts [32], e.g., metal-stabilized cyclohexadienyl cations [110-112]. These iron-stabilized carbocations are asymmetric due to the introduction of the $\mathrm{Fe}(\mathrm{CO})_{3}$ unit onto an achiral diene; they are highly reactive toward nucleophiles, leading to products that are also regiospecific and stereospecific, thus confirming the potential for asymmetric synthesis. In addition to its ability to stabilize dienyl cations, which led to useful, regiocontrolled nucleophile addition, the $\mathrm{Fe}(\mathrm{CO})_{2} \mathrm{~L}$ group $\left[\mathrm{L}=\mathrm{CO}, \mathrm{PPh}_{3}\right.$, or $\mathrm{P}\left(\mathrm{O} \mathrm{Ph}_{3}\right)$ ] shows a potential stereochemical directing effect, and can be employed for synthesis of natural-product intermediates [113]. Pearson $[89,114,115]$ made a thorough study of these complexes and, having established the rigid stereocontrol exercised by a tricarbonyliron group attached to either cyclohexanedienyl cations, conversion $(1 \rightarrow 5)$ [89] (Scheme 1), or to related cycloheptadienyliron complexes, conversions $(6 \rightarrow 9$ and $10 \rightarrow 12$ $[114,115]$ (Scheme 2) were achieved. The synthesis of cyclohexenone derivatives (e.g., 5) is summarized in Scheme 1, and cycloheptadiene derivatives (e.g., 7) (Scheme 2) show cis stereochemistry, as defined during the introduction of substituents at vicinal positions. Thus, the necessary stabilization and regio- and stereocontrolled functionalization of cyclohexadiene or cycloheptadiene systems using organoiron chemistry, can be accomplished. However, because of the fact that the cyclohexanedienyliron cation 3 possesses a plane of symmetry, the cation 3 and the nucleophile adduct 4 are in the racemic form. By the same reasoning, cyclohexanedienyl complexes of chromium (or molybdenum), or (arene) $-\mathrm{Cr}(\mathrm{CO})_{3}$ complexes $[77 \mathrm{a}, 77 \mathrm{~b}]$ are ( \pm ) racemic mixtures. Same argument can also be applied to the cycloheptadienyl-iron derivatives (e.g., complexes 6-8 and 10-12). Generally, optical resolution of these complexes is required when used as intermediates for synthesis of natural products. Indeed, classical organoiron chemistry has acquired a new dimension, namely, stereochemistry.

Today, dienyl- $\mathrm{Fe}(\mathrm{CO})_{3}$ cations occupy a prominent place as emerging synthetic intermediates $[14,110$ $112,116]$, largely due to their ready availability and low cost, and their reactivity toward nucleophiles that allows the preparation of substituted dienes which can be further transformed into a variety of natural products. To date, using the Pearson methodology $[117,118]$ most of the synthetic applications have involved iron-stabilized cyclohexa-dienyl carbocations [89,117-120]. These applications show how the ironcarbonyl unit directs the regio- and stereochemistry of nucleophile addition. They also show how the ironcarbonyl unit can be used to stabilize otherwise inaccessible carbocations, thereby making them readily available as synthetic intermediates that can be further applied to a range of natural-product syntheses. Indeed, an application of (cycloheptadienyl) $\mathrm{Fe}(\mathrm{CO}) \mathrm{L}$ cations to the stereocontrolled construction of acyclic fragments of the macrolide antibodies, for example, mangnamycin $\mathrm{B}$, has also been advanced [121] (see also sec. 7). Recently, Pearson et al. [122] reported an asymmetric induction as high as $90 \% e e$ during the reaction of enolates derived from optically pure sulfoximinyl esters with cyclohexadiene- or cycloheptadiene$\mathrm{Mo}(\mathrm{CO})_{2} \mathrm{Cp}$ and cyclohexadienyl-Fe $(\mathrm{CO})_{3}$ or cycloheptadienyl-Fe $(\mathrm{CO})_{2} \mathrm{P}(\mathrm{OPh})_{3}$ complexes. Renewed interest $[114,122]$ in methods for the preparation of homochiral organometallic $\pi$-complexes reflects new developments [123,124] employing their fully stereocontrolled alkylation reactions [125] in organic enantiomer synthesis. Recent work defined [126] strategic advantages available from the use of chiral organoiron complexes as intermediates in asymmetric synthesis. Recent extension to homochiral tricarbonyliron com- 


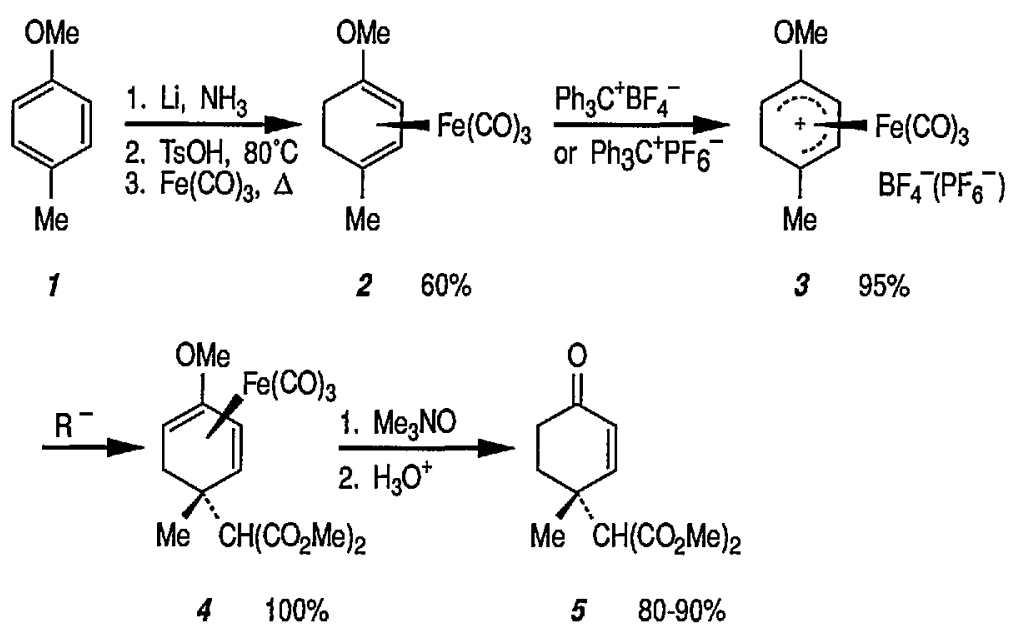

Scheme 1
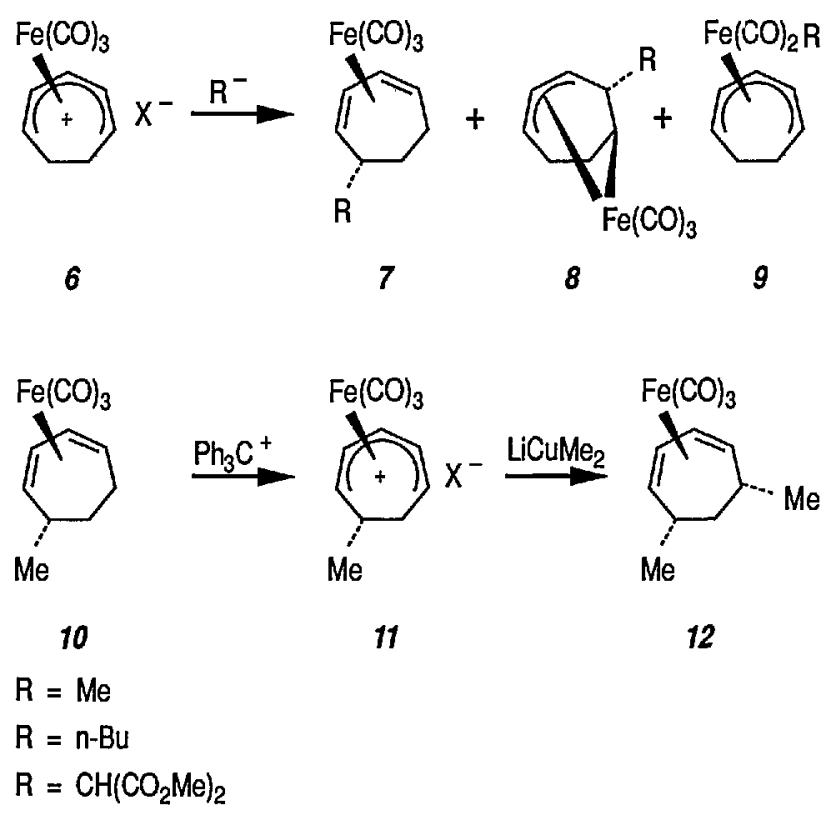

Scheme 2

plexes in the 1,3-cyclohexadienyl series has been described. Also homochiral 6-methoxy substituted cyclohexadienyl series has been described. Thus homochiral 6-methoxy substituted cyclohexadienyltricarbonyliron complexes of high stereoisomeric purity have been prepared by complexation of the dimethyl ether of 1-methoxycyclohexa-1,3-diene-5,6-diol (available via microbial oxidation of toluene) with $\mathrm{Fe}_{2}(\mathrm{CO})_{9}$ followed by demethoxylation with triphenylcarbenium tetrafluoroborate $\left(\mathrm{Ph}_{3} \mathrm{C}^{+} \mathrm{BF}_{4}^{-}\right)$[127]. The attachment of substituents to six- and seven-membered rings, with transition-metal moiety (e.g., $\left.\mathrm{Fe}(\mathrm{CO})_{3}\right)$ as a stereodirecting template is a new technology for the construction of subunits of potential value in natural product synthesis or drug synthesis.

Cationic dienyl- $\mathrm{Fe}(\mathrm{CO})_{3}$ complexes are very reactive toward nucleophiles, and show considerable promise as synthetic intermediates [117]; however, there are some problems associated with their use. For example, traditional hydride abstraction by $\mathrm{Ph}_{3} \mathrm{C}^{+} \mathrm{PF}_{6}^{-}$(to yield a dienyl cation) fails, or is not regioselec- 
tive in many cases $[128,129]$, and a number of dienyl complexes do not undergo nucleophile addition with the most desirable regiochemistry [130]. Thermal and photochemical cyclization of diene- $\mathrm{Fe}(\mathrm{CO})_{3}$ complexes with electron-deficient alkenes (to yield spiro compounds) has been suggested as an alternative [131].

The stereocontrolled construction of quaternary [132] or spiro carbon $[133,134]$ centers remains a challenging problem in organic synthesis. Recent extension [135] of the study [131] describes a unique, iron-mediated, intra-molecular ene-type reaction, leading to asymmetric, diastereospecific construction of quaternary carbon centers, with formation of spirolactones and spirolactams in enantiomerically pure form. Excellent stereocontrol during the ene-type coupling between diene- $\mathrm{Fe}(\mathrm{CO})_{3}$ groups and alkene in thermally induced spirocyclization can be achieved by appropriate substitution at C-5 of the diene ring; here, an electron-withdrawing cyano group yields a product without racemization, and an electron-donating phenyl group gives rearranged products, also optically active. For example, hydride abstraction from $N$-allyl- $N$ phenylamide derivative 14 (prepared from the enantiomerically pure acid 13) [136], followed by addition of cyanide, gave the optically pure nitrile 15 , which yielded enantiomerically pure spirolactam 16 $\left([\alpha]_{D}^{25}+96.70\right.$, acetone, 1.5$)$ in $87 \%$ yield under thermal conditions, e.g., thermal spirocyclization (Scheme 3). Similarly, optically pure spirolactones can be prepared [135]. This methodology permits application of asymmetric synthesis to a variety of spirocyclic, natural products and some new approaches to synthesis of natural products will be discussed later in the text.
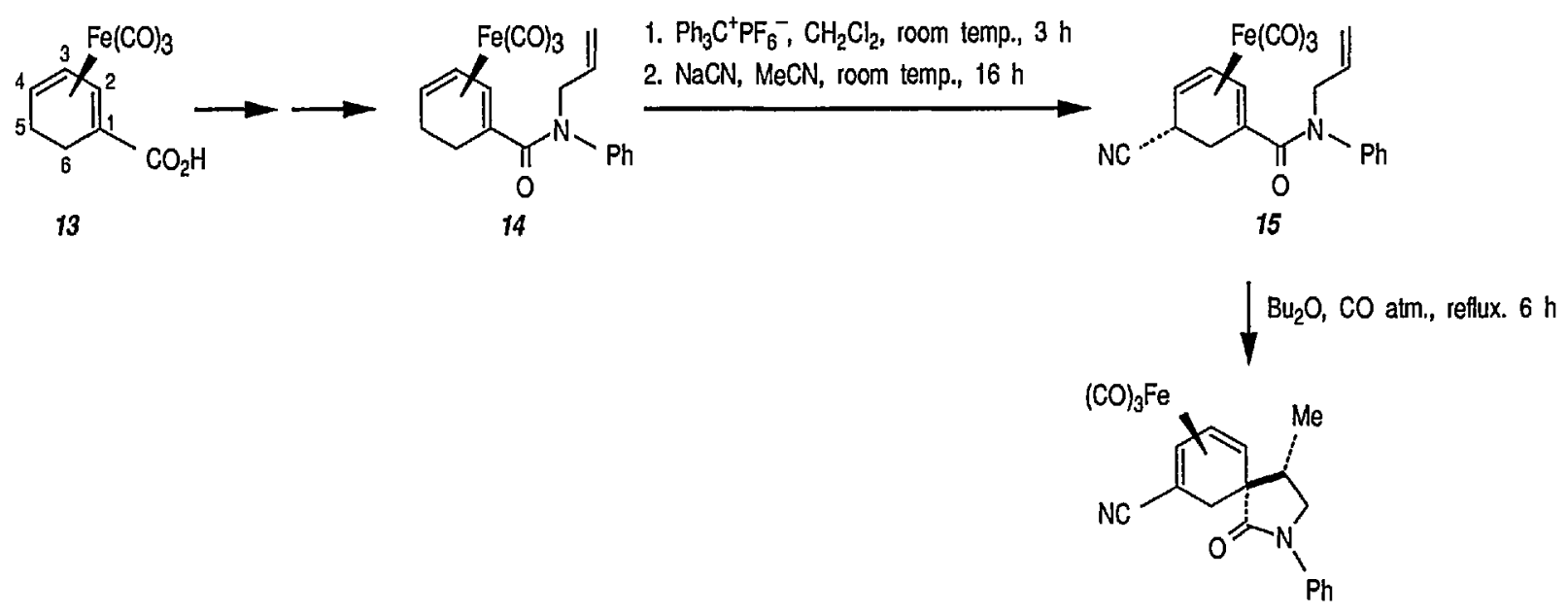

16

Scheme 3

\section{Iron-Stabilized Carbenes in Organic Synthesis}

One of the most outstanding properties of transition metals is their ability to stabilize short-lived molecules as ligands in coordination compounds, and this is partially observed in metal-stabilized carbenes [137]. Ligands bound through a disubstituted carbon atom are known collectively as carbenes (e.g., in metal carbenes) even though they neither give rise to, nor are made from, free carbenes [138]. Several theoretical studies have been carried out in attempts to evaluate the strength of, as well as the barrier to, rotation about the expected metal-carbon double bond in transition-metal carbene complexes [139]. The structures of metal-carbene complexes may be understood in terms of various limiting forms that contribute to the stabilization of the formally electron-deficient carbene carbon atom [74,137]. Three resonance structures, a larwlrl b larwlrl c, are shown in Scheme 4; structure a is stabilized by $\pi$ donation from the metal $M$ (this structure makes the carbene nucleophilic); the most stabilization to the carbene comes from structures $b$ and $c$, where substituents $X$ and $Y$ each serve as a $\pi$-donor. For heteroatom-substituted carbenes, there is thus a significant positive charge on the heteroatom $X$ or $Y(O R, N R)$, and substantial double-bond character between that heteroatom and the carbene atom. 


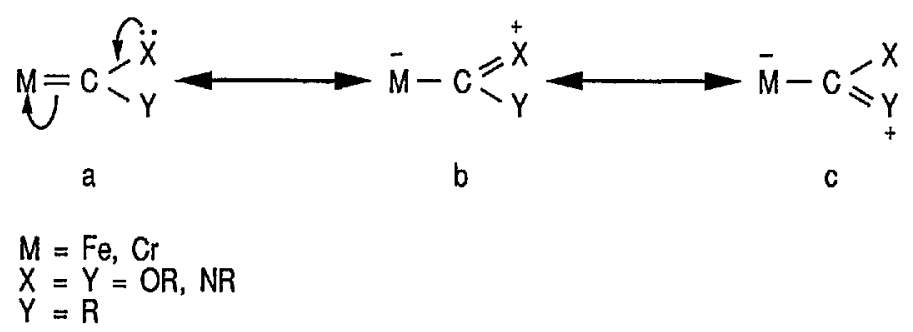

Scheme 4

The complexes that contain metal-stabilized carbenes are known for almost all transition elements; the development of the metal carbene chemistry is credited to the brilliant research of Fischer and his students $[32,33,137]$. The various transition-metal complexes can be divided into two groups on the basis of the chemical reactivity of the carbene atom [140-142]. The reactivity of carbene ligands is principally determined by the $\pi$-donor ability of the substituents on carbon. Carbene ligands with heteroatom substituents (e.g., O,N,Cl), or other substituents capable of $\pi$ interaction with the carbene atom, are called "electrophilic" or Fischer-type carbenes, for example, of chromium 17 [32,33,137,143-145] or iron 18 [146-147], and are usually subject to nucleophilic attack at the carbene carbon atom. Carbene ligands, without such substituents (for example, methylene or alkylidene ligands) require substantial $\pi$ donation from the electron-rich metal and are called "nucleophilic" or Schrock-type carbenes $[142,148]$ and are usually subject to electrophilic attack at the carbene carbon atom. Thus, in the Schrock-type alkylidene complexes the metalcoordinated $s p^{2}$-carbon atom is nucleophilic in character and displays an ylide-type reactivity. Electrophilic carbene ligands, including Fischer-type carbene complexes [32,143], may be viewed as singlet carbenes donating a pair of electrons via an $s p^{2}$ hybrid orbital, while receiving back-donation from the metal into an empty $p$ orbital $[144,145]$.

However, the reactivity of any given carbene ligand varies considerably from complex to complex; for example, methylene ligands are usually nucleophilic, but can become electrophilic for complexes bearing a positive charge. Thus, the discovery of heteroatom-stabilized carbene complexes $\left(\mathrm{L}_{\mathrm{n}} \mathrm{M}=\mathrm{CR}(\mathrm{OR})\right)$ by Fischer [33] and of heteroatom-free metal alkylidene complexes $\left(L_{n} M=C R_{2}\right)$ by Schrock $[142,148]$ laid the foundation for the recognition of reactive carbene complexes as decisive intermediates by many metal-catalyzed transformations of organic substrates [74,78,87,137].

$$
\begin{gathered}
(\mathrm{CO})_{5} \mathrm{Cr}=\mathrm{C}-\begin{array}{l}
\mathrm{OR}_{1} \\
\mathrm{R}_{2}
\end{array} \\
\mathrm{R}_{1}=\text { alkyl; } \\
\mathrm{R}_{2}=\text { alkyl, aryl }
\end{gathered}
$$

17

$$
\begin{aligned}
& (\mathrm{CO})_{4} \mathrm{Fe}=\mathrm{C}=\begin{array}{l}
\mathrm{OR}_{1} \\
\mathrm{R}_{2}
\end{array} \\
& \mathrm{R}_{1}=\mathrm{Et} ; \mathrm{R}_{2}=\mathrm{Ph} \\
& \mathrm{R}_{1}=\mathrm{Li} ; \mathrm{R}_{2}=\text { alkyl, aryl }
\end{aligned}
$$

18

Although carbene complexes have been studied intensively for more than 2 decades, it is only very recently that useful applications of these complexes to organic synthesis have been developed [137,139,149,150-154].

Transition-metal carbene complexes are generally recognized as important, reactive intermediates in organometallic chemistry, in particular in certain catalytic reactions, e.g., alkene metathesis [31,155], alkene polymerization [156], the Fischer-Tropsch synthesis [157,158], and important cyclopropanation reactions [159]. Carbenes and carbene precursors are known to react with transition-metal complexes to produce alkyl [160] and alkylidene [161] complexes, as well as a host of compounds in which the intact precursor molecule is coordinated to the metal center $[162,163]$.

As synthetically useful reagents, carbene complexes are not only suitable as carbene-transfer reagents but also undergo interesting cycloaddition with other ligands in the CO-ligand sphere. Their treatment requires techniques no more complicated than those used for Grignard reactions. However, recently devel- 
oped, stabilized carbene complexes are handleable in air, can endure temperatures of $100^{\circ} \mathrm{C}$ or more, are stable in mild aqueous acids and bases, and are soluble in organic solvents to the point where most can be rapidly eluted from silica gel columns with hexane [150-152]. Thus, carbene complexes can also be used in the synthesis of natural products; a few recent examples include synthesis of naturally occurring furochromones [153], $\beta$-lactams (penicillin analogs) [164], and antibiotics $[151,165,166]$.

In comparison to the wide application of chromium carbene complexes in organic synthesis $[18,19,74,137,151,165-170]$, the Fischer-type carbene complexes of iron (e.g., 18) have been but little explored [147]; indeed, many of the iron carbene complexes are of proven synthetic utility [66a,171-175].

\subsection{Preparation and Some Reactions of Iron-Carbene Complexes}

Synthesis of neutral and cationic metal-carbene complexes has been discussed [176]. Neutral iron-carbene complexes of type 21 are readily available by the method of Fischer [137,143] by treatment of iron pentacarbonyl 19 with lithium or a Grignard reagent, followed by alkylation of acyl complexes on oxygen $[147,177]$ (conversion $19 \rightarrow 20 \rightarrow 21$ ). Carbene complexes of type 21 have also been prepared by photochemical exchange of a $\mathrm{CO}$ ligand in $\mathrm{Fe}(\mathrm{CO})_{s}$ with alkylidene [178].

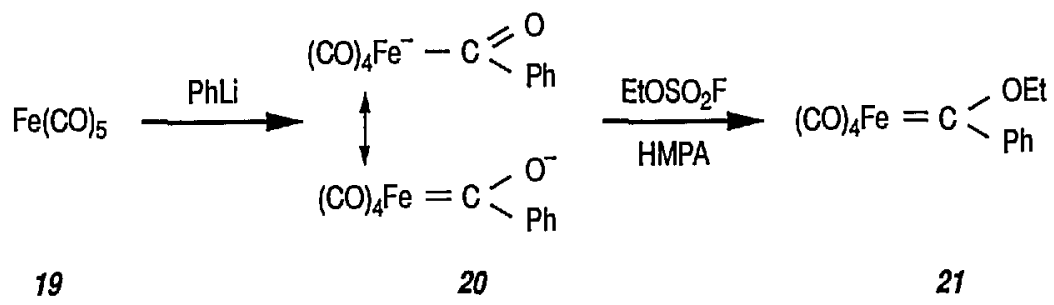

HMPA = hexamethylphosphoramide

A few additional routes to 0-substituted, Fischer-type carbene complexes are described next. For example, methoxycarbene complexes 24 are readily prepared by treatment of the bromide (22) with the appropriate lithium acetylide, to give (23), followed by protonation of the corresponding vinylidene complexes, and subsequent addition of methanol [179-181]. Alternatively, 24 may be obtained from the corresponding acyl complexes $25[61,64]$ following treatment with trimethyloxonium tetrafluoroborate [182].

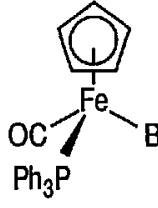

22

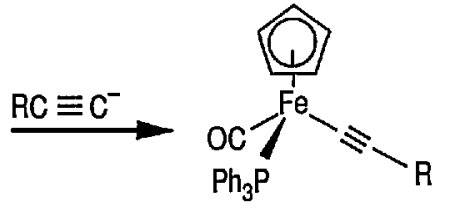

23

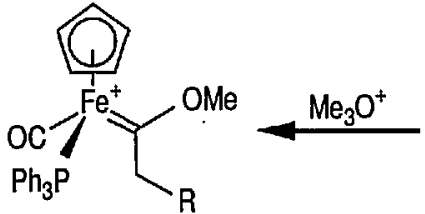

24

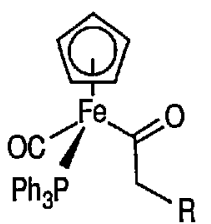

25

Cationic carbene complexes can also be prepared by the alkylation of neutral acyl complexes [183]. There are two efficient, general syntheses of electrophilic (cationic) metal-carbene complexes: the addition of (1) an electrophile to a M-CHR-X (X=OR, SR, Cl) derivative [184], and (2) acids to vinylmetal complexes [184-186]. For example, synthesis of important cyclopropanic reagent, e.g., the cationic iron-carbene complex 24 is based on the addition of an electrophile to $\mathrm{FeCH}=\mathrm{CH}-\mathrm{C}\left(\mathrm{CH}_{3}\right)_{2} \mathrm{X}$ system [185]. Thus, addition of $\mathrm{CH}_{3} \mathrm{Li}$ to the ketone group of the acyliron complexes 26 produced tertiary alcohol 27 (62\% yield). Addition of $\mathrm{HBF}_{4}$ in diethyl ether to an ether solution of 27 at $-23^{\circ} \mathrm{C}$ gave the iron-carbene complex 28 as a red-orange solid. 
<smiles>CC(=O)/C=C/[Pb]([O-])(O)c1ccccc1</smiles>

26

\section{$\underset{\text { 1. } \mathrm{CH}_{3} \mathrm{Li}}{\longrightarrow}$}<smiles></smiles>

27<smiles></smiles>

28

\subsection{Reactions of Electrophilic Iron-Carbene Complexes}

Electrophilic or Fischer-type iron-carbenes are usually subject to a two-fold nucleophilic attack, resulting in either exchange of the heteroatom substituents on the carbene carbon, or ligand substitution at the metal. The general patterns of reactivity of electrophilic carbene complexes are summarized in Scheme 5.

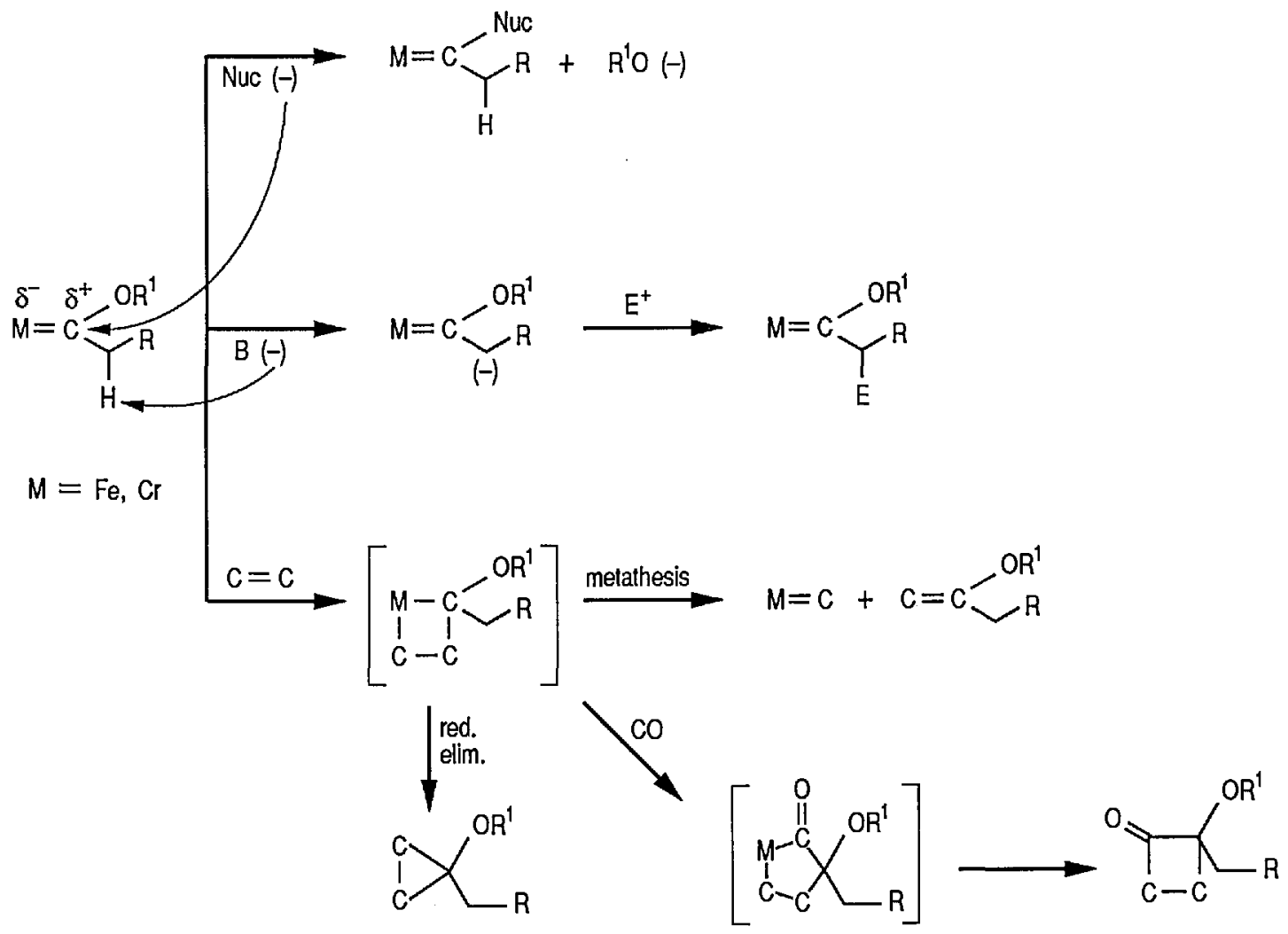

Scheme 5

Generally, interaction of carbene complexes with alkynes, metathesis, and cyclopropanation reactions are important reactions of metal carbenes. However, it is the carbene-transfer reactions, and particularly, cyclopropanation reactions, which probably proceed through metallic intermediates, that are of the most importance in organic synthesis.

\subsection{Additional Reactions of Iron-Carbene Complexes}

New coupling reactions of conjugated 1,3-dienes with iron-carbene complexes to give (1,3-diene) $\mathrm{Fe}(\mathrm{CO})_{3}$ derivatives have recently been reported by the Semmelhack group [187]. Thus, coupling of the 
iron-carbene $29(\mathrm{R}=\mathrm{Ph})$ with 1,3-butadiene gave via the ferracyclobutene intermediate 30 , a new way for the preparation of $\left(\eta^{4}-1,3-\right.$ diene $)-\mathrm{Fe}(\mathrm{CO})_{3}$ complexes, e.g, 31A $+31 \mathrm{~B}$, bearing an allylic ethoxyl group (Scheme 6). Complexes of 1,3-dienes with $\mathrm{Fe}(\mathrm{CO})_{3}$ provide starting points for useful synthesis methodology via direct nucleophile addition [188], and by conversion into ( $\eta^{5}$-pentadienyl) $\mathrm{Fe}(\mathrm{CO})_{3}$ cationic complexes which are powerful electrophiles $[189,190]$.

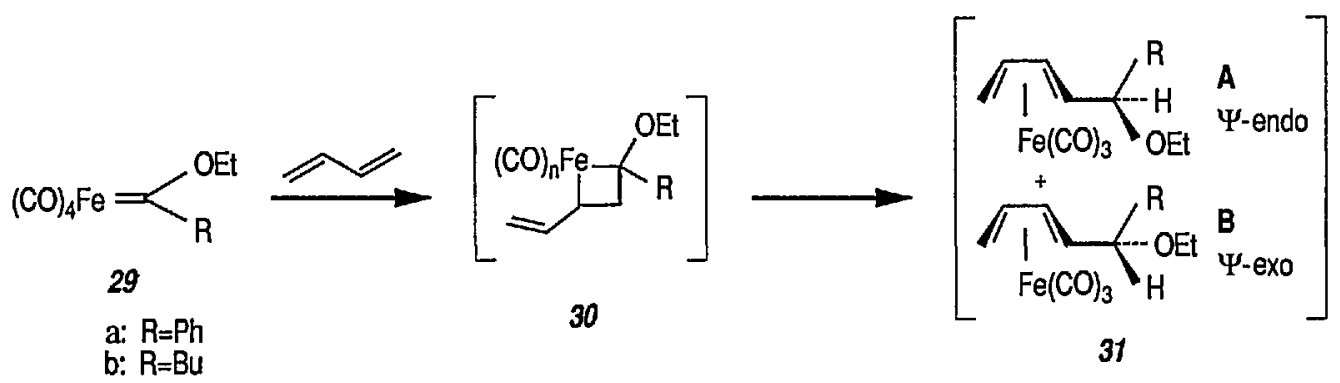

Scheme 6

Another synthetically interesting new reaction of iron-carbene complexes with alkynes has been reported by the same group [17,191]. It has been demonstrated [17] that iron-carbene complexes, e.g., 32 react with alkynes to form, also via the ferracyclobutene intermediate (33), pyrone complexes $34 \leftrightarrow 35$ (Scheme 7). Similar reaction of (aminocarbene)-iron complexes with alkynes [191] can lead to relatively little studied 5 -aminofurans (the major product) and 6-amino- $\alpha$-pyrones (the minor product), e.g., conversion $36 \rightarrow 37 \rightarrow 38 \rightarrow 39 \rightarrow 40$ (Scheme 8 ). This is a remarkable reaction, with a strong potential for future synthesis; however, the mechanism by which it occurs is not yet known, although a somewhat complex proposal can explain the products formed [17,191].

Recently, Ayscough and Davies reported [192] a stereoselective hydride reduction of a cationic ironcarbene complex $\left[\left(\eta^{5}-\mathrm{C}_{5} \mathrm{H}_{5}\right) \mathrm{Fe}(\mathrm{CO})\left(\mathrm{PPh}_{3}\right)=\mathrm{COCH}_{2} \mathrm{CH}_{2} \mathrm{C}^{-} \mathrm{Me}_{2}\right]^{+}$(41). This study demonstrates the remarkable stereocontrol exerted by the chiral auxiliary $\left(\eta^{5}-\mathrm{C}_{5} \mathrm{H}_{5}\right) \mathrm{Fe}(\mathrm{CO})\left(\mathrm{PPh}_{3}\right)$ in reactions on the $\alpha$-carbon atom, where reduction of (41) proceeds completely stereoselectively to give the kinetic product (42), which then epimerizes (43), also completely stereoselectively, to the thermodynamic product (44) (Scheme 9). These results are readily explicable in terms of a simple conformational model, and the phenomenon can be expected to be general for all cases where there is a very bulky $\mathrm{C} \alpha$ substituent (e.g., at carbon centers directly attached to the chiral auxiliary) [192].

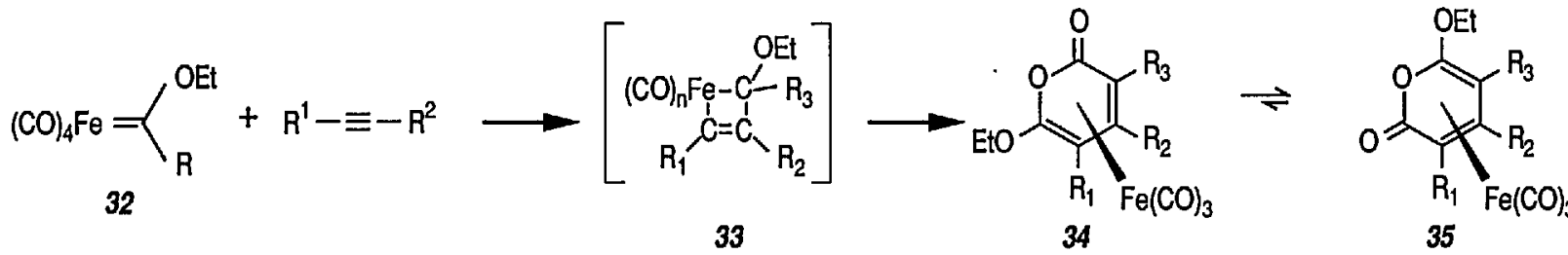

$$
\begin{array}{lc}
\mathrm{R}_{1}, \mathrm{R}_{2}=\mathrm{Me} ; \mathrm{R}_{3}=\mathrm{Ph} & \frac{\text { Yield of } \mathbf{3 4}}{89 \%} \\
\mathrm{R}_{1}, \mathrm{R}_{3}=\mathrm{Ph}_{\mathrm{R}} \mathrm{R}_{2}=\mathrm{H} & 74 \% \\
\mathrm{R}_{1}, \mathrm{R}_{2}, \mathrm{R}_{3}=\mathrm{P} 斤 & 93 \%
\end{array}
$$

Scheme 7 


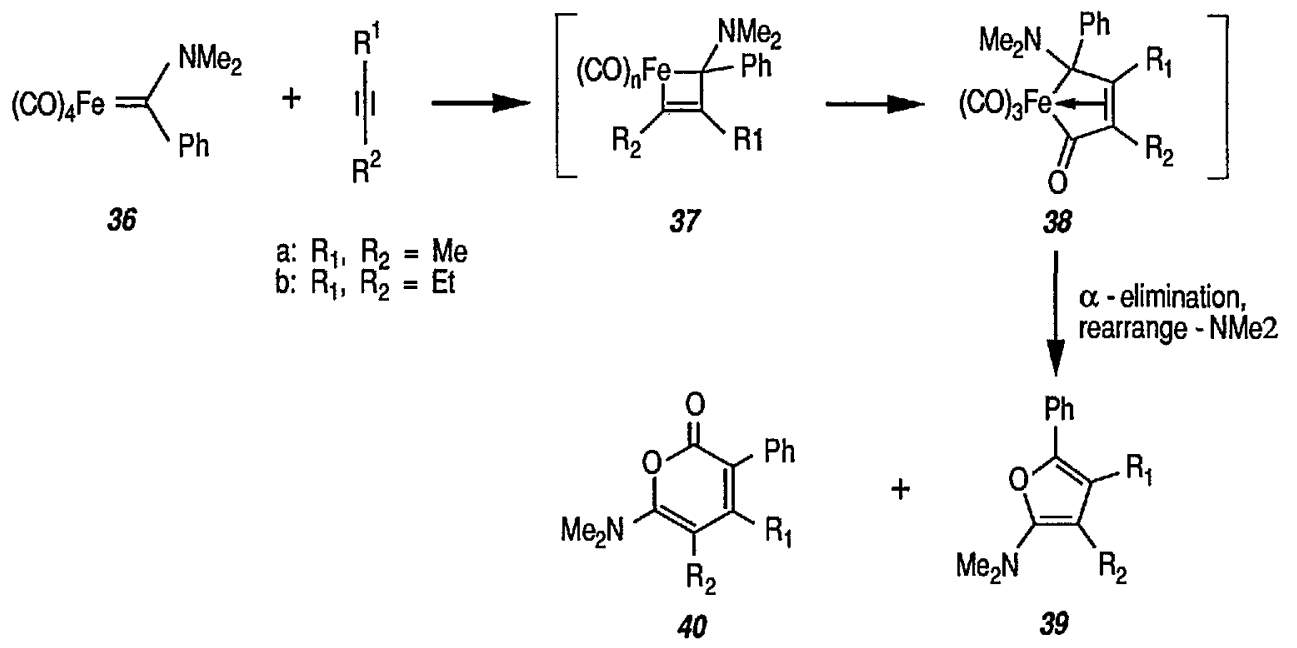

Scheme 8

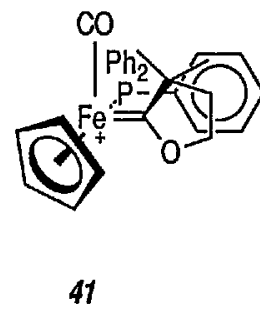

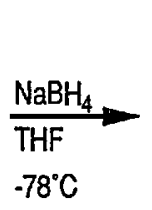

$-78^{\circ} \mathrm{C}$

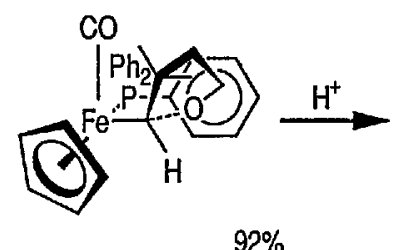

(RR, SS) - 42

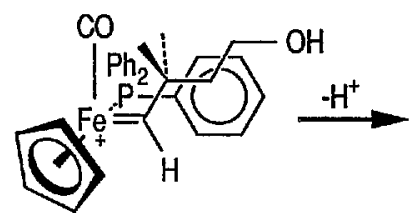

43

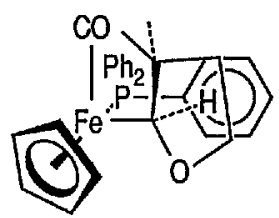

$97 \%$

(RS, SR) - 44

Scheme 9

\subsection{New Iron-Nitrene Complexes for Synthesis}

The chemistry of metal-carbene complexes (including those of iron and chromium) has been extensively investigated, and many such complexes have found impressive synthetic utility [137,150-153,193-195]. In contrast, the chemistry of nitrene ligands to iron or chromium, e.g., $\left[(\mathrm{CO})_{5} \mathrm{M}=\mathrm{NPh}(\mathrm{M}=\mathrm{Fe}, \mathrm{Cr})(\mathrm{metal}-\right.$ imides)], remains relatively unexplored [196], partially because of their instability [197]. Like that of many reactive organic ligands, stabilization of nitrenes by organometallics can be achieved through coordination of the ligand to adjacent metal in cluster compounds, with the $\mu_{3}$-NR coordination mode being the most common $[140,141,193-195]$.

Recently, formation of imidates, amides, amines, carbamates, and ureas from the $\mu_{3}-\mathrm{NPh}$ ligands of the complex $\mathrm{Fe}_{3}\left(\eta_{3}-\mathrm{NPh}\right)_{2}(\mathrm{CO})_{9}$ has been reported [198]. The bis(nitrene) cluster $\mathrm{Fe}_{3}\left(\eta_{3}-\mathrm{NPh}\right)_{2}(\mathrm{CO})_{9}$ reacts with $\mathrm{Li}\left(\mathrm{HBEt}_{3}\right), \mathrm{MeLi}, \mathrm{PhLi}$, or $\mathrm{NaOMe}$, to form formyl and acyl clusters of type $\left[\mathrm{Fe}_{3}\left(\eta_{3^{-}}\right.\right.$ $\left.\mathrm{NPh})_{2}(\mathrm{CO})_{8} \mathrm{C}(\mathrm{O}) \mathrm{R}\right]^{-}(\mathrm{R}=\mathrm{H} ; \mathrm{Ph} ; \mathrm{Me} ; \mathrm{OMe})$. On further treatment with EtOTf $\left(\mathrm{EtOSO}_{2} \mathrm{CF}_{3}\right)$, the benzoyl cluster $(\mathrm{R}=\mathrm{Ph})$ thus obtained yields the nitrene-carbene cluster $\left[\mathrm{Fe}_{3}\left(\eta_{3}-\mathrm{NPh}\right)_{2}(\mathrm{CO})_{8} \mathrm{C}(\mathrm{OEt}) \mathrm{Ph}\right]$, and this mixed cluster is used for the preparation of such useful derivatives as imidates, amides, or amines by utilizing the $\eta^{3}-\mathrm{NPh}$ ligands of $\mathrm{Fe}_{3}\left(\eta_{3}-\mathrm{NPh}\right)(\mathrm{CO})_{9}$. This is a new synthesis adventure, and no doubt more studies in this direction will be forthcoming.

\section{Iron-Catalyzed Synthesis and Some Reactions of Cyclopropanes. Cyclopropanation Reaction}

The limits of stability of strained hydrocarbons, including cyclopropanes, have been substantially clarified over the course of the past 30 years $[199,200]$. The chemistry of the cyclopropyl group has recently been discussed at length [201]. The torsional strain in the three-membered ring imparts a high degree of reactivity, which can lead to the fragmentation of cyclopropanes; this process is apparently regio- and stereo- 
chemically controlled [202]. Because of the various cleavage reactions and rearrangements in which they participate, cyclopropanes frequently serve as valuable synthetic intermediates leading to other ring systems, or to acyclic products. The cyclopropane ring system is also seen as an important structural feature among many classes of naturally occurring compounds [66]. Fused, and bridged, polycyclic systems containing a cyclopropane ring have been shown to be useful intermediates in organic synthesis $[203,204]$. New synthetic approaches to carbocycles via intramolecular cyclopropanation reaction have recently been discussed [202], and a recent summary on cyclopropanes as building blocks for organic synthesis has appeared [205]. The reaction of Fischer-type transition-metal carbene complexes with alkenes are known to occur under the proper conditions to give cyclopropane products in a formal [2+1] cycloaddition [66]. [4+2] cycloaddition of Fischer carbene complexes with 1,3-dienes to give cyclopropanes and involving a zwitterionic intermediate has recently been observed [206]. However, the reaction of Fischer carbene complexes with enyne substrates yields bi- and tricyclic cyclopropane-containing carbon skeletons [207]. The paper also discusses various modes of metal carbene-alkene and metal carbene-alkyne couplings, including intra- and intermolecular cyclopropanation reactions.

\subsection{Synthesis of Cyclopropanes via Carbene-Transfer Reaction}

A cyclopropanation reaction involving transition-metal carbene complexes has recently been reviewed $[66,208]$. Among the large number of methods developed for the synthesis of cyclopropanes, the majority of them may be placed in two broad categories: (1) addition of carbenes, carbenoids, or related species to alkenes (to yield intermediates for carbene-transfer reactions) and (2) intramolecular coupling, or alkylation reaction $[209,210]$.

Electrophilic, cationic complexes of iron are efficient cyclopropanating agents, particularly for unfunctionalized alkenes. These complexes are unstable, and are usually generated and used in situ. As observed earlier by Pettit et al. [211], and others [212], when methoxymethyliron complex 45 was treated with acid, it underwent cleavage to a short-lived, cationic methylidene complex 46 , as evidenced by the formation of norcarane 47 when the cleavage was performed in the presence of cyclohexene (Scheme 10). Several methods have been developed for the preparation of more-stable metal carbenes suitable for cyclopropanation [213]; some of these require replacement of the simple methylidene group by an ethylidene [172], isopropylidene $[159,214]$, allylidene $[185,215]$, or benzylidene [216] group.
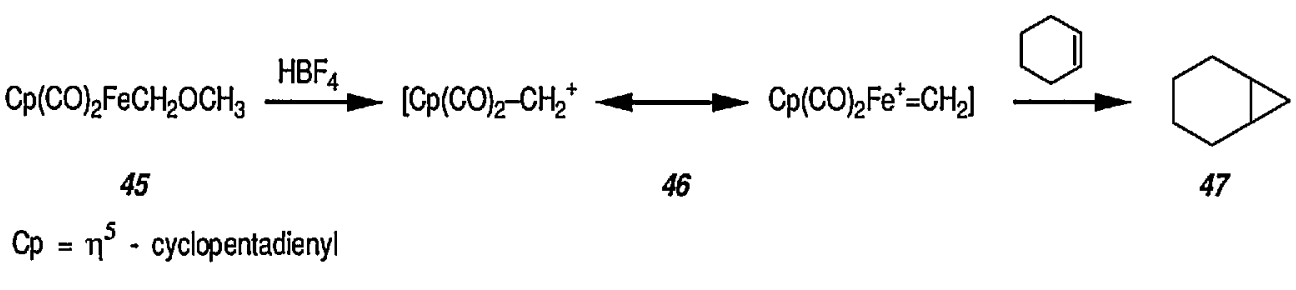

Scheme 10

Brookhart has used methoxyalkyliron complexes (Scheme 11) to generate relatively stable ethylidene $[217,218]$, benzylidene [66a,174,219], and cyclopropylidene [220] transfer reagents. Note the generation of the required cationic iron complex 49, following treatment of the methoxyalkyliron complex 48 with trimethylsilyl triflate at low temperature, and then with alkenes, to give the corresponding cyclopropanes 50 , 51 and 52. The most synthetically efficient and best studied cyclopropanating reagents [141] are the cationic carbene complexes of the general structure $\left[\left(\eta^{5}-\mathrm{C}_{5} \mathrm{H}_{5}\right)(\mathrm{CO})_{2} \mathrm{Fe}-\mathrm{CRR}^{1}\right]^{+}\left(\mathrm{R}=\mathrm{R}^{1}=\mathrm{H}\right)[147] ; \mathrm{R}=\mathrm{H}, \mathrm{R}^{1}=\operatorname{aryl}$ [174]; $\mathrm{R}=\mathrm{H}, \mathrm{R}^{1}=\mathrm{CH}_{3}[166,172,175], \mathrm{R}=\mathrm{R}^{1}=\mathrm{CH}_{3}$ [184], and their various phosphine derivatives $[147,159,221]$.

Recently, more-stable metal carbenes have been synthesized, and applied as cyclopropanation reagents in synthetic organic chemistry. The new procedure employs sulfonium derivatives of the structure $\left[\left(\eta^{5}-\right.\right.$ $\left.\left.\mathrm{C}_{5} \mathrm{H}_{5}\right) \mathrm{FeCH}_{2} \mathrm{SR}_{2}\right]^{+}$(metal-bonded sulfonium ylides) in which a neutral dialkyl sulfide serves as the leaving group. Thus, Helquist et al. [171,172,209] found that treatment of the stable (dimethylsulfonium) methyliron complex 53 with alkenes in refluxing 1,4-dioxane produced, via the carbene intermediate 54, and methyli- 


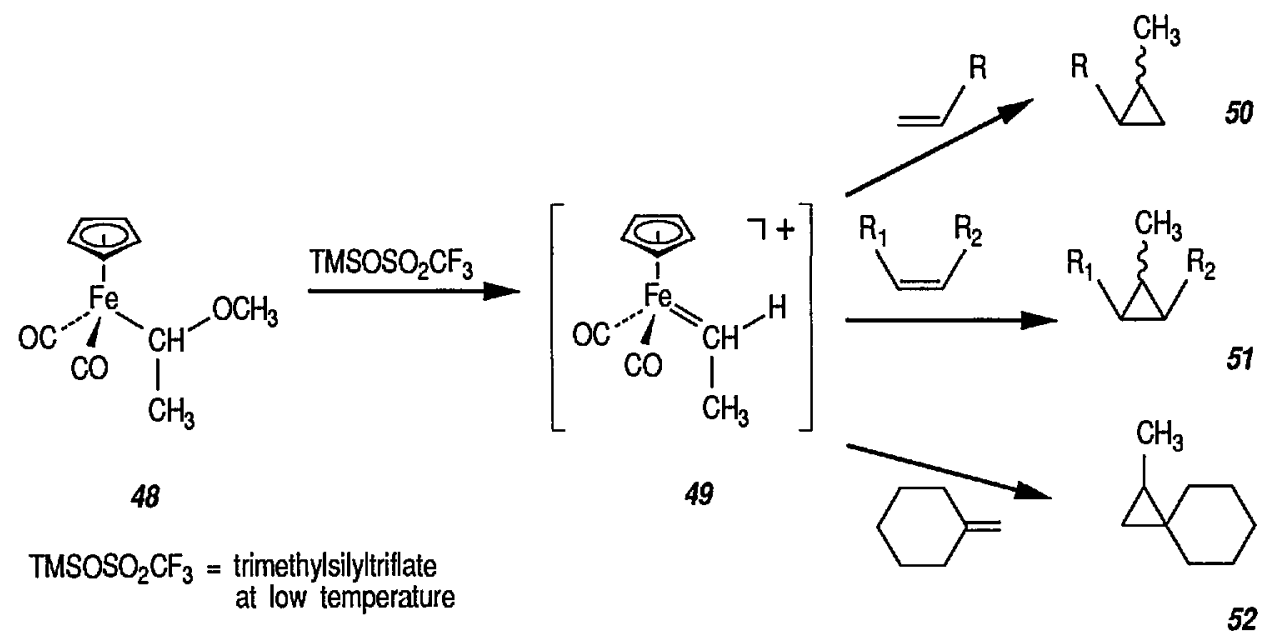

Scheme 11

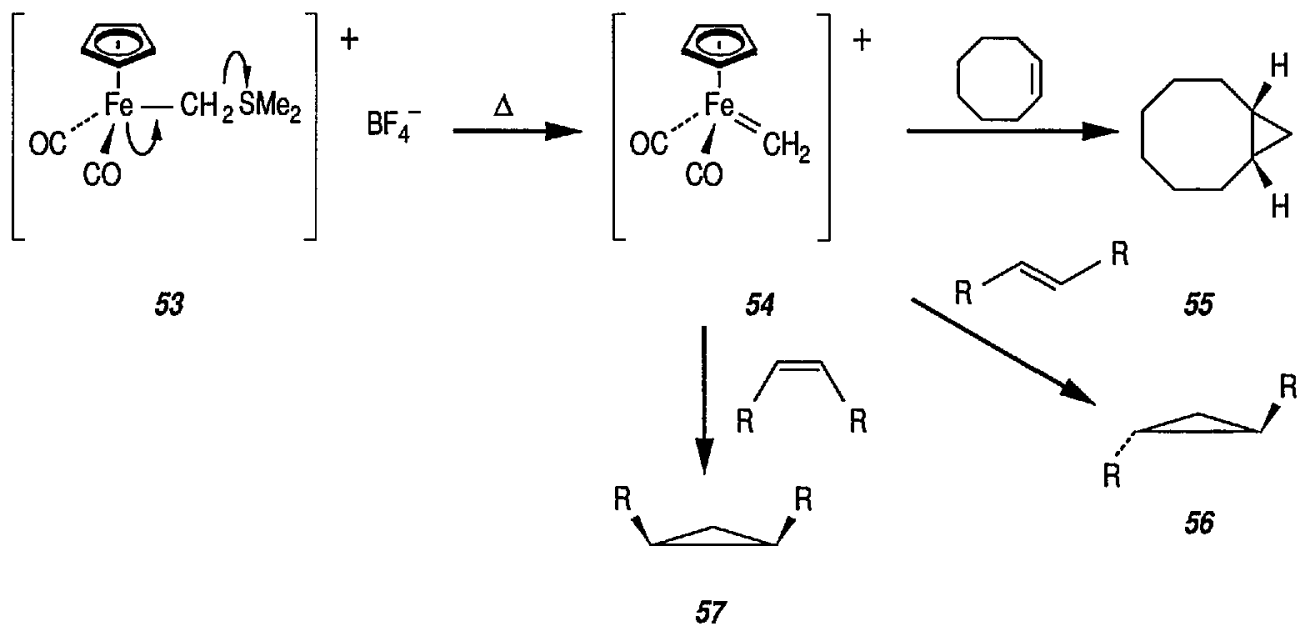

Scheme 12

dene group transfer, cyclopropanes 55, 56 and 57 in excellent yields (Scheme 12) (table 1). The reaction is stereospecific, giving cis-cyclopropanes with cis-alkenes, and trans-cyclopropanes with trans-alkenes. The ethylidene group is similarly transferred when the related (methylphenylsulfonium) ethyliron complex is used; in this case also, the stereochemistry of the alkene is maintained [172].

The precise mechanism of the cyclopropanation reaction is yet to be determined. It has been clearly established that, in the transfer reaction, the electrophilic carbene complex attacks the nucleophilic alkene with substantial charge development in the transition state. A transition state involving unsymmetrical attack, with partial charge build-up on only $\mathrm{C}-2$ and not a more-symmetrical model where equal charge builds up to $\mathrm{C}-1$ and $\mathrm{C}-2$ of the alkene, has been advanced [66]. The future challenging chemistry of, for example, metallo-bis (methylene)phosphoranes, e.g., $\left(\eta^{5}-\mathrm{C}_{5} \mathrm{H}_{5}\right) \mathrm{Fe}(\mathrm{CO})_{2}\left\{\mathrm{P}\left[=\mathrm{C}\left(\mathrm{SiMe}_{3}\right)_{2}\right]_{2}\right\}$ [222] or other metal-carbene-type complexes, comprising such highly reactive structures as $\mathrm{Fe}=\mathrm{N}, \mathrm{S}, \mathrm{P}$ or $\mathrm{Fe}=\mathrm{Si}, \mathrm{Ga}, \mathrm{B}, \mathrm{As}$, etc., still await exploration. Recently, reactions of iron $\omega$-haloalkyls with silver (I) to form cyclopropanes have been described, e.g., $\left(\eta^{5}-\mathrm{C}_{5} \mathrm{H}_{5}\right)(\mathrm{CO})_{2} \mathrm{Fe}\left(\mathrm{CH}_{2}\right)_{3} \mathrm{Br}+\mathrm{Ag} \mathrm{BF} 4 \rightarrow$ cyclopropane (73\% yield). The mechanism of this reaction and its relevance to the cyclopropanation reactions of cationic metal carbenes and alkenes has been discussed [223]. 
Table 1. Cyclopropanation of alkenes [209] with $\left[\left(\eta^{5}-\mathrm{C}_{5} \mathrm{H}_{5}\right)(\mathrm{CO})_{2} \mathrm{FeCH}_{2} \mathrm{~S}^{+}\left(\mathrm{CH}_{3}\right)_{2}\right] \mathrm{BF}_{4}^{-}(53)^{\mathrm{a}}$

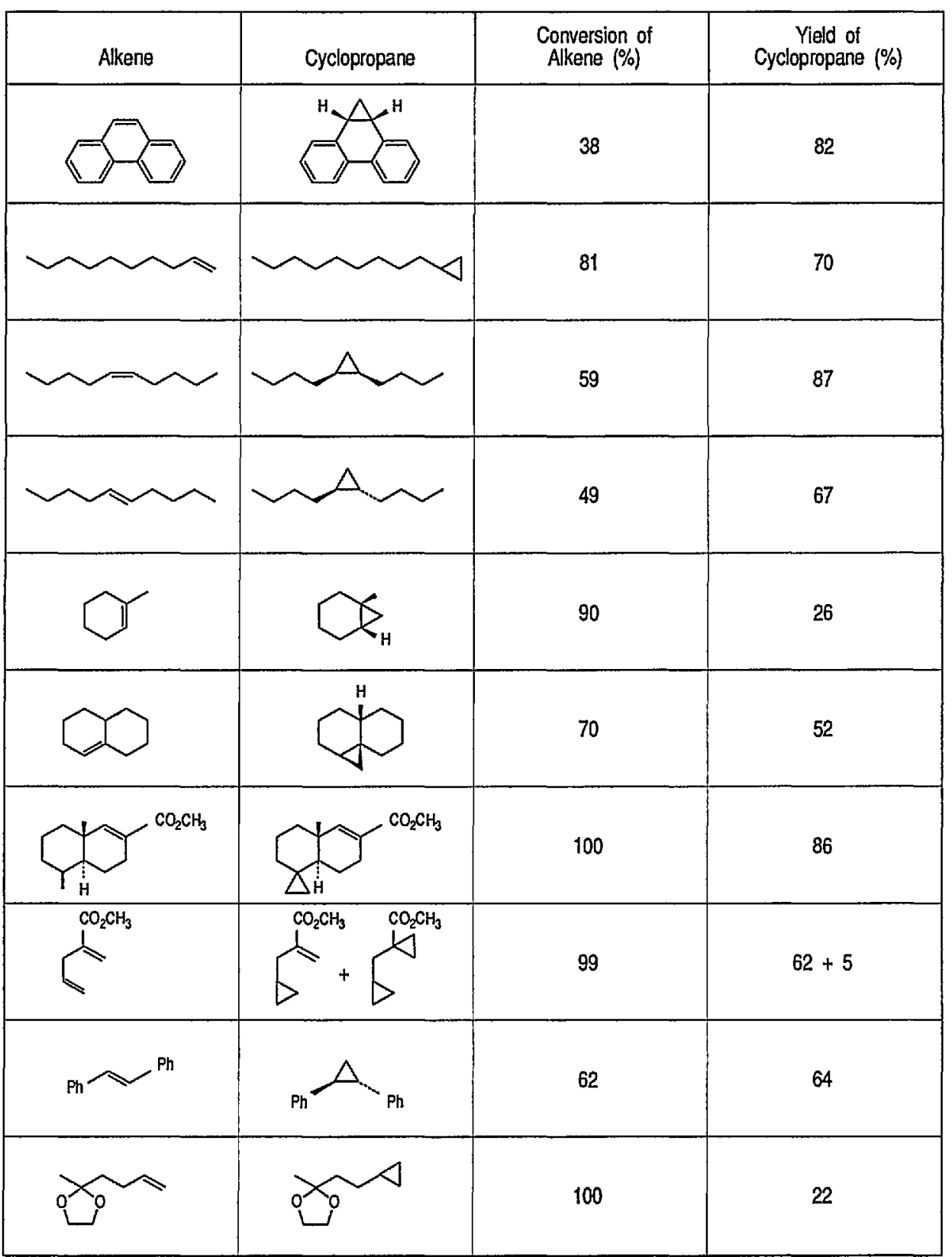

anless otherwise indicated, these reactions were conducted under a standard set of conditions employing 2 molar equiv. of 53 and $2 \mathrm{M}$ solution of alkene in boiling 1, 4 - dioxane at reflux for $12 \mathrm{~h}$. 
General Procedure for Cyclopropanation of Alkenes with the Sulfonium Salts (53), 1,1-Diphenylcyclopronane [209]:

The required $\mathrm{CpFeCH}_{2} \mathrm{~S}^{+}\left(\mathrm{CH}_{3}\right)_{2} \mathrm{BF}_{4}^{-}(53), \mathrm{Cp}=\left(\eta-\mathrm{C}_{5} \mathrm{H}_{5}\right)$ was readily prepared by the reaction of the ferrate $\mathrm{Na}^{+}\left[\left(\eta^{5}-\mathrm{C}_{5} \mathrm{H}_{5}\right) \mathrm{Fe}\right]^{-}$with chloromethyl methyl sulfide to give the alkylation product, which was then treated with a methylating agent as shown.

$$
\begin{gathered}
\mathrm{Na}^{+}\left[\mathrm{Cp}(\mathrm{CO})_{2} \mathrm{Fe}\right] \stackrel{\mathrm{ClCH}_{2} \mathrm{SCH}_{3}}{>}>\left[\mathrm{Cp}(\mathrm{CO})_{2} \mathrm{FeCH}_{2} \mathrm{SCH}_{3}\right] \stackrel{\left(\mathrm{CH}_{3} \mathrm{O}\right)_{2} \mathrm{CH}^{+} \mathrm{BF}_{4}^{-}}{>}> \\
{\left[\mathrm{Cp}(\mathrm{CO})_{2} \mathrm{FeCH}_{2} \mathrm{~S}^{+}\left(\mathrm{CH}_{3}\right)_{2}\right] \mathrm{BF}_{4}^{-}(53)}
\end{gathered}
$$

The unrecrystallized $53(35 \mathrm{~g}, 100 \mathrm{mmol})$ as a yellow powder was placed in a $200-\mathrm{mL}$, round-bottomed flask equipped with a magnetic stirring bar. 1,1-diphenylethylene $(9.3 \mathrm{~g}, 9.1 \mathrm{~mL}, 52 \mathrm{mmol})$ and 1,4-dioxane $(25 \mathrm{~mL})$ were added, the flask was equipped with a reflux condenser, and the mixture was stirred while it was boiled at reflux for 12-14 h under a nitrogen atmosphere. After the brown mixture had cooled somewhat, hexane $(75 \mathrm{~mL})$ was added, and the mixture was stirred in the air as it cooled to $25^{\circ} \mathrm{C}$, filtered, and the retained solid washed with additional hexane. The combined filtrates were concentrated by rotary evaporation, and the crude product was purified by flash chromatography (silica gel, hexane). The colorless oil was distilled through a short-path apparatus to give $8.76 \mathrm{~g} \mathrm{(88 \% )}$ of 1,1-diphenylcyclopropane as a clear, colorless liquid bp $89^{\circ} \mathrm{C}$ (0.8 Torr).

\subsection{Stereoselective Synthesis of Cyclopropanes}

Transfer of the carbene ligand from optically active transition-metal-carbene complexes to alkenes represents a potentially useful and general method for the enantioselective synthesis of cyclopropanes [224], and this task was successfully accomplished by the Brookhart group [225]. The starting complexes were obtained as a pair of iron acyl diastereoisomers, e.g., 58 (2SS) and 59 (2RS), differing in configuration at iron. These were converted into the desired cationic iron-carbene complexes 62 and 63 via intermediates 60 and 61, as shown in Scheme 13. The efficient transfer of the ethylidene group from these two diastereoisomeric ethylidene complexes, e.g., $\left[\left(\mathrm{S}_{\mathrm{Fe}} \mathrm{S}_{\mathrm{c}}\right)-\left(\eta^{5}-\mathrm{C}_{5} \mathrm{H}_{5}\right)(\mathrm{CO})\left(\mathrm{PPh}_{2} \mathrm{R}^{*}\right) \mathrm{Fe}=\mathrm{CHCH}_{3}\right]^{+}$(62) (1SS) and (63) (1RS) $\left.\left[R^{*}=(S)-2-m e t h y l b u t y l\right)\right]$, differing only in the configuration at iron, to styrene, gave respectively cisand trans-1-methyl-2-phenylcyclopropanes 64 and 65, and 66 and 67, with the high enantiomeric excesses shown. Since two diastereoisomers, e.g., 62 and 63 gave cyclopropanes having the opposite configuration in practically the same enantiomeric excesses, optical induction must be due to chirality at the metal. A study [225] discussed at length the role of the metal (e.g., iron) vs. ligand chirality in the optical induction. With iron-ethylidene complexes having a chiral phosphine in place of one $\mathrm{CO}$ ligand, high asymmetry induction was expected (and observed) [224].

A recent related study by the same group [226] discussed kinetic and thermodynamic diastereoselectivities of precursors to optically pure chiral-at-iron carbene complexes of the type $\left(\eta^{5}-\mathrm{C}_{5} \mathrm{H}_{5}\right)(\mathrm{CO})\left(\mathrm{PR}_{3}\right)$ $\mathrm{Fe}^{*}=\mathrm{CHR}^{+}(\mathrm{R}=\mathrm{Ph}, \mathrm{Et}) ;$ the study reports photosubstitution reactions, and hydride or methoxide addition to a series of carbene complexes. These complexes transfer the carbene moiety to alkenes to give cyclopropanes often with high enantioselectivity [225].

Additional syntheses of optically active cyclopropanes by the use of chiral butadiene-tricarbonyliron complexes have been reported [227-229]; particularly, preparation in this way of formylcyclopropanes of high enantiomeric purity provided the key intermediate for the synthesis of low toxicity insecticide pyrethroids [228,229]. 
<smiles></smiles>

(2SS) - 58

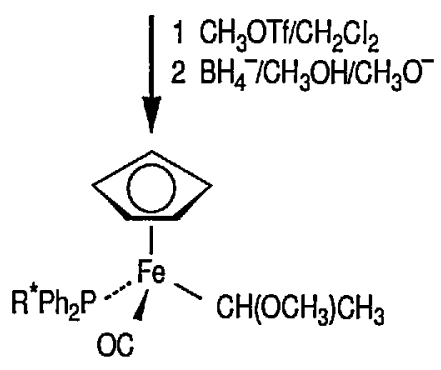

(3SS) - $60 \quad 90 \%$

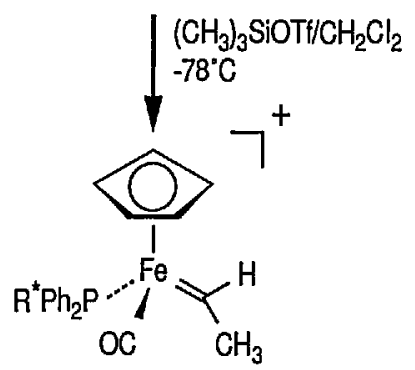

(1SS) -62<smiles>C/C=C/c1ccccc1</smiles><smiles>CC(=O)P(=O)(P)C1CCC1</smiles>

(2RS) - 59

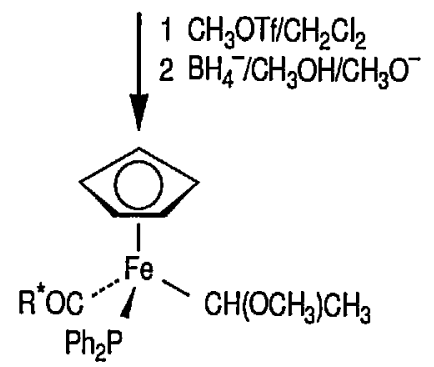

(3RS) - $61 \quad 90 \%$

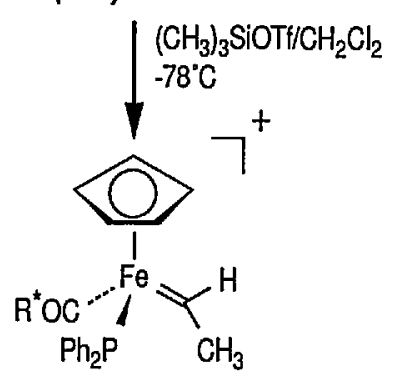

(1RS) -63<smiles>C/C=C\c1ccccc1</smiles><smiles>CC(C)(C)CC(C)(C)C(C)(C)C</smiles>

$\mathrm{Ph}$<smiles>CCC(C)(C)C(C)(C)CC(C)(C)C1c2ccccc21</smiles>

cis-(1R, 2S) - 64 trans-11R, 2R) - 65 cis-(1S, 2R) - 66 trans-(1S, 2S) - 67

Scheme 13

\subsection{Metal-Induced Rearrangements of Cyclopropyl Alkenes}

A brief overview of reactions of cyclopropane derivatives in the presence of iron pentacarbonyl, $\mathrm{Fe}(\mathrm{CO})_{5}$, or its dimer $\mathrm{Fe}_{2}(\mathrm{CO})_{9}$, is included for continuity. This exciting chemistry has been studied by Sarel, and many metal-induced rearrangements of, and insertions into, cyclopropyl alkenes have been reviewed by that author [44].

The polarizability of the cyclopropane $\sigma$ bonds, resulting in a tendency to undergo electrophilic attack by coordinatively unsaturated transition-metal complexes has been described $[230,231]$. The cyclopropane 
bonds are known to be weaker than normal $\sigma$ bonds, and they are consequently susceptible to attack by reagents that attack double bonds.

In analogy to dienes, vinylcyclopropanes (VCP) can be induced to form vinylcyclopropane-iron $\pi$ complexes by such zerovalent transition-metals as $\mathrm{Fe}(\mathrm{CO})_{5}$. Studies [44] led to discovery of at least five distinctly different modes of metal-mediated reactions of vinylcyclopropanes, depending on the substrate and the reaction parameters. These modes are as follows.

(1) Heat-induced rearrangement of vinylcyclopropanes to diene $\pi$ complexes. For example, the $\mathrm{Fe}(\mathrm{CO})_{5}$-mediated thermolysis of 1,1-dicyclopropylethylene (68) in boiling dibutyl ether led to the unexpected product 71 (via possible intermediate 70 ), together with the respective 1,3-diene tricarbonyliron $\pi$ complex 69 (an example of vinylcyclopropane-diene rearrangement) [232,233] (Scheme 14).

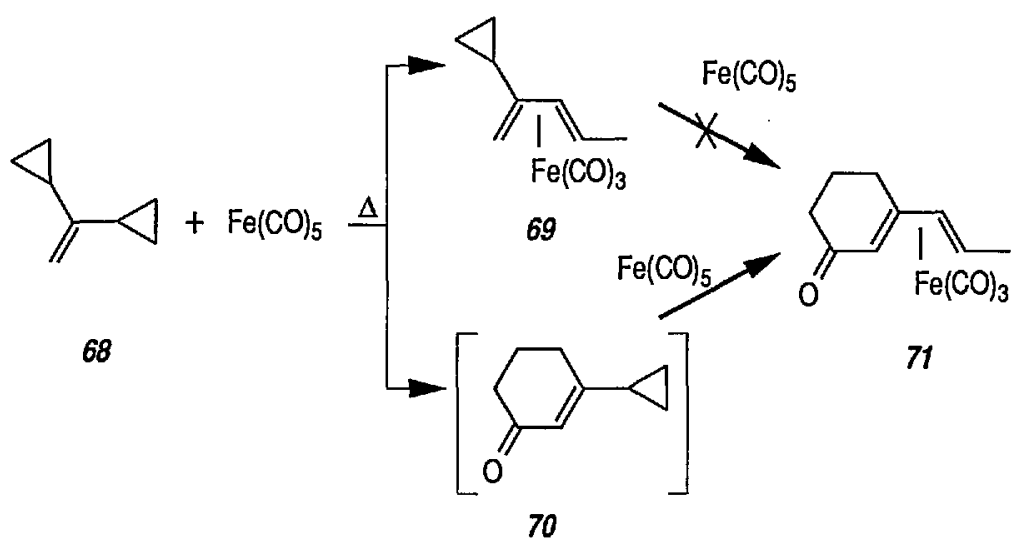

Scheme 14

(2) Photoinduced carbonyl insertions across the VCP system, to afford cyclohexenones, conversion $72 \rightarrow 73+74+75[232,234]$.<smiles>[R]C(=C)C1[CH+]C1</smiles>

72<smiles>CC(C)C1CC1</smiles>

73<smiles>[R]C1=CC(=O)CCC1</smiles>

74 and/or<smiles>[R]C1=CCCC(=O)C1</smiles>

75

$$
R=\mathrm{CH}_{3} ; b, \mathrm{R}=\mathrm{C}_{2} \mathrm{H}_{5}
$$

(3) Metal insertion into the VCP system to give $\sigma, \pi$-allyl complex, conversion $76 \rightarrow 77$ [235].

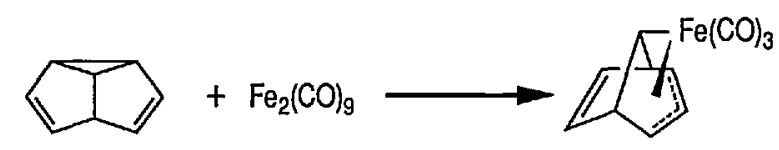

semibullvalene

76

77

(4) Photoinduced acyl-metal insertions into the vinylcyclopropane system. For example, photoreaction of $\alpha$-thujene 78 with $\mathrm{Fe}(\mathrm{CO})_{5}$ occurs in both a stereospecific and a regiospecific manner, conversion $78 \rightarrow 79$ [44]. More examples of acyl-metal insertions into vinylcyclopropane systems have been reported [236]. 


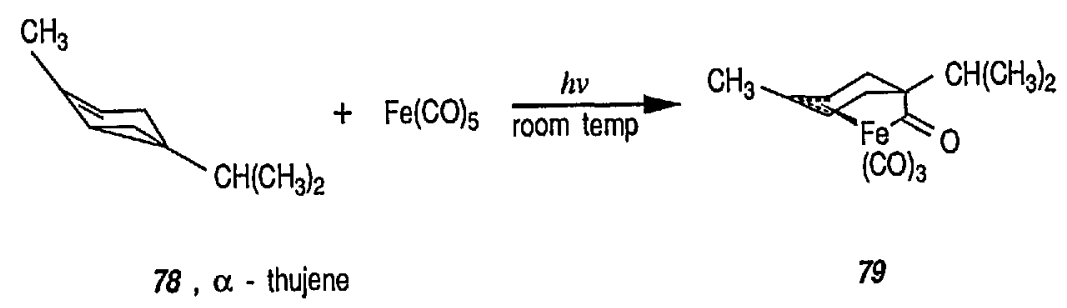

(5) Dicyclopropylacetylene as a multi-m-electron ligand. Adding extra unsaturation to the original $\mathrm{C}-\mathrm{C} \pi$ linkage was shown $[237,238]$ to render the cyclopropyl group inert to attack by iron carbonyl. For example, photoreaction of cyclopropylacetylene 80 with $\mathrm{Fe}(\mathrm{CO})_{5}$ gave rise to benzoquinones 81 and 82 originating from the insertion of carbonyls between the molecules of acetylene while leaving the cyclopropane ring itself intact [237].

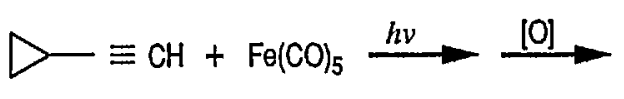

80<smiles>O=C1C=C(C2CC2)C(=O)C(C2CC2)=C1</smiles>

81<smiles>O=C1C=C(C2CC2)C(=O)C=C1C1CC1</smiles>

82

Thus, iron pentacarbonyl emerged as an efficient "homodienophile" having remarkable stereospecific and regiospecific characteristics. Vinylcyclopropanes and divinylcyclopropanes, on the other hand, emerge as novel sources of four and six $\pi$ electrons suitable for metal coordination. The special features characterizing the interaction between zerovalent transition metals (e.g., $\mathrm{Fe}(\mathrm{CO})_{5}$ or $\mathrm{Fe}_{2}(\mathrm{CO})_{9}$ ) and multi- $\sigma$, $\pi$-electron systems open up a new vista of chemical research of great synthetic interest [44].

Recently, Goldschmidt and Crammer [239] discussed vinylcyclopropane photorearrangements in the presence of $\mathrm{Fe}(\mathrm{CO})_{s}$ and extended the original Sarel's studies [232,233,240]. The reaction mechanism was elucidated by low-temperature $\left(-50^{\circ} \mathrm{C}\right)$ irradiation of vinylcylopropane and $\mathrm{Fe}(\mathrm{CO}) s$ giving two unstable $\mathrm{Fe}(\mathrm{CO})_{4}$-coordinated isomers [241].

\subsection{A New Class of $\sigma$-Cyclopropenyliron Complexes}

Whereas $\pi$-complexes of cyclopropenyl ligands with symmetrical as well as unsymmetrical coordination $[2,242]$ are today an extensive class of compounds, $\sigma$-cyclopropenyl complexes have thus far not been generally accessible [243]. An earlier report described the synthesis of $\sigma$-cyclopropenyl derivatives of $\mu^{5}$-cyclopentadiene dicarbonyliron 83 in which the metal is bonded to the methylene $C$ atom of the cyclopropane. Such $\alpha$-cyclopropenyl metal complexes as 83 can be viewed as derivatives of antiaromatic cyclopropenide ions. Recently, Gompper and Bartmann [43] extended this series, and reported the preparation of complexes, e.g., 85 , in which the metal is bonded to the double bond of the three-membered ring. The complexes of type 85 are simply prepared by reaction of the reported $[244,245]$ salt 84 with nucleophiles $\left(\mathrm{Nu}^{-}\right)$; these complexes are appreciably more stable than compounds of type 83 .

A recent report [246] on a related work described the reaction of 1,2,3-triphenyl-3-trifluorovinyl-cyclopropene with $\left[\mathrm{Fe}_{2}(\mathrm{CO})_{9}\right]$ to give a $\mathrm{Fe}(\mathrm{CO})_{4}$-complex containing a coordinated $\eta^{2}$-vinylcyclopropene; on subsequent irradiation a novel ring expansion occurred to give an air stable $\mathrm{Fe}(\mathrm{CO})_{3}-\eta^{4}$-cyclobutadiene complex. 


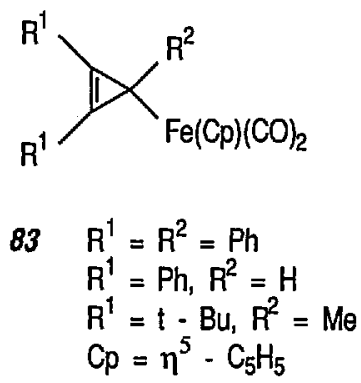

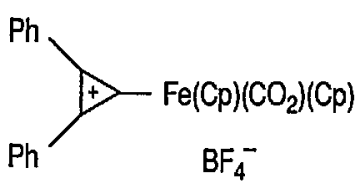

84

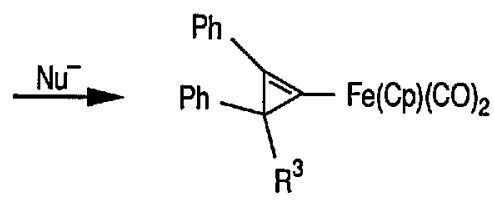

85

$$
\begin{aligned}
& R^{3}=H: 44 \% \\
& R^{3}=O M e: 54 \% \\
& R^{3}=C N: 70 \%
\end{aligned}
$$

\section{Stereochemical Control of Organic Reactions by Use of Chiral Organoiron Reagents}

Asymmetric synthesis is a widely pursued goal in modern synthetic chemistry [247-250]. A number of systems that feature $\mathrm{C}_{2}$ symmetry elements in their ligands, such as the Sharpless epoxidation reagent [249,251,252], the Noyori catalyst [253,254], Masamune's boranes [255], Davies' chiral acyliron auxiliary $[60,63]$, or Liebeskind's chiral iron complexes [64] have proved so successful that much confidence is now placed in the use of such symmetry elements in the design of reagents and catalysts [256]. Moreover, enantioselective catalysis with transition-metal complexes [31,257], enantioselective catalysis with enzymes [258-260], inorganic "enzymes" [261], chiral ligands for asymmetric synthesis [251], and asymmetric natural products as sources of chiral synthons [262-264] are now well established chiral synthetic methods [265-267]. Also, the importance of the spatial arrangement of molecular groups for asymmetric recognition has recently been emphasized [268]. Chiral synthesis is currently among the most exciting areas of organic chemistry [269-285]. Many syntheses, and very often the most elegant, have made use of the natural "chiral pool."

Organotransition-metal complexes form a class of very important compounds, not only because of their inherently interesting physical and chemical properties but also because of the significant impact they are having on synthetic organic chemistry [79,286-288]. Many novel synthetic applications of organotransitionmetal complexes have been reported in the recent literature, which provides methods for synthetic transformations difficult or impossible to achieve by more conventional routes. Among those, such organoiron complexes as $\left[\left(\eta^{5}-\mathrm{C}_{5} \mathrm{H}_{5}\right) \mathrm{Fe}(\mathrm{CO})\left(\mathrm{PPh}_{3}\right)\right][79,286,289]$ or $\left.\left[\eta^{5}-\mathrm{C}_{5} \mathrm{H}_{5}\right) \mathrm{Fe}(\mathrm{CO})_{2}\right][209,290-292]$ have been studied extensively as effective reagents for selective organic transformations. Triphenylphosphine-substituted analogues of the $\left[\left(\eta^{5}-\mathrm{C}_{5} \mathrm{H}_{5}\right) \mathrm{Fe}(\mathrm{CO})_{2}\right]$ group, however, have emerged as very versatile intermediates for organic synthesis with potential applications in the area of asymmetric induction [41,286,287,293]. In regard to triphenylphosphine-substituted organoiron complexes including iron-carbene complexes such as $\left[\left(\eta^{5}\right.\right.$ $\left.\left.\mathrm{C}_{5} \mathrm{H}_{5}\right) \mathrm{Fe}(\mathrm{CO})\left(\mathrm{PPh}_{3}\right)=\mathrm{CHR}^{+}\right]$it was established $[61,63,64,192]$ that the phosphine ligand $\left(\mathrm{PPh}_{3}\right)$ shields one face of the carbene moiety. Consequently reactions of iron-carbene complexes with nucleophiles can form two diastereomers. The pyramidal nature of the phosphorous atom in organophosphine complexes comprising the $\mathrm{PPh}_{3}$ ligand has been reported [293].

Recently Gladysz et al. [294-299] using $\left.\left[\eta^{5}-\mathrm{C}_{5} \mathrm{H}_{5}\right) \mathrm{Fe}(\mathrm{CO})\left(\mathrm{PPh}_{3}\right)\right]$ or $\left[\left(\eta^{5}-\mathrm{C}_{5} \mathrm{H}_{5}\right) \mathrm{Re}(\mathrm{NO})\left(\mathrm{PPh}_{3}\right)\right]$ as chiral auxiliaries carried out numerous diastereoselective and enantioselective transformations which could be of importance in stereoselective synthesis.

\subsection{Stereoselective Synthesis via Chiral Auxiliary $\left.\left[\eta^{5}-C_{5} H_{s}\right) F e(C O)\left(P P h_{3}\right)\right]$. Stereoselective Alkylation Reactions}

Introduction of the $\mathrm{Fe}(\mathrm{CO})_{3}$ group onto a substituted cyclohexadiene makes the molecule asymmetric. Should these complexes be produced in optically active form, any synthesis utilizing them would be asymmetric [300]. Since the demonstration by Brunner [41,301] that the iron acetyl complex $\left[\left(\eta^{5}\right.\right.$ $\left.\left.\mathrm{C}_{5} \mathrm{H}_{5}\right) \mathrm{Fe}(\mathrm{CO})\left(\mathrm{PPh}_{3}\right) \mathrm{COCH}_{3}\right]$ could be prepared in optically active form and was configurationally stable under ambient conditions, much work has focused on using optically active substrates to gain information about organometallic reaction mechanisms [302,303]. However, the main recent interest in iron acetyl complexes and related metal acyl complexes lies in their novel synthetic applications. Many organometallic reactions proceed through acyl-metal complexes, many of which are quite stable, and readily isolated and handled. With appropriate metal-acyl complexes, protons $\alpha$ to the carbonyl group are acidic, and can be 
removed by base, to generate the corresponding metal-acyl enolates, i.e., "chiral enolate equivalents" [304]. For example, deprotonation of the stable iron acetyl complex $\left[\left(\eta^{5}-\mathrm{C}_{5} \mathrm{H}_{5}\right) \mathrm{Fe}(\mathrm{CO})\left(\mathrm{PPh}_{3}\right) \mathrm{COCH}_{3}\right]$ with lithium diisopropylamide (LDA) or butyllithium in tetrahydrofuran (THF) at $-42^{\circ} \mathrm{C}$ generates a deep red-brown solution of a stable iron acyl enolate [305,306]. Solutions of this enolate have been shown to undergo a variety of highly stereoselective carbon-carbon bond-forming reactions such as alkylation [307-312], aldol reactions [305,311-317], imine condensation [64,318], Michael addition [319], and synthesis of $\beta$-lactams [64].

Enolates 87 and 90 derived from acyl ligands attached to the chiral auxiliary $\left[\left(\eta^{5}-\mathrm{C}_{5} \mathrm{H}_{5}\right) \mathrm{Fe}(\mathrm{CO})\left(\mathrm{PPh}_{3}\right)\right]$, e.g., complexes 86 and 89 , undergo highly stereoselective alkylation reactions [307,308] to give corresponding alkylation products 88 and 91 , conversions $86 \rightarrow 87 \rightarrow 88$ and $89 \rightarrow 90 \rightarrow 91$ (Scheme 15). The stereochemical control observed in these reactions is consistent with preferential formation of $E$-enolates exclusively ( $>200: 1)$ and their subsequent alkylation in the anti orientation $\left(\mathrm{O}^{-}\right.$to $\mathrm{CO}$ ) from the unhindered face; the other face being completely shielded by the bulky triphenylphosphine ligand [308,309]. The resulting, overall elaboration of a new chiral center via carbon-carbon bond formation also occurs with extremely high stereoselectivity (>200:1) [310]. Factors controlling the stereoselective alkylation reactions of iron acyl enolates have been discussed [310], and methylation and ethylation of $E$-enolates are depicted in Scheme 15.

A regioselective synthesis of a terminal alkene involving alkene- $\left[\left(\eta^{5}-\mathrm{C}_{5} \mathrm{H}_{5}\right)^{+} \mathrm{Fe}(\mathrm{CO})_{2}\right] \mathrm{BF}_{4}^{-}$complex has been described [320].

A chiral iron acyl of the type $\left(\eta^{5}-\mathrm{C}_{5} \mathrm{H}_{5}\right) \mathrm{Fe}(\mathrm{CO})\left[\mathrm{PPh}_{2}\left(\mathrm{C}_{6} \mathrm{~F}_{5}\right)\right]-\mathrm{CO}-\mathrm{Me}$ has recently been reported [321] as an effective chiral reagent for stereoselective reactions such as aldol condensations, alkylations or $\beta$-lactam synthesis.

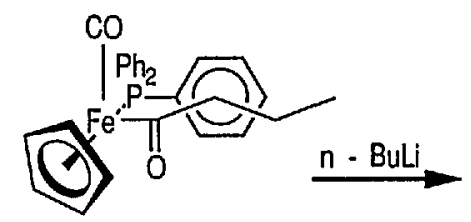

86

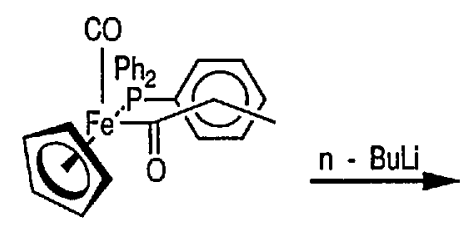

89

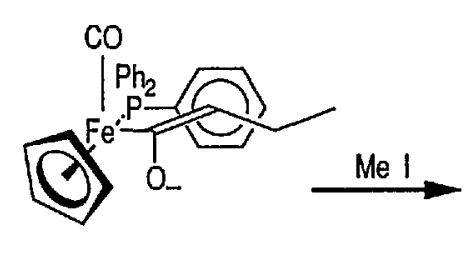

87 (anti)

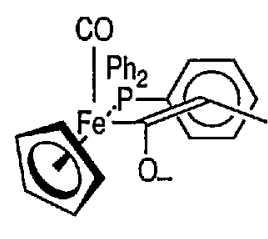

90 (anti)

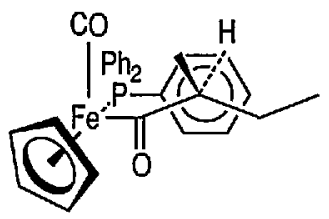

88

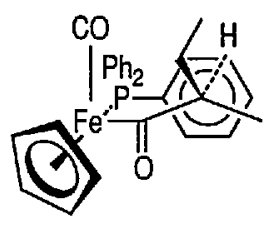

91

Scheme 15

The enolate 93 (from 92) reacts with a wide range of electrophiles to give a series of $C$-alkylation products [307-317] (Scheme 16). Because acyliron species are oxidatively cleaved to esters, this affords a method of homologation. The stereoselective elaboration of chiral acyliron complexes by addition of electrophiles to the anions combined with known procedures for the resolution [322] and decomplexation of acyl ligands without racemization [323], will allow the development of efficient asymmetric syntheses.

\subsection{Diastereocontrol of Aldol Reactions via Chiral Iron Acyl Complexes. Stereochemical Effect of Metal Counterions}

The profound influence of the chiral group $\left[\left(\eta^{5}-\mathrm{C}_{5} \mathrm{H}_{5}\right) \mathrm{Fe}(\mathrm{CO})\left(\mathrm{PPh}_{3}\right)\right]$ on the stereoselectivity in a series of conjugate addition reactions has recently been demonstrated. Conjugate additions and conjugate addition-alkylations usually proceed with very high stereoselectivity to $\alpha, \beta$-unsaturated acyls of $\left[\left(\eta^{5}-\mathrm{C}_{5} \mathrm{H}_{5}\right)\right.$ $\left.\mathrm{Fe}(\mathrm{CO})\left(\mathrm{PPh}_{3}\right)\right]$. Here, Liebeskind [64,314] and Davies [61,62,311,324] are independently credited for the development of novel chiral reactions of the acetyl iron complex (94). It has been shown [64,314] that the 


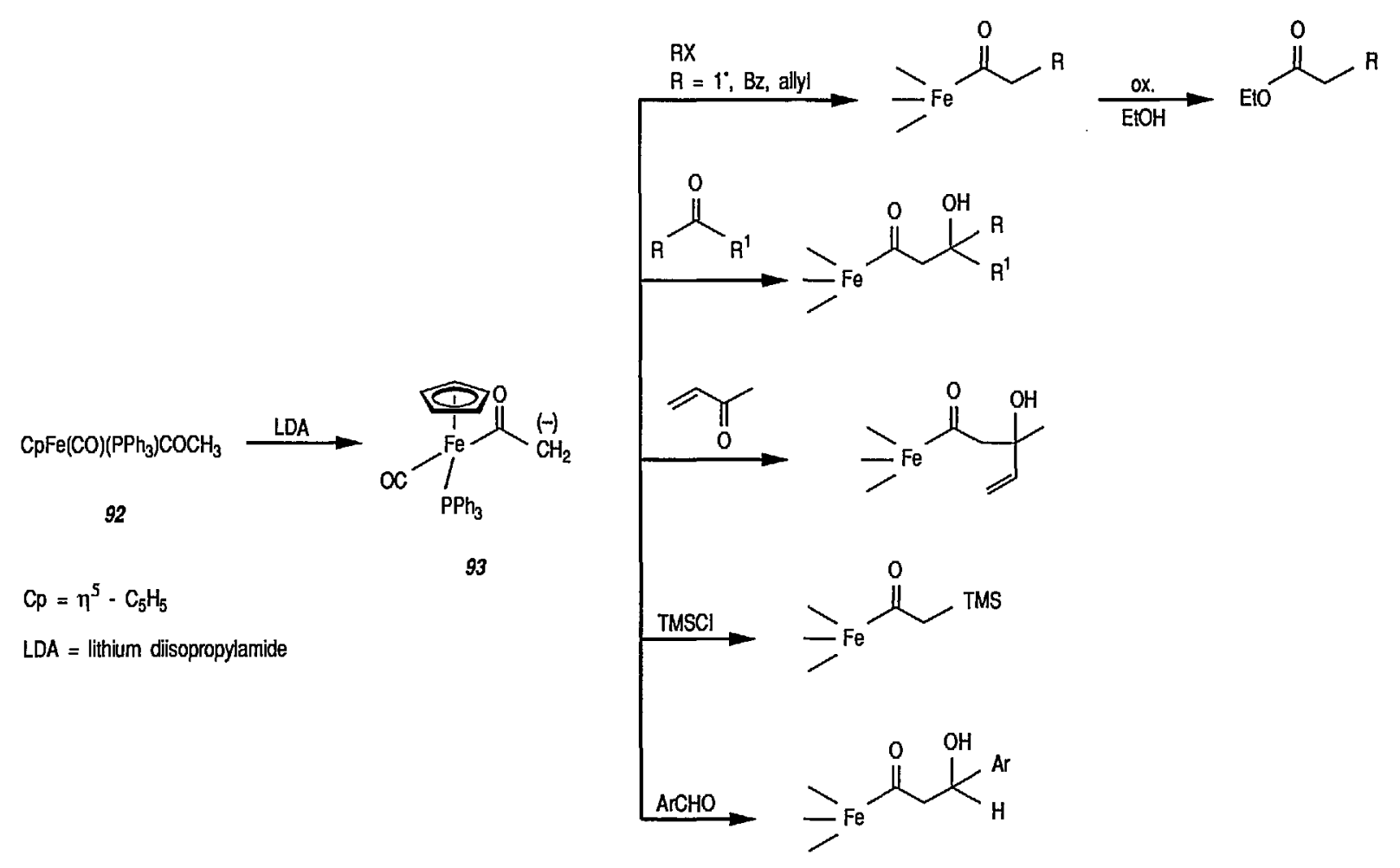

Scheme 16

enolate from (94), e.g., $\left[\left(\eta^{5}-\mathrm{C}_{5} \mathrm{H}_{5}\right) \mathrm{Fe}(\mathrm{CO})\left(\mathrm{PPh}_{3}\right) \mathrm{COCH}_{2}\right]$, reacts with aldehydes to afford aldol products 95 and 96 with high stereoselectivity (Scheme 17). In the presence of a Lewis acid catalyst, e.g., $i-\mathrm{Bu}_{2} \mathrm{Al}^{+}$, as the counterion diastereoisomer 95 preponderated with a 95:96 ratio of up to 8:2 being obtained. With $\mathrm{SnCl}^{+}$as the counterion, the opposite diastereoisomer 96 preponderated with a maximum 95:96 ratio of 1:12.

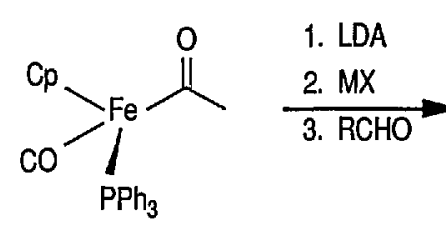

94

$\mathrm{Cp}=\eta^{5}-\mathrm{C}_{5} \mathrm{H}_{5}$<smiles>O=C(CC(O)F)P(=O)([O-])[Pb]</smiles>

95<smiles>[R]C(O)CC(=O)[P-]([O-])([O-])[PH3+]</smiles>

96

$\mathrm{R}=\mathrm{Et}, \mathrm{n}-\mathrm{Pr}, \mathrm{i}-\mathrm{Pr}, \mathrm{Ph}$, trans styryl

Scheme 17

Davies et al. [311,324] studied exactly this same system, and with the $\mathrm{Et}_{2} \mathrm{Al}^{+}$counterion, they obtain $>$ 100:1 diastereoselectivity. The origin of this disparity appears to be the use of an excess of alkylaluminum [311]. If $\mathrm{Cu}(\mathrm{I})$ is used as the counterion, the opposite stereochemistry is obtained. From these examples it can be seen that the nature of the metal counterion has a profound effect on the stereochemical outcome of the reaction. By changing from an aluminum to a copper or tin enolate, opposite stereoselectivity is obtained. Models to explain these observations have been proposed [64,309].

The copper enolate is also reactive toward ketones, again giving aldol products [317]. By generating the dianion 97 of the initial aldol product, and alkylating this enolate (to give 98), followed by oxidative removal of the iron moiety, it was found possible to prepare erythro $\beta$-hydroxy acid 99 with very high stereoselectivity. 


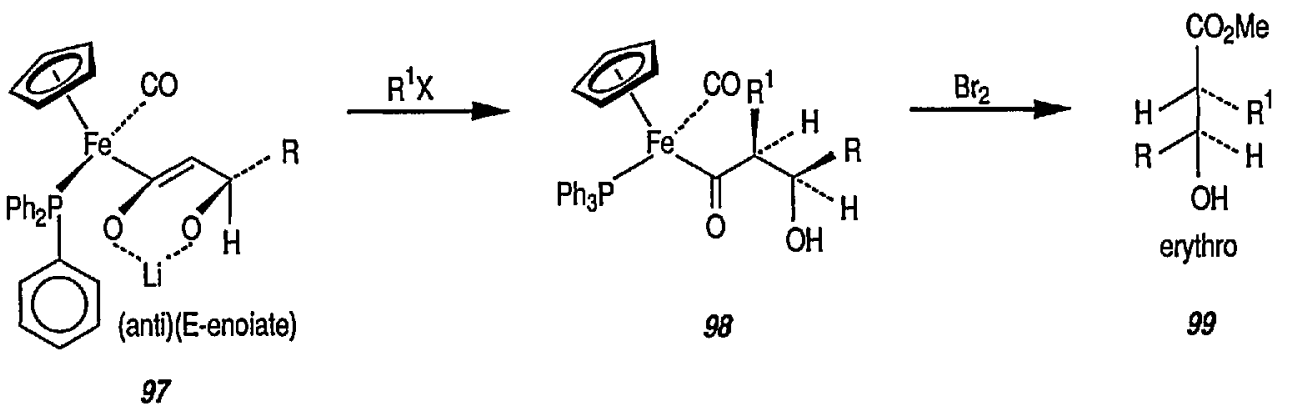

Scheme 18

Here again the relative configuration of the observed product results from alkylation of the $E$-enolate (97) in the anti $\left(\mathrm{O}^{-}\right.$to $\mathrm{CO}$ ) orientation from the unhindered face of the complex (Scheme 18).

Attempted dehydration of aldol products under a variety of acidic and basic conditions was not successful; however, acetylation of the hydroxyl group of 101 followed by acetate elimination with potassium tert -butoxide provided a practical method for preparing quantities of useful $\alpha, \beta$-unsaturated iron acyls, e.g., 102, conversion $100 \rightarrow 101 \rightarrow 102$ [325] (Scheme 19). These intermediates were needed in order to probe the possibility of chiral iron-controlled diastereoselectivity in conjugate addition reactions [326] or Michael additions [326-328].<smiles>O=C1PC(=O)P(=P)(C(=O)P)C12CC2</smiles>

100

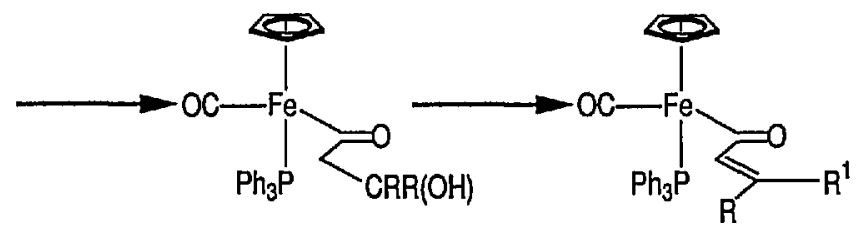

101

$\frac{\% 102}{93}$

87
$\% 101$

82

93 m. p. 102

$137-138.5$

$122.5-124.5$

Scheme 19

This study has been extended [326] to show that conjugate additions and conjugate addition-alkylations proceed with very high stereoselectivity to $\alpha, \beta$-unsaturated acyls of $\left[\left(\eta^{5}-\mathrm{C}_{5} \mathrm{H}_{5}\right) \mathrm{Fe}(\mathrm{CO})\left(\mathrm{PPh}_{3}\right)\right]$. Thus, treatment of $E$-unsaturated acyls $103\left(\mathrm{R}=\mathrm{CH}_{3}\right)$ or $(\mathrm{R}=\mathrm{Ph})$ with lithium nucleophiles $\mathrm{NuLi}(\mathrm{Nu}=\mathrm{Ph}, \mathrm{Bu}$, $\mathrm{PhCH}_{2} \mathrm{NH}, \mathrm{PrNH}, \mathrm{PhNH}$, allyl NH, $\left.\mathrm{CH}_{3} \mathrm{OCH}_{2} \mathrm{CH}_{2} \mathrm{NH}\right)$ resulted in an extremely selective conjugate addition reaction, to provide in high yield, practically only one product diastereomer 104, after low-temperature protonation of the intermediate enolate, conversion $103 \rightarrow 104$ [326]. Some stereoselective conjugate addition reactions are shown in Scheme 20. 


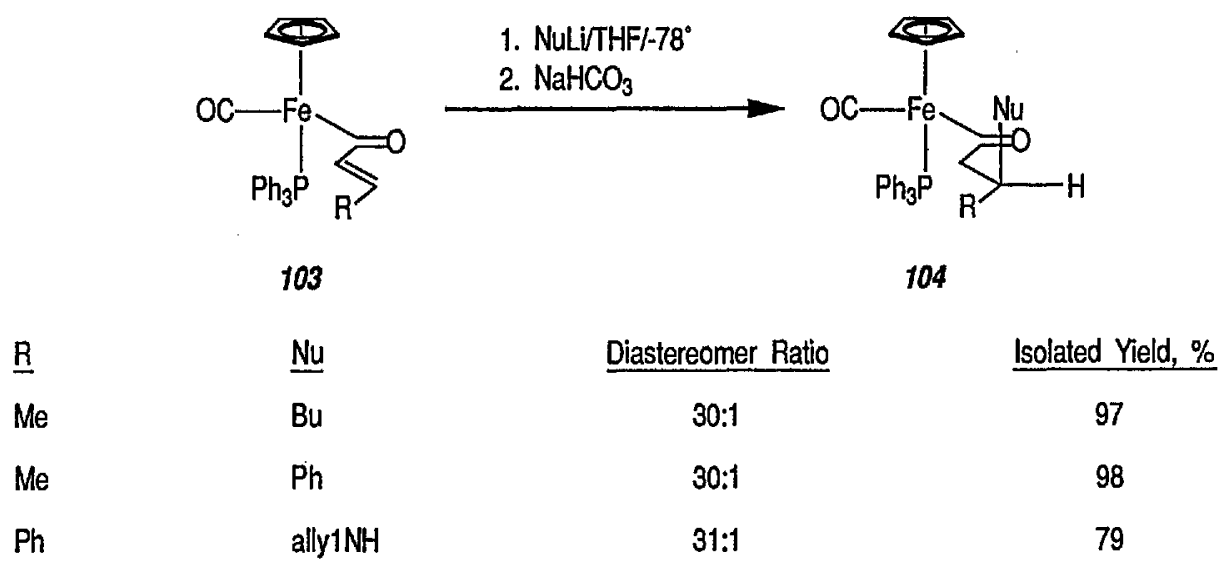

Scheme 20

\subsection{Stereoselective Synthesis of $\beta$-Lactams via Chiral Iron Acyl Complexes}

Optically active $\beta$-lactams are important antibiotics, and have long been a target of organic synthesis. In all cases, however, a chiral source is essential for enantiometric control, and this can apparently be achieved by using iron acyl complexes. Thus, oxidative cleavage of 105 provides high yields of organic acid derivatives (esters, $\beta$-lactams) with almost complete control of the relative stereochemistry. For example, treatment of $105\left(\mathrm{Nu}=\mathrm{Ph}, \mathrm{R}=\mathrm{CH}_{3}\right)$ with $1.1 \mathrm{eq}$ of bromine at $-78^{\circ} \mathrm{C}$ in $\mathrm{EtOH} / \mathrm{CS}_{2}$ gave the ethyl ester 106a in $83 \%$ yield; however, oxidative decomposition $\left(\mathrm{Br}_{2} / \mathrm{CS}_{2} /-78^{\circ} \mathrm{C}\right)$ of the benzylimine derivative 105 $\left(\mathrm{Nu}=\mathrm{PhCH}_{2} \mathrm{NH}, \mathrm{R}=\mathrm{CH}_{3}\right)$ without ethanol gave $\beta$-lactam 107 in $78 \%$ yield. The high-yield, stereospecific formation of $\beta$-lactam 107 suggested that the conjugate addition of amine anion nucleophiles to $\alpha, \beta$-unsaturated iron acyls followed by alkylation would provide a simple stereospecific route to 2,3-disubstituted $\beta$-lactams [64] (Scheme 21).

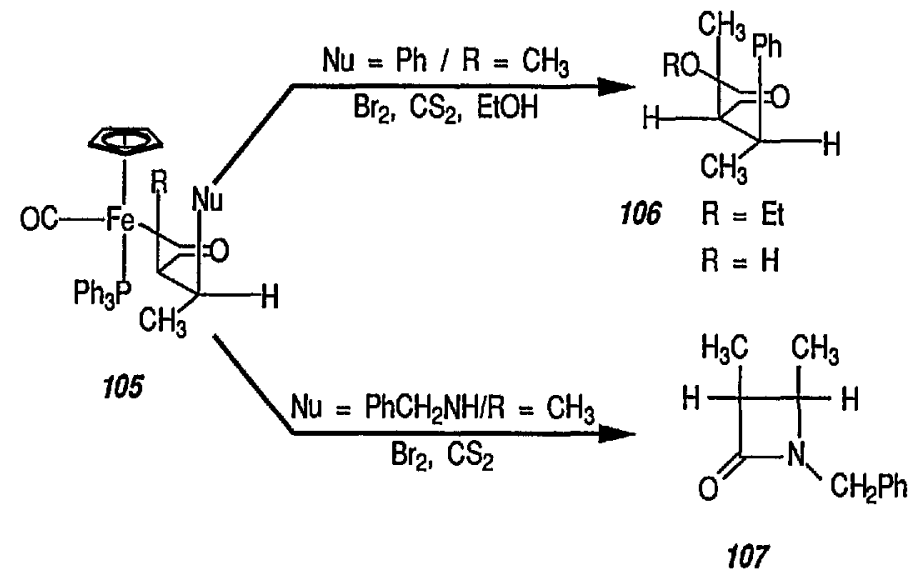

Scheme 21

Both Davies [327,328] and Liebeskind [329] have used this chemistry in a stereoselective synthesis of a series of $\beta$-lactams [330]. Davies began with racemic iron acyl complex 108 and its lithium enolate, and condensed it with the phenylimine of benzaldehyde. Only one diastereoisomer 109 is produced, which upon oxidative cleavage $\left(\mathrm{CuCl}_{2}\right)$, produces the $\beta$-lactam 110. Similarly, Liebeskind used both the lithium and the aluminum enolates and condensed them with a number of imines. In all cases, mixtures of diastereoisomers are obtained, which upon oxidation $\left(\mathrm{Br}_{2}\right.$ or $\left.\mathrm{I}_{2} / \mathrm{CS}_{2}\right)$ produce the $\beta$-lactam in $60-80 \%$ yield (table 2). Because the initial chiral iron-acyl complex can be resolved, this in principle, provides an asymmetric synthesis of $\beta$-lactams. Bulky $\beta$-amino ironacyls 111,112 and 113 were also converted into $\beta$-lactams (table 2). 
<smiles>CC(=O)P(=O)(c1ccccc1)c1ccccc1</smiles>
(racemic)

108<smiles>CC(C)(C)C=Nc1ccccc1</smiles><smiles>O=C(CC(c1ccccc1)P(C(=O)[O-])c1ccccc1)P(C1=CC1)c1ccccc1</smiles>

109<smiles>O=C1CC(c2ccccc2)N1c1ccccc1</smiles>

110

Table 2. Synthesis of $\beta$-lactams from $\beta$-amino iron acyls [329]

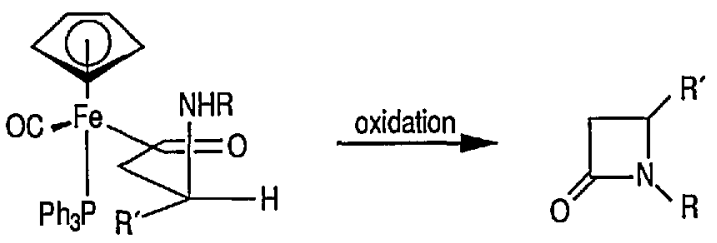

\begin{tabular}{|c|c|c|c|}
\hline $\mathrm{R}^{\prime}$ & $R$ & Reaction Conditions & $\begin{array}{l}\beta-\text { lactam } \\
\text { yield, } \%\end{array}$ \\
\hline $\mathrm{Ph}$ & $\mathrm{Ph}$ & $\begin{array}{l}\mathrm{I}_{2} / \mathrm{CH}_{2} \mathrm{Cl}_{2} / \mathrm{PhNMe}_{2} / \\
-42^{\circ} \mathrm{C}\end{array}$ & 80 \\
\hline $\mathrm{Ph}$ & $\eta-\operatorname{Pr}$ & $\begin{array}{l}\mathrm{I}_{2} / \mathrm{CH}_{2} \mathrm{Cl}_{2} / \mathrm{PhNMe}_{2} / \\
\text { room temp }\end{array}$ & 70 \\
\hline $\mathrm{Ph}$ & $\eta-\operatorname{Pr}$ & $\mathrm{Br}_{2} / \mathrm{CS}_{2} /-42^{\circ} \mathrm{C}$ & 82 \\
\hline $\mathrm{Ph}$ & $\mathrm{CH}_{2} \mathrm{Ph}$ & $\mathrm{Br}_{2} / \mathrm{CS}_{2} /-78{ }^{\circ} \mathrm{C}$ & 79 \\
\hline & & $\mathrm{Br}_{2} / \mathrm{CS}_{2} /-45^{\circ} \mathrm{C}$ & 56 \\
\hline & & $\mathrm{I}_{2} / \mathrm{CH}_{2} \mathrm{Cl}_{2} / \mathrm{Et}_{3} \mathrm{~N}$ & 62 \\
\hline & 113 & & \\
\hline
\end{tabular}


Still another approach to the stereoselective synthesis of $\beta$-lactams employing organoiron complexes as intermediates has been described by Rosenblum [331,332]. Thus, allylacetone 115 is converted in high yield into the corresponding $\pi$-complex $116\left[\left(\eta^{5}-\mathrm{C}_{5} \mathrm{H}_{5}\right) \mathrm{Fe}(\mathrm{CO})_{2}\right.$ (alkene) $\left.\mathrm{BF}_{4}\right]$ by exchange with $\left[\left(\eta^{5}-\mathrm{C}_{5} \mathrm{H}_{5}\right) \mathrm{Fe}(\mathrm{CO})_{2}\right.$ (isobutylene) $\left.\mathrm{BF}_{4}\right](114)$. No competitive complexation of the $\left[\left(\eta^{5}-\mathrm{C}_{5} \mathrm{H}_{5}\right) \mathrm{Fe}(\mathrm{CO})_{2}\right]$ group with the carbonyl function is observed in this reaction, as the oxygen atom is not sufficiently basic to interfere in the exchange reaction. On treatment with ammonia $\left(\mathrm{CH}_{2} \mathrm{Cl}_{2}\right.$, room temperature) complex 116 is converted into the pyrroline complex 117. Reduction with sodium borohydride in ethanol affords a 1:1 mixture of stereoisomeric pyrrolidine complexes; only one of which (118) is transformed into chelate complex 119 via a thermal rearrangement $\left(\mathrm{CH}_{3} \mathrm{CN}\right.$, three drops of tri-butylphosphine, $\left.65^{\circ} \mathrm{C}, 7.5 \mathrm{~h}\right)$. Oxidation of the chelate 119 with silver oxide in THF afforded the bicyclic lactam, 2-methylcarbopenam 120 in $72 \%$ yield (Scheme 22); oxidation with air can also be used [332].

An alternative new procedure for synthesis of $\beta$-lactams has recently been described [292]. Thus, Michael-type additions of amines and thiols to $\alpha, \beta$-enoyl-FeCp $(\mathrm{CO})_{2},\left(\mathrm{C}_{\mathrm{p}}=\eta^{5}-\mathrm{C}_{5} \mathrm{H}_{5}\right)$ (122) (prepared as shown $121 \rightarrow 122$ ) were carried out without solvent at ambient temperature to give the corresponding new $\beta$-aminoalkanoyl-FeCp$(\mathrm{CO})_{2}(123)$ and $\beta$-thioalkanoyl- $\mathrm{FeCp}(\mathrm{CO})_{2}(124)$ complexes in $60-90 \%$ yields (conversion $122 \rightarrow 123 \rightarrow 124$ ). These intermediates were then selectively oxidized to $\beta$-lactams, e.g., 125 . The lactam 125 apparently is a racemate; note the absence of the bulky, electron-donating (asymmetric) triphenylphosphine group in the starting material. Other syntheses of $\beta$-lactams are described in section 7 (Natural Products).

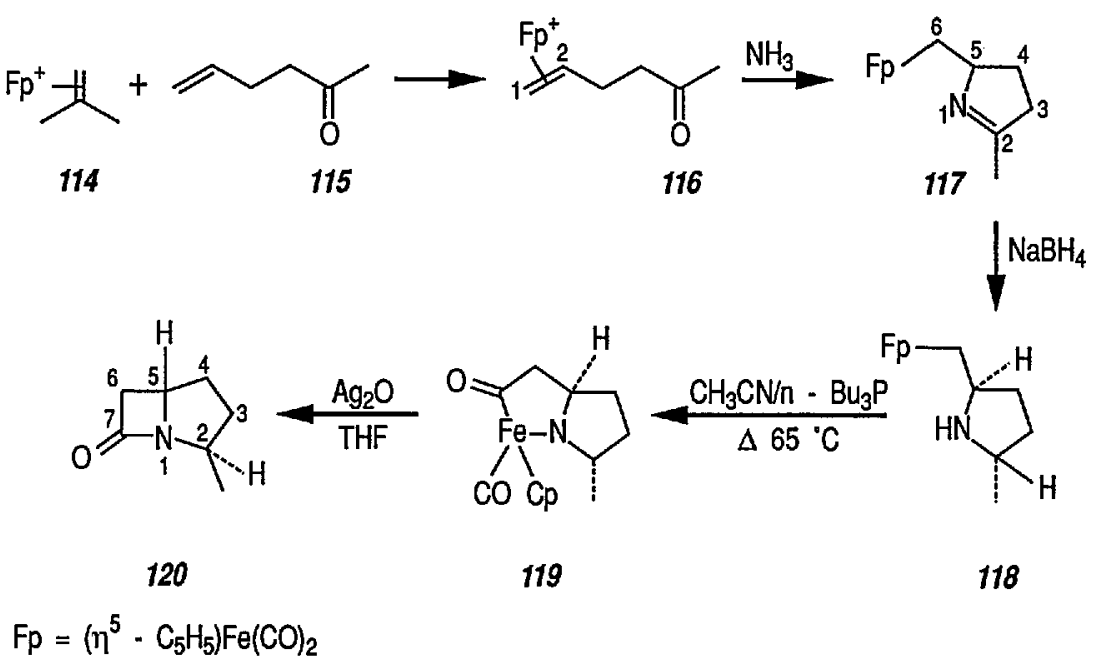

Scheme 22 


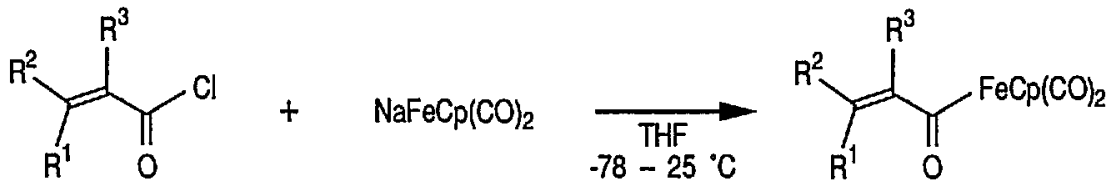

$$
\begin{aligned}
& 121 \quad R_{1}=R_{2}=M e, R_{3}=H_{3} 79.5 \% \\
& R_{1}=H_{1}, R_{2}=M e, R_{3}=H_{2} \\
& \left.R_{1}=M e, R_{2}=H, R_{3}=H^{3}\right\} 74.5 \% \\
& R_{1}=R_{2}=H, R_{3}=M e, 70.1 \% \\
& R_{1}=R_{2}=R_{3}=H, 72.2 \%
\end{aligned}
$$

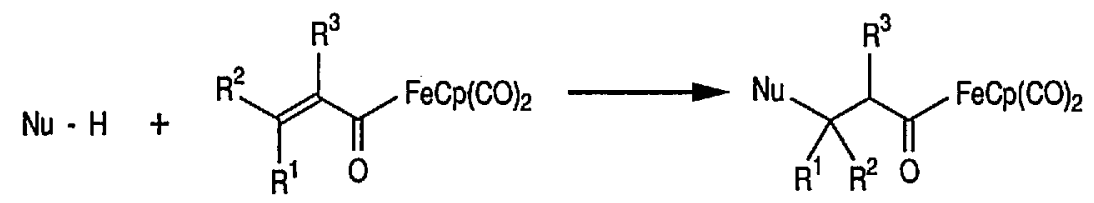

$$
\begin{aligned}
& 122 \\
& \text { 123: } \mathrm{Nu}=\mathrm{RR}^{\prime} \mathrm{N}- \\
& \text { 124: } \mathrm{Nu}=\mathrm{R}^{\prime \prime} \mathrm{S} \text {. } \\
& \mathrm{C}_{p}=\eta^{5} \cdot \mathrm{C}_{5} \mathrm{H}_{5}
\end{aligned}
$$

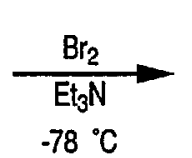

\subsection{Stereoselective Michael Addition via Chiral Iron Acyl Complexes}

The tandem stereocontrolled formation of two chiral centers via Michael addition of carbanions to iron $\alpha, \beta$-unsaturated carbonyl compounds and subsequent alkylation of the enolate thus formed has been recognized for some time [311,319]. It has recently been found $[319,328]$ that $\alpha, \beta$-unsaturated complexes of $\left[\left(\eta^{5}-\mathrm{C}_{5} \mathrm{H}_{5}\right) \mathrm{Fe}(\mathrm{CO})\left(\mathrm{PPh}_{3}\right)\right]$ undergo tandem stereoselective Michael addition, and subsequent methylation results in the stereocontrolled synthesis of $\alpha$ - and $\beta$-substituted iron acyl complexes. Thus, deprotonation of the acetyl complex 126 at $-78^{\circ} \mathrm{C}$ with butyllithium $(\mathrm{BuLi})$ generated the enolate 127 that, on addition of chlorotrimethylsilane underwent exclusive $C$-silylation to generate the $\alpha$-trimethylsilyl complex 128 (86\% yield). Treatment of 128 in tetrahydrofuran at $-78{ }^{\circ} \mathrm{C}$ with butyllithium produced the enolate 129 which after addition of a freshly prepared solution of formaldehyde in THF gave the $\alpha, \beta$-unsaturated acyl complex 130. Addition of methyllithium to a solution of (130) in THF at $-78^{\circ} \mathrm{C}$ in the presence of methyliodide stereoselectively (>30:1) generated the $(R S, S R)$ diastereoisomer (132) of the (S)-butyl acyl complex. The observed preferential formation of (132) is consistent with methyllithium attacking (130) in the cisoid orientation to generate the $E$-enolate (131) which, as reported previously, is methylated with high facial stereoselectivity to give (132) [316,317] (Scheme 23).

Thus, $\alpha$-alkyl- $\alpha, \beta$-unsaturated acyl groups attached directly to the chiral iron center (e.g., 126), undergo asymmetric Michael additions to yield $E$-enolates (e.g., 131) which can be trapped to yield quaternary carbon centers highly stereoselectively [319,327]. In case amines are used as nucleophiles then chiral $\beta-$ aminoacids are formed which can be cyclized to give stereodefined 2,3-disubstituted $\beta$-lactams in good yield [328].

Recently, the effect of phosphine substitution on nucleophilic addition to $\alpha, \beta$-unsaturated acyliron complexes has been studied by the Herndon group [57]; particularly Michael addition reactions of $\alpha, \beta-$ 
unsaturated acyliron complexes where the iron atom is chiral have been examined. The paper concludes [57] that the reaction of organolithium reagents (e.g., $\mathrm{R}^{\prime} \mathrm{Li}$ ) with $\alpha, \beta$-unsaturated acyliron complexes of the type $\mathrm{C}_{\mathrm{p}}-(\mathrm{CO})\left(\mathrm{PR}_{3}\right) \mathrm{FeCOCH}=\mathrm{CHR}^{\prime}\left[\mathrm{C}_{\mathrm{p}}=\left(\eta^{5}-\mathrm{C}_{5} \mathrm{H}_{5}\right)\right]$ is highly diastereoselective. This high diastereoselectivity can be obtained regardless which phosphine ligand is present at iron; a triphenylphosphine ligand is not required to obtain high diastereoselectivity. Contrary to earlier suggestions conformational preferences of the acyl group in these complexes is clearly due to more than steric interactions between the acyl oxygen and the aryl groups of a triphenylphosphine ligand. More work on this conformational preference is, evidently, in order.

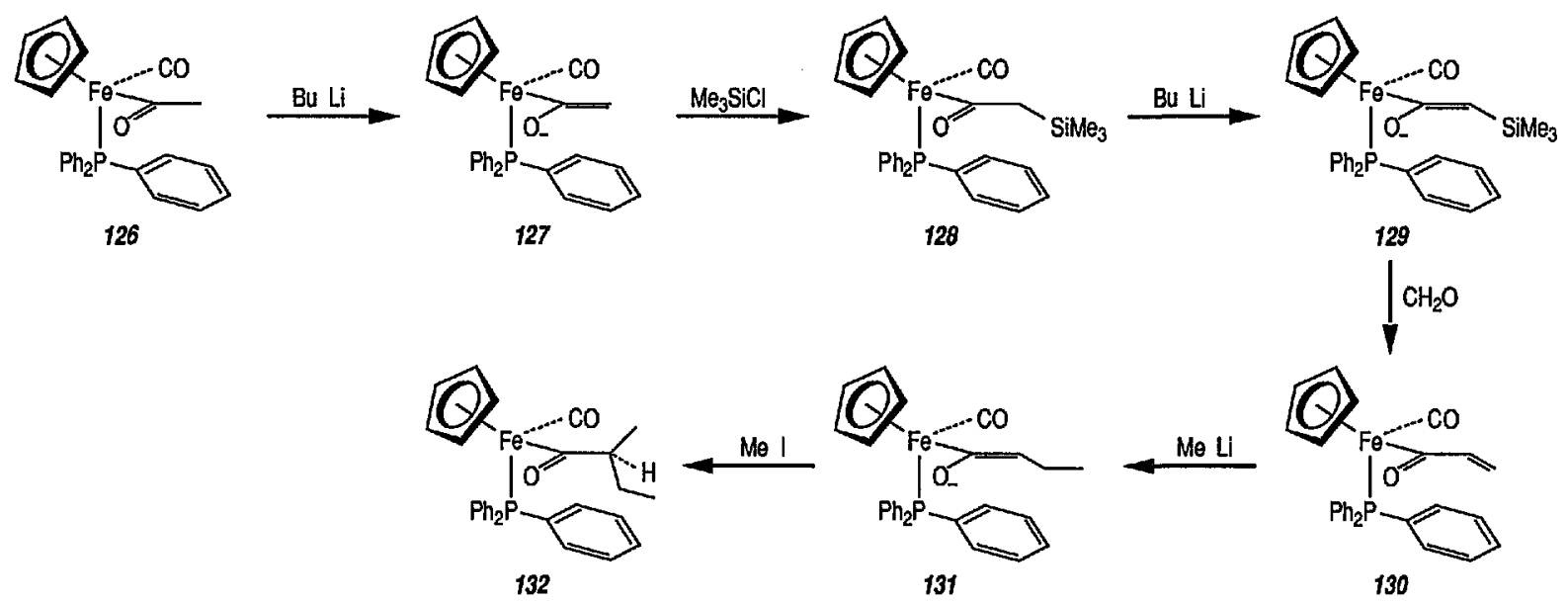

Scheme 23

\subsection{Tricarbonyliron Complexes in Synthesis of 1,4-Diketones}

Although tricarbonyliron complexes of $\alpha, \beta$-unsaturated ketones were first synthesized more than 20 years ago [333], the reactivity of the $\alpha, \beta$-unsaturated ketone fragments of these compounds has received little attention. Electrophilic addition to the complexes has been reported [334,335], but the reaction of tricarbonyliron complexes of $\alpha, \beta$-unsaturated ketones with nucleophiles has not yet been investigated. A recent paper [336] fills this gap; the reaction of Grignard and organolithium reagents with iron tricarbonyl complexes of $\alpha, \beta$-unsaturated ketones leads to 1,4 -diketones in a reaction controlled by the transition-metal center. Thus, tricarbonyl (benzylideneacetone) iron complex 133 was treated with methylmagnesium bromide at $-78^{\circ} \mathrm{C}$, and the reaction quenched with tert -butyl bromide as a proton source. Removal of the iron residue by filtration through alumina and column chromatography led to isolation of the 1,4-diketone 136 (53-79\% yield). The reaction probably proceeds intermolecularly through metal acyl anion intermediates 134 and 135 (Scheme 24). Acyl transfer to the $\alpha, \beta$-unsaturated ketone and protonation presumably occur while the $\alpha, \beta$-unsaturated ketone is attached to the metal ion. The use of iron tricarbonyl complexes for acyl addition to $\alpha, \beta$-unsaturated ketones should have wide synthetic applicability. A recently similar study [337] reports the reaction of tricarbonyliron complexes of $\alpha, \beta$-unsaturated ketones with organolithium reagents under an atmosphere of carbon monoxide, to yield $\alpha, \beta$-unsaturated ketone-tricarbonyliron complexes in $35-83 \%$ yield.

This synthetic reaction can apparently be extended to include iron tricarbonyl complexes of such other Michael acceptors as $\alpha, \beta$-unsaturated carboxylic acids and esters, amides, and nitriles.

Recently, the Helquist group [338] published a comprehensive study on highly diastereofacial selective chelation of a phosphite-containing $\alpha, \beta$-unsaturated ketone system to the $\mathrm{Fe}(\mathrm{CO})_{2}$ group. Conjugate addition to one of these complexes has demonstrated the potential utility of these systems in asymmetric synthesis.

Recently, Brookhart et al. [339] examined the reactions of the ( $\eta^{3}$-allyl) iron tricarbonyl anion, e.g., $\eta^{3}-\mathrm{C}_{3} \mathrm{H}_{5} \mathrm{Fe}(\mathrm{CO})_{3}^{-}$with carbon electrophiles such as $\mathrm{CH}_{3} \mathrm{I}$ or $\mathrm{PhCH}_{3} \mathrm{Br}$ and then with $\mathrm{PPh}_{3}$, to give $\alpha, \beta$ - or $\beta$ - $\gamma$-unsaturated ketones. As found for certain substituted allyl systems, e.g., $\left[\eta^{3}-\left(\mathrm{CH}_{2}-\mathrm{CH}=\mathrm{CHCH}_{3}\right)\right.$ $\mathrm{Fe}\left(\mathrm{CO}_{3}\right)^{-} \mathrm{Na}^{+}$] acyl migration occurred regioselectively to the more hindered methyl-substituted carbon of the $\pi$-allyl moiety. 


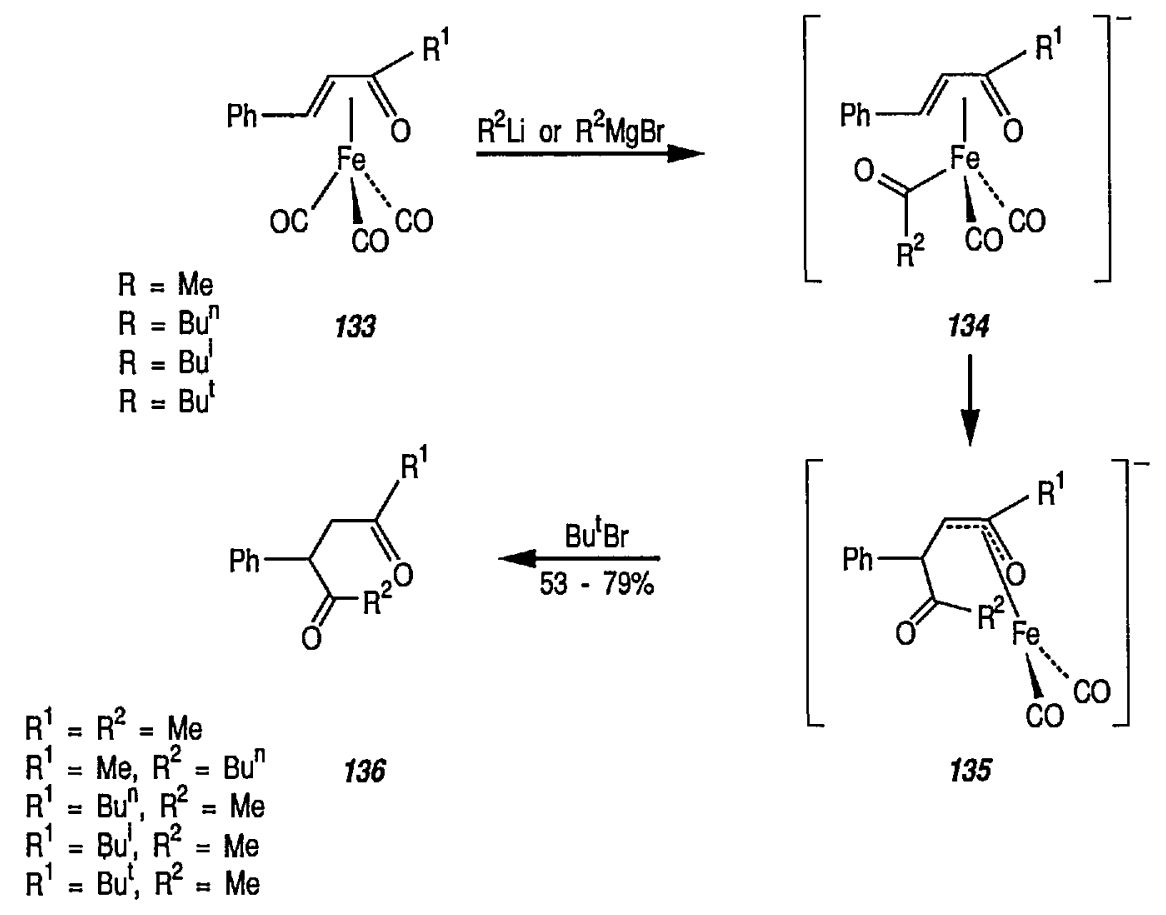

Scheme 24

\subsection{Davies' Chiral Auxiliary Reagent for Synthesis of Unsaturated Iron Acyls}

To illustrate the generality of the new methodology for the synthesis of carbon-carbon double bonds [340], the Davies group [61-63,341] recently expanded the chiral auxiliary Michael-type reaction to include a series of aldehydes. Thus, starting with the chiral acetyl complex $\left[\left(\eta^{5}-\mathrm{C}_{5} \mathrm{H}_{5}\right) \mathrm{Fe}(\mathrm{CO})\left(\mathrm{PPh}_{2}\right) \mathrm{COCH}_{3}\right]$, the authors [341] generated, in high yields, $E$ and $Z \alpha, \beta$-unsaturated acyl complexes $\left[\left(\eta^{5}-\mathrm{C}_{5} \mathrm{H}_{5}\right) \mathrm{Fe}(\mathrm{CO})\left(\mathrm{PPh}_{3}\right)\right.$ $\mathrm{COCH}=\mathrm{CHCH}_{3}$ ] by using the Peterson alkene synthesis reaction [342] between trimethylsilyl derivatives $\left[\left(\eta^{5}-\mathrm{C}_{5} \mathrm{H}_{5}\right) \mathrm{Fe}(\mathrm{CO})\left(\mathrm{PPh}_{3}\right) \mathrm{COCH}_{2} \mathrm{Si}\left(\mathrm{CH}_{3}\right)_{3}\right]$ and aldehydes RCHO $\left(\mathrm{R}=\mathrm{H}, \mathrm{CH}_{3}, \mathrm{Et}, \mathrm{n}-\mathrm{Bu}, \mathrm{t}-\mathrm{Bu}\right.$, $\mathrm{Ph}$, vinyl, 2-furyl). The procedure involves deprotonation of 137 with butyllithium (THF, $-78^{\circ} \mathrm{C}$ ) followed by trapping of the resulting enolate with chlorotrimethylsilane, to generate the complex 138. Deprotonation of the orange complex 138 with butyllithium (THF, $-78^{\circ} \mathrm{C}$ ) generates the corresponding $\alpha$-trimethylsilyl enolate 139 which is treated with aldehyde RCHO. Workup by evaporation, extraction with dichloromethane, and filtration through alumina gave a mixture of isomers $E$ - and $Z-\left[\left(\eta^{5}-\mathrm{C}_{5} \mathrm{H}_{5}\right) \mathrm{Fe}(\mathrm{CO})\left(\mathrm{PPh}_{3}\right)\left(\mathrm{COCH}=\mathrm{CHCH}_{3}\right)\right]$ $(140 E+140 Z)$. The $E$ and $Z$ isomers are readily separable by chromatography on alumina. Elution with dichloromethane gave the pure $Z$ isomer and subsequent elution with 2:3 dichloromethane-ethyl acetate gave the pure $E$ isomer (Scheme 25). The ratio of the $E$ and $Z$ diastereoisomers was deduced from integration of the methyl doublets and alkene protons in the NMR spectrum. Thus, the stereospecific syn-elimination of the $\mathrm{Si}-\mathrm{O}$ moiety in the base-catalyzed Peterson reaction is an important synthetic procedure for the preparation of $\alpha, \beta$-unsaturated acyl complexes.

The method [341] was also found useful for a Wittig reaction [340] between phosphoranes and carbonyl compounds for the synthesis of carbon-carbon double bonds. Thus, addition of $\mathrm{CH}_{2}=\mathrm{P}\left(\mathrm{CH}_{3}\right)_{3}$ to the cation $\left[\left(\eta^{5}-\mathrm{C}_{5} \mathrm{H}_{5}\right) \mathrm{Fe}(\mathrm{CO})_{2}\left(\mathrm{PPh}_{3}\right)\right]^{+} \mathrm{PF}_{6}^{-}(141)$ in a mixture of tetrahydrofuran and dichloromethane, initially at $-78^{\circ} \mathrm{C}$ and then warming to $20^{\circ} \mathrm{C}$, gave the phosphonium salt 142 . Treatment of 142 , without isolation, with butyllithium at $-78^{\circ} \mathrm{C}$ gave the phosphorane 143 ; on treatment with benzaldehyde this gave $\alpha, \beta$-unsaturated iron acyl complex 144 as the simple $E$ isomer, albeit in only $25 \%$ overall yield. The relatively poor yield of complex 144 by this route may have its origins in the fact that cation 141 is less susceptible to nucleophilic attack than is $\left[\left(\eta^{5}-\mathrm{C}_{5} \mathrm{H}_{5}\right) \mathrm{Fe}(\mathrm{CO})_{3}\right]^{+} \mathrm{PF}_{6}^{-}$, due to the presence of the electron-donating triphenylphosphine ligand. Furthermore, nucleophilic addition to cation 141 would be expected to be readily reversible [343] (Scheme 26). Exclusive $E \alpha, \beta$-unsaturated iron acyl complexes are also formed stereoselectively in high yield via sodium hydride-induced elimination of methanol from the $\beta$-methoxy complexes 
$\left.\left[\left(\eta^{5}-\mathrm{C}_{5} \mathrm{H}_{5}\right) \mathrm{Fe}(\mathrm{CO})\left(\mathrm{PPh}_{3}\right) \mathrm{COCH}_{2} \mathrm{CH}\left(\mathrm{OCH}_{3}\right) \mathrm{R}\right)\right]\left(\mathrm{R}=\mathrm{H}, \mathrm{CH}_{3}, \mathrm{Et}, n-\mathrm{Bu}, \mathrm{Ph}\right.$, vinyl, 2-furyl), involving an $O$-methylation-elimination procedure [341], e.g., conversions $145 \rightarrow 146 \rightarrow 147$. (Scheme 27). Other methods involve reactions of chiral salts with vinyl chlorides followed by photolysis in the presence of triphenylphosphine [341,344,345], conversions $148 \rightarrow 149 \rightarrow 150$ (Scheme 28).
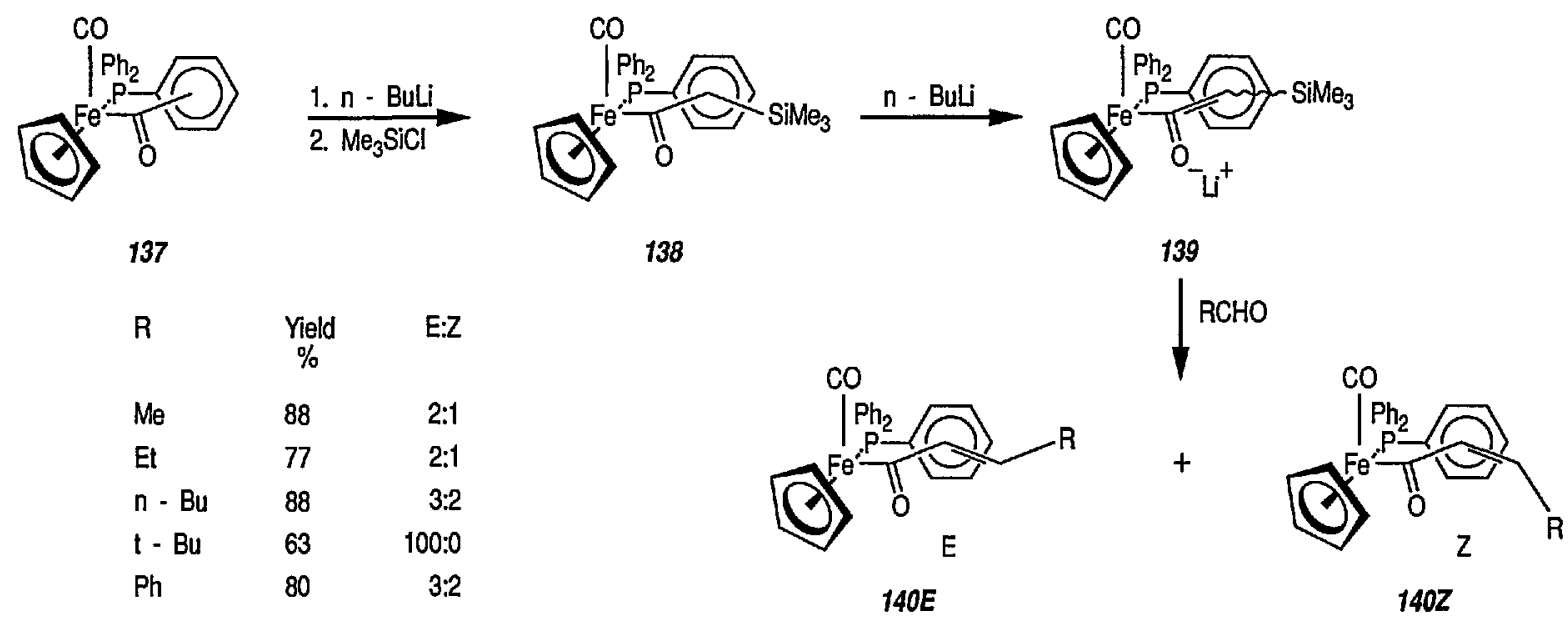

Scheme 25

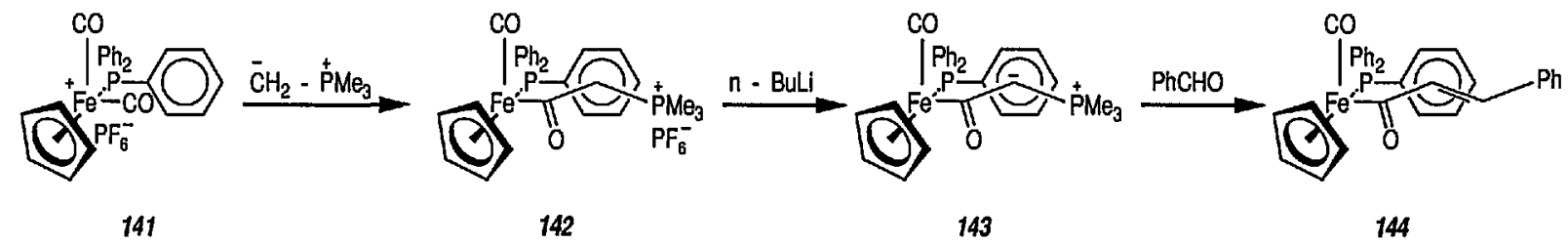

Scheme 26

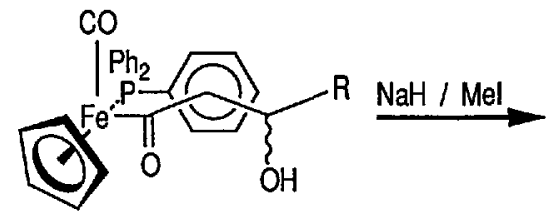

145<smiles>[R]c1ccc(P(=O)(O[Na])c2ccccc2)cc1</smiles>

146

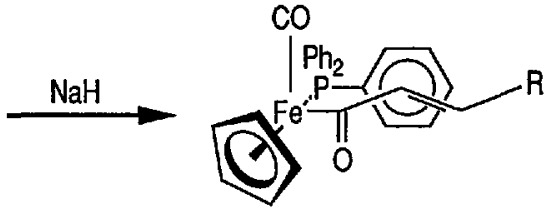

147

$\begin{array}{lll}\mathrm{R} & \text { Yield \% } & \mathrm{E}: \mathrm{Z} \\ \mathrm{Me} & 92 & 15: 1 \\ \mathrm{Et} & 95 & \mathrm{E} \text { only } \\ \mathrm{n}-\mathrm{Bu} & 50 & \mathrm{E} \text { only }\end{array}$

Scheme 27 


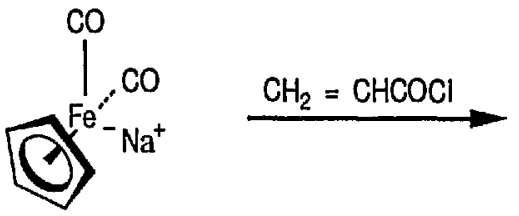

148

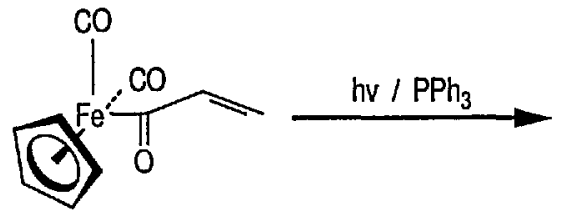

149

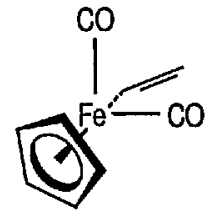

150

Scheme 28

An alternative synthesis of $\alpha, \beta$-unsaturated iron acyl complexes has been advanced [325]; it is a nonstereospecific reaction starting from $\beta$-hydroxy-acyl complexes and proceeding via acetylation and subsequent base-promoted elimination steps.

At present, most commercial applications rely on separating optical isomers from racemic mixtures by such physical processes as fractional distillation, recrystallization, or chromatography [346]. However, ongoing research is opening up prospects for direct asymmetric synthesis of chosen isomers in high optical purity.

Davies' chiral auxiliaries [60-63] offer stereochemical control of a variety of reactions involving acyl ligands, including enolate and dienolate chemistry, aldol and Diels-Alder reactions, and tandem Michael addition-alkylation reactions. After enantio- and diastereo-controlled reaction, the desired fragment can be liberated under mild conditions.

This technique is applicable to virtually all reactions associated with carbonyl functionality, and can simplify current multistage reaction procedures, giving substantial time saving, e.g., 99+ percent optical purity can be achieved by this direct method [347]. The parent chiral iron acetyl reagent [ $\left(\eta^{5}-\right.$ $\left.\left.\mathrm{C}_{5} \mathrm{H}_{5}\right) \mathrm{R}(\mathrm{CO})\left(\mathrm{PPh}_{3}\right) \mathrm{COCH}_{3}\right]$ is now commercially available as the $(-) R$ or $(+) S$ enantiomer or in the $(+)(-)$-racemate form $[347,348]$ (depicted).

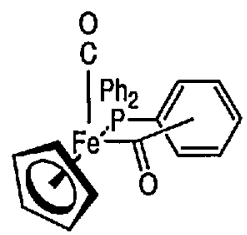

(R) $\cdot(-)$

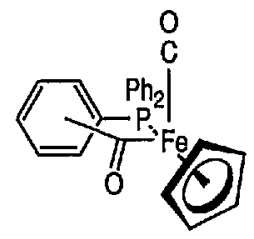

(S) - (t)

\footnotetext{
$\mathrm{R}(-)$ - Acetyl - cyclopentadlenyl - Iron carbonyl Triphenylphosphine Complex

$[\alpha]_{546}^{20}-290 \pm 10^{\circ},[\alpha]_{D}^{20}-160 \pm 1^{\circ}(c=0.04$ in benzene)
}

\author{
$S(+)$ - Acetyl - cyclopentadienyl - Iron carbonyl \\ Triphenylphosphlne Complex \\ $[\alpha]_{546}^{20}+290 \pm 10^{\circ},[\alpha]_{D}^{20}-160 \pm 1^{\circ}(c=0.04$ in benzene)
}

The use of transition-metal-based chirality for asymmetric induction is interesting for two reasons. First, metal-based chirality can occur in a number of geometries inaccessible to organic compounds. Second, steric and electronic perturbation to the inducing chiral center should be achievable with great flexibility in the organometallic system simply by varying the ligands about the metal. Purely organic systems seem inherently less flexible [320].

The results so far accumulated demonstrate the powerful influence that the chiral group $\left[\left(\eta^{5}-\right.\right.$ $\left.\left.\mathrm{C}_{5} \mathrm{H}_{5}\right) \mathrm{Fe}(\mathrm{CO})\left(\mathrm{PPh}_{3}\right)\right]$ can have over the stereochemical outcome of reactions that occur under its control; two mechanistic models to explain the factors responsible for the chiral high stereoselectivity have been proposed [320,349]. The most stable conformation for ligands attached to the chiral auxiliary $\left[\left(\eta^{5}-\right.\right.$ $\left.\left.\mathrm{C}_{5} \mathrm{H}_{5}\right) \mathrm{Fe}(\mathrm{CO})\left(\mathrm{PPh}_{3}\right)\right]$ can be predicted from the NMR analysis [349,350]; this includes recent conformational analysis and $x$-ray crystal structure of $\left[\left(\eta^{5}-\mathrm{C}_{5} \mathrm{H}_{5}\right) \mathrm{Fe}(\mathrm{CO})\left(\mathrm{PPh}_{3}\right) \mathrm{CH}_{2} \mathrm{CH}_{3}\right]$ [351] and conformational analysis of $\left[\left(\eta^{5}-\mathrm{C}_{5} \mathrm{H}_{5}\right) \mathrm{Fe}(\mathrm{CO})\left(\mathrm{PPh}_{3}\right) \mathrm{CH}_{2} \mathrm{CH}_{3}\right]$ (e.g., solvent dependence of conformer populations) [352]. 
The importance of chiral products has led to a growing interest in asymmetric synthesis including the synthesis of peptides [353] and ferrocenylpyrazolines [354]. For example, three enantiomerically pure $\alpha$ ferrocenyl-alkylamines were prepared from the natural(-)-menthone via the $\alpha$-ferrocenyl-alkyl carbocation intermediate; these amines were then used as chiral templates for the stereoselective synthesis of a model compound for peptides [353]. The future promises exciting possibilities for the use of stoichiometric chiral auxiliaries, e.g., the chiral template $\left.\left[\eta^{5}-\mathrm{C}_{5} \mathrm{H}_{5}\right) \mathrm{Fe}(\mathrm{CO})\left(\mathrm{PPh}_{3}\right)\right]$ for asymmetric synthesis. In particular, recent reports have described the self regeneration of chiral auxiliaries [355] so that they are not destroyed during the reactions and may be easily recycled; the paper also reports a new asymmetric synthesis of phenyl alkyl sulfoxides.

\subsection{Asymmetric Diels-Alder Reactions via Chiral Iron Acyl Complexes}

The development of both highly efficient and diastereoselective asymmetric Diels-Alder reactions for the construction of chiral starting materials for organic synthesis has attracted considerable synthetic effort $[356,357]$. The asymmetric Diels-Alder reaction is a powerful tool for the synthesis of enantiomerically pure, complex molecules.

As shown earlier [319,328], $E$ - $\alpha, \beta$-unsaturated acyl ligands bound to the chiral auxiliary [ $\left(\eta^{5}\right.$ $\left.\left.\mathrm{C}_{5} \mathrm{H}_{5}\right) \mathrm{Fe}(\mathrm{CO})\left(\mathrm{PPh}_{3}\right)\right]$ undergo highly diastereoselective, tandem Michael additions and alkylations. It was of interest to extend the synthetic potential of $\alpha, \beta$-unsaturated complexes to their use as chiral dienophile equivalents in asymmetric Diels-Alder cycloaddition reactions. Recently, Davies and Walker [358] reported such an asymmetric Diels-Alder reaction. Thus, $E$ - $\alpha, \beta$-unsaturated acyl complex 151 underwent sodium hydride-induced elimination of menthol (THF, room temperature) to give the chiral acrylate dienophile equivalent $(S)-(+)-\left[\left(\eta^{5}-\mathrm{C}_{5} \mathrm{H}_{5}\right) \mathrm{Fe}(\mathrm{CO})\left(\mathrm{PPh}_{3}\right) \mathrm{COCH}=\mathrm{CH}_{2}\right](152)\left[(87 \%),[\alpha]_{\mathrm{D}}^{20}+202\left(\mathrm{C}, 0.11, \mathrm{C}_{6} \mathrm{H}_{6}\right)\right]$. The Diels-Alder reaction between complex 152 and cyclopentadiene in the presence of one equivalent of zinc chloride at room temperature gave endo addition complex 153 as the major diastereoisomer (in addition to two other, minor diastereoisomers). The crude mixture was subjected to ammonium cerium(IV) nitrate oxidation in aqueous THF $\left(0^{\circ} \mathrm{C}\right)$ (decomplexation) to yield, after work-up, preponderantly $(2 S)$-(-)-bicyclo[2.2.1]hept-5-ene-2-endo-carboxylic acid (154). The formation of acid 154, whose absolute configuration is known, is consistent with endo addition occurring to $(S)-(+)-(152)$ in the cisoid orientation, the normal reactive conformation of $\alpha, \beta$-unsaturated acyl complexes [319], from the face away from the triphenylphosphine ligand. The endo enantioselectivity was determined by conversion of acid 154 into the corresponding iodolactone (155) (65\% yield). Purification by a single recrystallization gave optically pure $(+)-155\left\{[\alpha]_{436}^{20}+\right.$ $\left.238.40\left(0.55, \mathrm{C}_{6} \mathrm{H}_{6}\right)\right\}$. All of the important reaction steps in the conversion 151 to 155 are shown in Scheme 29.

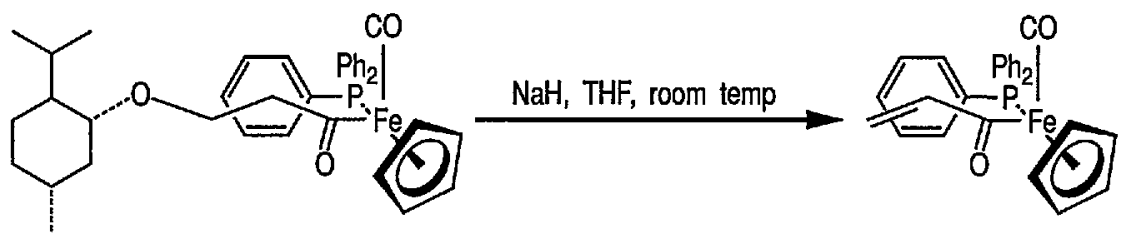

$(S)-(t) \cdot 151$

$(S) \cdot(+) \cdot 152$

$\downarrow \mathrm{C}_{5} \mathrm{H}_{6}, \mathrm{ZnCl}_{2}, \mathrm{CH}_{2} \mathrm{Cl}_{2} /$ room temp

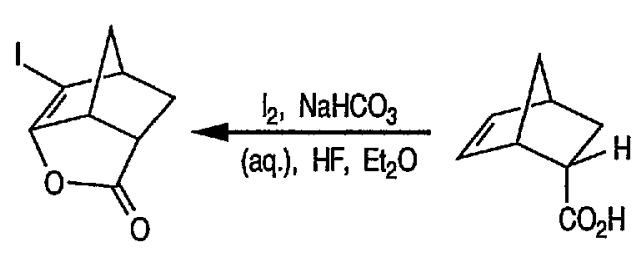

155

(S) $\cdot(-) \cdot 154$
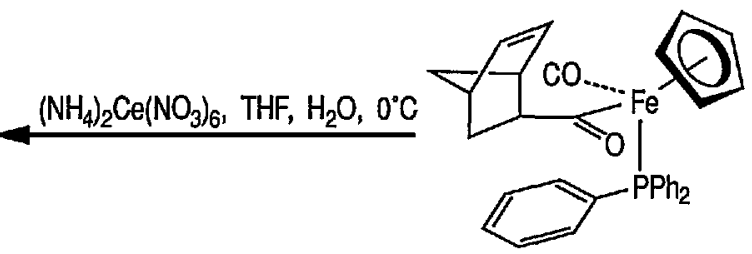

153

Scheme 29 
Another new stereoselective Diels-Alder reaction involving $\alpha, \beta$-unsaturated iron acyl-difluoride complexes has been reported. A series of Diels-Alder cycloaddition products between dienophiles methacrylate and crotonate derivatives of (ferra- $\beta$-diketonato) $\mathrm{BF}_{2}$ complexes, e.g., $\left[\left(\eta^{5}-\mathrm{C}_{5} \mathrm{H}_{5}\right) \mathrm{Fe}(\mathrm{CO})\right]\left\{\left[\mathrm{H}_{2} \mathrm{C}=\mathrm{C}\right.\right.$ $\left.\left.\left(\mathrm{CH}_{3}\right)\right] \mathrm{CO}\right\} \mathrm{BF}_{2}$ and such dienes as isoprene, 2,3-dimethyl-1,3-butadiene, trans-2-methyl-1,3-pentadiene, and cyclopentadiene has been synthesized and characterized. Due to the highly asymmetric Fe center within the methacrylate dienophile, diene cycloaddition occurs with unusually high stereoselectivity and regioselectivity [359].

Recently, Diels-Alder reactions between dienes (e.g., cyclopentadiene, isoprene, 3-methyl-1,3-diene) and dienophiles $\left[\left(\eta^{1}\right.\right.$-acryloyl $\left.)\left(\eta^{5}-\mathrm{C}_{5} \mathrm{H}_{5}\right) \mathrm{Fe}(\mathrm{CO})_{2}\right]$ complexes $(156)\left(\mathrm{R}=\mathrm{H}, \mathrm{R}=\mathrm{CH}_{3}\right)$ in the presence of some Lewis acids have been examined, and found to proceed in excellent yields under mild conditions, to give products of high regio- and stereoselectivity $[360,361]$. Thus, the reaction of $156\left(\mathrm{R}^{2} \mathrm{CH}_{3}\right)(\mathrm{Scheme} 30)$ in benzene at $25^{\circ} \mathrm{C}$ with cyclopentadiene in the presence of ethylaluminum dichloride as the catalyst gave the Diels-Alder product (158) in $84 \%$ yields. Here, the reacting species, i.e., the aluminum-complexed acylmetal complex comprising the polarized double bond is best represented by carbene structure (157). In the reaction of the carbene dienophile (157) with dienes, the regiochemistry and stereochemistry observed were consistent with that generally observed in Diels-Alder reactions [362-364]. The preferred mode of addition is endo; particularly, very high endo selectivity was observed in reaction with cyclopentadiene to yield (158) $\left(\mathrm{R}=\mathrm{CH}_{3}\right)$ (95:5 endo:exo) while only modest endo selectivity was observed with isoprene (77:23 endo:exo) (81\% yield), conversion $159 \rightarrow 160\left(\mathrm{R}=\mathrm{CH}_{3}\right)$ [360].
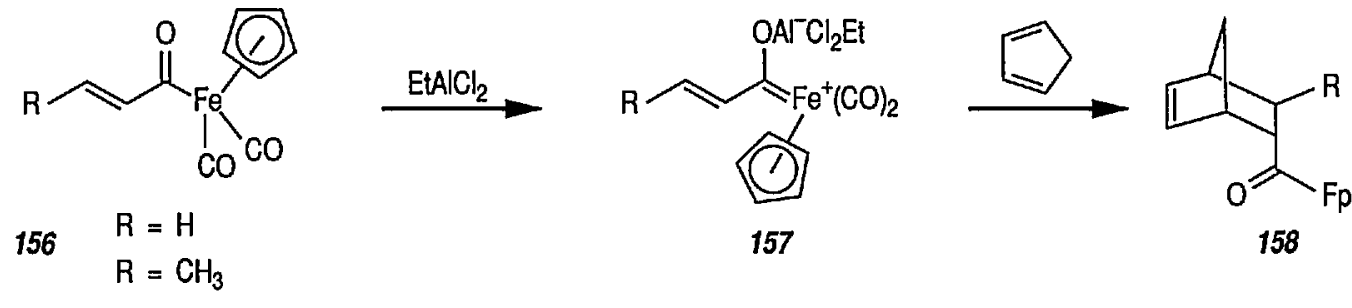

Scheme 30

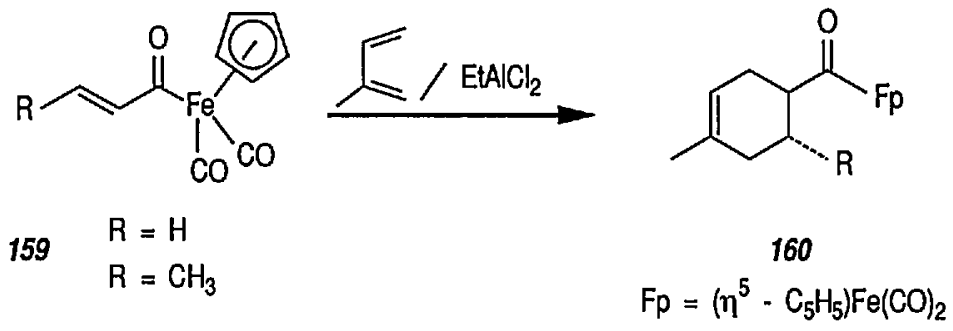

The author extended this study, and examined the reaction of allylstannanes with $\alpha, \beta$-unsaturated acyl iron complexes, e.g., 161; a novel [3+2] cycloaddition was observed [361]. As shown in Scheme 31, this process, catalyzed by aluminum chloride, does not give the expected 5-hexenoyl species 164, but provides the unexpected five-membered-ring adduct 165 . This reaction is an example of a novel and useful method for cyclopentanoid synthesis; numerous preparations were described. The proposed mechanism for [3+2] cycloaddition is outlined in Scheme 31 [361]. First, the aluminum chloride complexes with the acyliron, giving the carbene complex 162. The allylstannane then attacks the electrophilic carbene complex at C-2, yielding the intermediate tin-stabilized carbocation $163 \mathrm{a} \leftrightarrows 163 \mathrm{~b}$. Attack by the enolate at C-5 gives the five-membered-ring compound 165 . Here, iron donates significant electron density to the enolate in 163 , making it more reactive and making ring closure faster than with other enolates. 


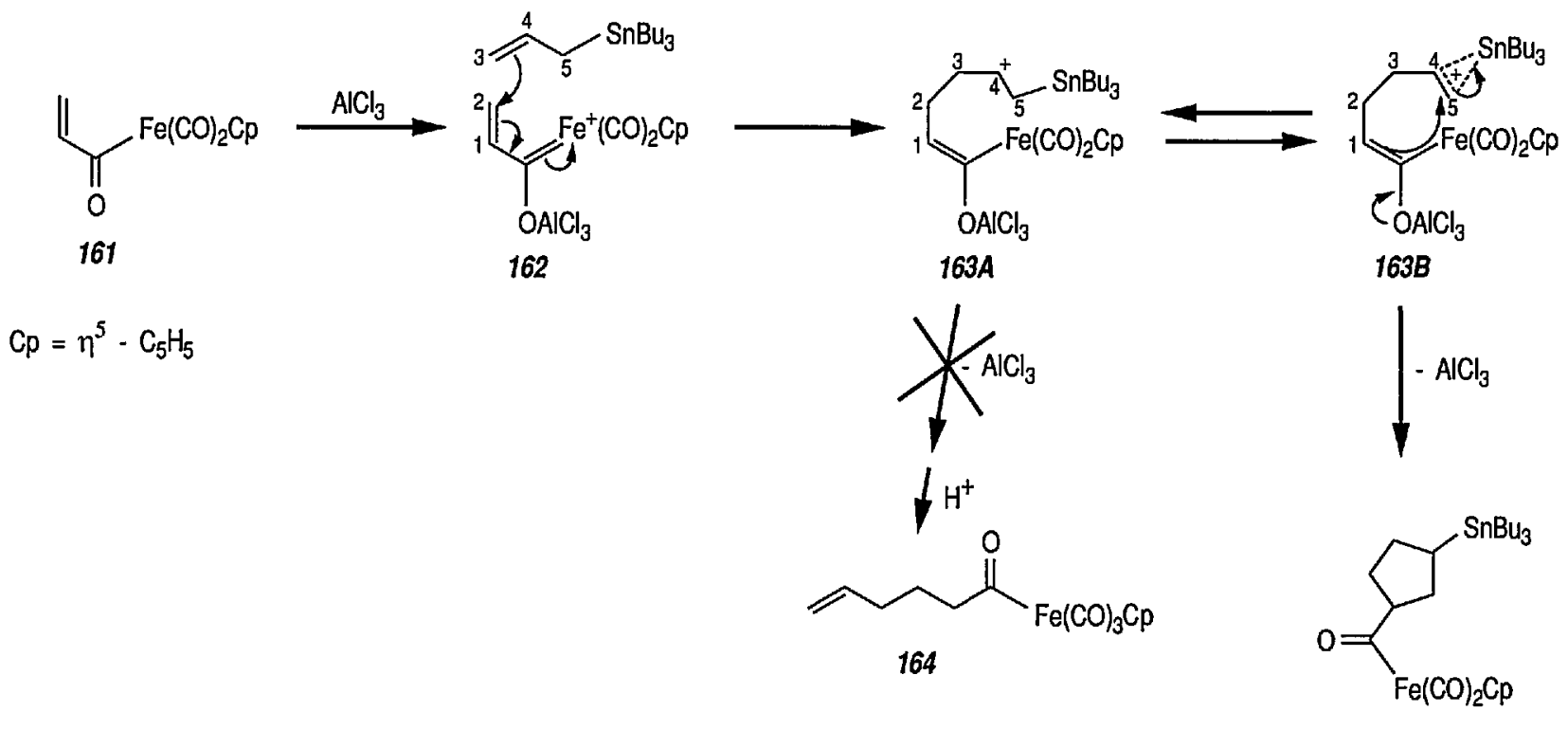

Scheme 31

\section{8 $\left[\left(\eta^{5}-\mathrm{C}_{5} \mathrm{H}_{5}\right) \mathrm{Fe}(\mathrm{CO})_{2}\left(\eta^{1}-\mathrm{C}_{5} \mathrm{H}_{5}\right)\right]$ a Useful Synthetic Equivalent of Substituted 1,3-Cyclopentadienes in Cycloaddition Reactions}

A new, useful approach for the stereoselective synthesis of substituted 2-norbornenes has recently been developed using Diels-Alder cycloaddition reaction. The reaction of $\left[\left(\eta^{5}-\mathrm{C}_{5} \mathrm{H}_{5}\right) \mathrm{Fe}(\mathrm{CO})_{2}\left(\eta^{1}-\mathrm{C}_{5} \mathrm{H}_{5}\right)\right](166)$ with a variety of unsaturated compounds to give cycloadducts 167 in good yield has been reported $[365,366]$. These reactions all occur regio- and stereoselectively to afford $7-\operatorname{syn}-\left[\left(\eta^{5}-\mathrm{C}_{5} \mathrm{H}_{5}\right) \mathrm{Fe}(\mathrm{CO})_{2}\right]$ cycloadduct 167 as shown in Scheme 32. Furthermore, stereospecific replacement of the $\left[\left(\eta^{5}-\mathrm{C}_{5} \mathrm{H}_{5}\right) \mathrm{Fe}(\mathrm{CO})_{2}\right]$ moiety in these adducts by a $\mathrm{CO}_{2} \mathrm{CH}_{3}$ group with retention of configuration to give 168 was found to occur in good yield by oxidation with ammonium cerium(IV) nitrate in methanol saturated with carbon monoxide $[365,366]$. This two-step sequence, cycloaddition followed by oxidation, renders $\left[\left(\eta^{5}-\mathrm{C}_{5} \mathrm{H}_{5}\right) \mathrm{Fe}(\mathrm{CO})_{2}\left(\eta^{1}-\mathrm{C}_{5} \mathrm{H}_{5}\right)\right]$ a synthetic equivalent of methyl 1,3-cyclopentadiene-5-carboxylate in cycloaddition reactions. It was subsequently found [367] that, when the oxidation of 167 was performed with ammonium cerium(IV) nitrate (or bromine or chlorine) in acetonitrile containing sodium azide, the product was acyl azide 169 in which the $\mathrm{CON}_{3}$ group replaced the $\left[\left(\eta^{5}-\mathrm{C}_{5} \mathrm{H}_{5}\right) \mathrm{Fe}(\mathrm{CO})_{2}\right]$ group with retention of stereochemistry in good yield. Thermolysis of the acyl azide 169 in a toluene-tert -butyl alcohol (2:1) solution at reflux produced, via Curtius rearrangement, the corresponding carbamate 170 in excellent yield; the reaction also proceeded stereospecifically. Selective hydrolysis ( $p$-toluenesulfonic acid, acetonitrile, $25^{\circ} \mathrm{C}, 15 \mathrm{~h}$ ) of carbamate 170 yielded new 7-syn-amino-2norbornene 171 in $84-94 \%$ yield also with retention of stereochemistry (Scheme 32). This reported synthesis of substituted 7-syn-amino-2-horbornenes provides an attractive route to these new compounds and substantially expands the known methodology for the synthesis of stereospecific norbornenes.

Some recent reports $[368,369]$ describe several instances in which iron complexes having planar chirality have been utilized with complete stereocontrol as equivalents of cyclohexanone cation synthones. In extension of this study [370], some uses of iron resolved complexes as chiral intermediates to 5-substituted 2-methylcyclohexanones required in terpene synthesis have been described; a general approach when applied inorganic enantiomer synthesis was also outlined. 


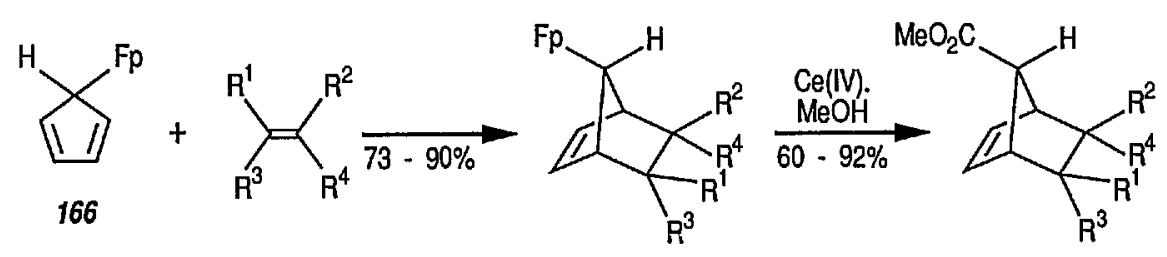

167

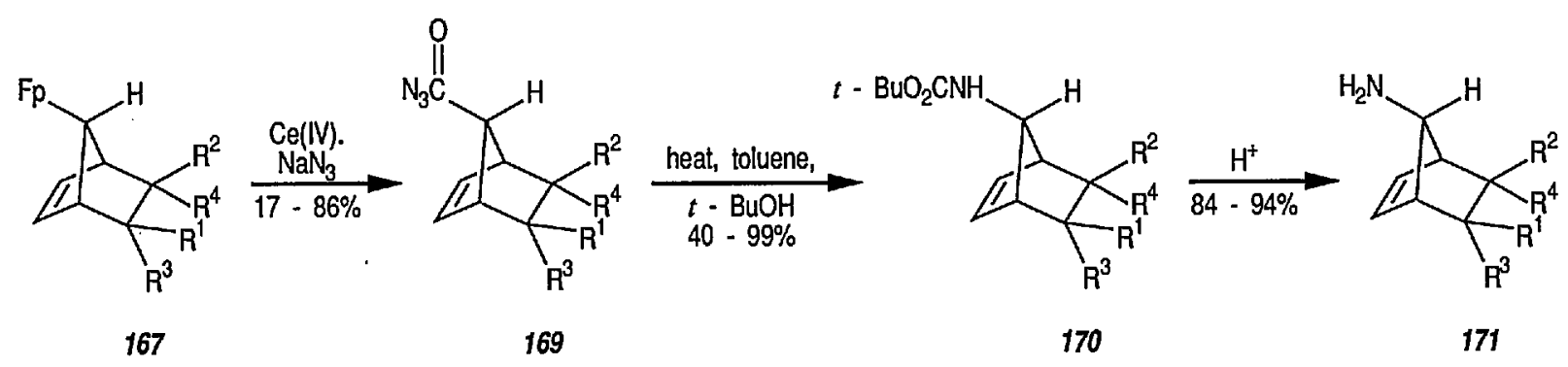

$\mathrm{Fp}=\left(\eta^{5}-\mathrm{C}_{5} \mathrm{H}_{5}\right) \mathrm{Fe}(\mathrm{CO})_{2}$

$R^{1}=R^{4}=C N, R^{2}=R^{3}=H$

$R^{1}=R^{2}=C N, R^{3}=R^{4}=H$

Scheme 32

\subsection{Stereoselective Syntheses of Coordinated Phosphines}

Recent results have shown [371] that metal complexes can be highly effective resolving agents, protecting agents, and chiral auxiliaries for stereoselective synthesis of macrocyclic quadridentate tertiary arsines. For example, highly selective alkylations of terminal phosphido-metal group ( $\mathrm{M}-\mathrm{PX}$, where $\mathrm{M}=\mathrm{Fe}, \mathrm{Cr}$, etc.) are required for syntheses of macrocyclic poly(secondary and tertiary phosphines) on metal ions in order to avoid separations of complex mixtures of diastereoisomeric product [372]. This is supplemented by recent findings [373] that asymmetric tertiary phosphido-metal group $\mathrm{Fe}-\mathrm{PMePh}$ can be generated stereospecifically, first by deprotonation of $\left[\left(R^{*}, R^{*}\right),\left(R^{*}\right)-\left(\eta^{5}-C_{5} H_{5}\right)\left\{1,2-C_{6} H_{6}(P M e P h)_{2} F e H M e P h\right] P F_{6}\right.$ with potassium-tert-butoxide at $-90^{\circ} \mathrm{C}$, followed by alkylation (iodomethane) to give kinetic products $\left[\left(\mathrm{R}^{*}, \mathrm{R}^{*}\right),\left(\mathrm{R}^{*}\right)\right]$ or $\left[\left(\mathrm{R}^{*}, \mathrm{R}^{*}\right)\left(\mathrm{S}^{*}\right)\right]$ in $>99 \%$ diastereoisomeric excess. These results auger well for stereoselective synthesis of poly(secondary or tertiary phosphines) on metal ions.

\section{Synthesis of Natural Products via Iron Carbonyls}

7.1 Synthesis of Alkaloid ( \pm )Limaspermine. The Pearson Synthetic Approach via Cyclohexadienyliron Complexes

Iron-stabilized carbocations as intermediates for organic synthesis, particularly the synthesis of natural products and the construction of molecules that might be useful for studying certain organic reactivity phenomena, have been developed for Pearson [21,110,117]. A few examples directed at the synthetic application of dienyl cations that are stabilized by their attachment to an iron(O) moiety, usually the $\mathrm{Fe}(\mathrm{CO})_{3}$ group, are discussed next.

An application of cyclohexadienyliron complexes is exemplified by the total synthesis of the alkaloid ( \pm )-limaspermine 176 (Scheme 33) in the racemic form [110,374]. The synthesis demonstrates successful application of regiocontrol, and illustrates the remarkable stability of the diene- $\mathrm{Fe}(\mathrm{CO})_{3}$ unit toward a wide range of chemical transformations, such as decarboxylation and homologation; indeed, the $\mathrm{Fe}(\mathrm{CO})_{3}$ allows functional-group interconversions on the side chain that would be troublesome to perform in its absence. The synthesis begins with the readily prepared isopropoxy-substituted (favorable directing effect) dienyl$\mathrm{Fe}(\mathrm{CO})_{3}$ cation 172 (compare Scheme 34). On treatment with a regiospecific nucleophile such as the potassium enolate of dimethyl malonate [i.e., $\mathrm{KCH}\left(\mathrm{CO}_{2} \mathrm{Me}\right)_{2}$ ] the cation 172 gave a mixture containing mainly the cis isomer 173 (10:1 ratio) from which pure 173 was obtained in high yield by simple recrystallation. 
Complex 172 was transformed, as shown in Scheme 33, by a multi-step procedure [374] to the decahydroquinoline 174 , again illustrating the remarkable stability of the diene- $\mathrm{Fe}(\mathrm{CO})_{3}$ unit toward chemical transformations. The decahydroquinoline intermediate 174 was then converted into ( \pm )-limaspermine 176 by the sequence illustrated (conversions $172 \rightarrow 176$ ). This constituted the first total synthesis of a complex natural product (five rings, four chiral centers) from organoiron precursors. A new synthetic approach to Aspidosperma alkaloids related to limaspermine 176 involving construction of the important quaternary $\mathrm{C}-20$ carbon, via the cyclohexadienyl-Fe( $\mathrm{CO})_{3}$ intermediate, has been advanced [375].

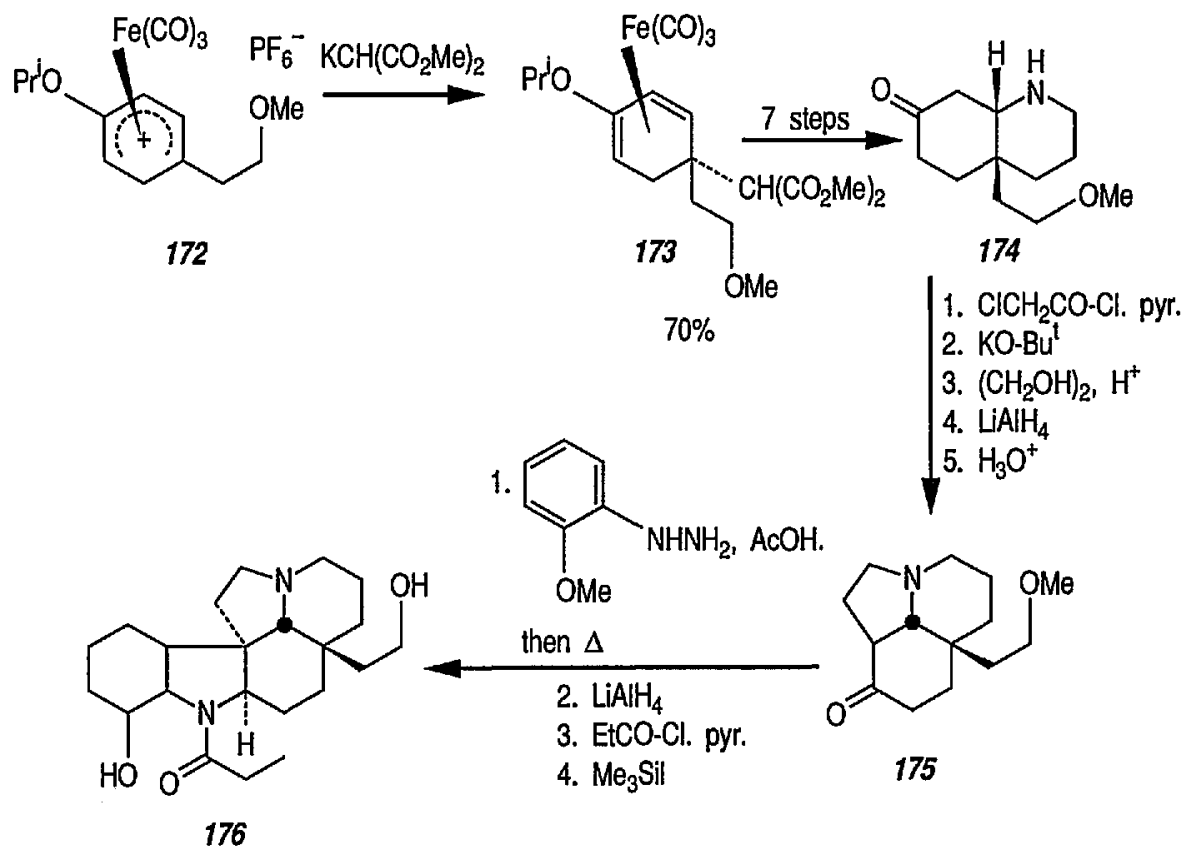

Scheme 33

\subsection{Synthesis of Alkaloid( \pm )- $O$-Methyljoubertiamine and Other Natural Products via Aryl Cation Equivalents}

The addition of carbon nucleophiles to simple cyclohexadienyl- $\mathrm{Fe}(\mathrm{CO})_{3}$ cations also provided an opportunity to examine the potential of these complexes as aryl cation equivalents [376] suitable for application to total synthesis. This was demonstrated by the synthesis of alkaloid ( \pm )- $O$-methyljoubertiamine 184 $[117,118,377]$ (Scheme 34). Thus, reaction of sodium enolate 177 with the dienyl complex 178 (readily prepared from anisole) gave the adduct-complex 179 ( $92 \%$ yield). Decomplexation of 179 followed by treatment of the resulting dienol ether 180 with DDQ in boiling xylene generated the aromatic key intermediate 181. The further sequence as shown in Scheme 34 generated enones 182 and 183; earlier [378] the enone 183 had been converted into alkaloid 184, thereby accomplishing a formal synthesis of 184 . 


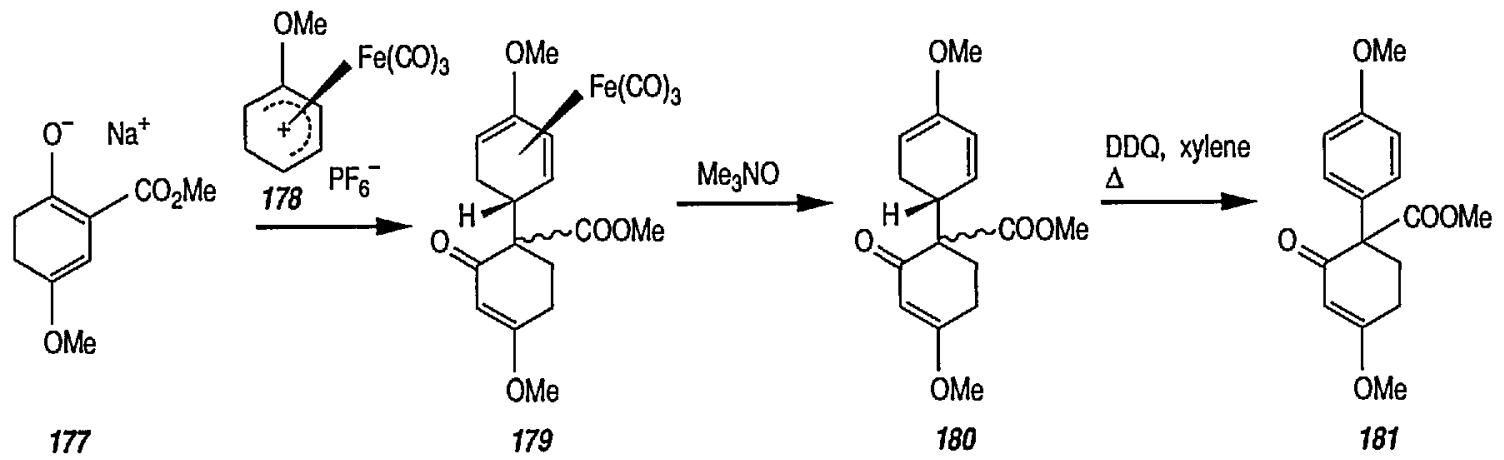

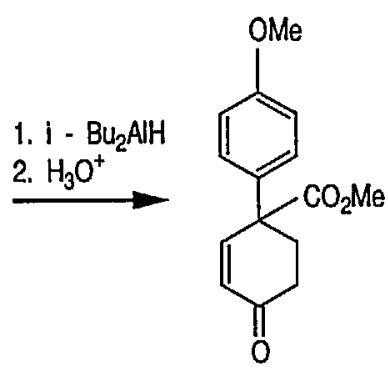

182
1. protect ketone

2. $\mathrm{LiAlH}_{4}$

3. $\mathrm{TsCl}$, py.

4. NaCN, HMPA, heat

5. deprotect ketone<smiles>COc1ccc(C2(CC#N)C=CC(=O)CC2)cc1</smiles>

183<smiles>CCCC1(c2ccc(OC)cc2)C=CC(=O)CC1</smiles>

184

Scheme 34

Similar cyclohexadienyl cations were applied in the synthesis (via spirocyclization) of such natural terpene analogs as acorenone (188) or cedrol (189) (conversions $185 \rightarrow 188 \rightarrow 189$ ) $[117,119]$ (Scheme 35). The total synthesis of sesquiterpene thrichothecene analogs 193 or 194 in which the initial carbon-carbon bond-forming step involved reaction between stabilized metal enolates and tricarbonyl(4-methoxy)-1methylcyclohexadienylium)iron hexafluorophosphate electrophile (190) has also been reported [95,120] (conversions $190 \rightarrow 193 \rightarrow 194$ ) (Scheme 36). Using cyclic and acyclic tributyltin enolate (instead of lithium enolate and silyl enol ether) for effecting the $\mathrm{C}-\mathrm{C}$ bond-formation, a new diastereoselective synthesis of sesquiterpene $( \pm)$ trichodiene or $( \pm)$ trichodermol has been described [379]. The sesquiterpene hydrocarbon trichodiene is the biosynthetic precursor of the trichothecenes, a class of over eighty fungal metabolites [380].

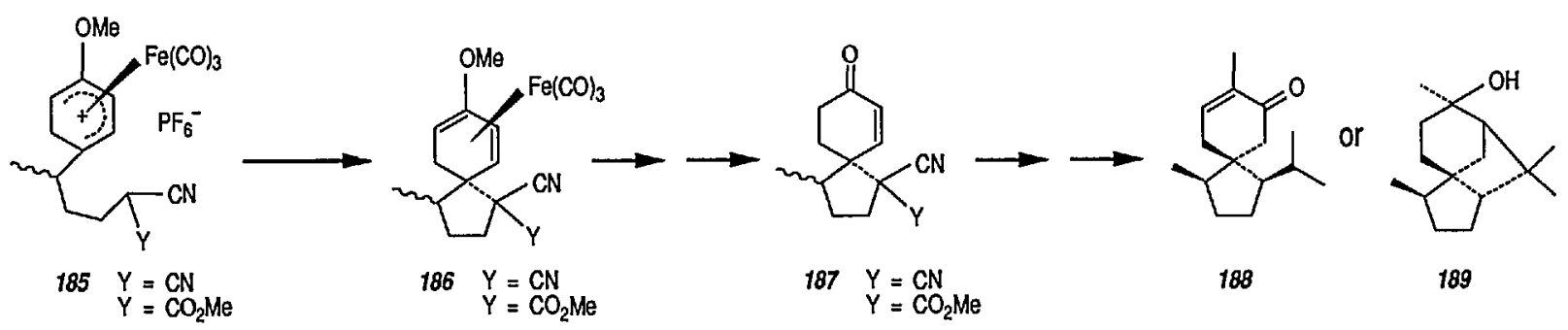

Scheme 35

The foregoing procedure demonstrates that efficient synthesis of complex, para-substituted anisole derivatives is extremely simple using organoiron precursors [376], and that the resulting cyclohexadiene$\mathrm{Fe}(\mathrm{CO})_{3}$ complexes can be used in an alternative approach to natural-product syntheses [89,113,381-383], for example, for the synthesis of quassinoid-type natural terpenes having high antitumor activity [384]. The total synthesis of the natural diterpene aphidicolin (active against herpes virus) involves cyclocarbonylation with sodium iron tetracarbonyl [385]. 


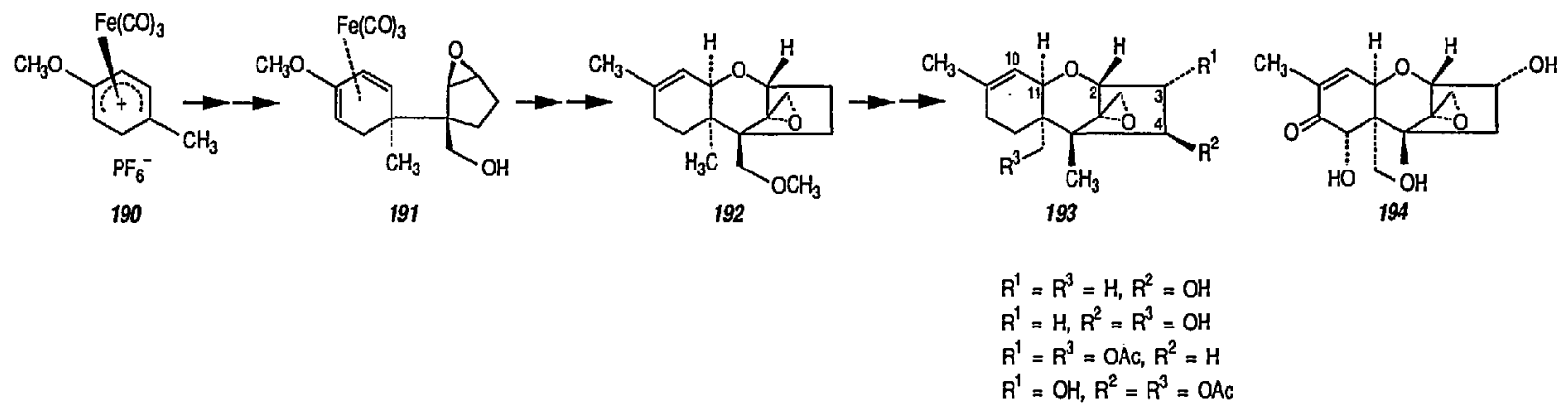

Scheme 36

Unfortunately, the use of cyclohexadienyliron complexes such as 172,185 or 190 in natural product synthesis is limited by the fact that these molecules possess a plane of symmetry, so that the products 176 , 188 or 193 were unavoidably obtained in racemic form. A recent work by the Pearson group [385a] offers a possible new approach to non-racemic natural-product synthesis. Thus, addition of chiral $N$-acyloxazolidinone enolates to dienyl-iron complexes (of type 172,185 or 190) or to diene-molebdenum complexes results in asymmetric induction and gives enantiomeric excess as high as $80 \%$. This method offers promise over other methods in that the oxazolidinones give acceptable high enantiomeric excess as well as a recoverable chiral auxiliary. Furthermore, coupling of this synthetic method with previously established manipulations of the resultant $\pi$-alkyl-molybdenum and diene-iron complexes $[95,120,374,379]$ provide a valuable tool for asymmetric synthesis of natural products.

\subsection{Synthetic Applications of Cycloheptadienyliron Complexes to Natural Products}

From the synthetic point of view, it is difficult to determine which of several available conformations for polysubstituted cycloheptane derivatives is the preferred, lowest-energy form [386]. However, this circumstance can be overcome via controlled functionalization in the cycloheptane ring [114,121,131,387-389]. For example, methods for functionalization of cyclopheptene and cycloheptadiene derivatives using a transitionmetal moiety, e.g., the $\mathrm{Fe}(\mathrm{CO})_{3}$ group, as a means of introducing conformational rigidity and achieving stereocontrolled $\mathrm{C}-\mathrm{C}$ bond-formation has been explored by the Pearson group [95,114,121,122]. The attachment of a transition-metal moiety to an alkenic (or dienyl) ligand offers a unique means of attaining stereospecificity during a variety of chemical transformations and $\mathrm{C}-\mathrm{C}$ bond-forming processes $[89,116]$. The cycloheptadienylmetal system is ideally suited for 1,3-stereocontrol, but inspection of the literature reveals that the reactivity of cycloheptadienyl- $\mathrm{Fe}(\mathrm{CO})_{3}$ complexes, e.g., 199, bears little resemblance to that of six-membered-ring counterpart. New approaches for functionalization [390,391], or breaking [392], of cycloheptatrienyliron complexes have been reported.

Recent efforts have been made [387-389, 393] at using cycloheptadienyliron complexes as precursor to the stereocontrolled construction of acyclic fragments of the macrolide antibiotics magnomycin B 195 [121] and aglycon tylonolide 196 [121,393]. Similarly, the strategy was designed [388,393] to use cycloheptadienyl$\mathrm{Fe}(\mathrm{CO})_{3}$ complex for the synthesis of the right-hand sections of the 16-membered-ring macrolide antibiotics tylosin 197 and carbomycin B 198 [388,393].

Construction of acyclic fragments of antibiotics 197 and 198 begins with cycloheptadiene 199, which is converted into cycloheptadienyl- $\mathrm{Fe}(\mathrm{CO})_{3}$ cation 200 . A successive nucleophile addition, followed by demetalation, leads to the racemic carboxylic acid 201, and this, on treatment with $N$-bromosuccinimide (NBS), is converted into the sensitive lactone 202, representing C-3 and C-9 sections of tylosine 197 and carbomycin B 198. Conjugate anti-displacement of bromide, followed by ozonolysis, treatment with vinylmagnesium bromide and then with $p$-toluenesulfonic acid, and oxidation, produced enone 209 , obtained as a single diastereoisomer representing the C-1-C-11 subunit of tylosine 197; see conversions $199 \rightarrow 209$ (Scheme 37).

The use of organoiron methodology, coupled with manipulation of the product diene, thus provides a potentially flexible approach to macrolide syntheses, and progress in this direction is continuous.

Free-radical coupling-reactions of organoiron complexes as a potential tool for stereoselectivity in synthesis has recently been recommended [394]. 
<smiles>COC(C)C/C=C/C=C/C(=O)C(C)C[C@H](CC=O)C(O)C(O)C(=O)CC(=O)O</smiles>

$195 \mathrm{R}=$ Sugar<smiles>CCC(OC(=O)CC(O)C(C)C1OC(O)C[C@@H]1C[C@@H](C)C(=O)/C=C/C(C)=C/CC(CO)C(C)CO)C(C)C</smiles>

196

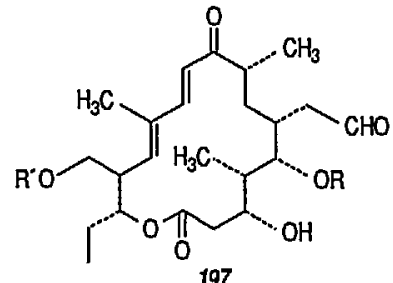

197<smiles>COC(C(O)O)C(O)CC(=O)O[C@@H](C)C/C=C/C=C/C(=O)C(C)C[C@H](CC=O)C(O)O</smiles>

198<smiles>O=P(O)(O)OC1CCCCC1</smiles>

199

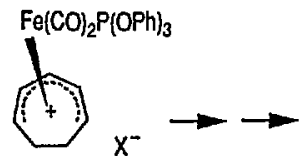

200

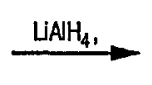

Pyridinium chlorochromate<smiles>CC1C=CC(C)C(CCO)C1O</smiles>

$\underline{\mathrm{O}_{3}, \mathrm{CH}_{2} \mathrm{Cl}_{2},-7 \mathrm{~B}^{\prime} \mathrm{C}}$<smiles>[14CH3]</smiles>
$205 \mathrm{R}=\mathrm{MOM}$ $\mathrm{CH}_{3} \mathrm{OCH}_{2} \mathrm{Cl}$<smiles>CC(C=O)CC(CCO)C(O)C(C)C=O</smiles>

$206 \mathrm{R}=\mathrm{MOM}$ $\mathrm{CH}_{2}=\mathrm{CHMgBr}$

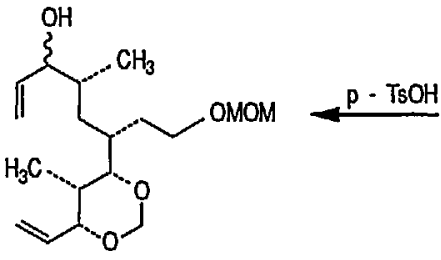

208<smiles>C=CC(O)C(C)CC(CCOC)C(OC)C(C)C(O)C=C</smiles>

207 a $3 \alpha \cdot \mathrm{OH}$ b $3 \beta-O H$

Scheme 37

\subsection{Natural-Product Syntheses via the Polybromo Ketone-Iron Carbonyl Reaction. The Noyori Synthesis}

Transition-metal carbonyls have been used widely, both as synthetic reagents and catalysts, and the development of significant synthetic methods via such complexes is still continuing [395-397]. The involvement of transition metals, and particularly, of organoiron complexes, in synthesis of natural products is a new, challenging field. A current synthetic approach involves either $\mathrm{Fe}(\mathrm{CO})_{3}$-substituted intermediates or use of iron carbonyls as specific reducing agents.

7.4.1 Reaction of the Noyori Intermediate with Alkenes and Dienes A new synthetic methodology using iron carbonyls, e.g., $\mathrm{Fe}(\mathrm{CO})_{5}$ or $\mathrm{Fe}_{2}(\mathrm{CO})_{9}$ (better reducing agent) as reducing agents in the reaction with polybromo ketones to give cyclic ketones has been developed by Noyori $[45,46,253,254]$. Thus, the iron carbonyl-promoted, cyclocoupling reaction of polybromo ketones and unsaturated substrates provides a powerful tool for the synthesis of five- and seven-membered carbocycles, and many of them are useful intermediates in the synthesis of alkaloids, terpenes, and related natural products $[45,251,398]$. Mechanistic investigation has provided many lines of evidence for the reduction initiated by two-electron reduction of the dibromo ketone 210 (directly or via oxidative addition of the $\mathrm{C}-\mathrm{Br}$ bond), to give the enolate 211 , which then eliminates the allylic bromine atom to produce the oxyallyl-iron(II) complex [399,400] 212. 


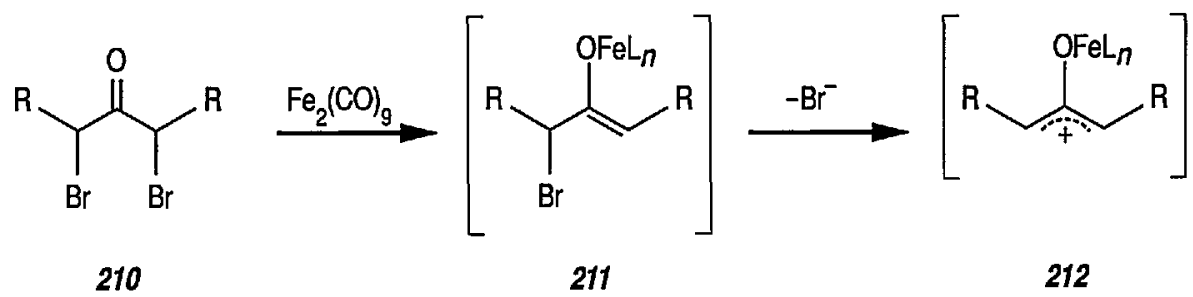

The unique reactivity of this new type of allylic dipolar species, e.g., 212, acting as both a uni- and a bi-functional, three-carbon electrophile, relies heavily on the presence of the central oxygen group. It has been found [45] that parent ketones thus functionalized can undergo cycloaddition with a variety of unsaturated substrates. Scheme 38 illustrates various types of valuable reactions. For instance, 212 underwent $[3+4]$ cycloaddition with open-chain dienes, producing substituted 4-cycloheptenones [401]. In addition, the

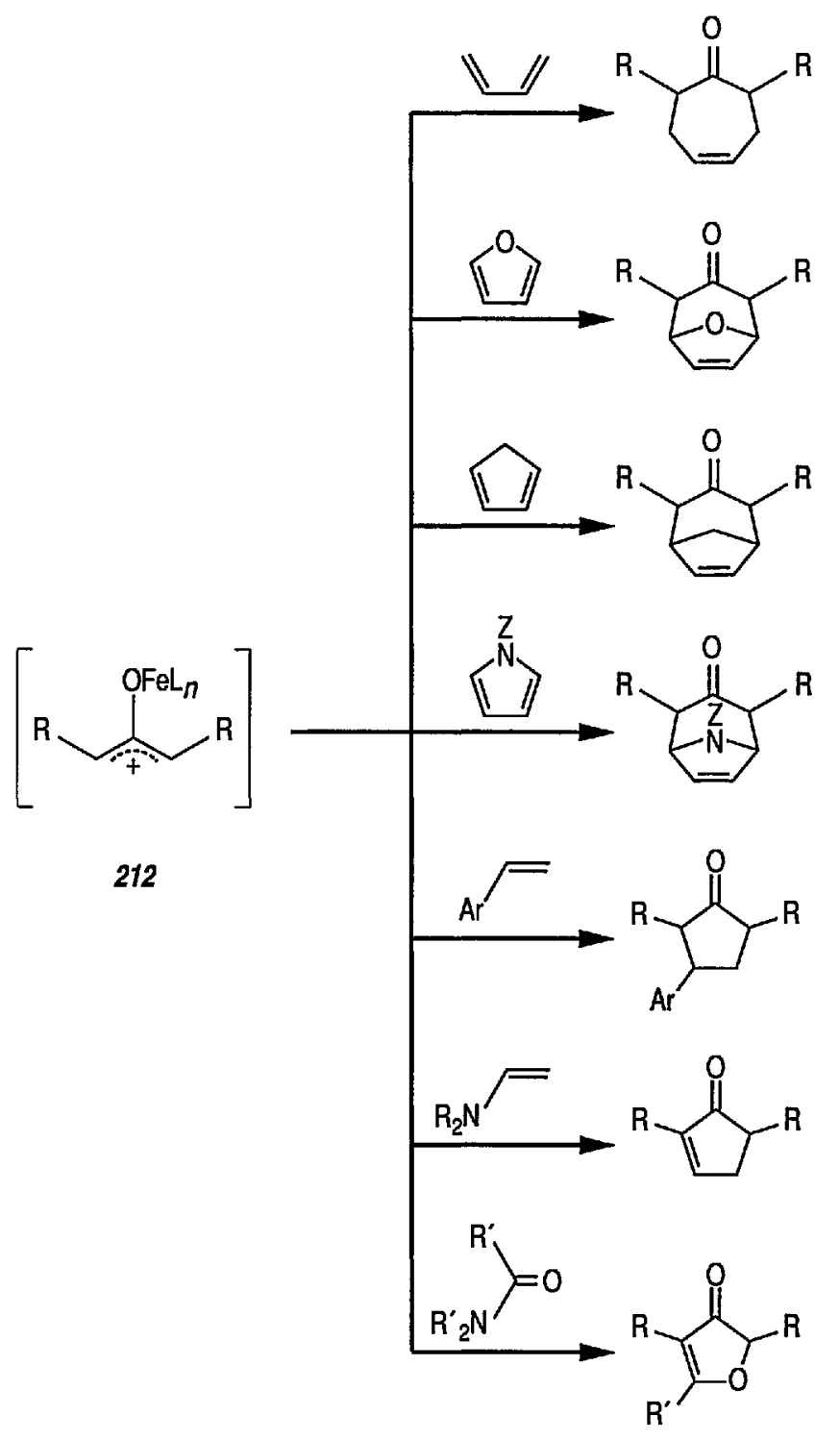

Scheme 38 
cycloaddition of cyclic dienes including cyclopentadiene [401,402], and heteroaromatics such as pyrroles $[401,403]$ and furans $[401,404]$, gives bridged ketone systems. The reaction with furans proceeds by a concerted process, with the regioselectivity controlled by the frontier molecular orbitals of the two reactants [405]. The oxyallyl cations not only react with dienes but also with certain alkenes in a [3+2] manner, producing five-membered-ring ketones [406,407]. The Noyori methodology [408] has recently been extended to synthesis of a series of such natural products as $C$-nucleosides, alkaloids, terpenes, and other classes of complex organic compounds.

7.4.2 Synthesis of $C$-Nucleosides The successful use of $s y m$-tetrabromoacetone as a $C_{3}$ unit in the iron carbonyl-aided, [ $3+4]$ cyclocoupling process has opened a new route to $C$-nucleosides [408]. Thus, the reaction of $\alpha, \alpha, \alpha^{\prime}, \alpha^{\prime}$-tetrabromoacetone 213 and $\mathrm{Fe}_{2}(\mathrm{CO})_{9}$ in furan gave the adduct 214 in $63 \%$ yield, and upon brief treatment with $\mathrm{Zn} / \mathrm{Cu}$ couple in methanol, compound 214 was quantitatively converted into oxabicyclic ketone 215 . When 215 was subjected to osmium tetraoxide-catalyzed dihydroxylation using tert butyl hydroperoxide, followed by acetonation, the oxygen functions were introduced to the double bond solely from the less-hindered side, to give the isopropylidene 216 as a single isomer in $68 \%$ yield. Bayer-Villiger oxidation of 216 with trifluoroperoxyacetic acid afforded the lactone 217 in $81 \%$ yield. The key compound 217 thus obtained has an adequate $C$ - $\beta$-glucosyl structure and serves as the precursor of various natural and synthetic $C$-nucleosides. For example, reaction of the optically active lactone 217 with tert -butoxyl-bis(dimethylamine)methane produced the $\alpha$-dimethylaminomethylene lactone 218 , a common synthetic intermdiate for pyrimidine $C$-nucleosides, in $91 \%$ yield. Thus, condensation of 218 with urea in ethanolic sodium ethoxide, followed by removal of the isopropylidene protecting group, afforded pseudouridine 219 (60\% yield). As shown in Scheme 39, the isopropylidiene lactone 218 was converted into pseudocytidine 220, and 2-thiopseudouridine 221 (60\% yield), and into chematherapeutically active pseudoisocytidine 222 (70\% yield) $[409,410]$. Thus, the highly chiral $C$-nucleosides were prepared from simple, achiral materials, namely, acetone and furan. Most of the synthetic approaches presented so far are based on introduction of the heterocyclic base into the ribose anomeric center, and do not allow strict stereochemical control [262-266,271,411-413]. Furthermore, because the key [3+4] cyclocondensation is applicable to a wide range of polybromo ketones and furans, this approach is capable of preparing various kinds of artificial $C$-nucleoside analogs, particularly those having unnatural carbohydrates possessing alkyl or hydroxyalkyl substituents at appropriate positions [414]. Homo- $C$-nucleosides were obtained by similar synthetic operations [415].

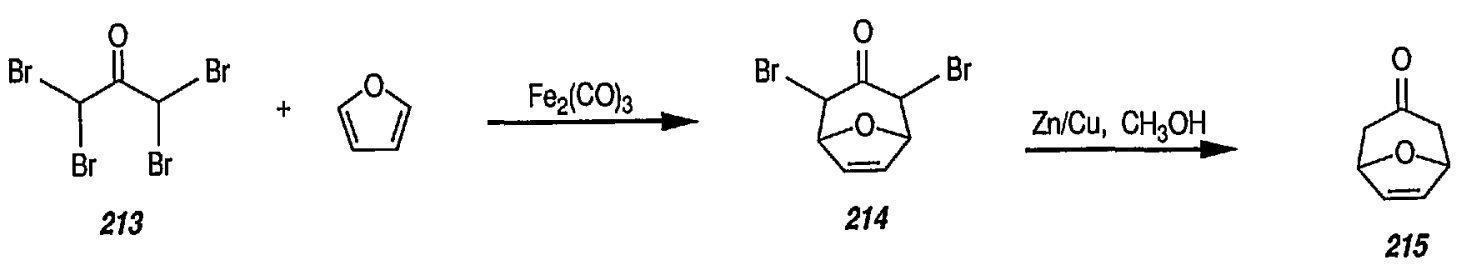




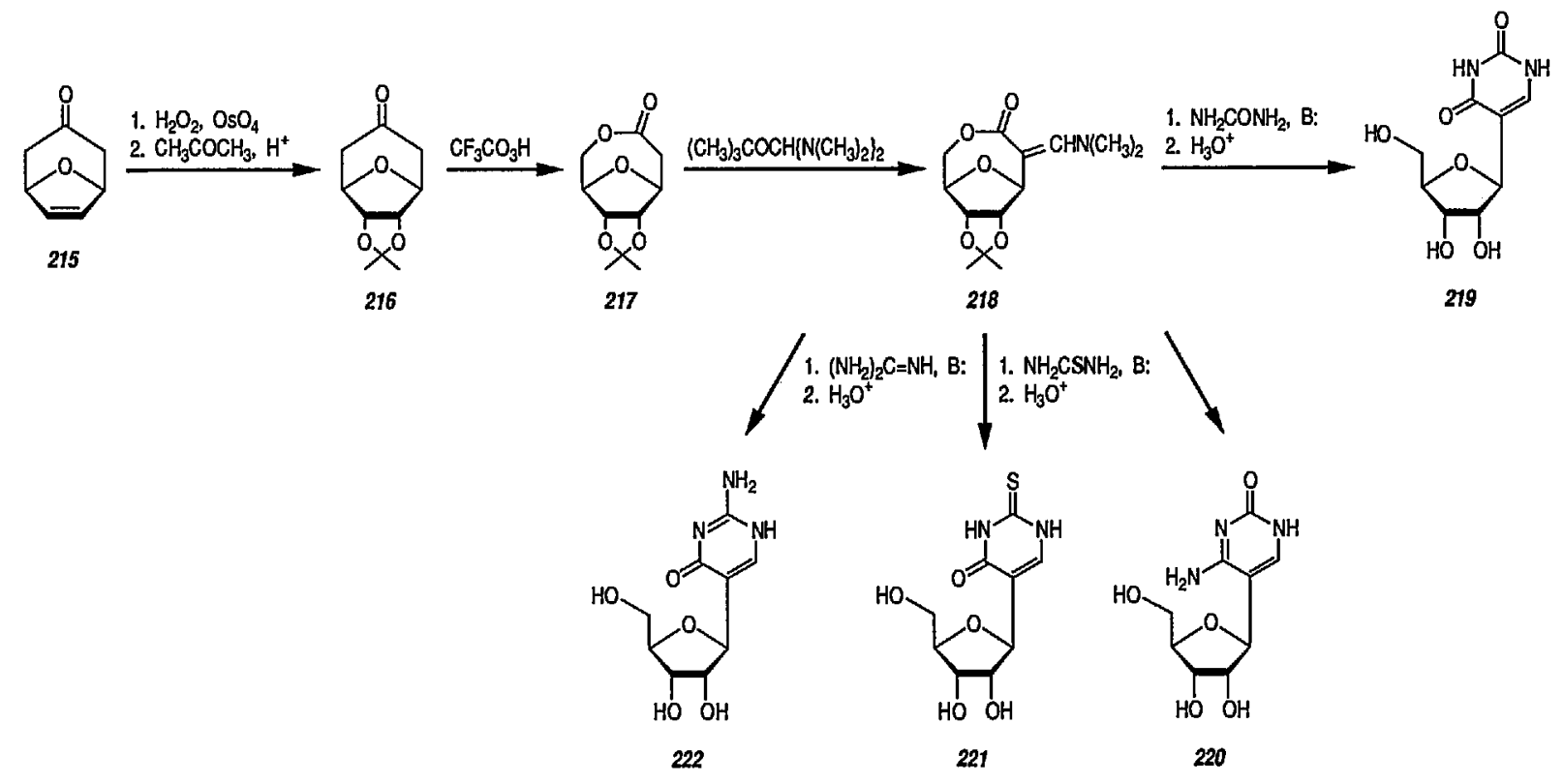

Scheme 39

7.4.3 Synthesis of Tropane Alkaloids The utility of $[3+4]$ cycloaddition reactions was applied for synthesis of tropane alkaloids having the 8-azabicyclo[3.2.1] octane system [416]. Thus, when tetrabromoacetone 213 was treated with $\mathrm{Fe}_{2}(\mathrm{CO})_{9}$ in the presence of $N$-(methoxycarbonyl)pyrrole 223, followed by the action of a $\mathrm{Zn} / \mathrm{Cu}$ couple in methanol, the azabicyclic ketone 224 was obtained in $57 \%$ yield. Reduction of 244 with diisobutylaluminum hydride gave stereoselectively 6,7-dehydrotropine 225 (having the natural $\alpha$-hydroxyl function) in $92 \%$ yield ( $\alpha: \beta$ ratio 93:7) [417]. The carbamate moiety was reduced to $N$-methyl at the same time. The alcohol 225 is convertible through appropriate reductive or oxidative modification of the double bond into most of the naturally occurring tropane alkaloids, such as tropine (226), scopine (227), tropanediol (228), and teloidine (229) [418] (Scheme 40).

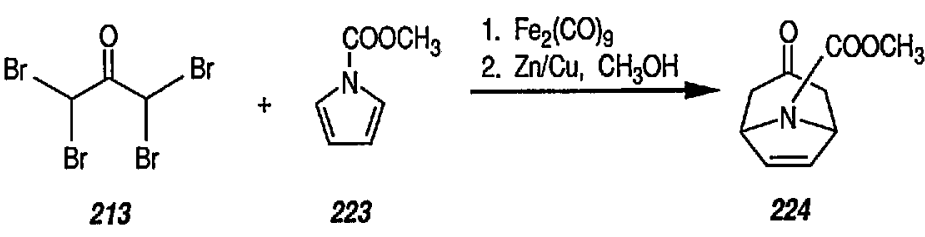<smiles>CC(C)N1C2C=CC1C1CC(C)(O)CC12</smiles>

225<smiles>CCN1C2CCC1C(C)[C@@H](O)C2</smiles>

226

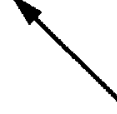<smiles>CCN1C2CC(C)(O)C1C1CC12</smiles>

227
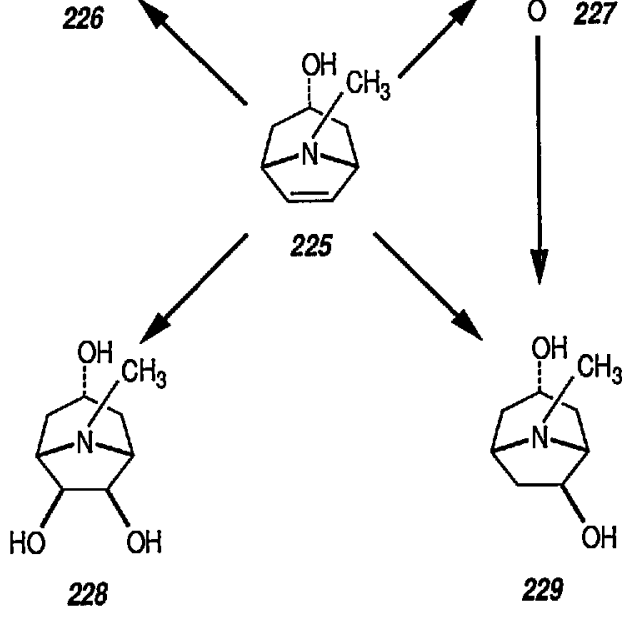

Scheme 40 
7.4.4 Synthesis of Terpenes The new method for cyclocoupling was further applied to the syntheses of terpenoids and related compounds. An example is the synthesis of naturally occurring troponids, achieved via a sequence of simple reactions starting from [3+4] adducts of the polybromo ketones and furan derivatives [419]. Thus, nezukone (232) was conveniently prepared by using the starting material, compound 230, obtainable from tetrabromoacetone and 3-isopropylfuran, through its hydrogenation on $\mathrm{Pd} / \mathrm{C}$, and dehydration with fluorosulfonic acid, giving the cross conjugated dienone 231, and then dehydrogenation using 2,3-dichloro-5,6-dicyano-1,4-benzoquinone (DDQ) [419,420]. In similar fashion, the bicyclic adduct 233 was converted into 2-isopropyltropone 234, and its $\alpha$-hydroxylation according to the standard method ( $\alpha$-amination with hydrazine hydrate followed by basic hydrolysis) produced $\alpha$-thujaplicin 235 [410,419]. Hinokitol ( $\beta$-thujaplicin)(238) was synthesized via a similar reaction sequence involving (236) and (237) as the key intermediates (see Scheme 41). The natural tropolone $\beta$-thujaplicin $1 \mathrm{X}$ has also been synthesized via Friedel-Crafts acylation of the tropone- $\mathrm{Fe}(\mathrm{CO})_{3}$ complex [421]. Terpenes having a bicyclo [2.2.1] heptane skeleton, e.g., ( \pm )-campherenone, are conceived to be biosynthesized by the double cyclization of the appropriate allylic cation. The iron carbonyl-promoted, intramolecular [3+2] process provided a chemical analog of this bioconversion $[422,423]$.

More syntheses of terpenes via the polybromo ketone-iron carbonyl reaction have been described [407].

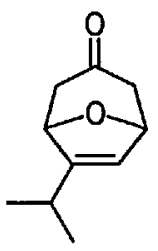

230<smiles>CC(C)C1C(=O)CC2C=CC1O2</smiles>

233

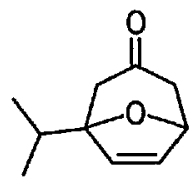

236

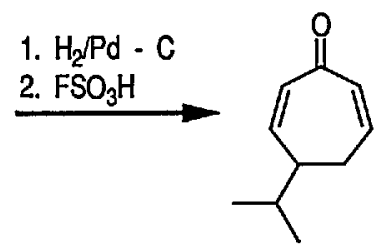

231

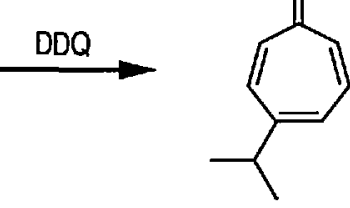

232
1. $\mathrm{H}_{2} \mathrm{Pd}-\mathrm{C}$

2. $\mathrm{FSO}_{3} \mathrm{H}$

3. $\mathrm{DDQ}$<smiles>CC(C)c1cccccc1=O</smiles>

234<smiles>CC(C)c1ccccc(O)c1=O</smiles>

235

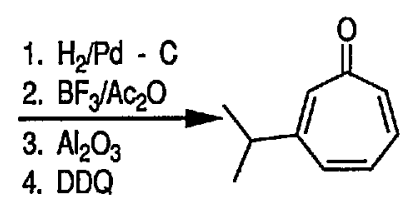

237

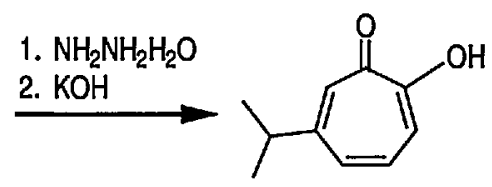

238

Scheme 41

7.4.5 Other Related Syntheses There have also been achieved in syntheses of other natural products and their analogs via the $[3+4]$ reaction of the polybromo ketones and furan as the key step. ( \pm )Nonactic acid 241 [409] was synthesized [424] through 239 and 240 [409]. The ketones 239 [409] served for the construction of the right-hand block of $( \pm)$-pederin 242 [425]. Preparation of a thromboxane $A_{1}$ analog 243 [426] was accomplished by starting from 215 [409] (Scheme 42).

A cycloaddition reaction between 2-cyanodimethylfumarate and $(\sigma-3-$ methoxyallyl $)\left(\eta^{5}-\mathrm{C}_{5} \mathrm{H}_{5}\right)$ dicarbonyliron yielded a cyclopentanoid derivative, used in a synthesis of the antitumor agent sarkomycin [427]. 


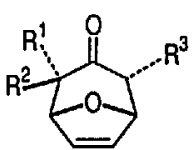

$239 R^{1}=R^{3}=\mathrm{CH}_{3} ; R^{2}=\mathrm{H}$ $240 R^{1}=R^{2}=\mathrm{CH}_{3} ; R^{3}=\mathrm{H}$<smiles>CC(C)C[C@@H]1[CH][C@H](C(C)C(=O)O)CC1</smiles>

241<smiles>C=C1CC(OC)(C(O)C(=O)NC(OC)C2C[C@H](O)C(C)(C)C(CC(COC)OC)O2)OC(C)C1C</smiles>

242<smiles>CCCCC[C@H](O)/C=C/C1CC2CCC1O2</smiles>

243

Scheme 42

\subsection{Synthesis of the $\beta$-Lactam Antibiotic $(+)$-Thienamycin via an Intermediate $\pi$-Allyltricarbonyliron-} Lactone Complex

Although the importance of $\beta$-lactam antibiotics has been recognized for many years [330,428-431], the recent discovery of some structurally new types of compounds [432-437] has generated a flood of interest in their methods of synthesis. Of the many novel routes to the azetidinone ring inherent in these systems, the use of iron carbonyl complexes is an attractive and growing area of study [327,329,332,438].

$\pi$-Allyltricarbonyliron lactone complexes have been used as novel precursors for the synthesis both of natural $\beta$-lactones, e.g., parasorbic acid (a bee pheromone) [439] and $\beta$-lactams [440-442]. Indeed, $\pi$-allyltricarbonyliron lactone complexes can be the key synthetic intermediates [440-442] to the important lactam antibiotics, such as (+)-thienamycin (255) (having a broad antibacterial activity) [443]. The synthesis of the lactam 255 [442] utilizes the reaction of vinyl epoxides with coordinately unsaturated iron carbonyl species to afford a precursor $\pi$-allyltricarbonyliron lactone complex 246 [441]. Preparation of the substituted vinyl epoxide (245) necessary was achieved in 55\% yield by reaction of 3,3-dimethoxypropanal with dimethyl-(2oxopropyl) phosphonate, to give the enone 244, followed by methylenation with dimethylsulfonium methylide [445]. Conversion of 245 into the tricarbonyliron lactone complex 246 was possible by treatment with $\mathrm{Fe}(\mathrm{CO})_{s}$ under photolytic conditions. Reactions of the lactone complex 246 with the chiral amine $(S)$-(-)- $\beta$-methylbenzylamine, mediated by $\mathrm{ZnCl}_{2}$, proceeded slowly, to give two readily separable diastereoisomeric ferrilactam complexes, i.e., 247 and 248 in 29 and $30 \%$ yield, respectively. Independent oxidation of the diastereoisomers 247 and 248 with ceric ammonium nitrate gave the cis-fused lactams 249 and 250 in 87 and $88 \%$ yields, respectively. Ozonolysis of the isopropenyl-substituted $\beta$-lactams (249 and 250 ) proceeded readily, to afford the 3-acetyl derivatives (251 and 252), each in $81 \%$ yield. Reduction of the acetyl group in 251 and 252 could be achieved with high stereoselectivity by using potassium tri-secbutylborohydride (K-selectride) in diethyl ether at room temperature, to give trans-(erythro-hydroxyethyl) derivatives in good yield. Debenzylation of these intermediates with sodium in liquid ammonia gave the desired enantiomeric (hydroxethyl)- $\beta$-lactams 253 and 254 in excellent yields, with optical rotations $[\alpha]_{D}^{2}+11.4^{\circ}$ and $-10.7^{\circ}$, respectively.

Applying the procedure of Kametani [446], the optically active lactam 253 can be converted in eight steps into thienamycin 255 in its naturally occurring (+)-form; this work, therefore constitutes a formal total synthesis [444] (Scheme 43). The novel route just described is reasonably short, and may be further modified and developed [442] for the synthesis of a wide range of $\beta$-lactam antibiotics.

\subsection{Highly Enantioselective Synthesis of Leucotriene $B_{4}$ and Its 14,15-Didehydro Derivative by the Use of Butadiene Tricarbonyl-Iron Complex}

Leucotriene $\mathrm{B}_{4}\left(\mathrm{LTB}_{4}\right)(261)$ is the major proinflammatory product of the 5-lipoxygenanse pathway in numerous dieases [447]. Recently, Grée et al. [448] devised a simple, efficient synthesis of the enantiomerically pure polyene alcohol (260) which is a key intermediate in preparation of (261) and its 14,15-didehydro derivative.

The new approach which starts from the readily accessible chiral complex(-)-256 [449], illustrates some of the key advantages in the use of butadiene tricarbonyl-iron complexes in organic synthesis. The reaction of (-)-256 (of known 1R, 4S absolute configuration [449] with allenyl silane (257) (2 equiv.) in the presence of $\mathrm{TiCl}_{4}$ (5 equiv.) at $-70^{\circ} \mathrm{C}$ gives the homoproparyl alcohol (258) (65\% yield after chromatography). The reaction is stereospecific ( $d e \geqslant 98 \%$ ) and leads only to the $\Psi$-endo derivative, with the $\mathrm{R}$ 


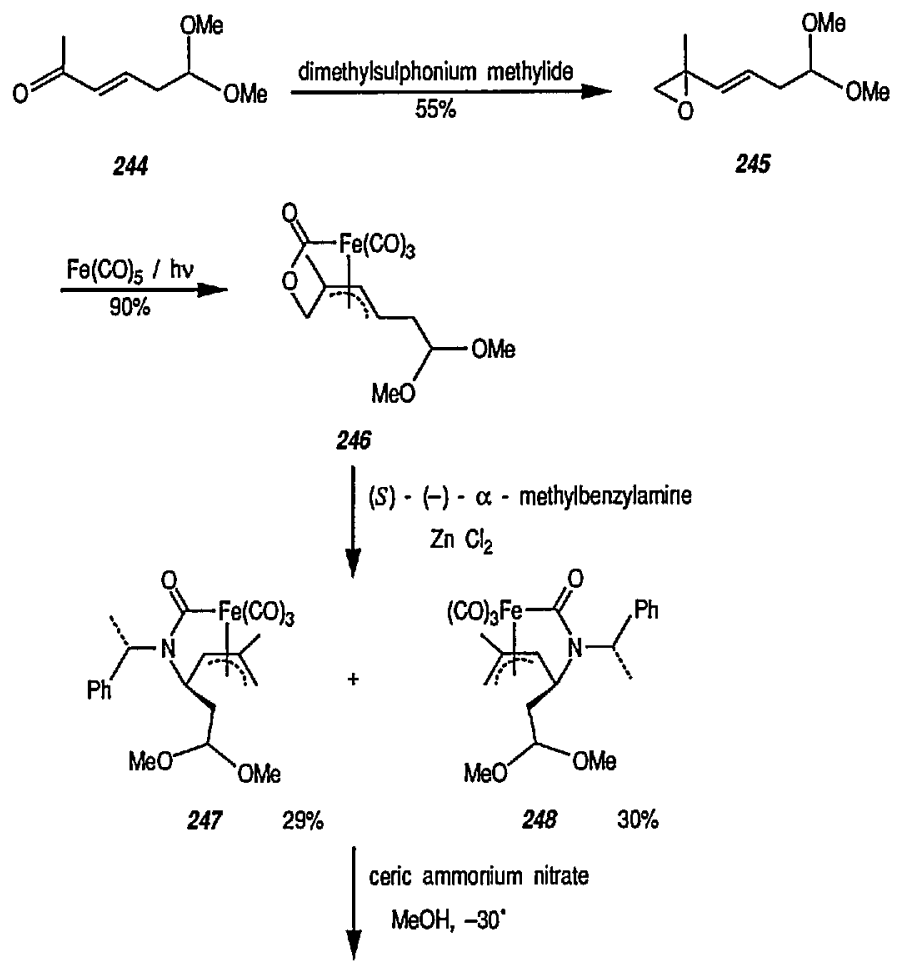<smiles>C=C(C)C1C(=O)N(C(C)c2ccccc2)C1CC(OC)OC</smiles><smiles>C=C(C)C1C(=O)N(C(C)c2ccccc2)C1CC(OC)OC</smiles>

249<smiles>CCOCCC(C)([10B]Br)CC</smiles>

$250 \quad 88 \%$<smiles>COC(CC1C(C(C)=O)C(=O)N1C(C)c1ccccc1)OC</smiles><smiles>COC(O)CC1C(C(C)=O)C(=O)N1C(C)c1ccccc1</smiles>

251 252

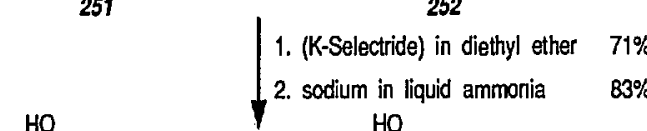<smiles>COC(CC1NC(=O)C1C(C)O)O[Na]</smiles><smiles>COC(CC1NC(=O)[C@H]1C(C)O)c1ccccc1</smiles>

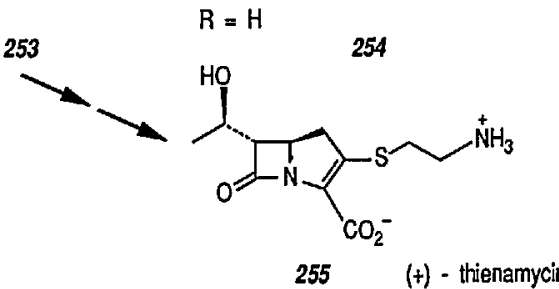

Scheme 43 
configuration at the secondary alcohol function. $\mathrm{Fe}(\mathrm{CO})_{3}$ acts here as an efficient diene-protecting group. Semireduction of (258) proceeds smoothly using Ni/Pt catalyst to give a quantitative yield of (259). Decomplexation $\left(\mathrm{Ce}^{4+}, \mathrm{MeOH},-15^{\circ} \mathrm{C}\right)$ occurs without racemization, leading to the desired key intermediate the polyene alcohol (260). The optical purity of (260) is ascertained by H-NMR using Eu(tfc) shift reagent. The polyene $(260)$ is then transformed to either 14,15-didehydro-LTB ${ }_{4}$ or Leucotriene $\mathrm{B}_{4}\left(\mathrm{LTB}_{4}\right)$ (including important labeled $\mathrm{LTB}_{4}$ ) according to the published procedure [450] (Scheme 44). Synthesis of (-)-verbenalol and (-)-epiverbenal via a common chiral iron complex, e.g., 256 has recently been described by the same group [451].

In another recent communication [452] the Grées group reported a new stereoselective synthesis of the erythro and threo carbonates 263 , which are key intermediates for the preparation of $(5,6)$-DIHETES and Lipoxin $\mathrm{A}_{4}$ (polyhydroxylated metabolities of the arachidonic acid cascade with their potent biological properties). Starting from the butadiene-tricarbonyl-iron complex 262, which has been resolved, the multi-step procedure includes a key step of highly diastereoselective osmylation of double bonds vicinal to the organometallic complex (e.g., the dienyl- $\mathrm{Fe}(\mathrm{CO})_{3}$ moiety). Interestingly, in each case, the addition of $\mathrm{OsO}_{4}$ onto the free double bond occurs anti to the $\mathrm{Fe}(\mathrm{CO})_{3}$ moiety. The stereochemistry of carbonates has been established by $\mathrm{x}$-ray crystallography. Being very bulky, the $\mathrm{Fe}(\mathrm{CO})_{3}$ group in 1,3-dienes is also a good stereodirecting group; the diastereoselectivity of the reactions depending essentially upon the structure and the conformational properties of the starting complexes. The potentialities of the butadiene tricarbonyl iron complexes in synthesis with extension to chiral synthesis appear to be noteworthy, and the topic is of current interest $[30,31,227,228]$.

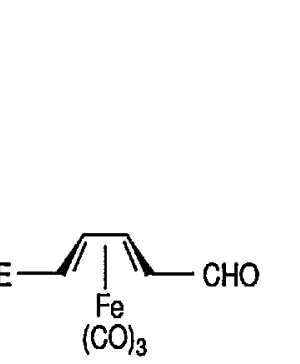

$(-) \cdot 256$

E<smiles>C/C=C/C=C/C=C\C(C)CO</smiles>

$260 \mathrm{R}=\mathrm{H}$

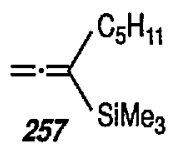

1. $\mathrm{TiCl}_{4}-70^{\circ} \mathrm{C}$

2. $1 \mathrm{~N}$ aqueous bicarbonate

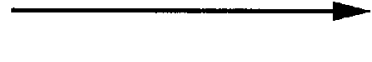

258
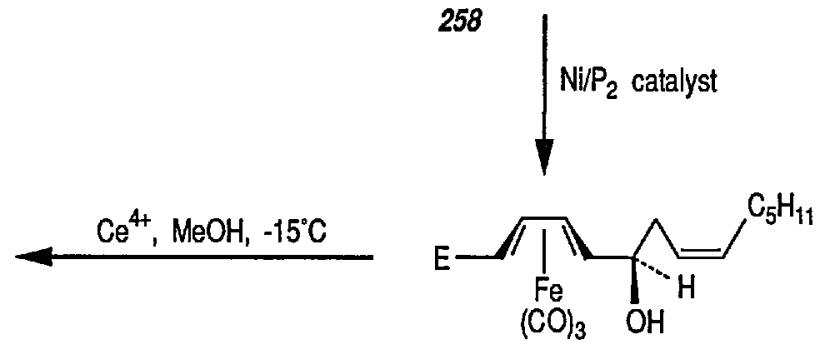

259

Scheme 44 


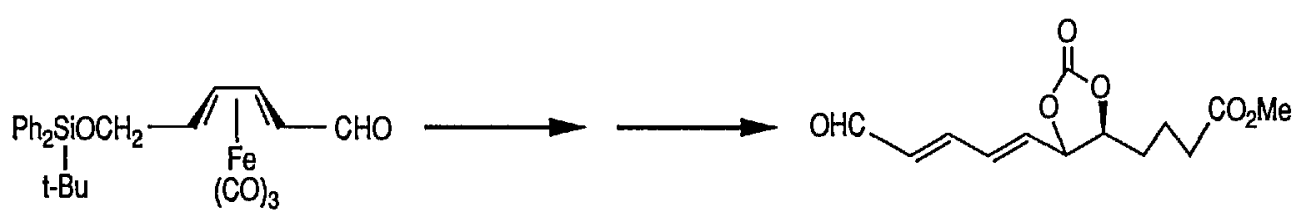

\subsection{Synthesis of Natural Products and Drugs via Chiral Organoiron Enolates. Use of Enolate from the} Davies' Chiral Auxiliary $\left[\left(\eta^{2}-\mathrm{C}_{5} \mathrm{H}_{5}\right) \mathrm{Fe}(\mathrm{CO})\left(\mathrm{PPH}_{3}\right)\right]$

Chiral enolates are an important class of reagents [304,356,453]. Excellent diastereoselectivity has been achieved with chiral organic auxiliaries [454], and transition-metal centers can also act as chiral adjuvants in enolate reactions. Stereoselective reactions of iron enolate species derived from $\left[\left(\eta^{5}-\mathrm{C}_{5} \mathrm{H}_{5}\right)(\mathrm{CO})\right.$ $\left.\mathrm{Fe}(\mathrm{CO})\left(\mathrm{PPh}_{3}\right) \mathrm{CH}_{2} \mathrm{R}\right]$ have been studied extensively $[60,62,64,317,319,341]$. Usually the iron chiral auxiliary $\left[\left(\eta^{5}-\mathrm{C}_{5} \mathrm{H}_{5}\right) \mathrm{Fe}(\mathrm{CO})\left(\mathrm{PPh}_{3}\right)\right]$ exerts powerful stereochemical control over the reactions of the attached acyl ligand $[61,63]$. By treating the acetyl complex with butyllithium we can efficiently generate the corresponding enolate, which may be trapped by a variety of allyl halides, and further treatment with butyllithium generates the corresponding $E$-enolates completely stereoselectively. This methodology was successfully applied to the synthesis of enantiomerically pure $\beta$-lactams [327,328,347].

The use of chiral organometallic nucleophiles as intermediates in the synthesis of natural products or drugs demonstrated the practical potential of these synthetic methods $[60,62]$. The potential of the iron chiral enolate for asymmetric synthesis is illustrated by asymmetric syntheses of $(-)$-shikimic acid (Scheme 45), of the bark beetle sex pheromone (Scheme 46), of the antihypertensive drug (-)-captropril (Scheme 47 ), and of the potent collagenase inhibitor (-)-actinonin (Scheme 48).

7.7.1 Synthesis of (-)-Shikimic Acid The stereochemical synthesis exercised by a complexed transition-metal atom can often mimic the control exercised by enzymes but with a wider range of reaction mechanisms of substrates $[445,456]$. As compared to the classical synthesis approach, a new concept of superimposed lateral control of reactivity, stereochemistry and structure, by attachment of complexed metal ions to alkene and diene systems, has been discussed at length [457].

A facile synthesis of $(-)$-shikimic acid (as its methyl ester) using $\mathrm{Fe}(\mathrm{CO})_{3}$ as a stereocontrol group has recently been described by Brich et al. [124]. The key intermediate in this enantiospecific synthesis was the resolved 1,3-cyclohexadieneiron complex $264(\mathrm{R}=\mathrm{H})$ obtained from benzoic acid via 1,4-dihydrobenzoic acid. The derived optically pure cation $265(\mathrm{R}=\mathrm{H})$ (obtained by a hydride abstraction from 264, compare sec. 3.1) has been shown to react with nucleophiles solely at the 5-oxo position [458]. Reaction of (+)$265(\mathrm{R}=\mathrm{H})$ in acetonitrile solution with aqueous sodium hydrogen carbonate yielded the alcohol complex $(+)-266(\mathrm{R}=\mathrm{H})$. Protection of its $\mathrm{OH}$ by reaction with tert-butyldimethylsilyl chloride (TBDMSCl) and diisopropylethylamine (to give 267) followed by decomplexation with anhydrous $\left(\mathrm{CH}_{3}\right)_{3} \mathrm{NO}$, provided the free diene $(+)-268\left(R=R^{\prime}=H\right)$ in $78 \%$ yield from $(+)-265(R=H)$. The conversion of this diene into $(-)$ methyl shikimate $\left(270, \mathrm{R}=\mathrm{R}^{\prime}=\mathrm{H}\right)$ was achieved in $67 \%$ yield via cis-diol $269(\mathrm{R}=\mathrm{R}=\mathrm{H})$ using osmium tetraoxide, followed by fluoride ion to remove the silyl-protected group. The product was identical in properties with (-)-methyl shikimate (Scheme 45). Applying a similar procedure deuterium was incorporated enantiospecifically to give (6R)- or (6S)-methyl 6-dideuterioshikimate. Shikimic acid is a very important biosynthetic intermediate, particularly in biological aromatization reactions. 


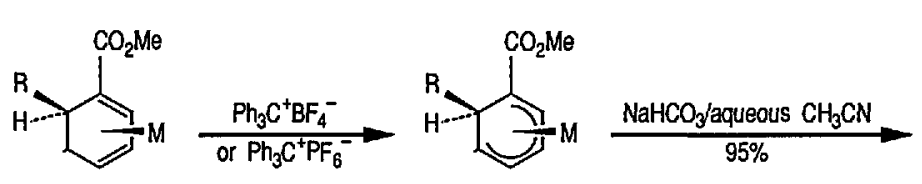

264

$\mathrm{R}=\mathrm{H}, \mathrm{M}=\mathrm{Fe}(\mathrm{CO})_{3}$
265

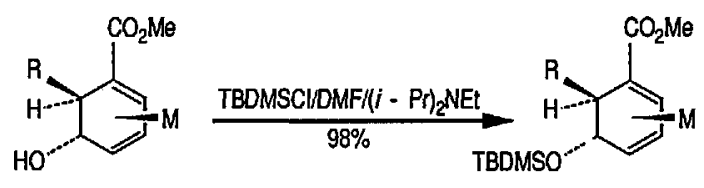

266 \begin{tabular}{r|}
267 \\
$\mathrm{Me}_{3} \mathrm{NO}^{2} \mathrm{C}_{6} \mathrm{H}_{6}$ \\
$(84 \%)$ \\
\hline
\end{tabular}

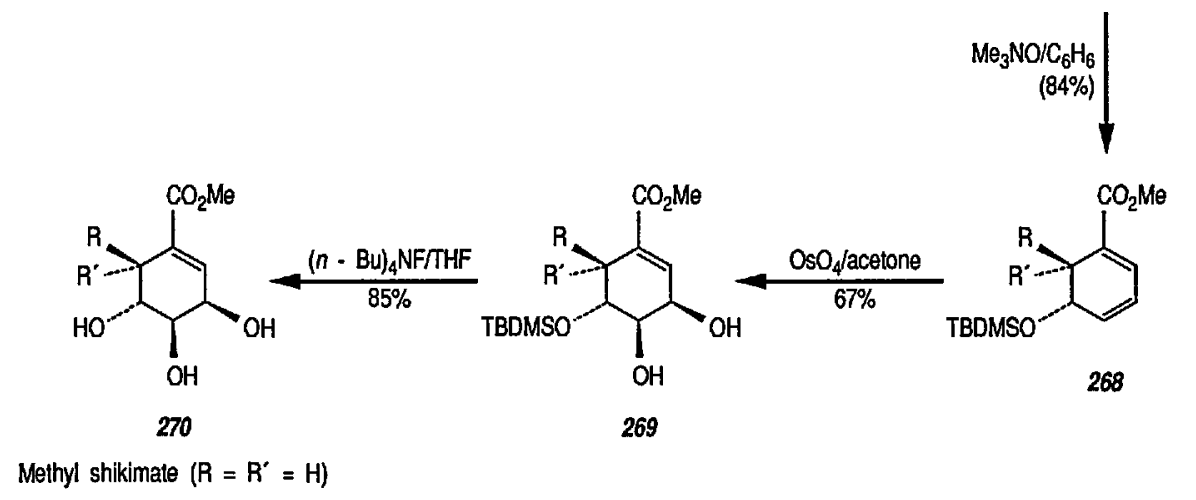

Scheme 45

7.7.2 Synthesis of the Bark Beetle Sex Pheromone $\left(\eta^{4}-\right.$ Isoprene $) \mathrm{Fe}(\mathrm{CO})_{3}(271)$ can be deprotonated at low temperature to give the isoprene anion equivalent (272), an attractive synthon for isopropenoid natural product synthesis; Semmelhack and Fewkes [459] have then reacted (272) with series of electrophiles. Reaction of (272) with the aldehyde (273) (to give 274), followed by decomplexation with hydrogen peroxide gave the bark beetle sex pheromone 275 in $91 \%$ yield (Scheme 46).
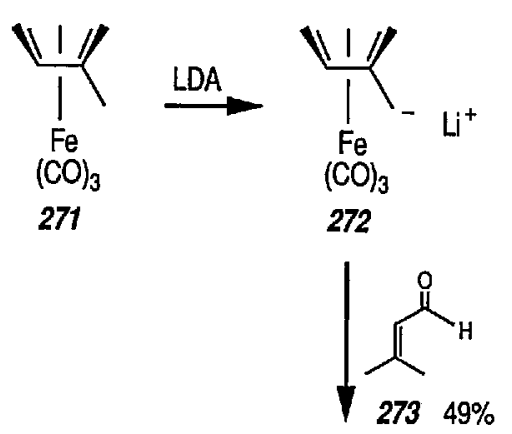

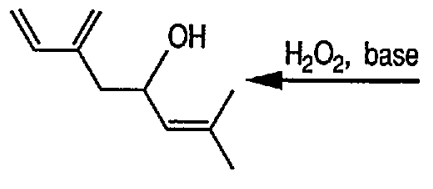

$27591 \%$

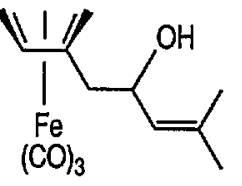

274

Scheme 46

7.7.3 Synthesis of (-)-Captropril The next asymmetric syntheses involve a novel application of enolates from the Davies' iron chiral auxiliary $\left[\left(\eta^{5}-\mathrm{C}_{5} \mathrm{H}_{5}\right) \mathrm{Fe}(\mathrm{CO})\left(\mathrm{PPh}_{3}\right)\right]$. The steps in the asymmetric synthesis of (-)-captropril (280) involve deprotonation and methylation of the R-(-)-acyl complex (276) to give the propanoyl derivative (277). Further alkylation with bromomethyl tert-butyl thioether stereoselectivity generated the new chiral center with the required absolute configuration yielding (278). Oxidative decomplexation with bromine in the presence of the tert-butyl ester of L-proline produced double protected (-)-captropril (279). Deprotection with trifluoroacetic acid and mercuric acetate then gave (-)-captropril (280) in 59\% overall yield $[60,460]$ (Scheme 47$)$. 


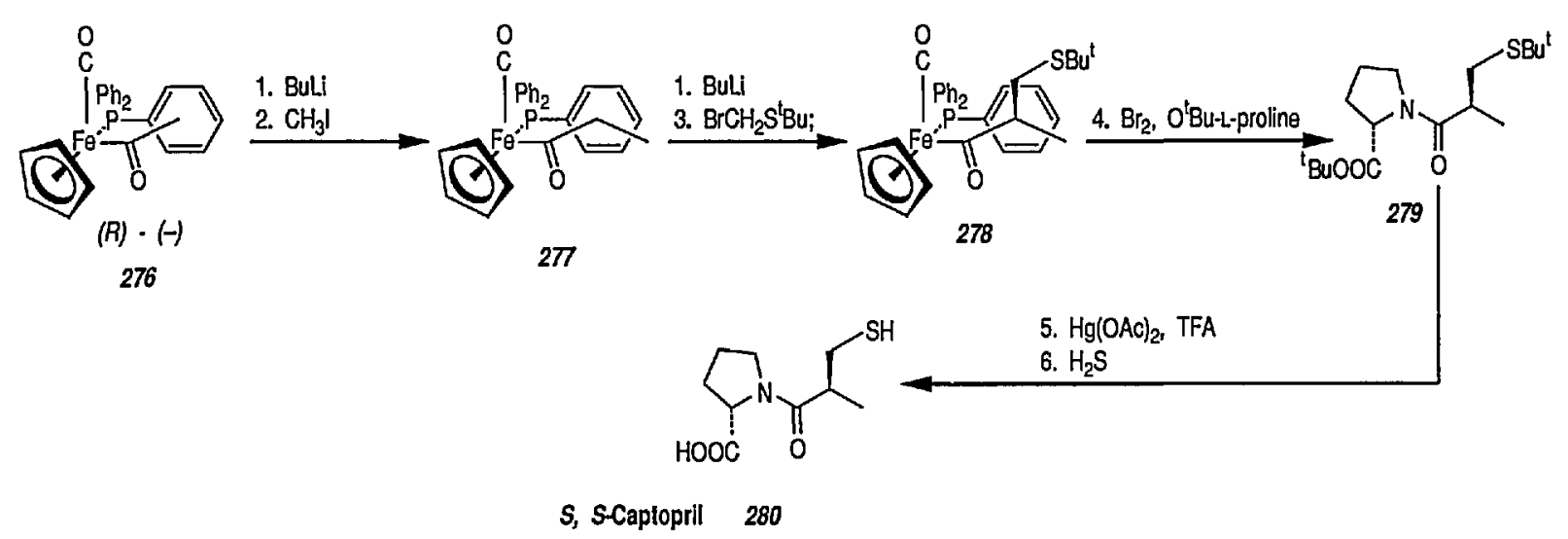

Scheme 47

7.7.4 Synthesis of (-)-Actinonin The seven-step asymmetric synthesis of (-)-actinonin (286) (Scheme 48) also demonstrates the use of the iron chiral auxiliary to provide a differentially protected chiral succinate enolate equivalent, as compared to a chiral propionate equivalent in the former case. Alkylation of the S-(+)-acetyl complex (281) with tert -butyl bromoacetate generated the corresponding succionyl complex (282). Deprotonation of (282) occurred $\alpha$ to the ester acyl function rather than $\alpha$ to the acyl function, to generate, on addition of pentyl iodide, the corresponding $\beta$-pentyl succionyl derivative (e.g., 283) regio- and stereoselectivity with the required absolute configuration at the new chiral center. Decomplexation with bromine in the presence of N,O-dibenzylhydroxyl-amine occurred with concomitant deprotection of the acid function, to give (284). Standard coupling procedures involving a chiral amine derived from prolinal and valine converted the free acid to tribenzyl actinonin (285). Debenzylation under hydrogenation conditions then yielded (-)-actinonin (286) in $41 \%$ overall yield [60,461]. (-)-Actinonin exhibits antibotic activity, anticancer activity and anticollagenase activity. The latter property makes it a potential candidate for the treatment and prevention of arthritis.

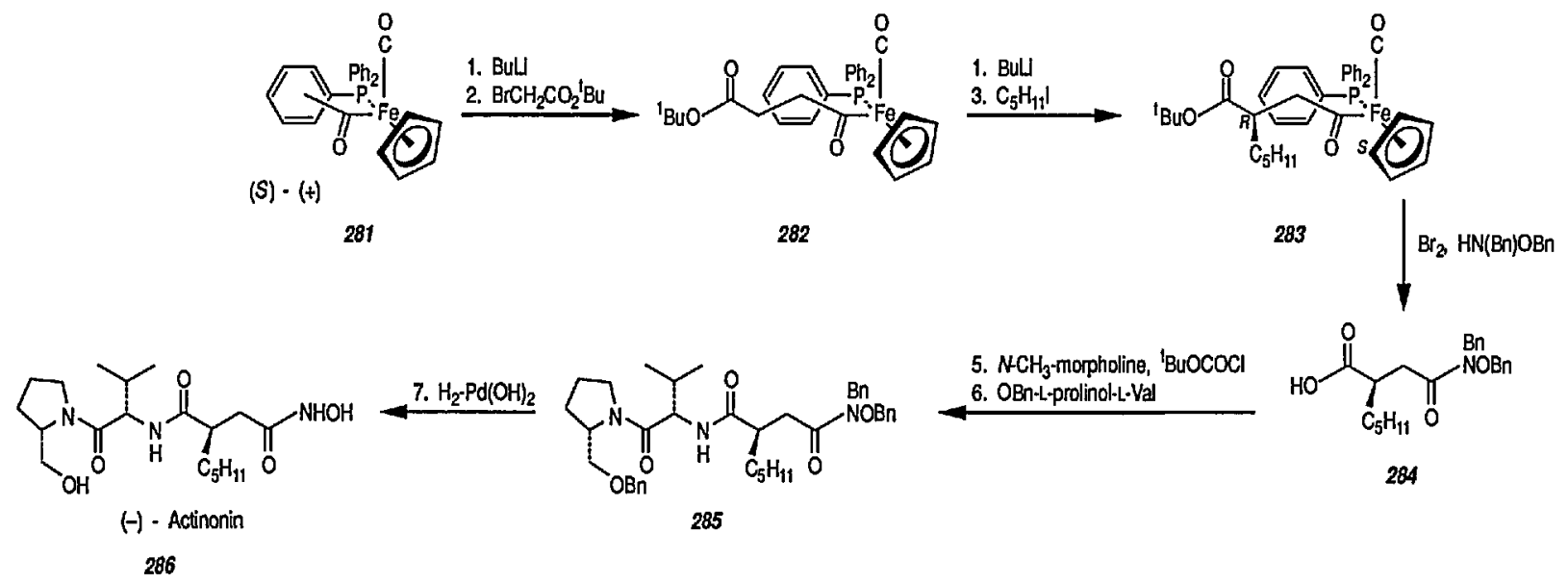

Scheme 48

7.7.5 Synthesis of (R,S)-1-Hydroxypyrrolidin-3-One The alternative procedure for the synthesis of alkaloids via cyclohexadienyliron complexes $[110,374]$ (sec. 7.1 ) has recently been reported by Beckett and Davies [462]; this procedure requires an aluminum enolate derived from the chiral iron acetyl $\left[\left(\eta^{5}-\mathrm{C}_{5} \mathrm{H}_{5}\right)\right.$ $\left.\mathrm{Fe}(\mathrm{CO})\left(\mathrm{PPh}_{3}\right)(\mathrm{Ac})\right](287)$. Here in the aldol reaction between the aluminum enolate derived from (287) and BOC- $L$-prolinal (S)-(288), the iron chirality overpowers the latent stereoselectivity inherent in the BOC-Lprolinal to allow, after deprotection and decomplexation, the synthesis of $(1 \mathrm{R}, 8 \mathrm{~S})$-1-hydroxypyrrolizidin-3one (291) (an important class of the plant-derived pyrrolizidine alkaloids). 
Thus deprotonation of (S)-(287) gave the corresponding lithium enolate. Transmetallation with diethylaluminum chloride and addition of (S)-(288) gave (S,R,S)-(289) as a single diastereoisomer $(>300: 1)$. Deprotection with toluene- $p$-sulfonic acid gave the corresponding (S,R,S)- $\beta$-hydroxy- $\gamma$-amino complex (290) which on oxidative decomplexation yielded $(1 \mathrm{R}, 8 \mathrm{~S})-(291)$ in $61 \%$ yield (Scheme 49$)$. The procedure was used for the synthesis of (S,S)-diastereoisomer starting from (R)-(287).

The future promises exciting possibilities for the use of transition metal based chiral auxiliaries for asymmetric synthesis. The ability of chiral auxiliary based reagents to discriminate between the two enantiomers of a racemic substrate allows the selective transformation of only one enantiomer of the substrate to product, leaving the other unaffected. This type of kinetic resolution [60] results in the conversion of racemic compounds into homochiral materials and represents one of the most promising topics for future research into the preparation of homochiral compounds.

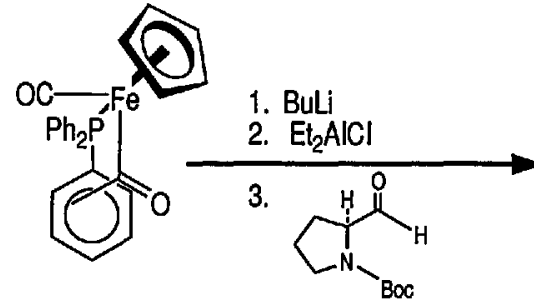

(S) -287

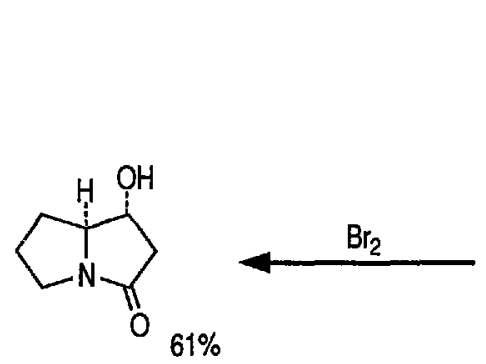

$(R, S)=291$

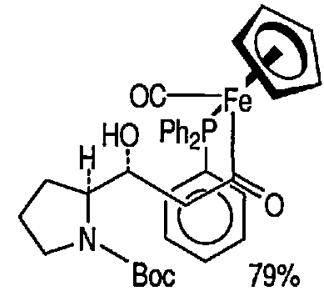

$(S, R, S) \cdot 289$

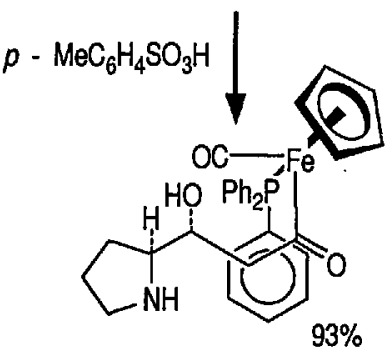

$(S, R, S) \cdot 290$

Scheme 49

\subsection{Asymmetric Synthesis with Chiral Ferrocenylamine Ligands: The Importance of Central Chirality}

The development of synthesis methodology for the diastereo- and enanthioselective formation of C-C bonds derived through the use of catalytic quantities of chiral transition-metal catalysts is today a topic of fundamental importance $[5,41,279,283,463-465]$.

In 1986, Ito and Hayashi reported an elegant synthesis of oxazolines utilizing a gold(I)-catalyzed aldol reaction in the presence of chiral ferrocenylamine ligands that possess both planar and central chirality [466].

For example, the reaction of benzaldehyde (292) with methyl- $\alpha$-isocyanoacetate (293) catalyzed by bis(cyclohexylisocyanide) gold(I) tetrafluoroborate (e.g., 294) in the presence of the chiral ferrocenylamine ligand(R)-(S)-295 give a mixture of trans - and cis-oxazolines 296 and 297, respectively. The trans isomer 296 was the dominant isomer formed in 91\% enantiomeric excess (ee) [467] (Scheme 50).

Recently, Pastor and Togni [468] examined the effect of varying ligand chirality in the ferrocenylamine side chain, e.g., 295 upon product enantio- and diastereoselectivity in a model reaction of 292 with 293 . The results of this study indicate that steric interactions due to the central chirality of the stereogenic carbon atom in the ferrocenylamine side chain play a more important role then previously supposed. Furthermore, the results of this study strongly suggest that planar chirality and central chirality may act in either a cooperative or noncooperative sense. This constitutes the first example in a chiral transition-metal ligand, e.g., ferrocyenylamine (S)-(S)-295 containing both planar and central chirality of internal cooperativity of chirality in the control of product diastereo- and enantioselectivity. 


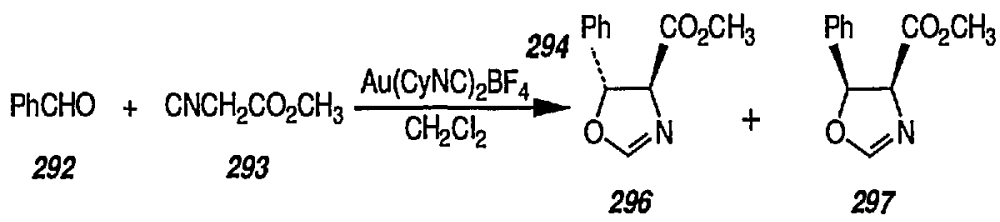<smiles>[2H]C([2H])(c1ccccc1[Tl])C([2H])([2H])N(C)CCN(C)C</smiles>

$(R) \cdot(S)-295 \mathrm{R}^{1}=\mathrm{CH}_{3} ; \mathrm{R}^{2}=\mathrm{H} ; \mathrm{L}^{1}=\mathrm{PPh}_{2} ; \mathrm{L}^{2}=\mathrm{H}$ (S) $-(R)-295 \mathrm{R}^{1}=\mathrm{H} ; \mathrm{R}^{2}=\mathrm{CH}_{3} ; \mathrm{L}^{1}=\mathrm{H} ; \mathrm{L}^{2}=\mathrm{PPh}_{2}$ $(R)-(R)-295 \mathrm{R}^{1}=\mathrm{CH}_{3} ; \mathrm{R}^{2}=\mathrm{H}_{;} \mathrm{L}^{1}=\mathrm{H}_{;} \mathrm{L}^{2}=\mathrm{PPh}_{2}$ (S) $-(S)-295 \mathrm{R}^{1}=\mathrm{H} ; \mathrm{R}^{2}=\mathrm{CH}_{3} ; \mathrm{L}^{1}=\mathrm{PPh}_{2} ; \mathrm{L}^{1}=\mathrm{H}$

Scheme 50

7.8.1 Synthesis of (t)-Corynoline A chiral ferrocenylamine ligand [353] played a key role in another recent chiral application [469]. The key step in the asymmetric synthesis of $(+)$-corynoline (303) involved the condensation of the chiral 1-ferrocenyl-2-methyl-propylamine Schiff base (300) [obtained by the reaction of the ferrocenylamine (298) $\left(\mathrm{Fe}^{*}\right)$ with the aldehyde (299)] with racemic homophthalic anhydride (301) to afford the required chiral intermediate (302) in $81 \%$ yield; the latter was then transformed into natural (+)-corynoline (303) (Scheme 51). Here the chiral auxiliary influences both the relative and the absolute configuration of two asymmetric centers [469].

A new chiral ferrocenylphosphine ligand with $C_{2}$ symmetry has recently been prepared and used for palladium-catalyzed asymmetric cross-coupling reactions [470].<smiles>CC(C)[C@H](N)c1cccc(Oc2ccccc2)c1</smiles>

298<smiles>CN1Cc2c(ccc3c2OCO3)C2(C)c3cc4c(cc3C[C@H](O)[C@H]12)OCO4</smiles>

303<smiles>O=Cc1ccc2c(c1)OCO2</smiles><smiles>CC1C(=O)OC(=O)c2c1ccc1c2OCO1</smiles><smiles>O=C1c2c(ccc3c2OCO3)[C@@](C(=O)O)(c2ccc3c(c2)OCO3)[C@H]1N1CCCC[C@@H](C(F)(F)F)C1=O</smiles>

$30281 \%$

Scheme 51 


\section{Miscellaneous Recent Results}

Some highlights of recent applications of organoiron complexes in synthesis are described next.

\subsection{Organoiron Complexes in Carbon-Carbon Bond-Formation Reactions}

8.1.1 Enantioselectivity in $\mathrm{Bu}_{4} \mathrm{~N}\left[\mathrm{Fe}(\mathrm{CO})_{3} \mathrm{NO}\right]-$ Catalyzed Nucleophilic Substitution of Optically Active Allylic Carbonates with Malonate Among the various carbon-carbon-bond-forming reactions promoted or catalyzed by transition metals, allylic alkylation has been one of the most aggressively sought after. Accordingly, in recent years, extensive studies have been devoted to the regio- and stereochemistry of these allylic alkylation reactions catalyzed by different metal complexes, including iron [100,471]. Encouraged by good regioselectivity, geometric selectivity, and diastereoselectivity exhibited in $\mathrm{Bu}_{4} \mathrm{~N}\left[\mathrm{Fe}(\mathrm{CO})_{3} \mathrm{NO}\right](304)-$ catalyzed allylic alkylation [100], the study has now been extended on the enantioselectivity of this iron-catalyzed reaction. Here the reaction of several optically active allylic carbonates with a nucleophile sodium dimethyl malonate catalyzed by $\mathrm{Bu}_{4} \mathrm{~N}\left[\mathrm{Fe}(\mathrm{CO})_{3} \mathrm{NO}\right]$ has been examined [472].

Thus, the allylic carbonate $(\mathrm{R}, \mathrm{E})-305[\alpha]_{D}^{25}+89.2(\mathrm{C}, 1.80$, chloroform, $73 \% e e)$ was allowed to react with 2 equiv. of sodium dimethylmalonate in refluxing THF in the presence of 25 mol\% of (304) under CO atmosphere for $12 \mathrm{~h}$. Workup followed by flash chromatography on silica gel gave $78 \%$ yield off the alkylated products consisting of [1-(E)-styrylethyl] malonate (306) and its regioisomer, dimethyl[1-phenyl-2(E)butenyl]malonate (307), in a ratio of 93:7. This method was also applicable in reactions of optically active allylic carbonates with a terminal double bond.

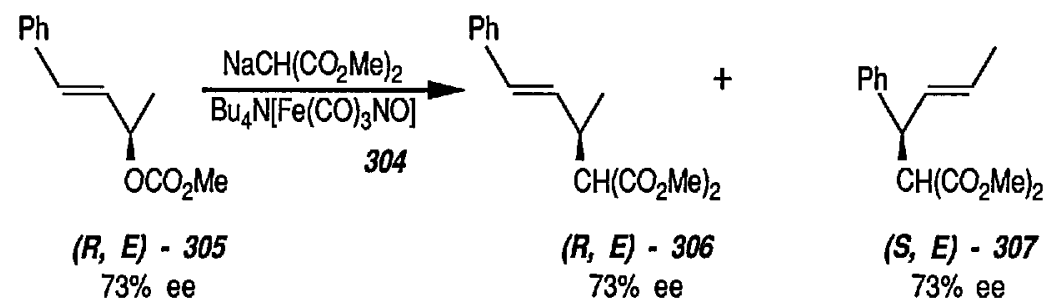

8.1.2 Regioselective Addition of Nucleophiles to Cationic Diiron $\mu$-Vinylcarbyne Complexes Recently Casey et al. [473] described a new procedure for the synthesis of functionalized diiron $\mu$-alkenylidene complexes. When $p$-tolyllithium was added to a purple suspension of the $p$-tolyl substituted vinylcarbene complex (308) in THF at $-78^{\circ} \mathrm{C},(308)$ gradually dissolved to form a red solution from which the alkenylidiene complex (309) was isolated in $49 \%$ yield as a red-orange powder. The complex (309) was formed by the regioselective addition of a $p$-tolyl group to the remote vinyl carbon of (308); its structure was established by spectroscopy.

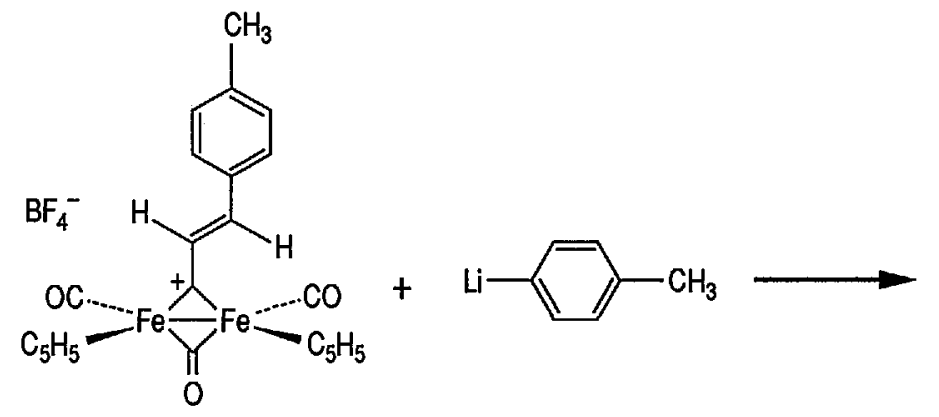

308

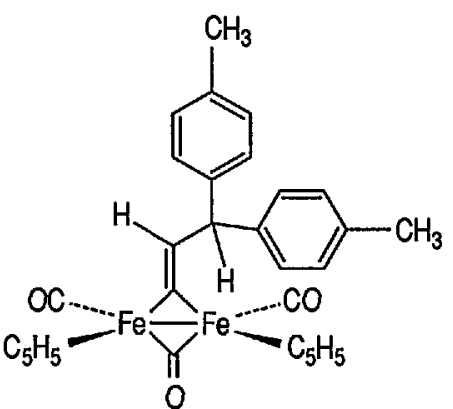

309 
The diiron methylidene complex $\left[\left(\mu-\mathrm{C}_{5} \mathrm{H}_{5}\right)(\mathrm{CO}) \mathrm{Fe}\right]_{2}(\mu-\mathrm{CO})(\eta-\mathrm{CH})^{+} \mathrm{PF}_{6}^{-}$forms $1: 1$ adducts with a variety of heteroatom and carbon nucleophiles such as $\left(\mathrm{CH}_{3}\right)_{3} \mathrm{~N}$; it also reacts with carbon monoxide to give 1:1 adduct. This adduct then reacted with nucleophiles at the acylium carbon to give a series of useful derivatives such as aldehydes, carboxylic acids, amides etc. [474].

A new procedure for regiospecific lithiation of permethylated ( $\eta^{6}$-tricarbonylchromium) phenylacetyl (tetracarbonyl) iron anion has recently been described [475]; this is a versatile method for the $\alpha, \alpha^{\prime}$-orthobifunctionalization of hexamethylbenzene.

8.1.3 Applications of Ferrocene Derivatives A recent survey of ferrocene chemistry has appeared [476]; additions to techniques developed for functional-group interconversion involve some ferrocene derivatives.

It has been presumed that catalytically formed alkyl-palladium species would undergo destructive betahydride elimination too rapidly for use in organic synthesis. However, a recent report [477] shows that 1,1'-bis(diphenyl-phosphine)ferrocene (dppf) ligand effectively suppresses beta-hydride elimination. For example, exposure of a primary alkyl Grignard reagent, such as 310 , to a relatively sluggish-acting iodide, such as 311 , in the presence of $5 \mathrm{~mol}$ percent of the dppf $\mathrm{PdCl}_{2}$ catalyst $\left(67^{\circ} \mathrm{C}\right.$ for $\left.16 \mathrm{~h}\right)$ gives the coupling product 312 in $91 \%$ yield (Scheme 52). Here, the dppf $\cdot \mathrm{PdCl}_{2}$ catalyst effects the cross-coupling of alkyl iodides with alkyl Grignard reagents; and this is a useful method for selective carbon-carbon bondformation.

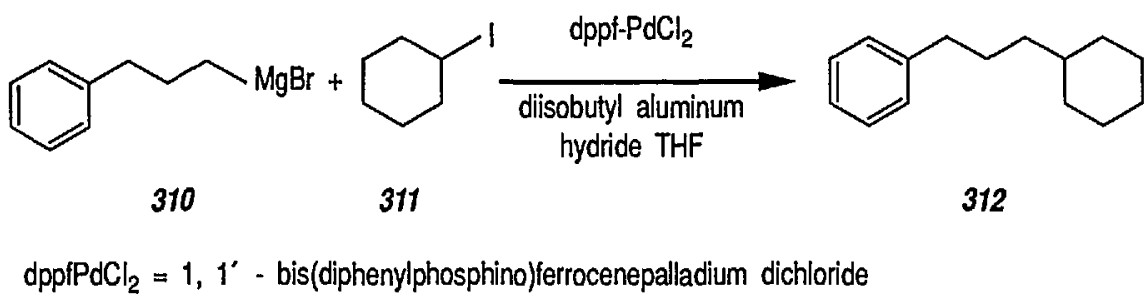

Scheme 52

Some isocyclopentadiene derivatives of ferrocene have been used as models for study of the mechanism of the $\pi$-facial, selective course of Diels-Alder cycloadditions [478]. Synthetic applications of mixed-valence ferrocenes have recently been explored [479].

8.1.4 Application of Iron Heterocyclics Today, the design of new catalytic transition-metal-mediated carbon-carbon bond-constructions that are of utility in the course of organic synthesis remains an important challenge; this is supported by a variety of new synthetic uses of organoiron complexes. For example, a new $2,2^{\prime}$-bipyridine- $\mathrm{Fe}(\mathrm{O})$-diene complex has been applied for the regio- and chemoselective cross-coupling reaction with various alkenes [480]. In the heterocyclic series, a new reaction of diazadiene-tricarbonyliron complex 313 with the electron-deficient alkynes (e.g., methyl propynoate) in the presence of $\mathrm{CO}$ as an additional ligand leads to the formation of (1,5-dihydropyrrol-2-one)-tricarbonyliron complex 314; a bicyclic reaction-intermediate has been isolated and characterized [481] (see Scheme 53).

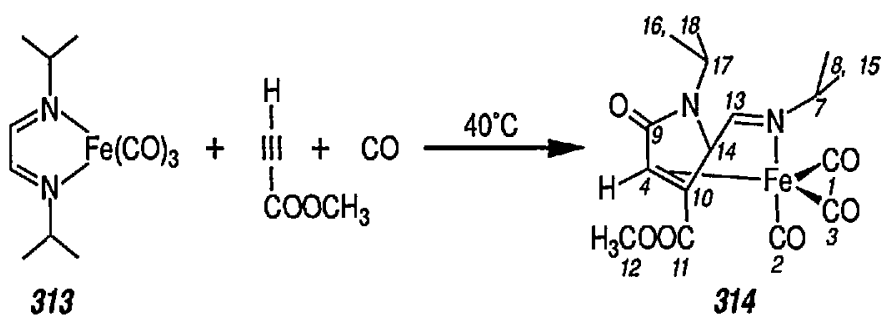

Scheme 53 
8.1.5 Use of Optically Active Iron-Alkene Complexes Optically active metal-alkene complexes in which the alkene itself is a center of asymmetry provide unique substrates for asymmetric carbon-carbon bond-formation [14]. Recently, Rosenblum et al. [37-40,482] reported the preparation of the optically active iron complex 315, which serves both as a unique platform for asymmetric $\mathrm{C}-\mathrm{C}$ bond-formation and for the preparation of optically active alkyl vinyl ether-iron complexes in which the exclusive locus of asymmetry is the alkene center. Complex 316 adds nucleophiles of a broad range of basicities (e.g., $\mathrm{NaBH}_{3} \mathrm{CN}, \mathrm{PhMgBr}$, $\mathrm{PhCH}_{2} \mathrm{SH}$, etc.) yielding the single, optically active adduct 317 . The high regioselectivity observed in the reaction of 316 with nucleophiles may be due to stereoelectronic control of addition. Complex 316 can be prepared from 315 by exchange etherification with ethylene glycol $\left(\mathrm{CH}_{2} \mathrm{Cl}_{2}, 0^{\circ} \mathrm{C}, 0.25 \mathrm{~h} ; \mathrm{Et}_{2} \mathrm{O}, 94 \%\right)$. Complex 317 is then quantitatively converted into (R)-318 $\left(\mathrm{E}_{480}=+1.34 \mathrm{M}^{-1} \mathrm{~cm}^{-1}, 0^{\circ}\right)$, on treatment with $\mathrm{Me}_{3} \mathrm{Si}$ triflate and $\mathrm{CH}_{2} \mathrm{Cl}_{2}-\mathrm{Et}_{2} \mathrm{O}$ at $-78^{\circ} \mathrm{C}$ for $10 \mathrm{~min}$. This may be further transformed by reduction $\left(\mathrm{NaBH}_{4}\right.$, $\left.-78^{\circ} \mathrm{C}\right)$ and treatment with $\mathrm{HBF}_{4} \cdot \mathrm{Et}_{2} \mathrm{O}\left(-78^{\circ} \mathrm{C}\right)$ into the first iron-alkene complexes 319 and 320 which owe their optical activity entirely to asymmetry of alkene complexation (see Scheme 54).

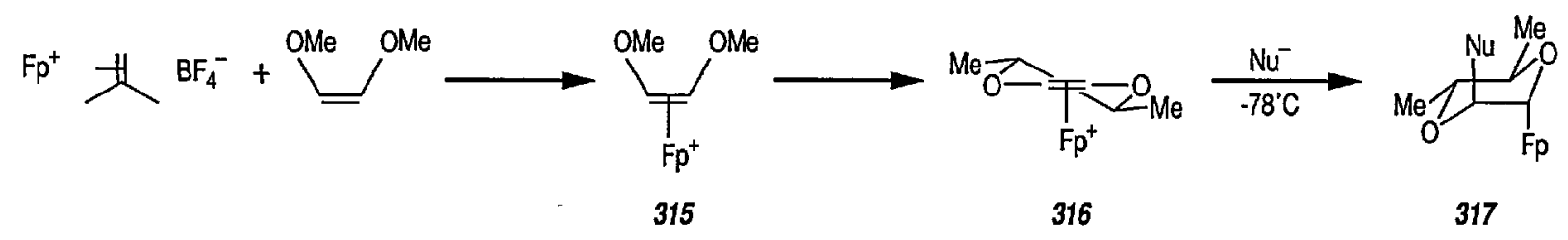

$\mathrm{Fp}=\left(\eta-\mathrm{C}_{5} \mathrm{H}_{5}\right) \mathrm{Fe}(\mathrm{CO})_{2}$

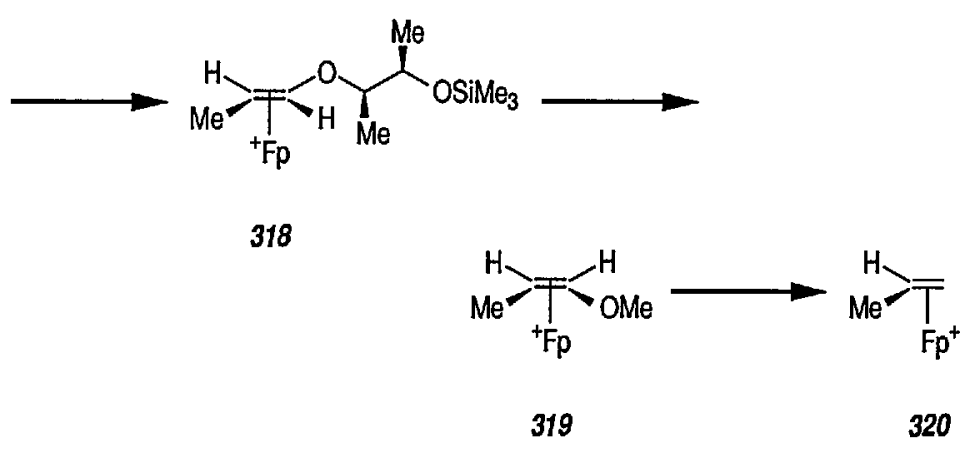

Scheme 54

Recently, a promising dynamic resolution of vinyl ether-iron complexes has been reported by the same group [40]. Thus, optically active vinyl ether-iron complexes (a prototype of 320) can be readily generated from the racemic ethyl vinyl ether-iron complexes by alkoxy exchange with optically active alcohols. The best results are achieved with $(-)$ or (+)-menthol yielding diastereomeric complexes with ratio $4.0: 1$ or 3.6:1 respectively.

A series of new, chiral, iron complexes of the type $\left[\eta^{5}-\mathrm{C}_{5} \mathrm{H}_{4} \mathrm{CH}(\mathrm{Ph}) \mathrm{Fe}(\mathrm{CO})-(\mathrm{L}) \mathrm{X}\right]$, where ( $L=$ phosphine, phosphite, $X=$ acyl, alkyl, halide, hydride), have been synthesized and characterized [48,53].

$\left(\eta^{4}\right.$-tropone) $\mathrm{Fe}(\mathrm{CO})_{3}$ and $\left(\eta^{4}\right.$-isoprene $) \mathrm{Fe}(\mathrm{CO})_{3}$ form separable diastereoisomers on replacement of $\mathrm{CO}$ by $(+)$-(neomenthyl) $\mathrm{PPh}_{2}$. In the tropone complex, diastereoisomer interconversion occurs by a $1,3-$ metal shift. The absolute configuration of this isoprene complex has been determined crystallographically [483].

It has recently been shown [585] that ( $\eta^{4}-1$-chloro-2,5-diphenylsilacyclopentadiene)tricarbonyliron complexes undergo nucleophilic displacement at silicon with complete retention of configuration at both the exo and the endo positions. The substitution is faster at the exo than at the endo position. The observations were discussed in terms of electronic factors.

\subsection{New Reactions of Bridged Organoiron Complexes}

The reaction of the cationic diiron bridging methylidene complex 321 (which is very electrophilic) with activated alkenes has recently been examined by Casey et al. $[47,485,486]$. The bridging methylidene com- 
plex alkenes, 321 adds its $\mathrm{C}-\mathrm{H}$ bond across the carbon-carbon double bond, to afford $\mu$-alkylidene complexes. For some alkenes, such as 1-methylcyclohexene, trans-stilbene, and 1,1-diphenylethylene, which are more steri-cally crowded and are capable of forming stabilized carbocation intermediates, the formation of bridging alkenyl complexes has been observed, conversions $321 \rightarrow 322 ; 321 \rightarrow 323 \rightarrow 324$ (Scheme 55) (Compare also sec. 8.1.2).

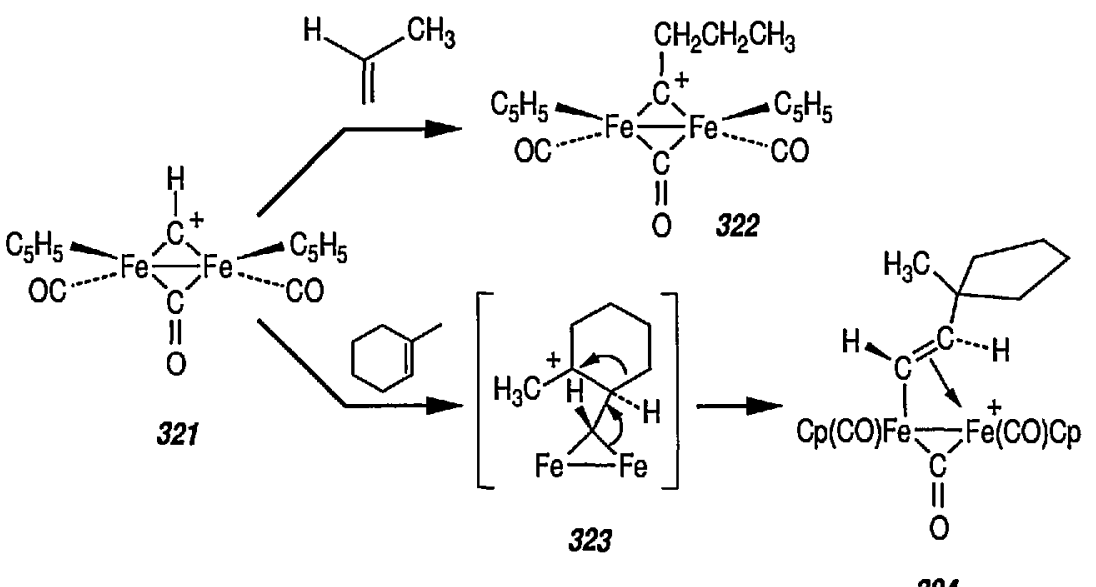

Scheme 55

\subsection{Enzymatic Resolution of Chiral Butadiene Tricarbonyliron Complexes by Pig Liver Esterase}

A few 1,3-diene tricarbonyliron complexes have been resolved, almost all by classical means (formation of diastereoisomeric derivatives) [449,457,487-490]. The first example of an enzymatic resolution of an organometallic complex has recently been reported [491]. Thus, the racemic ester (2-ethoxycarbonylbuta-1,3-dienetricarbonyliron) (325) was hydrolyzed enantioselectively to the corresponding crystalline acid (326) by pig liver esterase (PLE); the reaction reached completion in about $40 \mathrm{~h}$ at $\mathrm{pH} 7$. The optical purity of the acid (326) was found to be of $85 \% e e$ which was raised to $>98 \%$ by one recrystallization. The ability of hydrolytic enzymes to recognize chirality of the type exhibited by this complex warrants further exploration of this useful synthetic procedure.

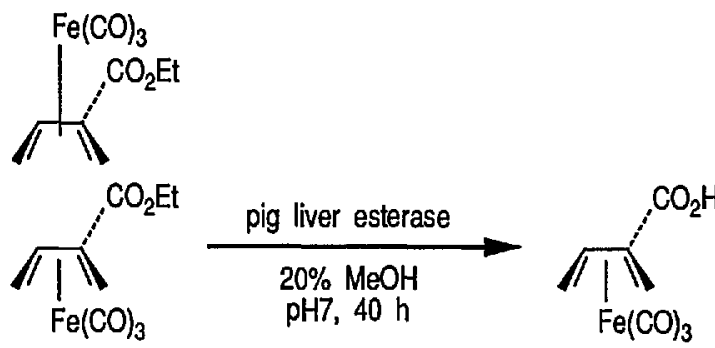

325

\subsection{The Stereoselective Reaction of Nonbornyl Aldehydes with Diiron Nonacarbonyl [ $\left.\mathrm{Fe}(\mathrm{CO})_{9}\right]$}

The reported reactions of aldehydes with iron carbonyl reagents have been limited to $\alpha, \beta$-unsaturated systems in which stable $\pi$-complexes are formed $[492,493]$. As recently found [494] the norbornyl aldehydes do not form stable complexes in the presence of $\mathrm{Fe}(\mathrm{CO})_{9}$, instead the reaction proceeds stereoselectively to "geminal-faced" esters or alcohols. 
Thus, in the presence of $\mathrm{Fe}(\mathrm{CO})_{9}$ in refluxing hexane or tetrahydrofuran (THF), norbornane-2-carboxaldehyde (327) $\left(\mathrm{R}=\mathrm{H} ; \mathrm{R}=\mathrm{CH}_{3}\right)$ was converted to the endo, endo congener (90\% isomeric purity) of norbornane-2-ylmethyl norbornane-2-carboxylate (328) $\left(\mathrm{R}=\mathrm{H} ; \mathrm{R}=\mathrm{CH}_{3}\right)$ in $54 \%$ and $71 \%$ yields, respectively, after $48 \mathrm{~h}$. In addition, a minor amount (4-6\%) of the reduction product, endo-2-(hydroxymethyl)norbornane (329) $(\mathrm{R}=\mathrm{H})$ was generated as well, which possessed an isomeric purity of $85 \%$. Although yield enrichments were observed for esters (328) $\left(\mathrm{R}=\mathrm{H} ; \mathrm{R}=\mathrm{CH}_{3}\right)$ with a change in solvent, alcohol formation remained approximately the same. These results emphasized the importance of solvent characteristics as a parameter for ester synthesis. It is well known [495] that THF stabilizes iron carbonyl through complexation, and this evidently contributed to the higher ester yields in that medium.

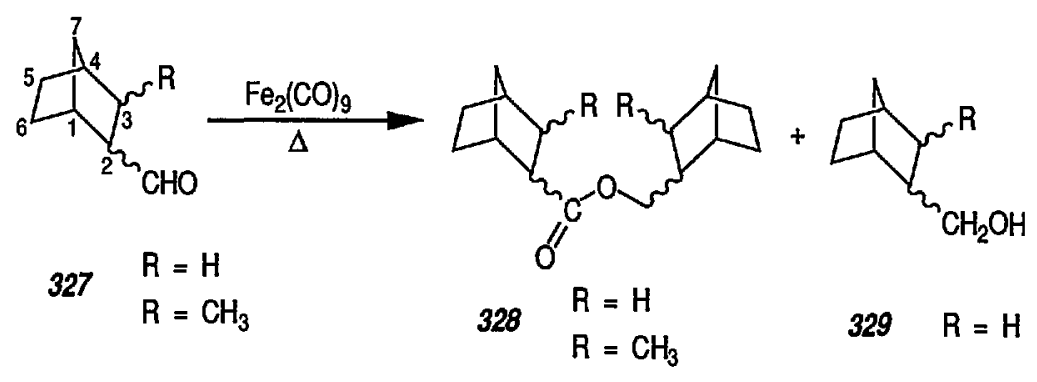

\subsection{Ring-Opening Reactions}

8.5.1 Novel Ring-Opening Reaction of Norbornadiene (Tricarbonyl)Iron This study describes an activation of nonconjugated cyclic polyene ligands like norbornadiene by iron and reports a novel ring-opening reaction of norbornadiene (tricarbonyl) iron (330) under mild conditions [496]. Thus reaction of (330) with aryl-lithium reagents ( $\mathrm{ArLi} ; \mathrm{Ar}=p, 0-\mathrm{CH}_{3} \mathrm{C}_{6} \mathrm{H}_{4} ; p=\mathrm{CF}_{3} \mathrm{C}_{6} \mathrm{H}_{4}$ ) at low temperature (ether, $-60^{\circ} \mathrm{C}$ ), followed by alkylation of the intermediate acylmetallates (331) with $\mathrm{Et}_{3} \mathrm{OBF}_{4}$ in aqueous solution at $0{ }^{\circ} \mathrm{C}$, leads to cleavage of the norbornadiene ring, to give novel ring-opened diallyl complexes (332) $\left(\mathrm{Ar}=p, 0-\mathrm{CH}_{3} \mathrm{C}_{6} \mathrm{H}_{4}\right.$; $\left.p=\mathrm{CF}_{3} \mathrm{C}_{6} \mathrm{H}_{4}\right)$ in moderate yields. This reaction implies that the $\sigma$-bonds of cyclic polyene ligand in the complex (330) are activated by the iron atom, resulting in the breaking of a $\mathrm{C}-\mathrm{C} \sigma$-bond and formation of a new one. All structures have been characterized by $x$-ray analysis (Scheme 56).

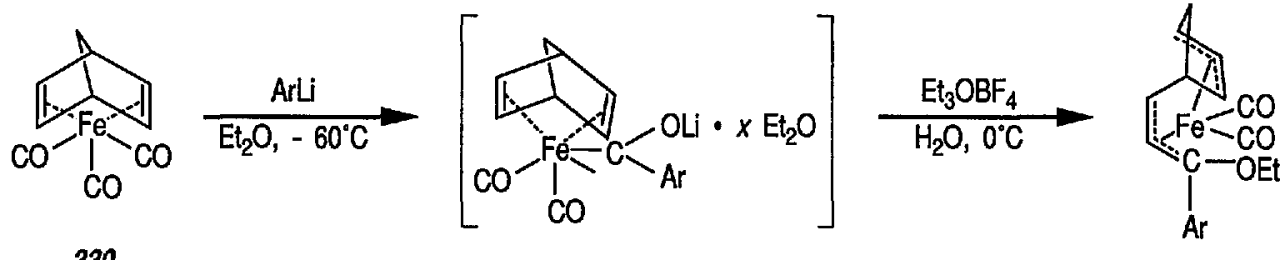

331
332

$$
\mathrm{Ar}=p-\mathrm{CH}_{3} \mathrm{C}_{6} \mathrm{H}_{4}, 43 \%
$$

$\mathrm{Ar}=0-\mathrm{CH}_{3} \mathrm{C}_{6} \mathrm{H}_{4}, 48 \%$

$\mathrm{Ar}=\rho-\mathrm{CF}_{3} \mathrm{C}_{6} \mathrm{H}_{4}, 51 \%$

Scheme 56

8.5.2 Step-Wise Cleavage of 1,1-Bis(Diphenylphosphino)Ethylene Iron Complex In another recent example, a step-wise cleavage of 1,1-bis(diphenylphosphino)ethylene (333) at di- and tri-iron centers under thermal and photochemical conditions has been reported [497]. In refluxing heptane the complex (333) loses a $\mathrm{CO}$ ligand to generate the phospha-allene complex (334), containing an unusual four-membered ring with an exocyclic double bond. The complex (334) is then brought into coordination via photochemically induced loss of a second $\mathrm{CO}$, yielding the $\alpha$-phosphinovinyl complex (335). Treatment of (335) with $\mathrm{Fe}(\mathrm{CO})_{5}$ under uv irradiation results in the insertion of an $\mathrm{Fe}(\mathrm{CO})_{4}$ fragment into $\mathrm{Fe}(1)-\mathrm{P}(2)$ bond to afford (336). In refluxing heptane two molecules of $\mathrm{CO}$ are lost from (336) resulting in the formation of the $\mu_{3}$-vinylidene complex (337 $\leftrightarrows 337 \mathrm{a}$ ). Thus, the sequence $333 \rightarrow 334 \rightarrow 335 \rightarrow 336$ comprises the step-wise fragmentation of (333) at a di-iron center, for the first $\mathrm{P}-\mathrm{CCH}_{2}$ bond cleavage and at tri-iron center, for the second. All pertinent structures have been established by $\mathrm{x}$-ray diffraction analysis (Scheme 57 ). 


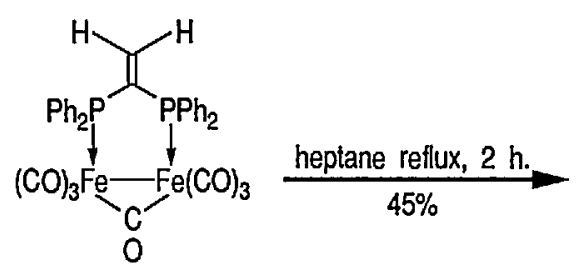

333

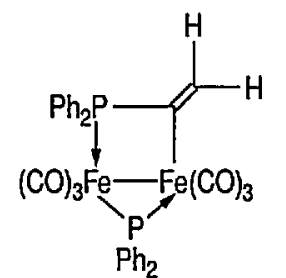

334 $\underset{90 \%}{\stackrel{\text { U.v., toluene, } 16 \text { h. }}{\longrightarrow}}$

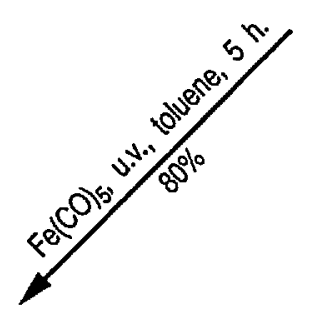

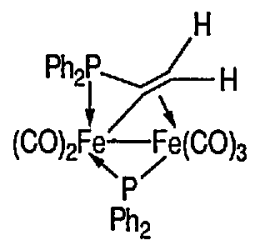

335

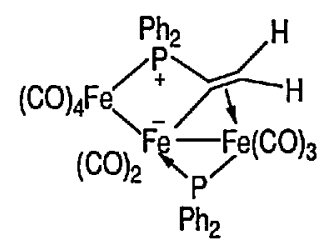

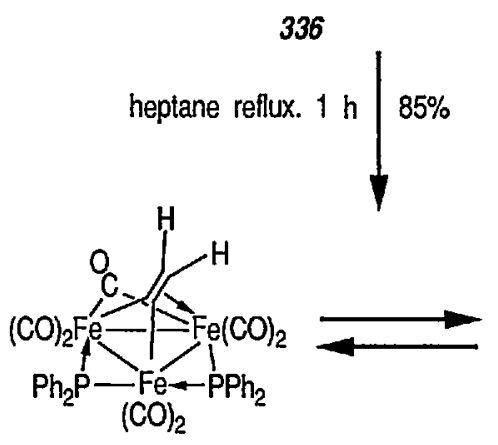

337

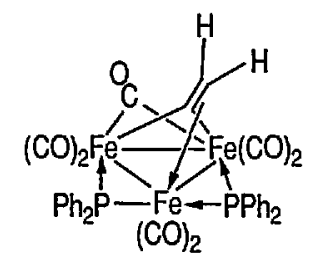

$337 a$

Scheme 57

\subsection{Reaction of Organosulfur Ligands in Bridged Ironcarbonyls}

As earlier found by Seyferth et al. [498], the S-S bond of ( $\eta$-dithio)-bis(tricarbonyl)iron 338 is readily cleaved by organometallic nucleophiles, to give the intermediate lithium thiolate 339 that could be protonated, alkylated, and acylated. However, as recently reported [59], the reaction of 338 with alkynylithium reagent in THF at $-78^{\circ} \mathrm{C}$, followed by protonation $\left(\mathrm{CF}_{3} \mathrm{CO}_{2} \mathrm{H}\right)$ gave "closed" 1,2 - or 1,1'-dithiolene products, e.g., 340 and 341 (Scheme 58). Formation of the sulfur-bridged products generally depends very much on whether the reaction mixtures were protonated, or not.

A selected recent work on organosulfur-iron complexes includes reactions of lithium bis $(\eta$-phenylphosphido)-bis(tricarbonyliron) with organic halides [499], synthesis and reactivity of ( $\eta$ - $\sigma$ - $\pi$-acetylide)( $\eta$-alkaneand $\eta$-arene-thiolate) bis(tricarbonyliron) complexes [500]; also synthesis of cis-trans $\mathrm{Fe}(\mathrm{CyNC})_{4}(\mathrm{SPh})_{2}$ [501], chelation of iron (II)dithiocarbamates [502], thiolate, thioether, and thiol derivatives of iron (0) carbonyls [503], reaction of $\left.\{\mathrm{CpFe}(\mathrm{CO}) \mathrm{MeCN})=\mathrm{C}\left[\mathrm{SMe}_{2}\right]\right\} \mathrm{PF}_{6}$ with $\mathrm{NaSMe}$ [504], cyclodextrin sandwiched $\mathrm{Fe}_{4} \mathrm{~S}_{4}$ cluster [505], and iron-sulfur proteins containing $\mathrm{Fe}_{2} \mathrm{~S}_{2}$ clusters [506,507]. 


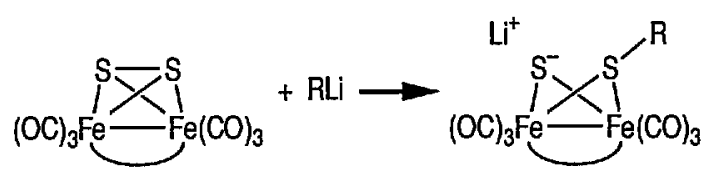

338

339

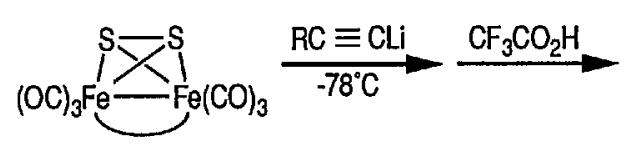

338

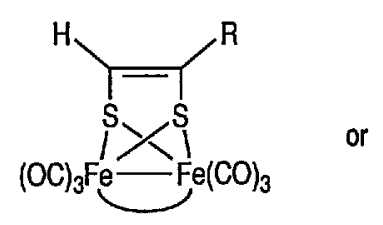

340

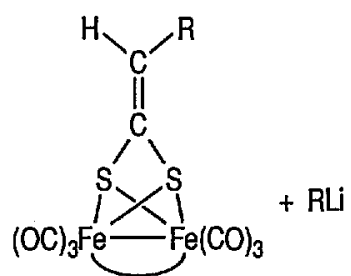

341

$$
\begin{aligned}
& \text { obtained for } \mathrm{R}=\mathrm{CH}_{3}, n-\mathrm{C}_{4} \mathrm{H}_{9}, n-\mathrm{C}_{5} \mathrm{H}_{11}, \\
& \mathrm{Ph}, \mathrm{C}\left(\mathrm{CH}_{3}\right)=\mathrm{CH}_{2}, \mathrm{H}
\end{aligned}
$$

Scheme 58

\subsection{Photoinduced Reactions Involving Ironcarbonyl Complexes}

Photochemical reactions of transition-metal carbonyl complexes find frequent application in synthesis and catalysis [508,509]. Interesting chemistry and photochemistry has developed on the basis of the tricarbonyliron moiety [510]. This functional group binds numerous alkenic substrates and can activate them toward nucleophilic attack $[34,35]$. Photosubstitution reactions of the tricarbonyliron fragment are of synthetic utility due to kinetic inertness of the $\mathrm{Fe}(\mathrm{CO})_{3}$ group. Pioneering work by Von Gustorf and his group [511] demonstrated efficient $\mathrm{CO}$ substitution when $\mathrm{Fe}(\mathrm{CO})_{3}$-(1,3-diene) complexes were excited with ultraviolet radiation. A few new examples from the recent literature are reported next.

A dinuclear species $\mathrm{Cp}_{2} \mathrm{Fe}_{2}(\mathrm{CO})_{2}(\eta-\mathrm{CO})_{2}\left(342, \mathrm{Cp}=\eta^{5}-\mathrm{C}_{5} \mathrm{H}_{5}\right)$ has a rich and diverse photochemistry, as evidenced by the plethora of synthetic and mechanistic studies of it in the literature [508,509,512]. A recent study reports [512] a photochemical addition of alkynes to 342 involving photochemical substitution and insertion reactions and formation of the photoproduct intermediate $\mathrm{CpFe}(\eta-\mathrm{CO})_{3} \mathrm{FeCp}(344)$ by $\mathrm{CO}$ loss. Thus laser flash photolysis of 342 in toluene in the presence of alkyne (e.g., 343) shows the formation of an intermediate (e.g., 344) with a strong absorbance at $515 \mathrm{~nm}$; further reaction of 344 with alkyne yields the insertion product 345 (Scheme 59). The mechanism of this reaction has been explained.

Photochemical substitution reactions of iron tricarbonyl 1,4-dimethyltetraazadiene (346) and related complexes have also been examined [513]. It has been shown that ligand field excited states generally promote substitution reactions, whereas charge-transfer states are considerably less reactive in this regard. Thus a photosubstitution of $\mathrm{CO}$ in tricarbonyliron 1,4-dimethyltetraazadiene (346) (in conversion

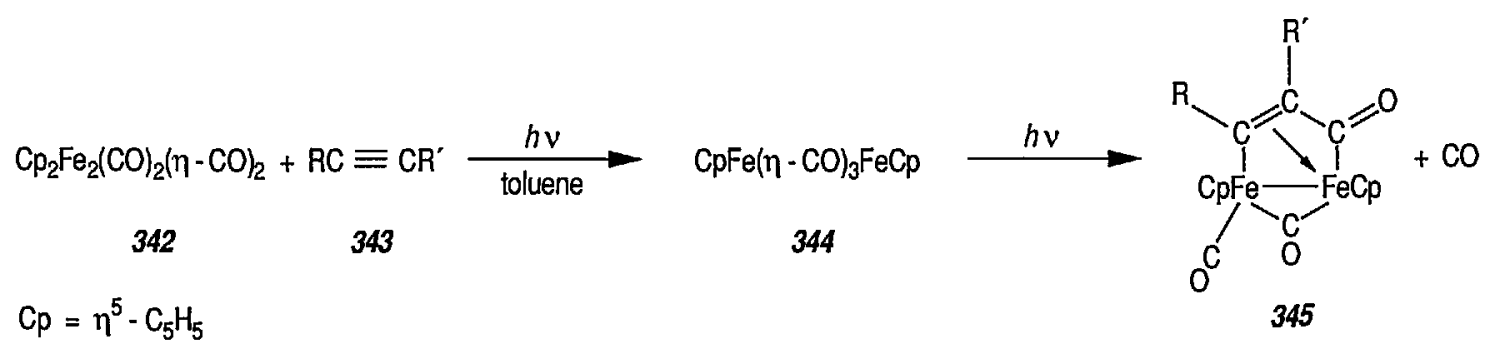

Scheme 59 
$346 \rightarrow 347$ ) proceeds via a dissociative mechanism, in contrast to the corresponding thermal reaction, which is of associative character. Although free tetraazadiene ligands are unknown, the iron carbonyl complex 346 is quite stable. No decomposition of 346 occurred, even after $70 \mathrm{~h}$ of refluxing in toluene.

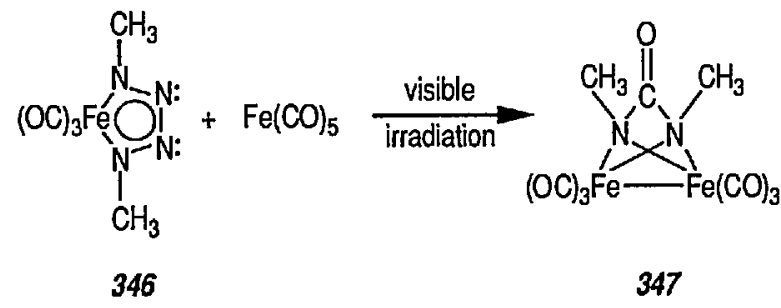

Another recent study showed [514] that photolysis of the organoiron complex 348 at low temperature (in n-pentane at $150 \mathrm{~K}$ ) can lead to two products depending on the wavelength of irradiation. The main product upon high-energy $(\lambda<500 \mathrm{~nm})$ excitation is a binuclear complex 349 with a bridging CO ligand. Upon irradiation with a longer wavelength $(\lambda>500 \mathrm{~nm})$ the main reaction is a change of coordination from $\sigma, \sigma-N N$ to $\eta^{4}-\mathrm{CN}, \mathrm{C}^{\prime} \mathrm{N}^{\prime}$ to give 350 with a retention of the $\mathrm{Fe}(\mathrm{CO})_{3}$ moiety (Scheme 60 ).

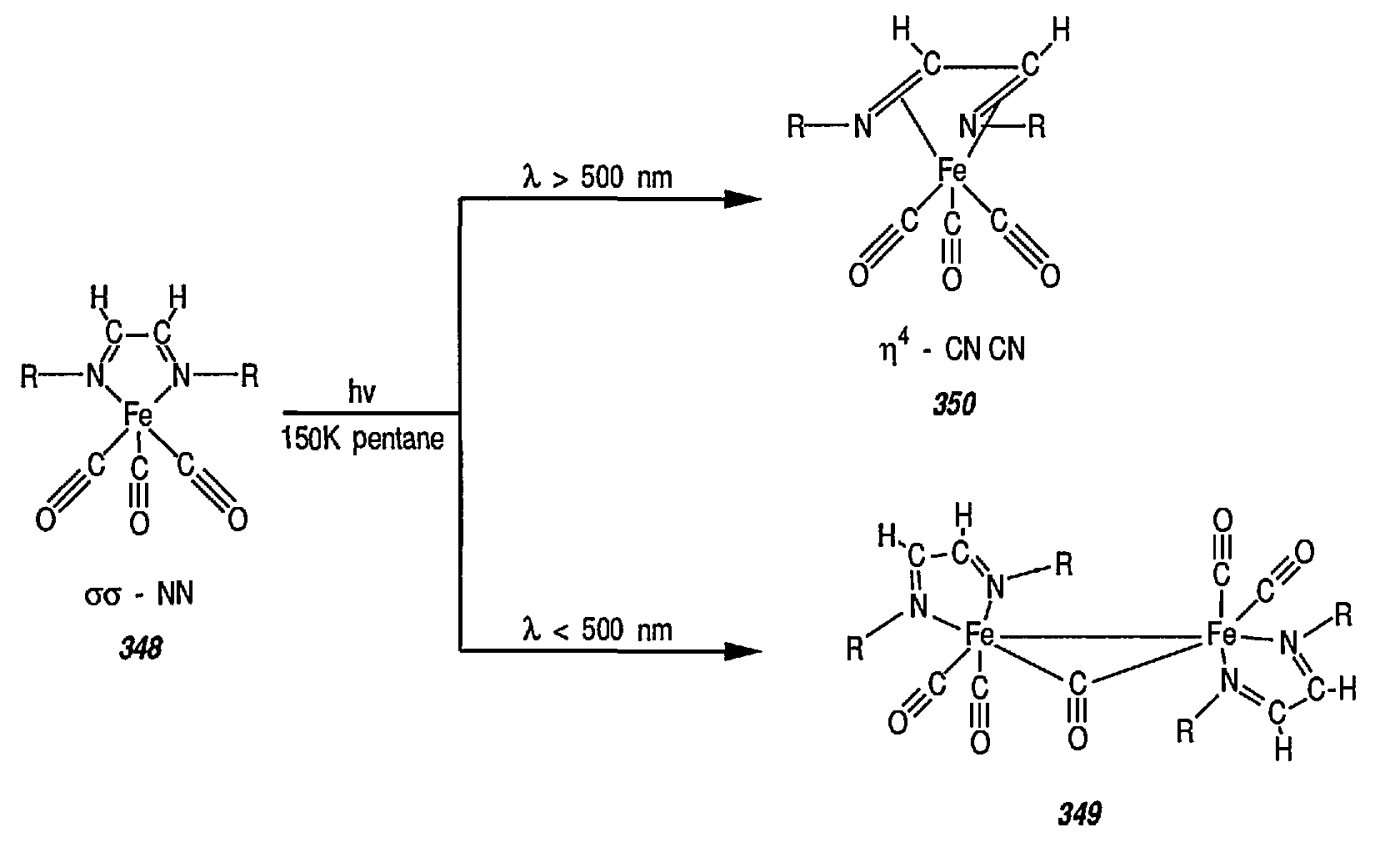

Scheme 60

Recently Casey and Austin [515] developed a new carbon-carbon bond-forming reaction based on unique photoreaction of the $\left[\left(\eta^{5}-\mathrm{C}_{5} \mathrm{H}_{5}\right)(\mathrm{CO}) \mathrm{Fe}\right]_{2}(\eta-\mathrm{CO})(\eta-\mathrm{CR})$ framework. Thus photolysis (366 nm, toluene, $0^{\circ} \mathrm{C}$ ) of the neutral $\mu$-ethenylidene diiron complex 351 in the presence of ethyl diazoacetate (a trapping agent) produced the $\mu$-allene complex $352 \leftrightarrows 352 \mathrm{a}$ in $48 \%$ yield; the complex then can be cleaved<smiles>N#Cc1ccccc1C=Cc1ccccc1Cl</smiles>

351

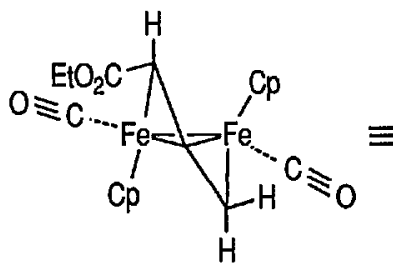

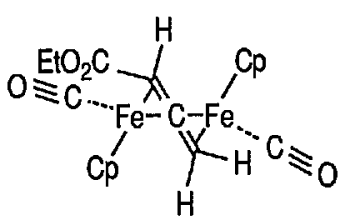


to free allene. The synthesis of the $\mu$-allene complex 352 required light and was inhibited by carbon monoxide. The use of hydrogen or trialkylsilanes as the trapping agents produces alkenes or vinyl-silanes.

A new, photoinduced, ring expansion, either of cyclopropaneiron [516] or of cyclobutyliron [517,518] $\sigma$ complexes has recently been described. Thus, photolysis of cyclopropaneiron 353 (benzene solution, $\mathrm{N}_{2}$, 450-W Hanovia lamp) gave the rearranged carbene complex 357 via the cyclobutane intermediate 356 (conversions $353 \rightarrow 357$ Scheme 61 ). The driving force for this rearrangement is a combination of relief of ring strain (357 is less strained than 355 ) and stabilization of the carbene 357 ; 357 is stabilized by electron donation from the methoxyl group more than is 355 .

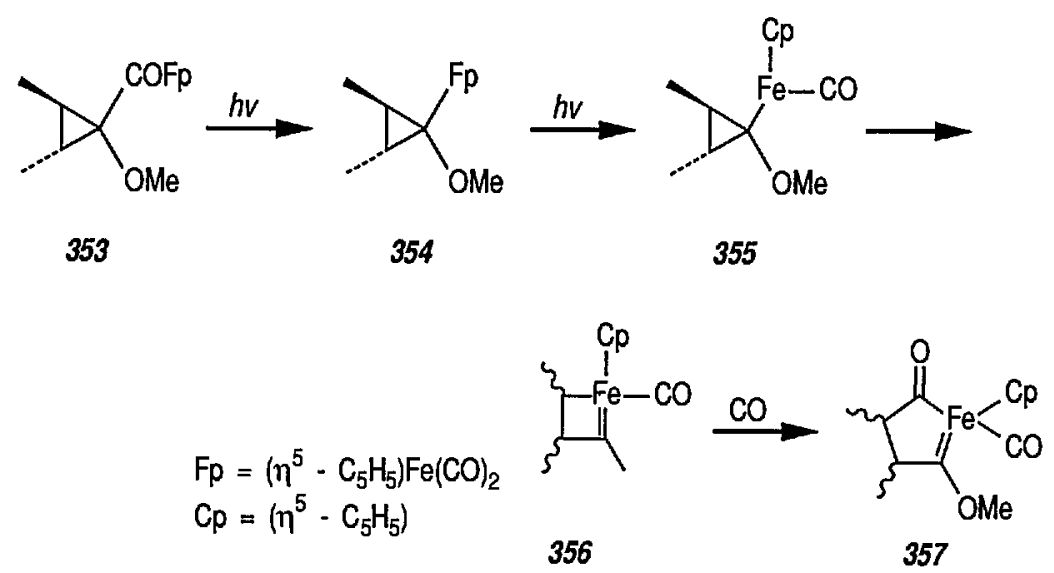

Scheme 61

Irradiation of 358 (5,6-bismethylene-7-oxabicyclo[2.2.1]hept-2-ene) in methanol in the presence of $\mathrm{Fe}_{2}(\mathrm{CO})_{9}$ at $-20^{\circ} \mathrm{C}$ resulted in formation of the cyclopentanone derivative 359 [519]; the latter can be oxidatively demetalated $\left[\left(\mathrm{CH}_{3}\right)_{3} \mathrm{NO}\right]$ to a very interesting, cyclic tetraalkene derivative.

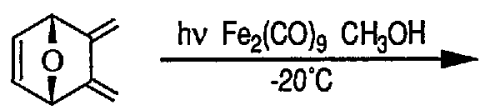

358

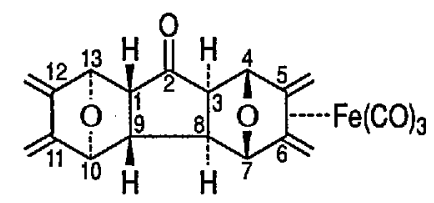

359

The readily available, chelated bis(silyl)iron complex 360 reacts photochemically with nitriles $\mathrm{RCH}_{2} \mathrm{CN}_{\text {, }}$ to give $N, N$-bis(silyl)enamines 361 in good yields. Aliphatic and benzylic nitriles give high yields of a $Z$ and $E$ mixture of enamines. With dinitriles, the reaction occurs only with the cyano compound, which has an $\alpha$-hydrogen atom. The procedure constitutes a novel, chemical transformation of nitriles into silylenamines [520].

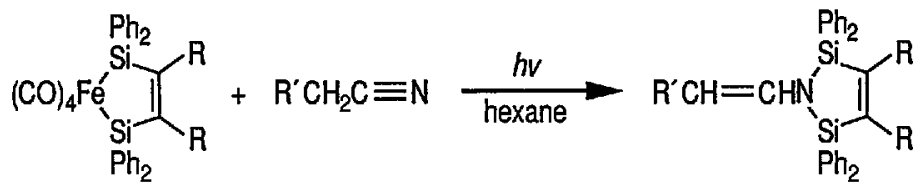

360

361

$R=E t, R^{\prime}=H, 84 \% ; R=E t, R^{\prime}=P h, 75 \%, E I Z=45 / 55 ; R=R^{\prime}=M e, 71 \%$, $E I Z=42 / 58$ 
Recently, an interesting, photochemically-induced reduction of nitrosoarenes by $\mathrm{Fe}(\mathrm{CO})_{s}$ to give azoxyand azoarenes has been reported. The mechanism for formation of azoxyarenes apparently involves a ligand exchange to give nitrosoarene-iron complex which on deoxygenation by a $\mathrm{CO}$ ligand produces an unsaturated iron-nitrene intermediate. The latter rapidly couples with unreacted nitrosoarene to generate azoxyarene [521] (conversions $362 \rightarrow 365$ ).

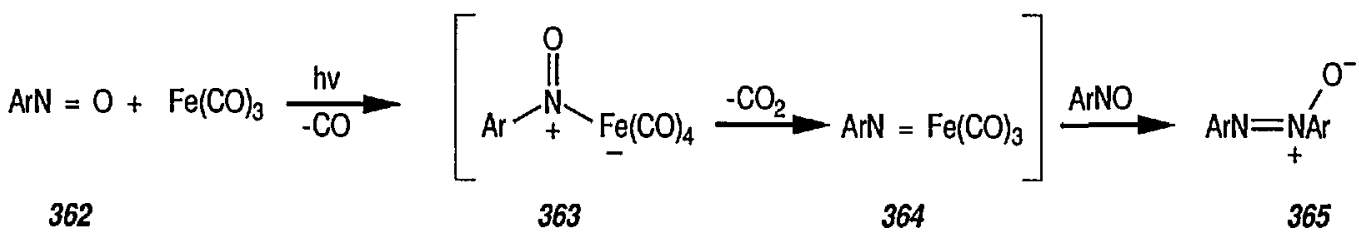

Other reported reactions involve the photoinduced, oxidative addition of an aromatic $\mathrm{C}-\mathrm{H}$ bond of a distal benzyl group to the Fe center [522], and photoinduced conversion of the $\left(\eta^{5}-\mathrm{C}_{5} \mathrm{H}_{5}\right) \mathrm{Fe}(\mathrm{CO})_{2}\left(\eta^{1}-\mathrm{C}_{5} \mathrm{H}_{5}\right)$ complex into the ferrocene derivative [523]; also the photochemistry of some ( $\eta^{4}$-cyclopentadiene $) \mathrm{Fe}(\mathrm{CO})_{3}$ complexes [524], and photochemical insertion of alkynes into the PR bridged clusters, e.g., $\left(\eta_{3^{-}}\right.$ $\mathrm{PR}) \mathrm{Fe}_{3}(\mathrm{CO})_{10}$ [525] and $\left(\eta_{4}-\mathrm{PR}\right)_{2} \mathrm{Fe}_{4}(\mathrm{CO})_{11}$ [526] have been reported. The low temperature studies also include photochemical reaction of alkenes with $\mathrm{Fe}(\mathrm{CO})_{5}[527]$, photochemical reaction of $\mathrm{Fe}(\mathrm{CO})_{2}(\mathrm{NO})_{2}$ with 1,3-butadienes [528]; also, photochemistry of $\left[\mathrm{Fe}_{2}(\mathrm{CO})_{7} \mathrm{~L}\right]\left(\mathrm{L}=2,2^{\prime}\right.$-bipyridine, 1,10'-phenanthroline), causing substitution of $\mathrm{CO}$ by nucleophiles [529], and photochemical rearrangement of $\left(\eta^{2}\right.$ $\left.\mathrm{C}_{5} \mathrm{Me}_{5}\right) \mathrm{Fe}(\mathrm{CO})_{2} \mathrm{CH}_{2} \mathrm{SiMe}_{2} \mathrm{H}$ into $\left(\eta^{5}-\mathrm{C}_{5} \mathrm{Me}_{5}\right) \mathrm{Fe}(\mathrm{CO})_{2} \mathrm{SiMe}_{3}$ [530,531]. The photopolymerization of heptadeca-2,4-diynylferrocenecarboxylate in the monolayer on a water surface has recently been investigated [532]; the polymerization behavior was found to depend markedly on the molecular packing in the monolayer.

\subsection{Other Recent Results}

8.8.1 Novel Phosphorus-Bridging Iron Carbonyl Complexes The stereodirection of the phosphine ligand $\left(\mathrm{PPh}_{3}\right)$ in triphenylphosphine-substituted organoiron complexes has been recognized $[60,64,192,209$, 286-289,293] and importance of the phosphorus atoms in transition metal complexes including organoiron complexes is of current interest [36,41,471,531,533-535]. A series of new iron complexes of phosphinine [537,538], phosphine [539-542] and phosphane [522,543,544] derivatives have been prepared and their reactions studied.

An interest in the chemistry of iron diphosphenes containing phosphorus-phosphorus double bond, e.g., $(\mathrm{OC})_{4} \mathrm{Fe} \leftarrow \mathrm{RP}=\mathrm{PR} \rightarrow \mathrm{Fe}(\mathrm{CO})_{4}[42,531,533]$ has led to numerous studies on their preparation by dehalogenation of $\mathrm{RPCl}_{2}$ derivatives with diverse strong reducing agents. Recently, the King group [36] extended this chemistry to reactions of iron carbonyl anions as reducing agents, e.g., $\mathrm{Na} a_{2} \mathrm{Fe}(\mathrm{CO})_{4}$ with (dialkylamino)dichlorophosphines, e.g., $\mathrm{R}_{2} \mathrm{NPCl}_{2}(\mathrm{R}=$ isopropyl, cyclohexyl) to yield products that may be regarded as iron carbonyl complexes of the diphosphenes. Thus, treatment of $\mathrm{R}_{2} \mathrm{NPCl}_{2}(366, \mathrm{R}=$ isopropyl) with $\mathrm{Na}_{2} \mathrm{Fe}(\mathrm{CO})_{4}$ (367) in diethyl ether provided a useful method for the synthesis of the phosphorus-bridging carbonyl derivatives, e.g., the orange complex $368(\mathrm{R}=i-\mathrm{Pr})$ or the orange triphosphine derivative 369 $(\mathrm{R}=i-\mathrm{Pr})$ in tetrahydrofuran solution. The formation of the complex 369 can be rationalized by the pathway involving the terminal (dialkylamino) phosphinidene complex $\mathrm{R}_{2} \mathrm{NP}=\mathrm{Fe}(\mathrm{CO})_{4}$ as a reaction intermediate, which can undergo a redox reaction with $\mathrm{Fe}(\mathrm{CO})_{4}^{2-}$ in tetrahydrofuran but not in diethyl ether. The structure determined [36] by $\mathrm{x}$-ray analysis of the complex 368 indicates the formation of the Fe-Fe bond bridged by two phosphorus atoms; in structure 369 , however, an $\mathrm{Fe}_{2}(\mathrm{CO})_{6}$ unit (the $\mathrm{Fe}-\mathrm{Fe}$ bond) is bridged by a triphosphine chain. A reductive elimination of the CO group in 368 (to give 369 ) was apparently effected in more polar tetrahydrofuran solvent as compared to diethyl ether (Scheme 62). 


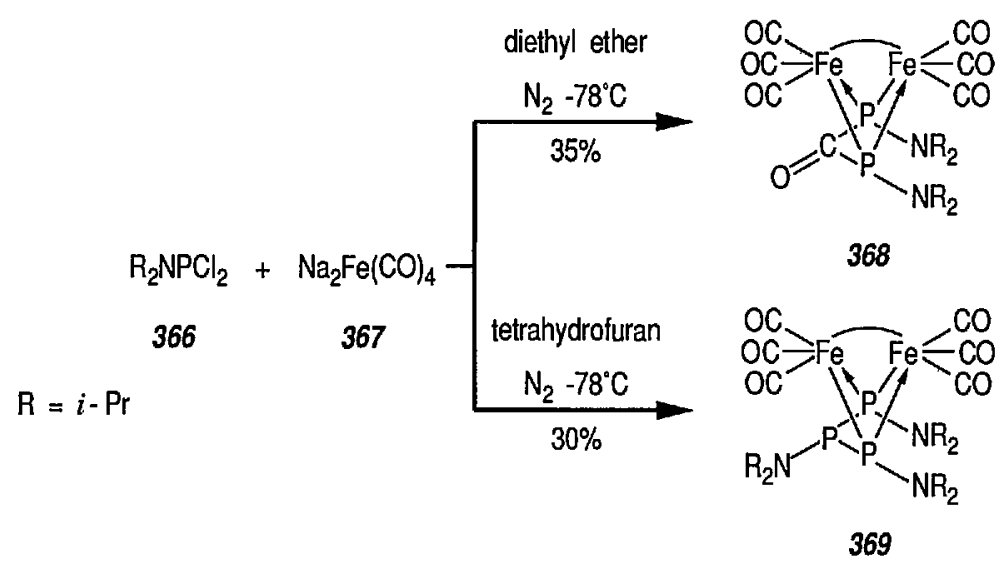

Scheme 62

8.8.2 Addition Reactions of Iron $\pi$-Alkynes The addition of nucleophiles to unsaturated ligands activated by coordination to transition metals has proven to be useful for the preparation of new organometallic complexes and as a versatile methodology in organic synthesis [14,79]. Despite the considerable interest in this area, addition reactions with $\eta^{2}$-alkyne complexes leading to ( $\eta^{1}$-alkenyl) metal species had only been briefly studied. Recently, Reger [49] discussed at length nucleophilic addition reactions with cationic iron $\pi$-alkyne and related complexes; some typical reactions are shown in Scheme 63.

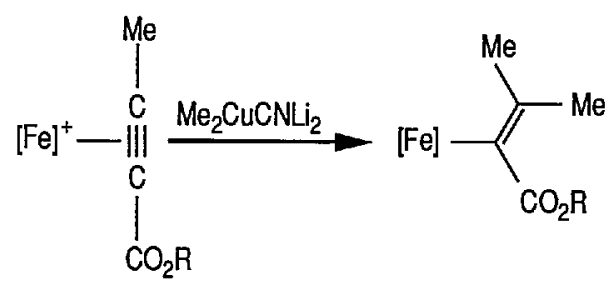

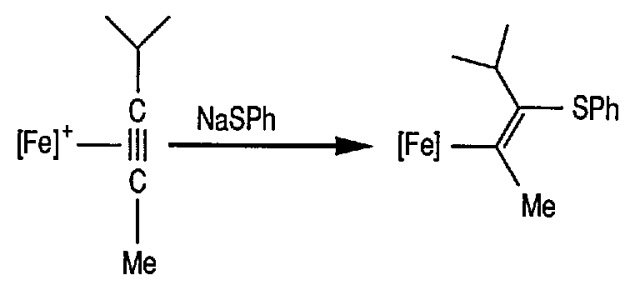

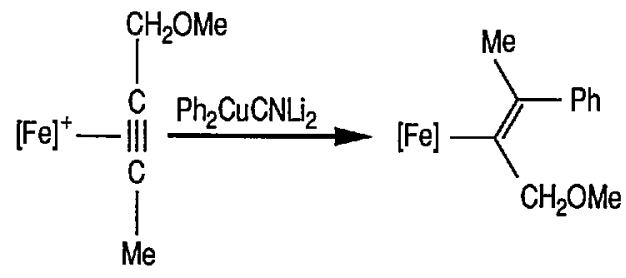

Scheme 63

8.8.3 Some Recent Work on the Chemistry of Ferrocenes and Porphyrins A new work on iron porphyrins, ferrocenes and related iron compounds has been summarized; among the topics discussed are organic reactions of selected $\pi$-complexes [545], stereochemistry of metallocenes [546] and the recent chemistry of ferrocene compounds [547,548]. Other topics of recent interest are: bridged ferrocenes [549], reaction of the isodicyclopentadiene anion with $\mathrm{Fe}(\mathrm{II})(\mathrm{acac})_{2}(\mathrm{Py})_{2}$ (to yield ferrocene derivatives) [550], 
preparation of iron-polyarene sandwich compounds [551], and crystal structure of [2]metacyclo[2](1,1') ferrocenophane [552].

The chemistry of porphyrins, including iron porphyrins, has been discussed in a comprehensive treatise [553] and in recent reviews [554,555]. Recent literature on porphyrins is abundant covering many aspects of biochemistry. Particularly, the reactions catalyzed by iron porphyrin complexes have attracted attention in relevance to the activation of molecular oxygen and oxygen atom transfer to organic substrates, which are processes dependent on cytochrome P-450 in biological systems [556-559]. A recent interest in porphyrins includes iron(III) porphyrins [560], iron $N$-substituted porphyrins [561], novel ferrocene bis-porphyrins [562], sterically encumbered iron(II) porphyrins [563], regio- and stereoselective reduction of $N(21), N(22)-$ bridged porphyrins [564], electroreductive alkylation of iron porphyrins [565] and synthesis of $(\alpha, \beta, \gamma, \sigma-t e-$ traphenylporphinato)iron(II) [566], and non-heme iron enzymes and proteins [567,568].

8.8.4 Some Recent Pertinent References Some important recent reviews include: organoiron chemistry [569,570], transition metals in organic synthesis [571,572], transition metals in organic synthesis: hydroformylation, reduction and oxidation [573], and the use of iron (in addition to other transition metals) complexes as catalysts for alkene epoxidation [574].

Recent methodology on chiral separation by high-pressure liquid chromatography has been surveyed [575]. [576].

An alkyne oligomerization in the presence of $\mathrm{Fe}(\mathrm{CO})_{5}$ (and other metal carbonyls) has been discussed

The transition-metal-mediated cycloaddition reactions of alkynes in organic syntheses have recently been reviewed [577].

The coordinated carbonyl-coupling reactions of iron, including the formation of a complex (TMS $)_{4} \mathrm{Fe}_{2}(\mathrm{CO})_{8}$ have recently been surveyed [578].

A recent book on modern aspects of organo-metallics in organic synthesis has been published [579].

Another book on the logic of chemical synthesis, including topological and stereochemical strategies, has appeared [580].

8.8.5 Other Pertinent Results Among the various carbon-carbon bond-forming reactions promoted by transition metals, allylic alkylation has been one of the most aggressively sought after. Accordingly, numerous studies have appeared dealing with the chemo-, regio-, and stereoselectivity of coupling between activated allyl substrates (e.g., acetates, carbonates) and nucleophiles, and the application of such reactions in synthesis. Recently, the mechanistic [581] and synthetic [582] aspects of iron-promoted, allylic alkylation have been discussed. Also reported are the iron methylidene complex $\left(\eta^{5}-\mathrm{C}_{5} \mathrm{H}_{5}\right)(\mathrm{CO})_{2} \mathrm{Fe}=\mathrm{CH}_{2}^{+}$as an alkylating agent toward coordinated ligands [583], alkylation of tricarbonyl(2-methoxycyclo-hexadienyl)iron ${ }^{+}$ $\mathrm{PF}_{6}^{-}$by substituted anilines [584]; acylation, alkylation, and formation of $\left(\eta^{3}: \eta^{1}\right.$-allylacyl)iron complexes [585], and alkylation of the carbide cluster $\left[\mathrm{Fe}_{4}(\mathrm{CO})_{12} \mathrm{C}\right]^{2-}[586]$.

Other recent carbon-carbon bond-forming reactions including stereoselective reactions are: $\left[\mathrm{Fe}(\mathrm{CO})_{9}\right]$ catalyzed intramolecular dimerization of alkynes [587], novel reaction of limonene-iron (tricarbonyl) [588], synthesis of a donor-stabilized bis(silylene)iron complex [589], and synthesis of a cycloheptatrienyl-bridged iron-iridium complex $\left(\eta-\mathrm{C}_{7} \mathrm{H}_{7}\right) \mathrm{Fe}(\mathrm{CO})_{3} \operatorname{Ir}(\mathrm{CO})_{2}$ [590]; also addition of pyridines to the tricarbonyl(cycloheptadienyl)iron(II) cation [591], iron-promoted coupling reaction of homohypostrophene [592], synthesis of alkyl (alkoxycarbonyl) tetracarbonyliron complexes [593], synthesis of a tricarbonyliron complex of 7-azabicyclo [2.2.1] heptadiene derivatives (a nitrene extrusion reaction) [594]; also the reaction of iron(II)-poly(amino carboxylate) complexes with $\mathrm{CO}_{2}^{-}$free radicals (formation of iron-carbon $\sigma$-bonds) [595], electroorganic synthesis using $\mathrm{Fe}(\mathrm{CO})_{s}$ at atmospheric pressure of carbon monoxide [596], and synthesis of a new type of surface-active cationic iron complexes [597].

New syntheses and reactions of organoiron complexes are recorded in numerous recent publications. Some of them are: synthesis and reactions of $\eta^{2}$-acrylonitrilecyclopentadienyldicarbonyliron(II) tetrafluoroborate complexes [290,598], synthesis of bis $\left(\eta^{3}\right.$-allyl)iron complexes containing basic phosphines [599]; also, synthesis of $\eta^{6}$-(biphenyl)- $\eta^{5}$-(cyclopentadienyl)iron(II) hexa-fluorophosphates [600], and synthesis of a new cluster containing $\mathrm{CH}_{3} \mathrm{C}=\mathrm{C}=\mathrm{CH}_{2}$ triiron-dirhodium ligand [601]. New iron-hydroperoxide reactions (Fenton chemistry) have been recently reported [602].

New reactions including insertion, isomerization, and dimerization are summarized in the following section. The topics selected are: isomerization reactions of terminal iron-alkenyl complexes [603], dimerization of (2,4-dimethylpentadienyl)iron tricarbonyl complexes [604], insertions of cyano- and dicyano- 
acetylenes into iron-hydride bonds [605], carbonyl insertion reactions and formation of $\left[\mathrm{HFe}(\mathrm{CO})_{4}\right]^{-}$, $\left[(\mathrm{CO})_{3} \mathrm{FeCHO}\right]^{-}$, and $\left[(\mathrm{CO})_{4} \mathrm{FeCHO}\right]^{-}[606]$; also, carbon dioxide fixation via $\left[\left(\eta^{5}-\mathrm{C}_{5} \mathrm{H}_{5}\right) \mathrm{Fe}(\mathrm{CO})_{2}\right]^{-}$metalate $\mathrm{Li}^{+}$or $\mathrm{Na}^{+}$salts [607], reaction of salt $\left(\eta^{5}-\mathrm{C}_{5} \mathrm{H}_{5}\right) \mathrm{Fe}(\mathrm{CO})_{2}^{-} \mathrm{Na}^{+}$with cyclopropylmethyl bromide [608], and reaction of $\left[\eta^{6} \text {-O-dichlorobenzene- }\left(\eta^{5}-\mathrm{C}_{5} \mathrm{H}_{5}\right) \text { iron }\right]^{+} \mathrm{PF}_{6}^{-}$with phenol [609]. Also covered are reactions of $\left(\eta^{5}-\mathrm{C}_{5} \mathrm{H}_{5}\right) \mathrm{Fe}(\mathrm{CO})_{2}\left(\eta^{1}-\mathrm{C}_{5} \mathrm{H}_{5}\right)$ with bis(tri-fluoromethyl) ketene (to give the 2:1 adducts) [610], reactions of stable mono(alkylthio)carbene complexes of the $\left(\eta^{5}-\mathrm{C}_{5} \mathrm{H}_{5}\right) \mathrm{Fe}(\mathrm{CO})_{2}$ system [611], conversion of a diiron $\mu$-ketone complex into a binuclear cationic complex [612], and reaction of a diiron bridging methylidene complex with an ethylidene complex [613]. Further new reactions are: reaction of $\left[\left(\eta^{5}-\mathrm{C}_{5} \mathrm{H}_{5}\right) \mathrm{Fe}(\mathrm{CO})_{2}\right]_{2}(\eta-$ $\left.\mathrm{C}=\mathrm{CH}_{2}\right)$ with $\mathrm{HC} \equiv \mathrm{CCN}$ [614], reaction of $\left[\left(\eta^{5}-\mathrm{C}_{5} \mathrm{H}_{5}\right) \mathrm{Fe}(\mathrm{CO})_{2} \cdot \mathrm{THF}\right]^{+} \mathrm{BF}_{4}^{-}$with 1,4-dithiane [615], reaction of $\left[\mathrm{Fe}_{2}\left(\eta^{5}-\mathrm{C}_{5} \mathrm{H}_{5}\right)(\mathrm{CO})_{2}(\mathrm{CNMe}) \mathrm{CN}(\mathrm{Me}) \mathrm{H}^{+}\right.$with $\mathrm{Ag}(\mathrm{I})$ salts $[616]$, reaction of $\left[\mathrm{Fe}_{2}\left(\eta-\mathrm{C}_{5} \mathrm{H}_{5}\right)_{2}\right.$ $(\mathrm{CO})_{4-n}(\mathrm{CNMe})_{n}(n=\mathrm{O}-4)$ complexes with halogens and mercury(II) salts [617], reaction of $\mathrm{Fe}(\mathrm{CO})_{5}$ with $N, N$-diethyl- $S$-ethylcarbamate [618], also, the reaction of $\mathrm{Fe}_{3}(\mathrm{CO})_{12}$ or $\mathrm{Fe}_{2}(\mathrm{CO})_{9}$ with 1-diethylaminopropyne [619], the reactivity of $\left[\mathrm{HFe}_{3}(\mathrm{CO})_{11}\right]^{-}$toward alkynes [620] were studied, and thermal decarbonylation of $\left(\eta^{5}-\mathrm{C}_{5} \mathrm{H}_{5}\right) \mathrm{Fe}(\mathrm{CO})\left(\mathrm{PPh}_{3}\right)-\mathrm{COR}\left(\mathrm{R}=\mathrm{CH}_{3}, \mathrm{CH}_{2} \mathrm{SiMe}_{3}\right.$ and $\left.\mathrm{CH}_{2} \mathrm{SiMe}_{2} \mathrm{Ph}\right)$ [621].

Complexes obtained by cycloaddition of $\left(\eta^{5}-\mathrm{C}_{5} \mathrm{H}_{5}\right)(\mathrm{CO})_{2} \mathrm{Fe}\left(\eta^{1}-\mathrm{CH}_{2} \mathrm{CH}=\mathrm{CH}_{2}\right)$ with heterocumunlenes such as $\mathrm{RN}=\mathrm{C}=\mathrm{O}, \mathrm{RN}=\mathrm{S}=\mathrm{O}$ or $\mathrm{RN}=\mathrm{S}=\mathrm{NR}$ represent potential precursors to synthesis of heterocyclic organic compounds [622-624].

Other recent interest centered on organoiron compounds involves physical, spectral, and thermodynamic studies. This area of interest covers: reaction of gas-phase iron(I), e.g., $\mathrm{FeCO}^{+}$with alkyne and dienes [625], the gas-phase ion chemistry of the $\left(\mathrm{C}_{4} \mathrm{H}_{6}\right) \mathrm{Fe}(\mathrm{CO})_{3}$ complex [626], the redox chemistry of alkyne$\mathrm{Fe}_{3}(\mathrm{CO})_{9}\left(\mathrm{RC}_{2} \mathrm{R}\right)$ cluster [627]; also, spectroscopic study of iron tetracarbonyl isocyanide complexes [628], an alkali ion effect on hydride migration in $\left.\left[\mathrm{HFe}(\mathrm{CO})_{4}\right)\right]^{-}[629]$, potassium permangante oxidation of $\eta^{6}$-arene $\left(\eta{ }^{5}-\mathrm{C}_{5} \mathrm{H}_{5}\right)$ iron cations (to yield ketones and sulfones) [630], and spectroscopic and kinetic studies of ligand substitution in the 33e dinuclear radical $\mathrm{Fe}_{2}(\mathrm{CO})_{7}\left(\eta-\mathrm{PPh}_{3}\right)$ [631].

Other recent studies report on $\mathrm{x}$-ray structure of $\left(N\right.$-heterocyclic) $\left(\eta^{4}\right.$-diene)-dicarbonyliron $(\mathrm{O}) \mathrm{com}$ pounds [632], theoretical study of tricarbonyliron complexes of para-quinodimethane [633]; labile benzeneiron complexes; crystal structure of cis- and trans-FeH1(CO) $)_{2}\left(\mathrm{PPh}_{3}\right)_{2}$ [634]; also, a carbon basicity scale based on the cation $\left[\left(\eta^{5}-\mathrm{C}_{5} \mathrm{H}_{5}\right) \mathrm{Fe}(\mathrm{CO})_{2}\left(\mathrm{C}_{2} \mathrm{H}_{4}\right)\right]^{+}[635]$, and the crystal structure of the novel di-ironanthracene complex $\mathrm{Fe}_{2}\left(\eta, \eta^{3}, \eta^{3}\right.$-anthracene $)(\mathrm{CO})_{6}[636]$.

Recent pertinent topics also include a review of organic reactions of $\pi$-complexes of transition metals [637]; a review of the photochemical reactions of metal carbonyl complexes of transition metals with conjugated and cumulated dienes [638]; spin-crossover complexes of $\mathrm{Fe}(\mathrm{II})$ and $\mathrm{Fe}$ (III) [639]; synthesis and reactions of anionic metallocarboxylates of iron, e.g., $\mathrm{M}\left[\left(\eta^{5}-\mathrm{C}_{5} \mathrm{H}_{5}\right) \mathrm{Fe}(\mathrm{CO})\left(\mathrm{PPh}_{3}\right)\left(\mathrm{CO}_{2}\right)\right](\mathrm{M}=\mathrm{K}, \mathrm{Li})[640]$; synthesis of a macrobicyclic iron(III) sequestering agent [641] and construction of models for iron-oxo proteins (e.g., mixed valence iron cluster) [642-644]; the importance of iron-oxo aggregates in biological cell systems [645-647]; organoiron-mediated oxygenation of allylic organotin compounds as a possible chemical model for enzymic lipoxygenation [648]. The interaction of carbohydrates with metals has been of much interest in recent years and progress in this direction is on the horizon [649-653].

Some additional methods that may be of interest in the synthesis of natural products are depicted next (Schemes 64-66).

The total syntheses of the alkaloids mukonine, murrayanine, and the cytotoxic carbazole koenoline by an iron-mediated arylamine cyclization with very active manganese dioxide are shown in Schemes 64 and 65; it may be noted that there is a specific action of very active $\mathrm{MnO}_{2}$ as compared to commercial $\mathrm{MnO}_{2}$ [28].

A successful synthesis of an optically active (+)-Prelog-Djerassi lactone (a degradation product of the macrolide antibiotic methymycin) involves a 13-step procedure, beginning with an iron stereodirecting template attached to 1,3-cycloheptadiene, and shown in Scheme 66 [393]. 


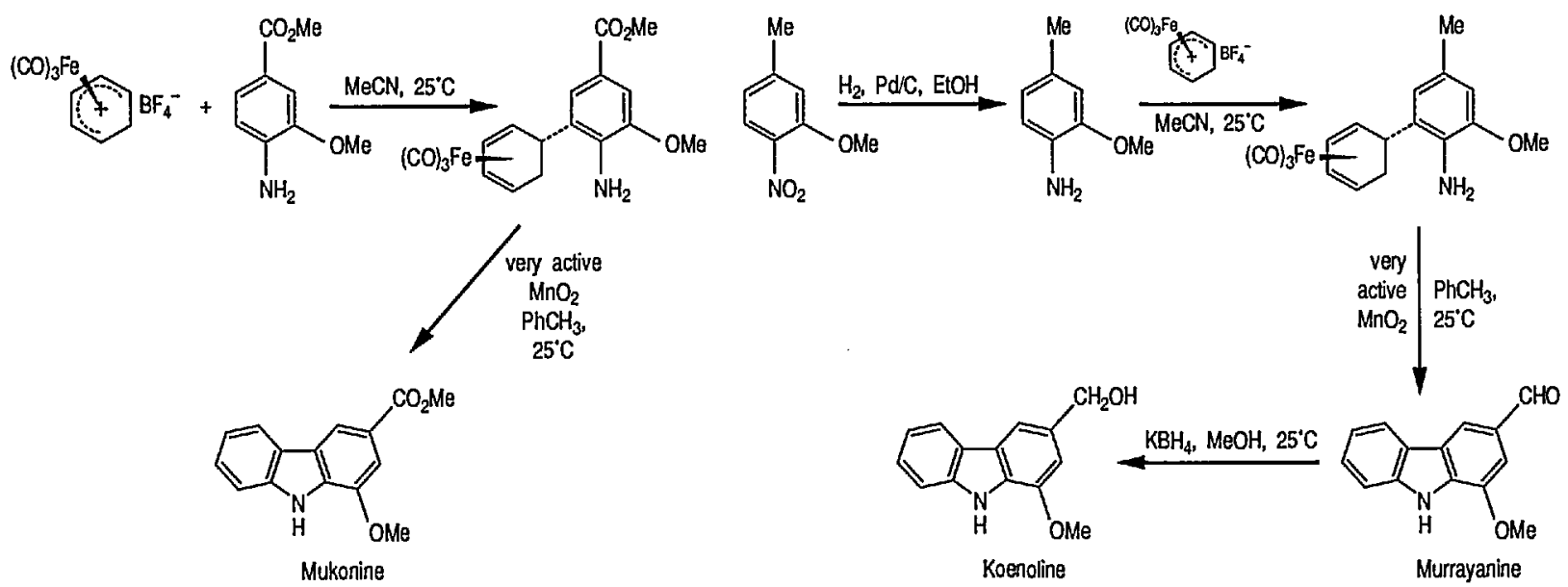

Scheme 64 [28]

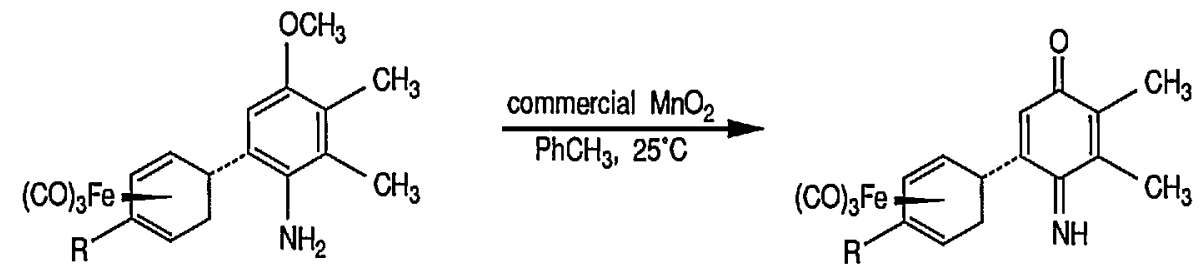

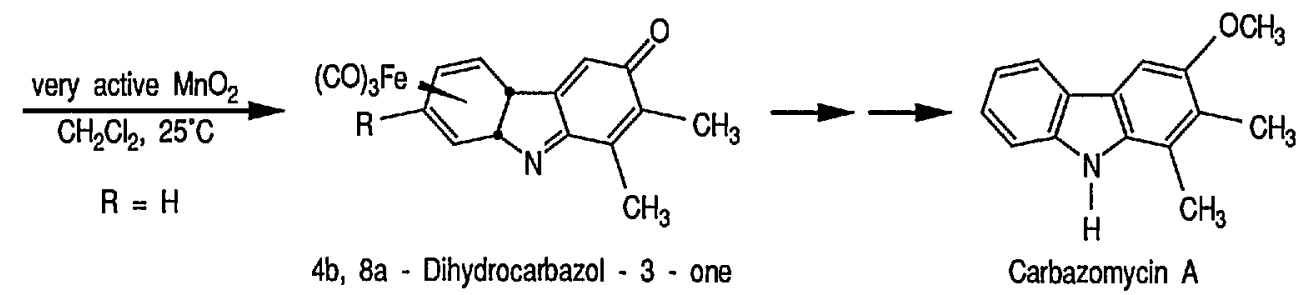

Scheme 65 [28] 


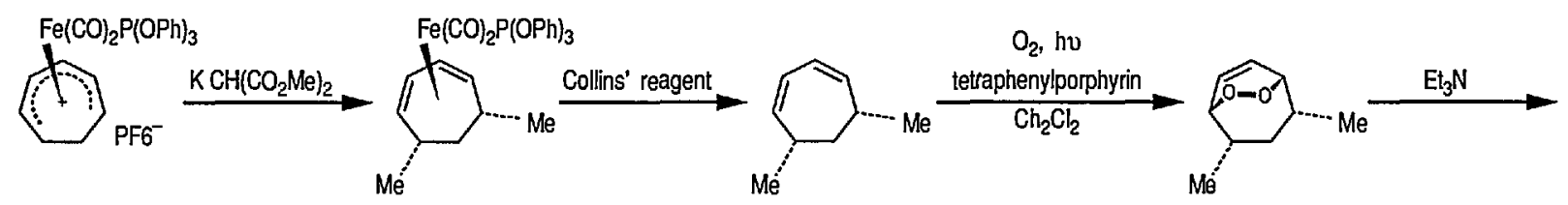

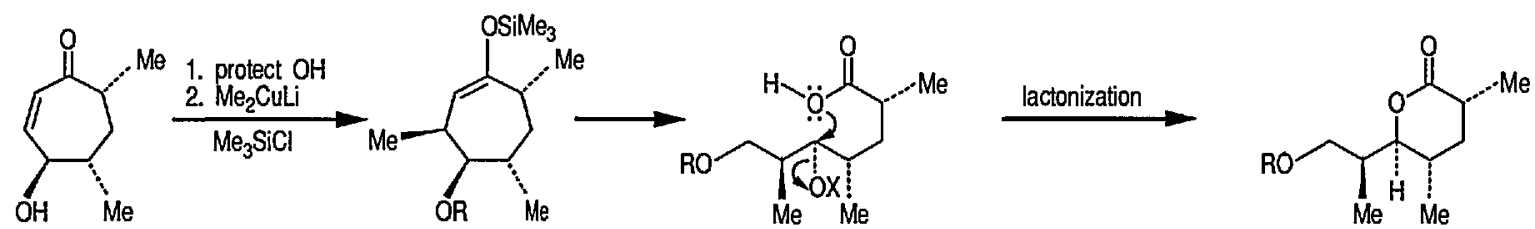

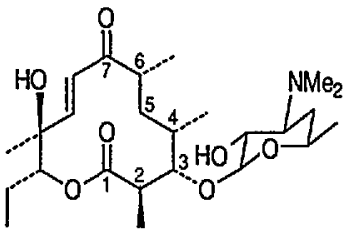

Methymycin

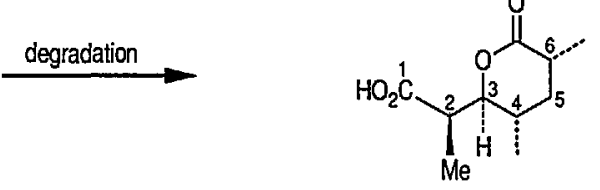

$(+)$ - Prelog-Djerassi lactone

Scheme 66 [393]

\section{Addenda}

Selected highlights regarding organoiron complexes from the recent literature are presented next.

\subsection{Mononuclear Iron Complexes. Iron Carbene Complexes}

Electrophilic transition-metal-carbene complexes $\operatorname{LnM}=\mathrm{CHR}(\mathrm{R}=\mathrm{H}$, alkyl, aryl) $(\mathrm{M}=\mathrm{Fe}, \mathrm{Cr})$ are much less stable than classical, Fisher-type heteroatom-substituted carbene complexes, especially where the organometallic fragment is not electron-rich. For example, the complexes $\mathrm{Cp}(\mathrm{CO})_{2} \mathrm{Fe}=\mathrm{CH}_{2}$ and $\mathrm{Cp}(\mathrm{CO})_{2} \mathrm{Fe}=\mathrm{CHCH}_{3}\left(\mathrm{Cp}=\eta^{5}-\mathrm{C}_{5} \mathrm{H}_{5}\right)$ are implicated as reactive intermediates. These highly electrophilic species may be stabilized either by substitution of better donor ligands for the $\pi$-acid CO ligands or by substitution, at the carbene atom, of hydrocarbon substituents which are effective at delocalizing positive charges $[66,654]$.

Indeed, electrophilic iron-carbene complexes of the general type $\mathrm{Cp}(\mathrm{CO})(\mathrm{L}) \mathrm{Fe}=\mathrm{CHR}^{+}\left(\mathrm{L}=\mathrm{CO}, \mathrm{PR}_{3}\right)$ readily transfer the carbene moiety to alkenes, to form cyclopropanes; and this transfer reaction has recently been applied to enantioselective syntheses of cyclopropanes [226,655-657]. The development of enantioselective methodologies for acyclic, multiple stereocontrol continues to present an important challenge for synthetic chemists [270,280]; and recent reports describe several highly diastereoselective reactions [658664].

Metal-carbene complexes are also useful reagents for the selective formation of carbon-carbon bonds and the synthesis of organic compounds [167]. The dimerization of carbene ligands, with carbon-carbon double-bond formation, is of special interest for the direct access it provides to functional alkenes displaying specific properties [137,167]. As for carbene-alkene coupling reactions or metal-carbene-initiated alkyne polymerization, the initial step of the carbene ligand dimerization process involves the generation of a vacant site by thermal or photochemical dissociation of a metal-ligand bond. In addition, it has been established that the thermal dimerization does not progress with the release of the uncoordinated carbene species but via a bimetallic intermediate [665].

The chemistry of transition-metal of vinylidene (or alkylidene) complexes has recently attracted considerable attention, and the topic has been extensively reviewed [666]. The vinylcarbene complexes are 
postulated to be key intermediates in the reaction of carbene complexes with acetylene involving the Dötz reaction [74] and polymerization of acetylenes. These processes sometimes involve "insertion" of carbon monoxide into the carbon-metal double bond of the vinylcarbene complexes, resulting in the formation of coordinated vinylketenes [667]; this reaction has recently been studied in detail for the formation of $\left(\eta^{3}: \eta^{1}\right.$ allylacyl)tricarbonyliron [668].

On the other hand, insertion of carbon monoxide into a transition-metal-carbon single bond (or the migration of an alkyl group on a coordinated carbon monoxide molecule) is one of the most important and fundamental reactions affecting carbon-carbon bonds in catalytic or noncatalytic organic synthesis by transition metals [669]. Other recent applications of iron-carbene complexes have been reported [665,670-678] and related carbyne complexes have been discussed [679].

\subsection{Dinuclear Iron Complexes}

Dinuclear transition-metal complexes can be considered to be the simplest model of metal surfaces, and they have the potential, through cooperativity of metal centers, to effect unique transformations of simple organic substrates not possible by a single metal center [680]. Heterodinuclear complexes are particularly interesting in this regard, because each metal may be able to effect a reaction that is not possible for the other, or the two metals in concert could facilitate a transformation unavailable to either metal alone.

The study of reactivity of organic molecules linked to dinuclear transition-metal (e.g., diiron) complexes has received a great deal of attention during the past 10 years. $\alpha$-Diimine ligands, $\mathrm{RN}=\mathrm{CHCH}=\mathrm{NR}$, are known to show very versatile coordination behavior, resulting from the possibility of donating from two to eight electrons, via the $\mathrm{N}$ lone pairs and the $\mathrm{C}=\mathrm{N} \pi$-electrons, to the metal center to which they are bonded $[681,682]$.

In certain dinuclear-metal complexes, metal carbonyl anions have been used to form metal-metal bonds to complexes containing carbene ligands $[683,684]$. For example, the reaction of the cationic iron complex $\mathrm{FeCp}(\mathrm{CO})(\mathrm{NCMe})\left[\mathrm{C}(\mathrm{SMe})_{2}\right]^{+} \quad\left(\mathrm{Cp}=\eta^{5}-\mathrm{C}_{5} \mathrm{H}_{5}\right)$, which contains bis(thiomethoxy)carbene ligand, with $\mathrm{Co}(\mathrm{CO})_{4}^{-}$led to facile replacement of the labile $\mathrm{NCMe}$ ligand and formation of a $\mathrm{Co}-\mathrm{Fe}$ bond [683]. The product contained a bridging $\eta^{2}-\mathrm{C}, \mathrm{S}$-coordinated carbene ligand, with a sulfur atom bonded to the cobalt atom.

There has been growing interest in the synthesis and characterization of polymetallic complexes whose metal centers are joined by polyfunctional organic ligands having delocalized $\pi$ systems [685]. This class comprises diiron, triiron and mixed iron complexes. The series includes a number of arene-bridged iron complexes [686-689]; also iron complexes having allene [690], alkyne [691], ylide [692], ketyl [693], carbyne [694], azoalkane [695], and similar organic bridges [696-705]. The cationic diiron bridging methylidene complex $\left[\left(\eta^{5}-\mathrm{C}_{5} \mathrm{H}_{5}\right)(\mathrm{CO}) \mathrm{Fe}\right]_{2}(\eta-\mathrm{CO})(\eta-\mathrm{CH})^{+} \mathrm{PF}_{6}^{-}$is extremely electrophilic, and reacts with $\mathrm{CO}$ to give a $1: 1$ adduct, $\left[\left(\eta^{5}-\mathrm{C}_{5} \mathrm{H}_{5}\right)(\mathrm{CO}) \mathrm{Fe}\right]_{2}(\eta-\mathrm{CO})(\eta-\mathrm{CHCO})^{+} \mathrm{PF}_{6}^{-}$. This complex, best regarded as a bridging acylium species, is readily attacked by nucleophiles at the acylium carbon atom [706]. Recently, a new, acid-catalyzed, trans to cis isomerization of the diiron methylidene complex has been reported by the same group [707].

Organometallic dinuclear complexes have been shown to be able to couple coordinated carbonyls. In this regard, synthetic organic chemists have benefited greatly from the use of these "inorganic" systems to effect reductive carbonyl coupling in which a carbon-carbon bond is created from two carbonyls [708].

\subsection{Iron Cluster Complexes}

The chemistry of metal cluster complexes containing heteroatom-substituted carbene ligands has recently been surveyed [709]; bonding in transition-metal clusters has been discussed [710]. There has been much recent interest in catalysis by metal clusters [711]. The preparation of transition-metal cluster carbonyl complexes has recently received increasing attention because of their potential for $\mathrm{CO}$ reduction. In a number of cases, the presence of different metal centers in the same molecular unit enhances the chemistry of the individual species as compared with their mononuclear analogues [712]. The presence of two or more metal centers may lead to unique reactivity as a result of metal-metal or metal-ligand-metal interactions that can readily accomplish otherwise difficult transformations, leading to new catalytic processes [713]. There has been considerable recent interest in the synthesis of clusters that provide a conceptual bridge between organometallic chemistry and the area of inorganic solid-state chemistry and surface chemistry [714]. In 
series of iron clusters, this class includes alkylidene [715], acetylene [716-718], carbide [719], and phosphaalkyne [720] bridging ligands. Recent work on mixed-metal clusters comprises $\mathrm{Fe}-\mathrm{Hg}$ [721], $\mathrm{Fe}-\mathrm{Sn}$ [722], F-Ge [723], Fe-Co [724], Fe-Ru [725], and Fe-Pt [726] clusters. A novel coordination behavior of ynamine ligands $\mathrm{RC} \equiv \mathrm{CNR}_{2}$ in diiron cluster complexes has been described [727,728]; some of these clusters incorporate carbene ligands [728]. A new cluster chemistry also includes skeletal rearrangement of $\left[\mathrm{Ru}_{2} \mathrm{Fe}_{4}(\mathrm{CO})_{16} \mathrm{~B}\right]^{-}$cluster anion [729] and the chirality and optical activity of cluster complexes [730].

\subsection{Iron-Main Group Element Complexes}

Recent advances in the chemistry of mixed main-group element-transition metal complexes or clusters has revealed the important role played by the main-group elements [731-733]. The interactions of the main-group elements, for example, group IVA (silicon, germanium, and tin) or group VA (nitrogen, phosphorus, arsenic, antimony, and bismuth), or group VIA (oxygen, sulfur, and selenium) with iron carbonyls produced a number of new heteroatomic complexes and clusters. Intriguing structures and bonding patterns have been observed in these complexes.

From among the main-group elements, of special interest are complexes incorporating the phosphorusiron bond [734-736]; this includes the important stereo-electronic properties of phosphorus(III) ligands $[737,738]$.

The separation of phosphorus(III) ligands into two distinct groups identified as pure $\sigma$-donor ligands and $\boldsymbol{\sigma}$-donor- $\pi$-acceptor ligands for the acetyl and methyl complexes $\left(\eta{ }^{5}-\mathrm{C}_{5} \mathrm{H}_{5}\right) \mathrm{FeL}(\mathrm{Co}) \mathrm{Me}$ has recently been accomplished [738].

Phosphorus compounds having a low coordination number have been the subject of considerable interest ever since they were first described. One of the showpiece examples is tert-butyl-phosphaacetylene or 3,3-dimethyl-1-phospha-1-butyne; these can be incorporated into heterocycles, used as new ligands, or cyclooligomerized by $\mathrm{Fe}_{2}(\mathrm{CO})_{9}$, to yield a new, mixed phosphocyclopentadieneiron complex [739].

The complexation of transition-metal complex fragments to compounds in which phosphorus is involved in multiple bonding has been intensively investigated in recent years. Both terminal $\left(\eta^{1}\right)$ coordination, as found for phosphanes, and side-one $\left(\eta^{2}\right)$ coordination, as found for alkenes and alkynes, have been observed. A recent report [740] describes the first diphosphaallyl complex in which, in addition to the $\eta^{3}$ coordination of the tricarbonyliron fragment via the lone pairs of two phosphorus atoms, a further metal atom is bonded.

Transition-metal complexes containing a $\eta^{5}$-cyclopentadienyl group (Cp) and three monodentate ligands that may incorporate a phosphorus ligand are referred to as "piano-stool" complexes because of their molecular shape. Recently, reactions of cyclopentadienyl complexes have been reported in which one of the monodentate ligands on the transition metal undergoes base-induced migration to the $\mathrm{Cp}$ ring: silyl from iron [741], acyl from iron [742,743], and alkoxycarbonyl from iron [744]. Migration of the phosphorus ligand from iron to the $\mathrm{Cp}$ ring in complexes of the type $\left(\eta^{5}-\mathrm{C}_{5} \mathrm{H}_{5}\right)(\mathrm{CO}) \mathrm{LFeP}(\mathrm{O}) \mathrm{YZ}(\mathrm{L}=\mathrm{CO}, \mathrm{Y}=\mathrm{Z}=\mathrm{OEt})$ has been reported for the first time [745]; synthesis of the four-legged piano stool complexes of iron are also described [746]. The mechanism of phosphine migration from a metal to a carbon site in a trimetallic cluster, e.g., anion $\left[\mathrm{Fe}_{2} \mathrm{Co}(\mathrm{CO})_{8}\left(\mathrm{PR}_{3}\right)(\mathrm{CCO})\right]^{-}$has been investigated [747].

Further challenging chemistry involves complexes comprising silicon-, arsenic-, or sulfur-iron $\sigma$ bonds, groups IVA, VA, and VIA, respectively. Selected from the main group IVA are silicon-iron [748-752], silicon-iron and silicon-germanium [753], germanium-iron [745], and tin-iron [755] complexes. Selected from group VA are nitrogen-iron [756,757], phosphorus-iron [758-764], phosphorus-arsenic-iron [765], and tiniron [766-768] complexes. Complexes containing iron and main-group elements from group VIA have also attracted considerable interest; these are sulfur-iron [769-786], sulfur-selenium-iron [787], and seleniumtellurium-iron [788] complexes.

9.4.1 Iron-Sulfur Clusters Many of the electron-transfer processes of cellular biochemistry are mediated by redox enzymes containing iron-sulfur centers, the two most important being [2Fe-2S] and a cubene-type cluster [ $4 \mathrm{Fe}-4 \mathrm{~S}]$ [789]. These iron-sulfur clusters are widely distributed both in plant and animal tissues, and they have been found to react very readily with nitrite. Thus, vegetative cells of Clostridium botulinum, which contain [4Fe-4S] centers, were found [790] to react with nitrite, destroying the ironsulfur cluster and simultaneously forming paramagnetic dinitrosyliron complexes of the type $\left[\mathrm{Fe}(\mathrm{NO})_{2} \mathrm{X}_{2}\right]^{++}$ $(\mathrm{X}=$ cysteinate). Thus, there is a clear association between the ingestion of high levels of nitrite, the forma- 
tion of cation-radical complexes $\left[\mathrm{Fe}(\mathrm{NO})_{2} \mathrm{X}_{2}\right]^{-+}$, and the existence of cancerous states in experimental animals [789]. A special recent interest has been placed on the cubane-type iron-sulfur, clusters containing the $[4 \mathrm{Fe}-4 \mathrm{~S}]^{+}$core oxidation level [791], the heterometal cubane-type clusters $\left[\mathrm{MFe}_{3} \mathrm{~S}_{4} \mathrm{~L}_{n=3-5}\right]^{1-t o 4-}(\mathrm{M}=\mathrm{Mo}, \mathrm{W})$ with anionic terminal ligands $[792,793]$, or cationic iron-sulfur clusters $\left[\mathrm{VFe}_{3} \mathrm{~S}_{4}\right]^{2+}$ and $\left[\mathrm{MoFe}_{3} \mathrm{~S}_{4}\right]^{3+}[794]$.

The reaction of $\mathrm{CO}_{2}$ to give useful materials is an important chemical reaction having biological implications. And this is now achieved with iron-sulfur clusters. An efficient electrochemical fixation of $\mathrm{CO}_{2}$ into formate was recently carried out by using an $\left[\mathrm{Fe}_{4} \mathrm{~S}_{4}\right]$ cubane cluster catalyst bearing a 36-membered methylene backbone, in $\mathrm{N}, \mathrm{N}$-dimethyl-formamide [795].

A recent interest has also been exhibited in the products generated in iron-sulfur cluster self assembly systems; for example, the synthesized cluster $\left[\mathrm{Fe}_{6} \mathrm{~S}_{6}\left(\mathrm{PEt}_{3}\right)_{6}\right]^{+}$has a unique, basket-type of stereochemistry [796].

\subsection{Oxo-Bridged Iron Complexes}

9.5.1 Novel Iron-Based Catalyst for Dioxygenation The chemisorption of oxygen, and reaction pathways at metal surfaces, as well as the role of surface oxygen, are the topics of a recent survey [797].

A homogeneous, iron-based catalyst, e.g., [bis(2,6-carboxylpyridine)iron(II)] has recently been found [798] to activate dioxygen to ketonize methylenic carbon atoms or dioxygenate acetylenes, arylalkenes, and catechols. For example, the catalyst transforms cyclohexane into cyclohexanone and diphenyl-acetylene into benzil, in what is believed to be the first such one-step process using dioxygen under ambient conditions. For the dioxygenation of unsaturated $\alpha$-diols, such as catechol, the system parallels the action of catechol dioxygenase enzymes. Hence, the reactive intermediate of the reaction may be a useful model and mimic for the activated complex of dioxygenase enzymes.

9.5.2 Biological and Enzymatic Application of Oxo-Bridged Iron Clusters Oxo-bridged polyiron complexes (clusters) are usually taken to involve a bridging oxygen atom derived from an oxo ligand, but the term also refers generically to species having bridging $\mathrm{OH}^{-}$or $\mathrm{OR}^{-}$ligands. Oxo-bridged clusters of iron are important structural and functional units of many redox enzymes [799-801]. In recent years, the binuclear iron-oxo center has emerged as a common structural component in the active sites of several metalloproteins $[799,802,803]$. These centers have important functional roles in hemerythrin [804], ribonucleotide reductase [805], methane monooxygenase [806], and the purple acid phosphatases [802,807], including reduced uteroferrin [808]. The binuclear center in such proteins is known or is postulated to exist in either an oxidized $\mathrm{Fe}$ (III)-Fe(III), a reduced $\mathrm{Fe}$ (II)-Fe(II), or mixed $\mathrm{Fe}$ (II)-Fe(III) form.

In recent years, a steadily increasing number of oxo/hydroxo-bridged clusters of iron(III) have been synthesized and structurally characterized. Complexes of nuclearity $\mathrm{Fe}_{3}, \mathrm{Fe}_{4}, \mathrm{Fe}_{6}, \mathrm{Fe}_{8}$, and $\mathrm{Fe}_{11}$ have been investigated in considerable detail [799]; the study by the same group includes synthesis of a novel oxobridged dinuclear iron(III) complex containing only oxygen-donating ligands [809], and assembling of phosphate ligand-oxo-bridged diiron(III) proteins [810] and asymmetric oxo-bridged diiron(III) complexes [811].

A new class of iron proteins having dinuclear iron centers bridged by oxide and carboxylate groups has emerged [799,802]. Structural and spectroscopic models of the ( $\eta$-oxo)bis( $\eta$-carboxylato)diiron(III) center found in the marine invertebrate respiratory protein hemerythrin have been synthesized with a variety of facially coordinated tridentate ligands [812]. In accord with this trend, a new class of $\left[\mathrm{Fe}_{2} \mathrm{O}\left(\mathrm{O}_{2} \mathrm{CR}_{2}\right)\right]^{2+}$ model complexes having terminal bridging dicarboxylate ligands [813] or a ( $\eta$-oxo)( $\eta$-carboxylate)diiron(III) complex having distinct iron sites [814] have recently been assembled. Recent related studies on metalloproteins and metalloenzymes include the synthesis of the lactoferrin analog $\left[\mathrm{LFe}(\eta-\mathrm{O})\left(\eta-\mathrm{CO}_{3}\right)\right.$ $\mathrm{FeL}] \cdot 4.25 \mathrm{H}_{2} \mathrm{O}$ ( $\mathrm{L}=1,4,7$-trimethyl-1,4,7-triazacyclononane) [815], the interaction of the $N$-[2-(o-hydroxyphenyl)glycino)ethyl]salicylideneamine iron(III) complex with catechol [816], iron-activated alcohol dehydrogenase [817]; also, the chemistry of ferro- and ferri-verdins derived from microorganisms [818], evidence for water coordinated to the active-site iron in soybean lipoxygenase-1 [819], and a structural study of the molybdenum-iron protein of nitrogenase [820]. Other reported studies are the oxidative cleavage of $(\eta-$ oxo)iron(III) tetraarylporphyrins [821], cleavage of DNA by a binuclear iron(III)-peroxide adduct [822], and a possible model of hemoprotein-hydrogen peroxide complex [823]; also oxo-bridged iron(III) complexes containing substituted benzothiazole and benzimidazole ligands [824], proton-coupled electron transfer in oxo-bridged clusters of iron and manganese [825], and the geometry of binuclear transition-metal complexes containing two paramagnetic metal ions joined by an oxo bridge [826]. 


\subsection{Photochemistry of Organoiron Complexes}

The electronically excited-state lifetimes of organometallic compounds in solution are typically very short. Single electron-transfer reactions of organometallic complexes are known to be initiated by their irradiation with visible or UV light in the presence of an appropriate ligand $[827,828]$ or reagent $[829,830]$. For example, the photochemistry of the cationic $\left[\left(\eta^{5}-\mathrm{C}_{5} \mathrm{H}_{5}\right) \mathrm{Fe}(\mathrm{ArH})\right]^{+} \mathrm{X}^{-}$complexes has been explored from both synthetic and mechanistic viewpoints. Their irradiation in a ligand-containing solution leads to release of the arene, and formation of a new, triply ligated iron(II) complex [831]. However, irradiation of similar complexes, e.g., (2-naphthylmethyl)triphenylborate $\left[\mathrm{NpCH}_{2} \mathrm{~B}(\mathrm{Ph})_{3}\right]^{-}$salts of $\left.\left[\eta^{5}-\mathrm{C}_{5} \mathrm{H}_{5}\right) \mathrm{Fe}(\mathrm{ArH})\right]$ cations in tetrahydrofuran solution generates the 2-naphthylmethyl free-radical, e.g., $\mathrm{NpCH}$ [832].

The photochemistry of iron piano-stool dimers has been studied [833]. Generally, dimers of the type $\left(\eta^{5}-\mathrm{C}_{5} \mathrm{H}_{5}\right)_{2} \mathrm{Fe}_{2}(\mathrm{CO})_{2}(\eta-\mathrm{CO})_{2}$ have a rich and diverse photochemistry $[834,835]$, and the photochemical insertion (by laser flash-photolysis) of alkynes in to those dimers (to yield diironcyclopentenones) has recently been described [836].

Other selected photoreactions of iron complexes include syntheses [837,838], elimination of the CO ligand in $\left(\eta^{5}-\mathrm{C}_{5} \mathrm{H}_{5}\right) \mathrm{Fe}(\mathrm{CO})_{2}\left(\eta^{1}-\mathrm{CH}_{2} \mathrm{C}_{6} \mathrm{H}_{5}\right)$ [839], $\alpha$-elimination of carbon (to give metal $\pi$-complexes) [840], disproportionation of $\left(\eta^{5}-\mathrm{C}_{5} \mathrm{H}_{5}\right) \mathrm{Fe}(\mathrm{CO})_{4}$ [841], rearrangement of $\left(\eta^{5}-\mathrm{C}_{5} \mathrm{H}_{5}\right) \mathrm{Fe}(\mathrm{CO})_{2}$-substituted oligosilanes [842], substitution of $\mathrm{CO}$ ligand in $\left[\mathrm{Fe}_{2}(\mathrm{CO})_{6}(\mathrm{~L}) \mathrm{P}\left(n-\mathrm{Bu}_{3}\right)\right]\left(\mathrm{L}=2,2^{\prime}\right.$-bipyridine $)$ [843], and breaking of the iron-nitrogen bond in $\left[\mathrm{Fe}(\mathrm{CO})_{3}(i-\mathrm{Pr})_{2}(1,4\right.$-diaza-1,3-butadiene $\left.)\right][844]$.

\subsection{Gas-Phase Reaction of Organoiron Complexes and Iron Ions}

Gas-phase inorganic chemistry focuses on the chemical reactions of metal ions and metal clusters and on the study of these species by using modern spectroscopic methods and Fourier-transform mass spectrometry (FTMS) [845]. Gas-phase organometallic chemistry derives its interest from the fact that, by the very nature of the physical isolation, the inherent properties of specific metal ions (or complexes) can be probed in the absence of other disturbing influences. These include ligand and solvent effects, as well as ion pairing, which prevail in the condensed state. The transition metal-ligand bond has been described as being the key to linking organometallic chemistry, surface chemistry, and catalysis. In particular, metal-ligand bond energies are useful in assessing whether a proposed reaction-pathway is energetically feasible. To provide such quantitative data, a growing number of mass-spectrometric techniques have been developed. With regard to the understanding of many catalytic processes, a fundamental problem is concerned with the mechanism of activation of $\mathrm{C}-\mathrm{H}$ and $\mathrm{C}-\mathrm{C}$ bonds, which constitutes a crucial step in catalytic cycles [846,847] and which is also observed in the reactions of bare transition-metal ions with organic substrates in the gas phase [848-850].

Recently, several reactions in the gas phase have been reported; these are reactions of iron ions with allenes [851], reaction of 1 -alkanols [852] or linear and $\alpha$-branched aliphatic nitriles [853] with bare iron ions; also, reaction of $\left[\mathrm{FeCH}_{3}\right]^{+}$with nitrogen-containing species [854], reaction of iron-alkyl complexes $(\alpha-$ hydrogen migration) [855], reaction of phenyl halides with iron ions (formation of oligomer) [856], and protonation and decomposition of $\left[\left(\eta^{5}-\mathrm{C}_{5} \mathrm{H}_{5}\right)(\mathrm{CO}) \mathrm{Fe}\right](\eta-\mathrm{CO})\left(\eta-\mathrm{C}=\mathrm{CH}_{2}\right)[857]$.

\subsection{New Ferrocene Chemistry. Novel Multiple-Decker Ferrocenes}

Organotransition-metal chemistry has, since the discovery of ferrocene in 1951, attained considerable importance in organic synthesis, in both stoichiometric and catalytic processes. In the meantime, classical ferrocene chemistry has also undergone significant transformation and new chemistry has emerged.

Recent interest in ferrocene chemistry concerns a new development of polymetallocenes [858], namely, the one-dimensional stacking of alternating metal and ring. Thus, the versatile chemistry of metallocenes has indeed catalyzed the study of new monomeric, dimeric, and oligomeric metal complexes obtained by sandwiching additional metal-ring combinations.

Addition of a ring, e.g., a double-layered organic $\pi$-ligand to ferrocene may lead to various polymeric metal complexes whose $\pi$-systems interact strongly, thus allowing efficient metal-metal communication. Three types of double-layered organic $\pi$-ligands have been utilized for the construction of columnar polymeric ferrocene complexes; these $\pi$-ligands are cyclophanes [859,860], indenophanes [861], and sterically fixed, naphthalene-bridged cyclopentadienyl systems [862]. Addition of a metal and a ring to ferrocene leads 
to triple-decker sandwiches, a new and popular topic of research [863]. The number of valence electrons in triple-decker sandwich complexes is 30 [863]. Addition of one metal and ring to a triple-decker complex leads to tetradecker sandwiches [864]. The number of valence electrons in these complexes varies from 40 to 46. Higher homologs of ferrocenes $[863,865,866]$ and polymetallocenes $[859,864]$ provide exciting challenges.

Several new reactions of ferrocenes and substituted ferrocenes have been reported $[867,876]$, including interesting photochemical conversion of ( $\eta^{1}$-butadinyl)iron complexes to hydroxyferrocenes [877], photolysis of (arene- $\left.\mathrm{C}_{5} \mathrm{H}_{5}\right)$ ferrocene to a novel $\left(\mathrm{C}_{5} \mathrm{H}_{5}-\mathrm{Fe}\right)$ complex [878], and new chiral ferrocenylphosphines having $\mathrm{C}_{2}$ symmetry [879].

9.8.1 Pseudo-Ferrocenes, A New Class Pseudo-ferrocenes are complexes wherein a bridging, cyclic $\pi$-ligand (a $6 \pi$-electron donor) is arene, fulvalene, or heterocyclic, in a sandwich coordination with the cyclopentadiene ring. Bis(arene) or other mixed-ring sandwich complexes, and substituted open and halfopen ferrocenes also belong to this new class.

Over the past several years there has been growing interest in the synthesis of polymetallic complexes whose metal centers are joined by polyfunctional organic ligands having delocalized $\pi$-systems $[685,880]$. The localization of an electron inside a three-dimensional, molecular framework is a key property of electron-reservoir complexes, and this is another topic of recent interest in the ferrocene field [881]. The $\pi$-complexation of aromatics, polyaromatics, or heteroaromatics via sandwiching by a transition metal brings about a tridimensionality which should have a dramatic influence on the physical properties, and could open up new synthetic routes. As compared to simple ferrocenes, sandwiched aromatic (e.g., polyaromatic) complexes can have a weaker arene-metal bond, which is useful in catalysis and for any purpose requiring free coordination sites. By applying pseudo-ferrocenes, a new vista of chemistry has recently been discovered. This chemistry includes arene-ferrocenes [882], bis(arene)-ferrocenes [883,884], naphthalene-ferrocenes [885], polyaromatics-ferrocenes [886]; also, heptafulvalene-ferrocenes [887], bis(fulvalene)- and arenefulvalene-ferrocenes [888,889], cyclooctatetraene-ferrocene [890], (1,2-azaboride)-ferrocene [891], pentaphosphaferrocene [892]; also, tentacled iron sandwich complexes [893], tetracarbonyl ferrate- $\left(\eta^{6}\right.$ arene) $\mathrm{Cr}(\mathrm{CO})_{3}$ complex [894]; substituted open, half-open, and closed ferrocenes [895], half-open ferrocenes [896], spiro (closed)-ferrocenes [897], a porphyrin-ferrocene-quinone complex [898], and ferrocene-substituted high polymeric phosphazenes [899].

In contrast to the alkali-metal coordination studies of electrochemically reducible redox-active macrocyclic systems, until quite recently little had been reported about the effects of cation binding on the oxidation potential of redox-active macromolecules containing an oxidizable moiety such as ferrocenyl, e.g., ferrocene crown and biscrown ethers [900].

\subsection{Iron Porphyrins}

Iron porphyrins constitute a widely studied class of complexes because of their prevalence in biological systems, notably the iron protoporphyrin IX (heme) proteins $[555,901,902]$. The extended $\pi$-orbital network of these macromolecules also leads to applications in electronics and solid-state chemistry. Particularly, porphyrin derivatives play a crucial role in many chemical and biological electron-transfer reactions [901]; these include iron(IV) porphyrin as a model for the peroxidases [903].

Metalloporphyrins can also mimic enzymes in reactions. As recently reported [904], the protonation of transition-metal porphyrin hydrides has yielded the first known dihydrogen complex of a metalloporphyrin and a system that performs some functions of hydrogenase enzymes.

Several aspects of metalloporphyrin chemistry, including the active-site structure and reactivity, have recently been investigated. The success of these studies often depends upon the unique steric properties of the porphyrin employed. Steric control at the metal site has been facilitated by the use of capped, singleand double-strapped [905,906], bis-pocket, picket-fence [907], and basket-handle [908] type porphyrins. In many cases, the polarity and hydrogen-bonding properties of the porphyrin substituent stabilize the coordination of an axial ligand, such as dioxygen, by the metal ion [905,906]. A new porphyrinatoiron complex, 5,10,15,20-tetrakis(2,6-bispivaloyloxyphenyl)porphyrinatoiron(II), has been synthesized; axial-base ligation was sterically depressed by the four ester groups on each side of the porphyrin, and a stable dioxygen adduct was formed reversibly at $25^{\circ} \mathrm{C}$ in toluene [909].

Recent applications of iron porphyrins cover fields of biochemistry [910,911], medicine [912,913], and chemistry [914-917], including asymmetric hydroxylation by a chiral iron porphyrin [918]. 
The reactions of metalloporphyrins have also received particular attention in relation to biological systems, including cytochrome P-450, cytochrome C, or cytochrome $b_{5}[556,920]$. Because reactions take place as for the substrate and/or the reagent coordinated to the metal on a rigid macrocycle of porphyrin, notable stereospecificities are expected, and, in fact, results of some investigations into stereochemical aspects have been used in exploiting metalloporphyrins as cytochrome P-450 model systems $[556,919,921,922]$. An iron porphyrin unit functions as the redox site in many electron-transfer enzymes. A sub-section of this class of enzymes has the iron with either one or two axial imidazole ligands; in the cytochrome $\mathrm{C}$ group, the porphyrin is attached to the peptide chain by sulfur bridges between cysteine residues and the two porphyrin vinyl groups [923]. Recently, the reaction between the cytochrome-C-derived heme octapeptide microperoxidase (MP) and hydrogen peroxide leading to the formation of hypervalent iron-oxo-porphyrin cation-radical [924], the generation of the $\mathrm{Fe}$ (III)-OEP- $\mathrm{H}_{2} \mathrm{O}_{2}$ complex (OEP = octaethylporphyrinato) [925], or of the $\mathrm{Fe}(\mathrm{III}) \mathrm{TPP}-\mathrm{H}_{2} \mathrm{O}_{2}$ adduct (TPP = tetraphenylporphyrinato), all important in electron-transfer in a novel synthetic membrane analog for cytochrome C [926], have been reported.

\subsection{Additional Recent Results}

Some important recent reviews include organoiron chemistry, an annual survey for the year 1988 [927], enantioselective catalysis with metal complexes [928], multiple stereocontrol using organometallic complexes as applied in organic synthesis [929], and new synthetic applications of cyclopropanes containing $\mathrm{C}_{5}$ - building blocks [930]. There are new books on stereoselective synthesis [931], metal-DNA chemistry [932], and electron-transfer between metal centers, including biological systems [933].

9.10.1 New Carbon-Carbon Bond-Forming Reactions. New Seven-Membered Ring Iron Complexes

Among the various carbon-carbon bond-forming reactions promoted by iron, functionalization of a seven-membered ring via (cycloheptatriene)iron tricarbonyl has been one of recent synthetic interest. Thus, deprotonation of (cycloheptatriene) $\mathrm{Fe}(\mathrm{CO})_{3}$ provides a species that can be considered to be the antiaromatic cycloheptatrienide anion stabilized by a transition-metal fragment [934]. This deep-red organometallic anion can be considered in terms of two limiting bonding alternatives, one of which delocalizes the negative charge in the ring as an allylic carbanion, and one that places the charge density on the metal [935]. Thus, the $\left(\eta^{5}-\mathrm{C}_{7} \mathrm{H}_{7}\right) \mathrm{Fe}(\mathrm{CO})_{3}$ anion has been used to prepare a number of heterobimetallic complexes linked by either a metal-metal bond or through the seven-membered ring [936]. This anion is also an attractive substrate for the regio- and stereocontrolled elaboration of seven-membered rings, particularly because of its reactivity with organic electrophiles and their derivatives (e.g., acid chlorides [935] or in the synthesis of natural products [929]. The reaction of the cycloheptadienyl cation $\left(\eta^{5}-\mathrm{C}_{7} \mathrm{H}_{9}\right) \mathrm{Fe}(\mathrm{CO})_{3}^{+}$with $\mathrm{KI}$ [to give $\left.\left(\eta^{5}-\mathrm{C}_{7} \mathrm{H}_{9}\right) \mathrm{Fe}(\mathrm{CO})_{2} \mathrm{I}\right]$ [937], and the chemistry of the related $\left(\eta^{3}\right.$-pentadienyl)iron tricarbonyl halides [938], have been studied. Also, an optically pure(tropone)iron tricarbonyl [939] useful for the synthesis of natural products [940] has been prepared. The synthesis and separation of the [(tropone $) \mathrm{Fe}(\mathrm{CO})_{2}(+)$-neomenthyldiphenylphosphine] diastereoisomer of $6 \mathrm{~S}$ planar chirality has recently been accomplished [941].

Other new carbon-lengthening methods are the reaction of $\mathrm{KHFe}(\mathrm{CO})_{4}$ with an excess of ethyl acrylate in ethanol (to give ethyl propanoate and diethyl 4-oxopimelate) [942], the coordination of the dinitrogen complex $\eta-\mathrm{N}_{2}\left[\mathrm{Fe}(\mathrm{CO})_{2} \mathrm{~L}_{2}\right]_{2}\left(\mathrm{~L}=\mathrm{P}\left(\mathrm{OMe}_{3}\right) ; \mathrm{PEt}_{3}\right)$ with diphenylketene diphenyl-p-tolylketene imine to form $\eta^{2}-\mathrm{C}, \mathrm{O}$ ketene compounds $\mathrm{Fe}(\mathrm{CO})_{2} \mathrm{~L}_{2} \mathrm{Ph}_{2} \mathrm{C}_{2} \mathrm{O}\left(\mathrm{L}=\mathrm{P}(\mathrm{OMe})_{3} ; \mathrm{PEt}_{3}\right)$ [943], the reaction of iron(II) acetylide complexes with diphenylketene, diketene, and 1,3-dicyano-1,3-butadiene to produce the corresponding $[2+2]$ and [4+2] cycloadducts [944], the reaction of an electrophilic iron carbene complex [( $\eta^{5}-$ $\left.\left.\mathrm{C}_{5} \mathrm{H}_{5}\right)(\mathrm{CO})_{2} \mathrm{Fe}=\mathrm{CHAr}\right]^{+}\left(\mathrm{Ar}=\mathrm{p}-\mathrm{C}_{6} \mathrm{H}_{4} \mathrm{OMe}\right)$ with nitrosoarenes $\mathrm{O}=\mathrm{N}-\mathrm{Ar}^{\prime}\left(\mathrm{Ar}^{\prime}=\mathrm{C}_{6} \mathrm{H}_{5}, \mathrm{p}-\mathrm{C}_{6} \mathrm{H}_{4} \mathrm{NMe}_{2}\right)$ or azobenzene $\mathrm{PhN}=\mathrm{NPh}$ (to cause insertion of the $\mathrm{ArN}=\mathrm{X}$ moiety into the $\mathrm{Fe}=\mathrm{CHAr}$ bond, by formation of a nitrene complex) [945]; also, insertion of isocyanates into $\mathrm{M}-\mathrm{H}$ bonds is illustrated by the reaction of $\left(\eta^{5}-\mathrm{C}_{5} \mathrm{H}_{5}\right) \mathrm{HFe}(\mathrm{CO})_{2}$ with $t-\mathrm{BuNCO}$ to give $\left(\eta^{5}-\mathrm{C}_{5} \mathrm{H}_{5}\right) \mathrm{Fe}(\mathrm{CO})_{2}[\mathrm{C}(\mathrm{O}) \mathrm{NH}(t-\mathrm{Bu})]$ [946] or by formation of pentakis(trifluoromethyl isocyanide)iron, $\mathrm{Fe}\left(\mathrm{CNCF}_{3}\right)_{5}$ [947]; also, the synthesis of (methyl-2-butenoate)iron complexes by the reaction of $\left(\eta^{5}-\mathrm{C}_{5} \mathrm{H}_{5}\right) \mathrm{Fe}(\mathrm{CO})_{2} \mathrm{Na}$ with methyl-4-chloro-2-butenoate) [948].

Other recent work involves an interesting transformation of the cluster $\mathrm{Fe}_{3}(\mathrm{CO})_{10}\left(\eta^{3}-\mathrm{PR}\right)$ into two carbene-functionalized clusters under the conditions of Fischer-type carbene synthesis. The first cluster thus obtained contains a terminal carbene ligand $\mathrm{R}^{\prime} \mathrm{COR}^{\prime \prime}$, whereas the carbene ligand in the second cluster coordinates to two metal atoms via the carbene atom, and to the third iron center through the oxygen atom of the $\mathrm{R}^{\prime \prime} \mathrm{O}$ substituent [949]. 
Other recent studies examined rearrangements of cyclopropanes $\sigma$-bonded to iron [950], iron-mediated diene activation [951], $\sigma, \pi$ complexes of benzene, e.g., $\left(\eta^{6}-\mathrm{C}_{6} \mathrm{H}_{6-n} \mathrm{Fp} n\right) \mathrm{Cr}(\mathrm{CO})_{3}\left(\mathrm{Fp}=\left(\eta^{5}-\mathrm{C}_{5} \mathrm{H}_{5}\right) \mathrm{Fe}(\mathrm{CO})_{2}\right.$ and $n=2$ or 3) [952], synthesis of $\left[\left(\eta^{5}-\mathrm{C}_{5} \mathrm{H}_{5}\right)(\mathrm{CO})_{2} \mathrm{FeCH}_{2}\right]_{3} \mathrm{CH}$ complex and the study of hydride transfer from carbon-hydrogen bonds therefrom [953]; also, catalytic alkylations of allylic carbonates in the presence of nitrosylcarbonyliron complexes [954], the electrochemical oxidation of $\left(\eta^{5}-\mathrm{C}_{5} \mathrm{H}_{5}\right)(\mathrm{CO})_{2} \mathrm{FeMe}$ in acetone [955], $N$-analogues of metal acetylacetonates:bis(1,2,6,7-tetracyano-3,5-dihydro-3,5-diimino-pyrrolizinido) iron(II) [956], metalladiboranes of the iron group: $\mathrm{K}\left[\mathrm{Fe}(\mathrm{CO})_{4}\left(\eta^{2}-\mathrm{B}_{2} \mathrm{H}_{5}\right)\right.$ ] [957], and fluorine-substituted ferracyclopentadiene complexes with an unprecedented fluorine bridge between boron and carbon [958].

9.10.2 Tripodal Polyphosphine Metal Complexes Over the past decade, tripodal polyphosphines have proved to be useful and versatile ligands in inorganic and organometallic chemistry [959-961]. Recently, transition-metal complexes of tripodal polyphosphines have begun to attract interest because of their potential as catalysts in several homogeneous reactions, including (a) hydrogenation of alkynes, alkenes, and organic nitriles, (b) hydroformylation and isomerization of alkenes; (c) polymerization of alkynes, (d) oxidation of inorganic and organic substrates, and (e) synthesis of vinyl ethers from terminal alkynes and carboxylic acids [962]. The principal reasons explaining why tripodal polyphosphine ligands participate in such a wide range of catalyst systems can be summarized under six main headings [962,963]; (i) excellent bonding ability, (ii) strong trans influence, (iii) formation of stable complexes in a variety of metal oxidation states, (iv) great control of the stereochemistry, (v) adaptability to many different coordination numbers and (vi) high nucleophilicity of the metal centers.

There is ongoing interest in other iron complexes incorporating diphenylphosphino ligands. Thus, the nitrosyl dimer $\left[\mathrm{Fe}\left(\mathrm{NO}_{2}\right) \mathrm{Cl}\right]_{2}$ in the presence of 1,2-bis(diphenylphosphino)ethane (dppe) yields the complex $\left[\mathrm{Fe}\left(\mathrm{NO}_{2}\right) \mathrm{Cl}\right]_{2}$ ( $\eta$-dppe); this is the first structurally characterized binuclear complex where dppe constitutes the single bridge between two metallic centers without the presence of a metal-metal bond [964].

It is now recognized that the ease of carbon-phosphorus bond cleavage at metal centers is dependent upon the hybridization of carbon, following the order: $\mathrm{P}-\mathrm{C}(\mathrm{sp})>\mathrm{P}-\mathrm{C}\left(\mathrm{sp}^{2}\right)>\mathrm{P}-\mathrm{C}\left(\mathrm{sp}^{3}\right)$ [965]. Examples of $\mathrm{P}-\mathrm{C}\left(\mathrm{sp}^{3}\right)$ cleavage are rare, but the unprecedented cleavage of both of the $\mathrm{P}-\mathrm{CH}_{2}$ bonds in an $\eta$-alkylidene iron complex has recently been reported [966]. Thus, treatment of $\left[\mathrm{Fe}_{2}(\mathrm{CO})_{6}(\eta-\mathrm{CO})\left(\eta-\mathrm{Ph}_{2} \mathrm{PCH}_{2} \mathrm{PPh}_{2}\right)\right.$ with ethyl diazoacetate under UV irradiation gives $\left[\mathrm{Fe}_{2}(\mathrm{CO})_{6}\left(\eta-\mathrm{CHCO}_{2} \mathrm{Et}\right)\left(\eta-\mathrm{Ph}_{2} \mathrm{PCH}_{2} \mathrm{PPh}_{2}\right)\right.$, which, on heating, undergoes $\mathrm{P}-\mathrm{CH}_{2}$ bond cleavage and $\mathrm{C}-\mathrm{C}$ bond formation, affording $\mathrm{CH}_{2}=\mathrm{CH}\left(\mathrm{CO}_{2} \mathrm{Et}\right)$ and $\left[\mathrm{Fe}_{2}(\mathrm{CO})_{6}(\eta-\right.$ $\left.\left.\mathrm{PPh}_{2}\right)_{2}\right]$.

Transition-metal oxophilicity [967] and steric factors [968] have emerged as crucial parameters that determine the relative stability of mono- and bi-dentate acyl coordination modes, and these factors have recently been examined in relation to a solution structure of the $\left.\left(\mathrm{PPh}_{2} \mathrm{Me}\right)_{2} \mathrm{Fe}(\mathrm{CO}) \eta^{2}-\mathrm{C}(\mathrm{O}) \mathrm{Me}\right) \mathrm{I}$ complex, in which there was found facile alkyl $\leftrightarrow \eta^{2}$-acyl equilibrium [969]. Activations of $\mathrm{H}-\mathrm{X}$ bonds by transitionmetal complexes are key steps in many catalytic functionalizations of $\mathrm{C}-\mathrm{C}$ multiple bonds. Accordingly, $\mathrm{N}-\mathrm{H}$ bond activation by metals [970] may play a key role in some catalytic alkene hydroamination [971] pathways. The facile activation of amide $\left(\mathrm{RCONH}_{2}\right) \mathrm{N}-\mathrm{H}$ bonds by iron phosphine complexes, e.g., cis $-\mathrm{FeH}_{2}(\mathrm{dmpe})_{2}$ (dmpe) =1,2-bis (dimethylphosphino)ethane, and $\mathrm{FeH}\left(\mathrm{C}_{6} \mathrm{H}_{4} \mathrm{PPhCH}_{2} \mathrm{CH}_{2} \mathrm{PPh}_{2}\right)(\mathrm{dppe})(\mathrm{dppe}=1$,2-bis (diphenylphosphino)ethane, has recently been described [972].

9.10.3 Novel Charge-Transfer Complexes and Ferromagnets Donor-acceptor (DA) interactions in molecular solids provide to a large extent the foundation of the extensive interest in these materials $[973,974]$. The present goal has been the better to understand structure-function relationships in these materials, which may result in new concepts for rational modification of structural and electronic properties that are relevant to possible electronic applications [975]. The behavior of the organometallic DA solids recently studied [976] demonstrated that the design of donor-acceptor complexes need not invoke components having planar molecular structures, as face-to-face stacking of $\pi$-networks is not required for chargetransfer behavior.

One-dimensional (1-D) charge-transfer complexes frequently exhibit unusual optical, electrical [973], and, as recently discovered, unusual cooperative magnetic properties [977]. For example, the reaction of decamethylferrocene, $\mathrm{Fe}\left(\mathrm{C}_{5} \mathrm{Me}_{5}\right)_{2}$, and 7,7,8,8-tetracyano-p-quinodimethane, TCNQ, gives three major products of various stoichiometry, conductivity, and magnetism [978]. Replacement of [TCNQ]' by $\left[\mathrm{TCNE}^{-}\right.$(TCNE = tetracyanoethylene) led to the similarly structured decamethylferrocenium tetracyanoethenide [ $\left.\mathrm{Fe}(\mathrm{III})\left(\mathrm{C}_{5} \mathrm{Me}_{5}\right)_{2}\right]^{+}[\mathrm{TCNE}]^{-}$, which has been characterized as being a bulk ferromagnet [979]. The search for ferromagnetic organic compounds and polymers, however, maintains academic interest [980]. Recently, a novel, crystalline, ferromagnetic, inorganic-organic host-guest complex has been synthesized 
by a procedure wherein magnetite $\left(\mathrm{Fe}_{3} \mathrm{O}_{4}\right)$ was sequestered by bis(pyridoxylidenehydrazino)phthalazine at ambient temperature and neutral $\mathrm{pH}$ [981].

9.10.4 Recent Physical, Spectral, and Catalytic Studies of Organoiron Complexes Few iron complexes have been found to be efficient hydrogenation catalysts [982]. However, a homogeneous iron(II) system that brings about the selective reduction of terminal alkynes to alkenes has recently been reported [983]. Thus, terminal alkynes are selectively hydrogenated to alkenes by the iron(II) catalyst precursors $\left[\left(\mathrm{PP}_{3}\right) \mathrm{FeH}\left(\mathrm{N}_{2}\right) \mathrm{BPh}_{4}\right]$ and $\left[\left(\mathrm{PP}_{3}\right) \mathrm{FeH}\left(\mathrm{H}_{2}\right) \mathrm{BPh}_{4}\right]$ in tetrahydrofuran at 1 atm of $\mathrm{H}_{2}$ at 20 to $66^{\circ} \mathrm{C}$ $\left[\left(\mathrm{PP}_{3}=\mathrm{P}\left(\mathrm{CH}_{2} \mathrm{CH}_{2} \mathrm{PPh}_{3}\right)_{3}\right]\right.$.

As determined by mass spectrometry, for nitriles containing four to seven carbon atoms, the "anchored" transition-metal ion $\mathrm{Fe}^{+}$exclusively activates the $\mathrm{C}-\mathrm{H}$ bond of the terminal methyl group by oxidative addition [984]. Other areas of interest include mechanism in the hydrometalation and hydrogenation reactions of $\left(\eta^{5}-\mathrm{C}_{5} \mathrm{H}_{5}\right) \mathrm{Fe}(\mathrm{CO})_{2} \mathrm{H}$ with conjugated dienes [985], conformational studies of five-membered chelate rings in iron(III) complexes [986], reactions of hydroxyl radical with 2,2'-bipyridyl iron(II) complexes [987], and dynamics of spin-state interconversion of iron(III) complexes in solution as a function of the pressure [988]; characterization of the first stable iron-methylene complex $\left[\left(\eta^{5}-C_{5} \mathrm{M}_{5}\right) \mathrm{Fe}(\mathrm{dppe})\right.$ $\left.\left(=\mathrm{CH}_{2}\right)\right]^{+} \mathrm{BF}_{4}^{-}$(dppe $\left.=\mathrm{p}, \mathrm{p}^{\prime}-\mathrm{Ph}_{2} \mathrm{PCH}_{2} \mathrm{CH}_{2} \mathrm{PP}\right)$ [989], the structure of iron(II) molecular hydrogen complexes containing monodentate phosphine ligand [990], characterization of ethyl oxalyl tetracarbonyl iron anion $\left[(\mathrm{CO})_{4} \mathrm{FeCOCO}{ }_{2} \mathrm{Et}\right]^{-}[991]$, structure of a triangular cluster $\left[\mathrm{Fe}_{2}(\mathrm{CO})_{8}\left(\eta-\mathrm{AuPPh}_{3}\right)\right][992]$, structural characterization of iron(III) complexes of chlorin and isobacteriochlorin macrocycles [993], the first fully characterized hexaminoiron(III) complex [994], and the molecular structure of $\eta^{3}-\mathrm{Bi}\left[\mathrm{Fe}\left(\eta^{5}-\mathrm{C}_{5} \mathrm{H}_{5}\right)(\mathrm{CO})\right]_{3}$ [995]. Other recent interests encompass the carbon-13 NMR spectrum of solid iron pentacarbonyl [996], axialequatorial exchange of carbonyl groups in $\left[\mathrm{HFe}(\mathrm{CO})_{4}\right]$ anion in the solid state as determined by carbon-13 NMR spectroscopy [997], the charge distribution in bimetallic organoiron complexes by ${ }^{57} \mathrm{Fe}$ Mössbauer spectroscopy [998], electrical conductivities of $s$-tetrazine-iron complexes [999], and intramolecular Kharasch cyclizations of the alkenic trichloromethyl substrates in the presence of the $\mathrm{FeCl}_{2}\left[\mathrm{P}(\mathrm{OEt})_{3}\right]_{3}$ catalyst, to afford five- or six-membered-ring exo-closure products, e.g., trichlorocyclopentane or trichlorocyclohexane derivatives [1000].

Additional pertinent, recent references include: a new book on organometallic chemistry of transition elements [1001], spectroscopic studies of the mixed-valent [Fe(II), $\mathrm{Fe}(\mathrm{III})]$ forms of the non-heme iron protein hemerythrin [1002], a survey of tetraphenylporphyrins and metallotetraphenylporphyrins [1003], carbon monoxide insertion into iron-carbon bonds of $\sigma$-alkyl porphyrins [1004], and the gas-phase chemistry between $\mathrm{Fe}^{+}$-benzyne and alkenes [1005].

The solubilization and mediation of iron uptake by aerobic microbes occurs via the production of low molecular weight ligands that have very high affinities for ferric ion [1006,1007]. It has been shown that the microbial transport process generally involves a recognition of the geometry and chirality at the metal center of the coordination complex (siderophore). The characterization of the coordination chemistry of the siderophores and the mechanisms by which they deliver iron to the microbial cell is the topic of a recent study [1008]. Iron uptake and inhibition studies with a number of siderophores, semisynthetic siderophores, and synthetic siderophore analogues have demonstrated remarkable stereospecificity and enantioselectivity of the microbial receptors $[1006,1007]$.

\subsection{Addenda to Addenda}

Selected work from the most recent literature on organoiron complexes is presented next.

9.11.1 New Carbon-Carbon Bond-forming Reactions In a series of diiron complexes, the diiron methylidene complex $\left[\mathrm{C}_{5} \mathrm{H}_{5}(\mathrm{CO}) \mathrm{Fe}\right]_{2}(\eta-\mathrm{CO})(\eta-\mathrm{CH})^{+} \mathrm{PF}_{6}^{-}$is interesting in its relation to $\mathrm{CH}$ groups bound to metal surfaces. It is also an important intermediate in the synthesis of a wide range of hydrocarbylbridged diiron compounds [1009]; it adds its $\mathrm{CH}$ bond across the carbon-carbon double bond of simple alkenes in a hydrocarbation reaction, to produce a new series of ( $\eta$-alkylidyne) diiron complexes [1010]. Because of the central importance of these diiron methylidene complexes to the new chemistry of $\eta$-alkylidene, $\eta$-acylium, and $\eta$-nitrilium complexes, the mechanism of its formation has been studied in detail [1011].

Dinuclear iron $\eta$-acetylide complexes, e.g., $\left.\left[\mathrm{FP}_{2}(\mathrm{C} \equiv \mathrm{C})-\mathrm{R}\right] \mathrm{BF}_{4}(\mathrm{R}=\mathrm{H}, \mathrm{Ph}) ; \mathrm{FP}=\left(\eta^{5}-\mathrm{C}_{5} \mathrm{Me}\right)_{5}\right) \mathrm{Fe}(\mathrm{CO})_{2}$ [1012], in which the acetylide ligand is bound to one metal center in a $\eta^{1}$ fashion ( $\sigma$-bonded) and to the other metal center in a $\eta^{2}$ fashion ( $\pi$-bonded), have attracted much attention as a model for surface-bound 
species. Oscillation of the bridging acetylide ligands between two metal centers in a manner reminiscent of a windshield wiper often results in fluxional behavior, and this is observed for the diiron acetylide complex.

Interest in metal-bound vinylketenes as reaction intermediates [1013-1015] led to facile preparation of (vinylketene)tricarbonyliron $(\mathrm{O})$ complexes [1016], and the synthesis of (vinylketeneimine)tricarbonyliron(O) complexes [1017].

Phosphaacetylenes have been successfully cyclooligomerized in the presence of suitable metal complexes [1018,1019]. The degree of cyclooligomerization, and the structure of the resulting metal complexes, seem to depend mainly upon the nature of the metal used. An example of a novel cyclodimerization of phosphaalkyne (e.g., 3,3-dimethyl-1-phospha-1-butyne) in the presence of nonacarbonyliron, $\mathrm{Fe}(\mathrm{CO})_{9}$, at $100^{\circ} \mathrm{C}$ (to give 2,4-di-tert-butyl-tricarbonyl-1,3-diphosphacyclobutadineiron, $63 \%$ yield) has been reported [1020].

Electrophilic carbene complexes $[\mathrm{M}=\mathrm{CHR}]^{+}$are key intermediates in single and double carbon-carbon bond formation $[66,1021,1022]$. The classical route to carbene complexes $[\mathrm{M}=\mathrm{CHR}]^{+}[\mathrm{M}=\mathrm{Fe}, \mathrm{Cr}]$ involves the ionization of $\alpha$-alkoxyalkyl derivatives, $\mathrm{M}-\mathrm{CH}(\mathrm{OR}) \mathrm{R}$ which are generally prepared from alkoxycarbene complexes by hydride reduction or by using organolithium reagents [1023]. Thus, the bimetallic complex $\left[\left(\eta^{5}-\mathrm{C}_{5} \mathrm{Me}_{5}\right) \mathrm{Fe}(\mathrm{CO})_{2}\left\{\eta-\eta^{1}, \eta^{6}-\mathrm{CH}(\mathrm{OMe}) \mathrm{CH}_{2} \mathrm{C}_{6} \mathrm{Me}_{5}\right\} \mathrm{Fe}\left(\eta^{5}-\mathrm{C}_{5} \mathrm{H}_{5}\right)\right]\left[\mathrm{PF}_{6}\right]$, which is readily prepared by an electrophilic carbene-alkene coupling reaction, is specifically converted into either pentamethyl- $\eta^{6}$-vinyl benzene or a related dinuclear $\left(\eta-\eta^{1}, \eta^{6}\right.$-vinylarene) complex. This procedure offers access to new $\pi$ - and $\sigma, \pi$-vinylarene complexes (e.g., single and double carbon-carbon bond formation, respectively) via iron-carbene intermediates [1024].

Syntheses involving the use of metal atoms on a preparative scale are of growing interest. The starting point of some new strategies is the generation of highly reactive intermediates, from, for example, atomic iron and arenes. They then can be transformed into clusters, $\pi$ complexes, organoboron and phosphorus cages, and organic cycloadducts [1025].

In the photochemically generated tricarbonyliron complex of 9-fluorenylidene (tetramethylpiperidine)borane, the metal complex fragment is bonded in an $\eta^{4}$ fashion to a cis-borabutadiene unit, thereby strongly perturbing the aromaticity of one benzene ring. Consequently, the $\eta^{4}$ complex reacts readily with two-electron donors, to afford $\eta^{2}$ complexes [1026].

Additional carbon-carbon bond formations are: synthesis of $\left[\mathrm{Fe}_{2}(\mathrm{CO})_{6}(\eta-\mathrm{C}(\mathrm{OR}) \mathrm{H})\left(\eta-\mathrm{CR}^{\prime}=\mathrm{CR}^{\prime} \mathrm{H}\right)\right]^{-}$ anions $\left(\mathrm{R}=\mathrm{Me}, \mathrm{Et} ; \mathrm{R}^{\prime}=\mathrm{Ph}, \mathrm{H}\right)$ (at a dinculear iron center) [1027], synthesis of a new tert -butylnitroso complex $\left[\mathrm{CpFe}(\mathrm{CO})\left(\mathrm{PPh}_{3}\right) \mathrm{N}(\mathrm{O}) \text { tert }-\mathrm{Bu}\right]^{+} \quad\left(\mathrm{Cp}=\eta^{5}-\mathrm{C}_{5} \mathrm{H}_{5}\right) \quad[1028]$, synthesis of a new bis(phosphino)methanideiron complex $\mathrm{Cp}(\mathrm{CO}) \mathrm{Fe}\left(\mathrm{Ph}_{2} \mathrm{PCH} \mathrm{PPh}_{2}\right)$ [1029]; also preparation of derivatives from doubly-bridged diiron complexes of the type $\left[\left(\eta-\eta^{2}-\mathrm{ROC}(1) \mathrm{S}\right) \mathrm{Fe}_{2}(\mathrm{CO})_{6}(\eta-\mathrm{SMe})\right]$ (via ligand-exchange reactions) [1030], synthesis of cycloheptatriene complexes $\left(\eta^{3}-\mathrm{C}_{7} \mathrm{H}_{7}\right) \mathrm{Fe}(\mathrm{CO})_{3} \mathrm{EPh}_{3}(\mathrm{E}=\mathrm{Sn}, \mathrm{Pb})[1031]$, and synthesis of benzophenones through carbonylation of aryl iodides catalyzed by the $\mathrm{Fe}(\mathrm{CO})_{5}-\mathrm{CO}_{2}(\mathrm{CO})_{8}$ system [1032].

9.11.2 Stereoselectivity and Asymmetric Synthesis Cyclic and acyclic ( $\eta^{4}$-polyene) $\mathrm{Fe}(\mathrm{CO})_{3}$ complexes continue to attract attention as intermediates, particularly for asymmetric syntheses [31,122]. For such $\eta^{4}$-triene complexes as (tropone)- or (cycloheptatriene)- $\mathrm{Fe}(\mathrm{CO})_{3}$, interest has centered particularly on the regio- and stereoselectivity of reactions at the uncoordinated double bond [20-21]. (Tropone $) \mathrm{Fe}(\mathrm{CO})_{2}\left(\mathrm{PR}_{3}\right)$ complexes are attractive candidates due to their enhanced reactivity toward electrophiles [1033] or regiospecificity of the reactions of the derived dienyl salts with nucleophiles [1034]; furthermore, there is a possibility of using a chiral phosphine as a center of induction and resolution [1035]. The synthesis, structure, reactivity, and diastereoisomer separation of (tropone) $\mathrm{Fe}(\mathrm{CO})_{2} \mathrm{~L}$ complexes $\left(\mathrm{L}=\mathrm{PR}_{3},(+)\right.$-neomenthyldiphenylphosphine) have been described. Here, the changes in reactivity induced by phosphine substitution in (tropone) $\mathrm{Fe}(\mathrm{CO})_{3}$, and the application of (+)-neomenthyldiphenylphosphine as a new resolving center for this chiral complex, are highlighted [1036].

In the development of synthetic methodology that preferentially leads to the formation of a single enantiomer of a targeted chiral compound, of particular importance are carbon-carbon bond-forming reactions whose diastereo- and enantioselectivity are derived through the use of catalytic quantities of chiral transition-metal catalysts [41,257,279,283,464, 1037-1039]. For example, an elegant synthesis of oxazolines utilizing a gold(I)-catalyzed aldol reaction in the presence of chiral ferrocenylamine ligands that possess both planar and central chirality has been reported $[466,467,470]$. The mechanistic aspects of this interesting, carbon-carbon bond-forming reaction, using chiral ferrocenylamines (the Hayashi-Ito catalyst) have been studied in considerable detail $[468,1040]$. The stereochemistry of the metallocenes, and especially of 
ferrocene derivatives, has been a topic of considerable interest for many years [41,546]; the ferrocene derivatives have also been used as chiral ligands in asymmetric, catalytic processes [464,1041]. Diastereo-isomeric 1,2,3-trisubstituted ferrocenes have been synthesized via introduction of sulfur and phosphorus substituents into the ferrocene nucleus in chiral 1-(N,N-dimethylamino)ethylferrocene by stereoselective lithiation and reaction with electrophiles [1042]. An asymmetric synthesis took a big step forward because of the discovery of a cheap method for catalytic chiral epoxidation of unsubstituted alkenes. The new reaction creates two dissymmetric carbon atoms in one step [1043].

The ability of esterases and lipases to produce optically active alcohols by the kinetic resolution of racemic esters is well established [1044]. A new approach to the enzymatic resolution of racemates via stereoselective transformations catalyzed by enzymes in organic solvents constitutes a new chapter in modern synthetic methodology [1044-1050]. The enantioselective esterification of chiral alcohols using lipases in organic solvents [1047], and inter-esterification reactions involving chiral acyl units and achiral alcohols, have been described [1048]. A number of racemic primary and secondary alcohols were successfully resolved following acylation (e.g., transesterification) by using Pseudomonas lipase as an asymmetric catalyst in organic solvents [1045]. An indicative example is the enzymatic resolution of 1 -ferrocenylethanol. This organometallic compound is decomposed by water, thus making the conventional methodology of resolution in aqueous media impossible; in contrast, enzymatic transesterification in benzene [1051] or tert-butyl methyl ether [1052] results in facile resolution.

9.11.3 Ferrocene and Ferrocene Derivatives During this decade, there has been considerable interest in electron-transfer, chain-catalyzed organometallic reactions, i.e., reactions of organometallic complexes catalyzed by electrons or electron holes [1053-1055]. The intimate mechanism of the two-electron transfer (ET) process has attracted the interest of theoreticians and experimentalists for many years [1056-1057]. Two ET systems are useful redox mediators for energy conversion devices that require multi-electron steps. For example, the $\mathrm{x}$-ray crystal structure of the model mixed-arene ferrocene $\left[\left(\mathrm{FeC}_{5} \mathrm{Me}_{5}\right)_{2}\left(\eta^{2}, \eta^{10}\right.\right.$. biphenyl) $]^{+} \mathrm{PF}_{6}^{-}$showed a 37 -electron configuration, indicating that two-electron transfer proceeded with structural reorganization and stabilization in the second electron-transfer [1058]. This supplements a study [1059] on electron-transfer chelation of dithiocarbamate complexes, e.g., $\left[\mathrm{Fe}\left(\eta^{5}-\mathrm{C}_{5} \mathrm{R}_{5}\right)\left(\eta^{1}-\mathrm{SC}(\mathrm{S}) \mathrm{NMe}_{2}\right)\right.$ $\left.\left(\mathrm{CO}_{2}\right)\right](\mathrm{R}=\mathrm{H}, \mathrm{Me})$ catalyzed by ferrocenium salts $\left[\mathrm{Fe}\left(\mathrm{Cp}_{2}\right)\right]^{+}\left(\mathrm{PF}_{6}\right)^{-}$. Another related study involving ferrocenes reports $[1060]$ that, although most carbanions react with $\left[\mathrm{Fe}\left(\eta^{6}-\mathrm{C}_{6} \mathrm{Me}_{6}\right)_{2}\right]^{2+}\left(\mathrm{PF}_{6}^{-}\right)_{2}$ by electron-transfer without $\mathrm{C}-\mathrm{C}$ bond formation, functionalization of the mesitylene $\left(\mathrm{C}_{6} \mathrm{Me}_{6}\right)$ ligand can proceed via protection by a hydride; in this fashion, activation of a single aromatic ligand in a complex can be achieved.

A large number of interesting, cage hydrocarbons have been synthesized, and some attempts have been made to entrap a metal ion or a small neutral atom into the cavity of such cage hydrocarbons. A series of macrocyclic ferrocenes as molecular pivots has been developed, including superferrocenophane [1061], ferrocene-cryptands [1062], and inclusion of ferrocene in $\beta$ - or $\gamma$-cyclodextrin (cyclodextrin host-guest complexes) [1063]. A review of macrocyclic, receptor molecules includes a discussion on ferrocenyl ionophores and ferrocene-cryptand complexes [900]. An interest in macrocyclic (host) ferrocenes continues, with the synthesis of ferrocene-dicoronands, as possible biological regulators (e.g., mimicking of allosteric interactions) [1064].

A series of decaphenylmetallocenes has been extended by the synthesis and characterization of decaphenylferrocene having a novel, zwitterionic structure; the compound is readily protonated, to give $\left[\mathrm{Fe}\left(\eta^{5}\right.\right.$ $\left.\left.\mathrm{C}_{5} \mathrm{Ph}_{5}\right)\left\{\left(\eta^{6}-\mathrm{C}_{6} \mathrm{H}_{5}\right) \mathrm{HC}_{5} \mathrm{Ph}_{4}\right\}\right]^{+} \mathrm{X}^{-}$[1065]. Additional syntheses of ferrocenes include the synthesis of ferrocene-containing carbamates [1066], of 2,3-dimethylindole-ferrocenes [1067], and of cynichrodenylferrocenyl carbinol [1068]; also, of isocyanoferrocenes [1069], of azaferrocenes [1070], of 1,1-bis(tributylstannyl)ferrocene [1071], of ring-substituted ferrocenes [1072], and possibly, of a phosphorus analogue of ferrocene [1073].

9.11.4 Porphyrins and Cytochrome Enzymes The family of heme-containing enzymes called cytochrome P-450 are important in the degradation of xenobiotic agents and in the biosynthesis of steroids, and the mechanism of their inactivation has been an area of extensive research [1074-1076]. The many oxidative transformations performed by cytochrome P-450 on substrates can be classified into four main types: alkane and arene hydroxylation, heteroatom oxidation, dealkylation of heteroatoms, and alkene epoxidation [1076,1077]. Cytochrome P-450 enzymes, comprising iron porphyrins, constitute an extraordinarily versatile class of biological oxidation catalysts $[556,1078,1079]$. In their function as monooxygenases, they are responsible for the metabolism of endogenous, as well as exogenous, lipophilic substrates. For monooxygenase activity, molecular oxygen is bound by the heme iron(II). In a sequence of redox processes, the bound 
oxygen is cleaved, with formation of water and a high-valent oxoiron complex, believed to be Porph ${ }^{+}$ $\mathrm{Fe}(\mathrm{IV})=\mathrm{O}$ (a cation-radical). This oxoiron complex subsequently transfers its oxygen atom to the complexed substrate. A porphyrin-bridged cyclophane complex has been prepared in order to mimic monooxygenase activity and to serve as a supramolecular catalyst for the hydroxylation of polycyclic arenes. In methanol, such arenes as anthracene, acenaphthylene, and phenanthrene are firmly complexed in the nonpolar interior of a cyclophane complex $(\mathrm{M}=2 \mathrm{H})$. In 2,2,2-trifluoroethanol in the presence of iodobenzene, an iron(III)-cyclophane complex $(\mathrm{M}=\mathrm{FeBr})$ catalyzes the oxidation of acenaphthylene to acenaphthen-1one (65\% yield) [1080].

In regard to references [553 and 556], a useful addition concerning cytochrome $\mathrm{C}$ is in order. Cytochrome $\mathrm{C}$, a component of the respiratory chain, is an electron-transfer heme protein having a molecular weight of 12,500; the topic has been reviewed [1081], and recently discussed [1082, 1082a]. Cytochrome C exhibits a visible spectrum characteristic of heme-containing proteins (the Soret absorbance maximum is at $410 \mathrm{~nm} ; E=1.05 \mathrm{~mol}^{-1} \mathrm{~cm}^{-1}$ ). This protein is unusual, in that the heme prosthetic group is covalently attached to the protein backbone via thioether linkages involving cysteine residues, whereas histidine serves as an axial ligand to the ferric ion. Possible pathways for electron transfer from histidines 33 and 39 to the heme in cytochrome $\mathrm{C}$ have been discussed $[1082,1082 \mathrm{a}]$.

Photodynamic therapy is an experimental cancer treatment modality that effectively destroys cancer cells by interaction of light with a photosensitizing dye, presumably to form singlet oxygen [1083]. Some porphyrins have been shown to be particularly effective sensitizers in this regard. Several ether-ester linked oligomers containing between two and six hematoporphyrin units have been found to be biologically active and to show significant tumorcidal activity $[1084,1085]$. This study has now been extended to include some deuteroporphyrins, particularly the synthesis and use of regioselective methyl- and vinyl-deuterated hemins [1086].

Heme proteins participate in a diverse array of biochemical phenomena, including oxygen transport (hemoglobin) and oxygen activation (cytochrome P-450 enzymes). Recently, the self-assembly of a new porphyrin complex has been accomplished [1087,1088]; this novel analog of heme proteins has a hydrophobic groove that is a potential site for substrates. Synthesis of the complex, a template-driven, self-assembly process propelled by noncovalent interaction, begins with formation of an inclusion complex between a tetraaminoporphyrin and two cylindrical, O-methyl-substituted cyclodextrin species. Upon addition of sodium tetraphenylboron, a supramolecular complex forms that has eleven separate units: one porphyrin, two encapsulating cyclodextrins, two sodium ions, and six tetraphenylborones situated about the periphery. A hydrophobic groove between the cyclodextrins, lined with fourteen methyl groups, circumscribes the metal-binding site of the porphyrin. Replacement of the cyclodextrin moieties with other hosts may be useful in controlling substrate specificity (e.g., the size, shape, and hydrophobicity of the groove).

Chemists have designed a synthetic, five-part molecule that undergoes multistep electron-transfer to convert the energy of light into chemical potential, as in photosynthesis [1089]. The pentad consists of a carotenoid polyene (C), two porphyrin moieties (P), and two quinone groups (Q) linked linearly (C-P-P-P$\mathrm{Q}-\mathrm{Q})$. The excitation of one form of the pentad by light yields the charge-separated state $\left[\mathrm{C}^{\cdot+}-\mathrm{P}-\mathrm{P}-\mathrm{Q}-\mathrm{Q}^{\cdot-}\right]$, having a lifetime of $55 \mu \mathrm{s}$. Irradiation of another form of the pentad gives a similar charge-separated state having a longer lifetime $(340 \mu \mathrm{s})$. More than half of the initial excitation energy is preserved in the chargeseparated states. Thus, it appears that there is no a priori reason why the essential features of photosynthetic energy conversion cannot ultimately be reproduced successfully by use of man-made molecular devices.

Substrate activation by cytochrome P-450, and monosubstituted hydrazine reactions with myoglobin and hemoglobin, have revealed the formation of $\boldsymbol{\sigma}$-bonded alkyl- or aryl-iron(III) porphyrin complexes $[556,1090]$. The potential biochemical relevance of organometallic complexes has led in large part to the synthesis of $\sigma$-bonded alkyl- or aryl-iron(III) porphyrins. There are three primary routes for synthesis of the alkyl- or aryl-iron(III) porphyrins; these are (1) reaction of iron(III) porphyrins with a source of carbanions, (2) combination of an alkyl or aryl radical with an iron(II) porphyrin, and (3) reaction of iron(I) porphyrin anions with a source of carbocations, typically alkyl or aryl halides. The synthesis and characterization of the first paramagnetic alkyl- or aryl-iron(III) porphyrin complexes has been described [1091].

A variety of one-side-hindered iron porphyrins has been synthesized and studied [905-909]. The discrimination of binding between carbon monoxide and oxygen in model hemes may lead to a straightforward explanation of the natural regulatory mechanism. So far, there is only one demonstrated example of a model compound that exhibits a tilt of the $\mathrm{CO}$ relative to the heme that is normal in the solid state of the pocket porphyrin [1092]. In the series of hybrid, basket-handle porphyrins, the effect of a decrease in the length of 
the aliphatic chain spanning one side of the porphyrin is not to increase the degree of the tilt of the bound carbonyl but rather to increase the degree of ruffing of the porphyrin core [1093]. As a ${ }^{57} \mathrm{Fe}$ NMR study shows [1094], in the hybrid, basket-handle porphyrins, the ruffing leads to large changes in the iron- $d$-orbital energies that may be important in understanding ligand binding in heme proteins and models. Studies on porphyrins include the synthesis of $\mathrm{S} / \mathrm{N}, \mathrm{S} / \mathrm{O}$ mixed ligand complexes of iron(III) tetramesityl-porphyrin [1095], and synthetic and structural studies of a sapphyrin, a 22- $\pi$-electron pentapyrrolic "expanded porphyrin" [1096]; also, insertion of iron into porphyrins [1097], gable porphyrin metal complex as a double recognition model [1098], and fixation of amino acids with bifunctional metalloporphyrin receptor [1099]. Molecular recognition by chromoionophores and porphyrins is a new chapter in the chemistry of macromolecules. Molecular recognition, a "magic" expression in modern organic chemistry, circumscribes the already well known, and, for biochemical processes, particularly important phenomenon that certain molecular structures match and interact with each other. An example is the agonist-receptor interaction. The spectrum of receptor model compounds has been extended rapidly in the past few years, for example, by cleft structures, which are readily accessible by reaction of the Kemp tricarboxylic acid with benzene-1,3-diamine (or its dimethyl derivative). Derivatives of the Kemp triacid are useful as scaffolds for molecular recognition and as probes for stereoelectronic effects at carboxyl oxygen [1099a].

Other studies on iron porphyrins, including synthesis and spectral characterization, are iron(III) porphyrin-promoted aerobic oxidation of sulfur dioxide [1100], fluoride ion-promoted oxidative cleavage of ( $\eta$-oxo)iron(III) tetraarylporphyrins [1101], electrochemical and spectral characterization of stable iron(IV)tetrakis-5,10,15,20-( $N$-methyl-4-pyridyl)porphyrin in aqueous solution at room temperature [1102], reaction of dioxygen with paramagnetic $(\mathrm{S}=1 / 2)$ tetraarylporphyrin $\mathrm{Fe}$ (III) $\mathrm{CH}_{2} \mathrm{CH}_{2}$ dianion $[1103,1104]$; electrochemical characterization of intermolecular nitrosyl transfer between iron and cobalt porphyrins [1105], theoretical study of the electron density in iron(II) porphyrin bis(water) [1106], binding sites for nitrite binding in iron(III) porphyrinates [1107], instability of the nitrite-iron(III) porphyrinate system [1108]; synthesis and characterization of low-spin bis(imidazole) (tetraphenyl-porphyrinato)iron(II) complexes [1109], synthesis of five-coordinate mercaptoiron(II) porphyrins [1110], x-ray absorption spectral study of ferric, high-spin hemoproteins [1111], synthesis and optical properties of conformationally constrained trimeric and pentameric porphyrin arrays [1112], and related porphyrin pyrrole sequencing by mass spectrometry [1113].

9.11.5 Biological and Biochemical Applications Proteins and nucleic acids carry out specific functions, such as molecular recognition, information transfer, and catalysis, which depend in detail on the structure of each macromolecule. Cleavage of DNA or transfer RNA by metal chelates is an important new approach to characterizing structural features of nucleic acids and their complexes in solution [1114-1118], because chain scission by reactive oxygen species occurs close to where the redox-active metal complex is bound. Likewise, cleavage of a protein by metal complexes bound at a particular site could give information about the folding of the polypeptide chain [1119], or help in deducing the major secondary, and even tertiary, structure features in DNA and tRNA molecules [1117].

Specific cleavage of a protein has been achieved by introducing a metal-binding site at one position in a polypeptide chain. Thus, the iron chelate [Fe(II)-1-(p-bromoacetamido)-EDTA] attached to a residue on the protein bovine serum albumin was treated with $\mathrm{H}_{2} \mathrm{O}_{2} \mathrm{~L}$-ascorbate at $\mathrm{pH} 7.0$ and $25^{\circ} \mathrm{C}$, to give three peptide fragments which together account for the entire polypeptide chain [1118]. Cleavage of DNA or tRNA by the $\mathrm{Fe}(\mathrm{EDTA})^{2-}$ chelate is apparently mediated by hydroxyl radicals $[1116,1120]$, in contrast to the action of other transition-metal complexes [1118].

Interaction of bleomycin (an antitumor antibiotic), Fe(II), and limiting oxygen, or bleomycin, $\mathrm{Fe}$ (III), and $\mathrm{H}_{2} \mathrm{O}_{2}$ with the hexamer d(CGCGCG) (a hexa-nucleotide) results in the production of an oxidatively damaged sugar lesion, 2-deoxy-4-pentulose, that is produced stoichiometrically with respect to free nucleic acid base release. The implications of these results with respect to the mechanism of nucleic base release in bleomycin-mediated DNA degradation have been presented [1121].

Isopenicillin $\mathrm{N}$ synthase (IPNS) is a non-heme, $\mathrm{Fe}$ (II)-dependent enzyme found in $\beta$-lactam antibioticproducing microorganisms that catalyzes the formation of isopenicillin $\mathrm{N}$ from $\delta$-(L- $\alpha$-aminoadipoyl)-L-cysteinyl-D-valine (ACV) [1122]. Unlike the reactions catalyzed by the $\mathrm{Fe}$ (II)-containing dioxygenases, which incorporate the elements of dioxygen into their substrates [1123], the two oxidative ring closures of $\mathrm{ACV}$, forming $\beta$-lactam and thiazolidine rings catalyzed by IPNS, result in the complete four-electron reduction of 1 equivalent of dioxygen to 2 equivalents of water [1122]. Here, spectroscopic evidence for the metal-binding site of Fe-IPNS, and the nature of its endogenous ligands, was presented [1124]. 
Transferrins are globular proteins $\left(M_{\mathrm{r}}=80,000\right)$ acting as physiological iron carriers involved in the biosynthesis of hemoglobin and other iron-containing proteins [1125]. These double-site proteins show remarkable metal-binding properties that have led to the characterization of several metal-transferrin derivatives, both tripositive and dipositive metal ions [1126].

Nickel as a trace element in biology occurs in several enzymes; for example, [NiFe)-hydrogenase enzymes contain mononuclear nickel sites and $\mathrm{Fe}-\mathrm{S}$ clusters [1127-1128], and, in a [NiFeSe]-hydrogenase, a selenocysteinate residue is bound to nickel [1128]. Work related to [NiFe]-hydrogenases has been described [1129].

Self-assembly is a process by which organized supramolecular structures are spontaneously generated from their component molecular parts in high yield and specificity. Prominent biological examples [1130] are double-helix formation of nucleic acids [1131] and self-assembly of viral protein coats, or highly organized supramolecular entities (for example, membranes, ribosomes, and multicomponent enzyme complexes) from relatively simple subunits [1132]. In addition, it was proposed the self-assembly phenomenon might have been an essential component in the molecular events that comprise protobiogenesis [1130].

A new synthesis of the singly-bridged double cubane cluster $\left[\left(\mathrm{Fe}_{4} \mathrm{~S}_{4} \mathrm{Cl}_{3}\right)_{2} \mathrm{~S}\right]^{4-}$ tetraanion, involving coupling of two simple unfunctionized $\left[\mathrm{Fe}_{4} \mathrm{~S}_{4} \mathrm{Cl}_{4}\right)^{2-}$ dianions has been reported [1133]. This cubane cluster cannot, however, be prepared by well developed "spontaneous self-assembly reactions" [1134-1136], and thus its elaboration must be executed by use of a carefully controlled coupling reaction. Many other "spontaneous self-assembly reactions" that include formation of polynuclear metal complexes, multidentate ligands, and bridging ligands are well known; the topic has been discussed [1137] and reviewed [1138-1140].

9.11.6 Miscellaneous Recent Results New additions to the chemistry of organoiron complexes are the following: reaction of $\left[\left(\eta^{5}-\mathrm{C}_{5} \mathrm{H}_{5}\right)(\mathrm{CO}) \mathrm{Fe}\left\{\eta-\mathrm{C}\left(\mathrm{CF}_{3}\right)=\mathrm{C}\left(\mathrm{CF}_{3}\right) \mathrm{SMe}\right\}_{2} \mathrm{Fe}(\mathrm{CO})\left(\eta^{5}-\mathrm{C}_{5} \mathrm{H}_{5}\right)\right]$ with $\left[\mathrm{Fe}_{3}(\mathrm{CO})_{12}\right]$ (to yield di- and tri-nuclear iron-alkyne complexes) [1141], synthesis of $\mathrm{FeCH}(\mathrm{SR}) \mathrm{COC}$ $\left(\mathrm{CO}_{2} \mathrm{Me}\right)=\mathrm{C}\left(\mathrm{CO}_{2} \mathrm{Me}\right) \mathrm{S}(\mathrm{CO})\left(\mathrm{PR}_{3}\right)_{2}$ complexes [1142], synthesis of the novel $\eta^{2}$-carbido complex [(TPP) $\left.\mathrm{Fe}=\mathrm{C}=\mathrm{Re}(\mathrm{CO})_{4} \mathrm{Re}(\mathrm{CO})_{5}\right][1143]$, and synthesis of $\left(\eta^{5}-\mathrm{C}_{5} \mathrm{H}_{5}\right) \mathrm{Fe}(\mathrm{L}) \mathrm{S}_{2} \mathrm{CR}\left(\mathrm{L}=\mathrm{Ph}_{2} \mathrm{PCH}_{2} \mathrm{PPh}_{2} ; \mathrm{R}=\mathrm{Me}, \mathrm{Ph}\right)$ [1144], a new chemistry of iron-methylene complexes $\left[\mathrm{Fe}\left(\eta^{5}-\mathrm{C}_{5} \mathrm{Me}_{5}\right)(\mathrm{CO})(\mathrm{L})\left(=\mathrm{CH}_{2}\right)\right]^{+} \mathrm{BF}_{4}^{-}\left(\mathrm{L}=\mathrm{CO}, \mathrm{Ph}_{3}\right)$ [1145], Friedel-Craft acetylation of $(\mathrm{CO})_{2}(\mathrm{NO})\left(\eta^{5}-\mathrm{C}_{5} \mathrm{H}_{4}\right) \mathrm{CH}_{2}\left(\eta^{5}-\mathrm{C}_{5} \mathrm{H}_{4}\right) \mathrm{Fe}\left(\eta^{5}-\mathrm{C}_{5} \mathrm{H}_{5}\right)$ [1146], reaction of ditert -butylcyclopentadienyllithium $\mathrm{Li}\left[\eta^{5}-\mathrm{C}_{5} \mathrm{H}_{3}\left(\mathrm{C} \mathrm{Me}_{3}\right)_{2}-1,3\right]$ with $\mathrm{FeCl}_{2}$ [1147], reaction of the dianion [( $\eta$ $\left.\mathrm{Te})_{2} \mathrm{Fe}_{2}(\mathrm{CO})_{6}\right]^{2-}$ with metal halides [1148], reaction of $\alpha, \beta$-unsaturated aldehydes complexed at the $\mathrm{C}=\mathrm{C}$ bond with $\mathrm{Fe}(\mathrm{CO})_{3} \mathrm{~L}$ units $\left(\mathrm{L}=\mathrm{CO}, \mathrm{L}=\mathrm{P}(\mathrm{OMe})_{3}\right)$, with stabilized phosphoranes [1149]; also synthesis of $\left[\mathrm{Fe} \text { (diars) }(\mathrm{La})(\mathrm{CO})_{2}\left(\mathrm{CH}_{3}\right)\right]^{+}$(diars $=o$-phenylenebis(di-methylarsine) [1150], synthesis of bis(iron) $\eta^{1}-\mathrm{O}: \eta^{1}-$ $\left.\mathrm{O}^{1}\right)$ formate complexes, and their heterobimetallic analogs [1151], iron-promoted nitrene-extrusion reactions in 7-azanorbornadiene derivatives [1152], and regio- and diastereoselectivity in the rearrangement of cationic iron(II) $\eta^{1}-1-(1-$ methylcycloalkyl)methylidenes [1153].

Other work included the synthesis of heterobimetallic Fe(III)-Mn(II) complex (containing a heptadentate polyimidazole ligand) [1154], formation of iron thiolate complexes, for example, $\mathrm{FeH}(\mathrm{RS})(\mathrm{DMPE})_{2}$, and $\mathrm{Fe}(\mathrm{RS})_{2}(\mathrm{DMPE})_{2}$ [DMPE $=1$,2-bis(dimethylphosphino)enthane] [R=Ph-, $\left.\mathrm{CH}_{3} \mathrm{CH}_{2-},\left(\mathrm{CH}_{3}\right)_{3} \mathrm{C}-\right]$ [1155], photolysis of alkoxy-substituted disilanyliron complexes, e.g., $\mathrm{CpFe}(\mathrm{CO})_{2} \mathrm{SiMe}_{2} \mathrm{Me}(\mathrm{OMe})_{2}\left(\mathrm{Cp}=\eta^{5}-\mathrm{C}_{5} \mathrm{H}_{5}\right)[$ to afford novel, donor-stabilized bis(silylene)iron complexes] [1156], and thermal- and light-induced spin transition in the iron(II) spin-crossover complex [Fe(1-methyl-1H-tetrazole $\left.)_{6}\right]\left(\mathrm{BF}_{4}\right)_{2}$ [1157]. Other selected topics include synthesis of the chiral cluster $\left.\mathrm{Fe}_{3}(\mathrm{CO})_{9}\left[\eta^{3}-\mathrm{B}(\mathrm{H}) \mathrm{C}(\mathrm{H}) \mathrm{CMe}\right)\right](\mathrm{B}=$ boracyclopropene $)$ [1158], iron carbonyl complexes of isobenzofulvene [1159], iron-trichloride-phosphine adducts [1160], and protonation of $\mathrm{FeP}\left(\mathrm{CH}_{2} \mathrm{CH}_{2} \mathrm{CH}_{2} \mathrm{PMe}_{2}\right)_{3} \mathrm{H}_{2}$ with alcohols [1161]; preparation of the complex $\left(\mathrm{NEt}_{4}\right)\left[\mathrm{Fe}_{2}(\mathrm{CO})_{8}\left(\eta-\mathrm{AuPh}_{3}\right)\right]$ [1162], preparation of $\mathrm{Fe}_{2}{ }^{+}$-benzyne ion in the gas phase [1163], rearrangements of cyclopropanes $\sigma$-bonded to iron [1164], iron-catalyzed oxidation of bis(imidazol-2-yl)methane [1165], and synthesis and characterization of a new T-form hemoglobin model [1166].

Other studies reported on the resonance Raman spectra of iron(II) porphyrins [1167], electronic and steric effects in $\mathrm{Fe}(\mathrm{CO})_{2} \mathrm{~L}\left(\eta^{4}\right.$-benzylidene-acetone) [1168], the crystal structure of $\mathrm{Fe}_{3}(\mathrm{CO})_{10}\left(\mathrm{CNBu}^{t}\right)_{2}$ [1169], the crystal structure of the dimer $\left\{\mathrm{K}_{2} \mathrm{Fe}\left(\mathrm{C}_{2} \mathrm{O}_{2} \mathrm{~S}_{2}\right)_{2} \mathrm{NO} \cdot \mathrm{H}_{2} \mathrm{O}_{2}\right.$ [1170], and an ESR study of the spincross over complex [ $\mathrm{Fe}$ (2-aminoethyl)pyridine] $\mathrm{Cl}_{2} \cdot \mathrm{C}_{2} \mathrm{H}_{5} \mathrm{OH}$ [1171]; the dynamics of molecular hydrogen in the complex trans - $\left[\mathrm{Fe}\left(\eta^{2}-\mathrm{H}_{2}\right)(\mathrm{H})\left(\mathrm{PPh}_{2} \mathrm{CH}_{2}-\mathrm{CH}_{2} \mathrm{PPh}_{2}\right)_{2}\right] \mathrm{BF}_{4}$ (in the solid state) [1172], rotation of the cyclopentadienyl ligand in the Fe-Fe complex $\left(\eta-\mathrm{CO}_{2}\right)[\mathrm{FeCp}(\mathrm{CO})]_{2}\left(C_{\mathrm{p}}=\mathrm{ca} 70 \% \eta^{5}-\mathrm{C}_{5} \mathrm{H}_{5}\right)$ (in the solid state) [1173], the ESR spectrum of the $\mathrm{Fe}_{2}(\mathrm{CO})_{8}{ }^{-}$radical [1174], reaction of hydroxy radicals with $\mathrm{Fe}$ (II) complexes, e.g., $\left[\mathrm{Fe}\left(2,2^{\prime} \text {-bipyridyl }\right)_{3}\right]^{2+}$ and $\left[\mathrm{Fe}\left(2,2^{\prime} \text {-bipyridyl }\right)_{2}(\mathrm{CN})_{2}\right][1175]$, and the $\mathrm{x}$-ray crystal structure of iron dithiocarbamates, e.g., $\mathrm{Fe}\left(\eta^{5}-\mathrm{C}_{5} \mathrm{Me}_{5}\right)\left(\eta^{1}-\mathrm{SC}(\mathrm{S}) \mathrm{NMe}_{2}\right)(\mathrm{CO})_{2}$ and $\mathrm{Fe}\left(\eta^{5}-\mathrm{C}_{5} \mathrm{Me}_{5}\right)\left(\eta^{2}-\mathrm{S}_{2} \mathrm{CNMe}_{2}\right)\left(\mathrm{PPh}_{3}\right)$ 
[1176]. Further structural studies and reactions included a structural study of disilanes bridging two [ $\left(\eta^{5}-\right.$ $\left.\mathrm{C}_{5} \mathrm{H}_{n}\right) \mathrm{Fe}(\mathrm{CO})_{2}$ ] groups $(n=4,5)$ via both iron atoms or via both cyclopentadienyl ligands [1177], the crystal structure of the heteroatomic trinuclear cluster $\mathrm{Fe}_{2} \mathrm{Os}(\mathrm{CO})_{12}$ [1178], the binding and activation of halocarbons by iron(II) complexes; the halocarbon coordinated via $\sigma$-donation of a halogen lone pair with retention of their carbon-halogen bonds [1179]; electron mobility in electroactive polymer films of iron complexes of the type $\left[\mathrm{M}(\mathrm{v}-\mathrm{bpy})_{n}(\mathrm{~L})_{\mathrm{m}}\right](\mathrm{M}=\mathrm{Fe}, \mathrm{Ru}$; v-bpy =4-vinyl-4'-methyl-2,2'-bipyridine; $\mathrm{L}=\mathrm{CN})$ [1180], iron(III)induced cleavage of cyclic allylic hydroperoxides to dicarbonyl compounds [1181], and site-specific cleavage of proteins using the iron chelate of ethylenediaminetetraacetic acid (EDTA) [1182,1183].

9.11.7 Additional Miscellaneous Results Some pertinent reviews include: reactions of carbon dioxide catalyzed by transition-metal complexes [1184], oxo- and hydroxo-bridged diiron complexes in regard to a chemical perspective on a biological unit [1185], a classification of organometallic complexes [1186], and non-enzymatic, asymmetric transformations involving symmetrical, bifunctional compounds [1187].

Some pertinent books are concerned with the following topics: organometallic chemistry [1188], carbon dioxide activation by metal complexes [1189], carbyne complexes [1190], structure and reactivity [1191]; organometallic radical processes [1192], mechanisms of inorganic and organometallic reactions [1193], and spectroscopic properties of inorganic and organometallic compounds [1194].

Some pertinent books on biotransformations treat the following topics: enzyme catalysis processes [1195], dynamics of proteins and nucleic acids [1196], enzymes as catalysts in organic synthesis [1197], biotransformations in preparative organic chemistry [1198], biomineralization [1199], and bioseparations [1200]; a dictionary of biochemistry and molecular biology [1201], and metalloproteins, their chemical properties and biological effects [1202].

Other selected topics are summarized next. A study [1203] may serve to supplement an earlier report [1089] in providing a better understanding of the mechanism of electron transfer in photosynthesis. The fluorescence found in certain neutral porphyrin dimer complexes may help clarify the nature of the lowest excited state of the bacteriochlorophyll "special pair," the primary electron donor in the photosynthetic reaction center [1203].

Other pertinent studies included hydrogen-atom transfer vs electron transfer in iron(III) porphyrin catalyzed benzylic oxidations [1204], electrocatalytic hydroxylation of alkanes and identification of a fluoroiron(V) porphyrin intermediate [1205], and modulation of interprotein electron-transfer energetics by heme-ligand variation [1206].

Oxygen transfer to a nucleophilic addend typically involves the cleavage of a relatively weak oxygen-oxygen or metal-oxygen $\sigma$-bond [1077, 1207]. Chiral oxaziridines provide synthetically useful reagents for the asymmetric transfer of an oxygen atom to a variety of substrates such as sulfides and sulfoxides; the mechanism of oxygen transfer has been discussed [1208].

Electron transfer in biological systems (e.g., proteins) and electron relays that are bound to an enzyme (to give enzyme electrodes) is a topic of current interest [1209]. This comprehensive topic also includes electron transfer between porphyrin-bound $\mathrm{Fe}^{2+}$ centers and histidine-bound $\left[\mathrm{Ru}^{2}\left(\mathrm{NH}_{3}\right)_{5}\right]^{3+}$ ions $[1210,1211]$, electrical properties of enzyme proteins modified via ferrocene-ferricinium carboxylate electron relays [1212], biosensor electrodes based on ferrocenes [1213], biosensors in medicine [1214], chemical sensors [1215], and the interfacial electrochemistry of promoter-modified electrodes for rapid electron transfer of cytochrome $\mathrm{C}[1216]$.

The bleomycins are glycopeptide-derived antitumor antibiotics believed to exert their therapeutic effects via DNA degradation [1121,1217]. Bleomycin-mediated DNA degradation requires $\mathrm{O}_{2}$ and a redoxactive metal ion such as $\mathrm{Fe}, \mathrm{Cu}$, or $\mathrm{Mn}[1218,1219]$. Fe-bleomycin cleaves DNA by initial abstraction of $\mathrm{H}-4^{\prime}$ from 2-deoxy-D-ribose [1218-1220], by a putative high-valent iron-oxo species; the primary kinetic isotopeeffect for the cleavage reaction is $K_{\mathrm{H}} / K_{\mathrm{D}}=2.1-4.0$ [1220]. Extensive mechanistic studies of DNA degradation, including examination of $\mathrm{O}_{2}$ - vs $\mathrm{H}_{2} \mathrm{O}_{2}$-supported activation of Fe-bleomycin, have been addressed and discussed [1220-1222].

Other sequence-specific oxidative cleavages of DNA by designed metalloproteins have been reported [1223].

A kinetics study of how the tyrosine free-radical generated by an $\mathrm{Fe}(\mathrm{III})_{2}$ subunit can abstract a $\mathrm{H}$-atom from $\mathrm{C}-3^{\prime} 2 \mathrm{H}$ of $E$. coli ribonucleotide reductase has been reported [1224]. The subunit has been found to be similar to an $\eta$-oxo-bridged $\mathrm{Fe}(\mathrm{III})_{2}$ site of hemerythrin [1225]. 
The non-heme iron monooxygenase system from Pseudomonas oleovorans was examined for possible octene epoxidation. There was no evidence for the involvement of an iron-carbene species in the mechanism of octene epoxidation by $P$. oleovorans monooxygenase [1226].

Porphyrins that contain metal-oxo bonds have been extensively studied as models for the active sites of the heme protein of the peroxidases, catalases, and cytochrome P-450. Catalases decompose hydrogen peroxide to afford oxygen and water, whereas peroxidases oxidize organic and inorganic substrates via reaction with peroxides and other oxidants. The active sites of both enzymes are porphyrin cation radicals that contain ferryl $(\mathrm{Fe}=0)$ bonds. Cytochrome P-450 [556,1227], which hydroxylates a variety of organic molecules (e.g., hydroxylation of $\mathrm{C}-\mathrm{H}$ bonds) via an oxygen atom transfer mechanism, reduces molecular oxygen, to generate a ferryl intermediate. Studies on this putative iron-oxo species are difficult, and efforts have been directed to synthetic iron porphyrins as models for the heme porphyrins [1228]. Resonance Raman spectroscopy has been used extensively to characterize the metal-oxo bonds in ferryl porphyrins $[1229,1230]$. It is now generally recognized that binding of ligands to heme proteins is regulated by multiple free-energy barriers [1231].

Other work includes the catalytic [1232] and photophysical [1233] properties of porphyrins or tetraarylporphyrins [1234] anchored to synthetic vesicles, and ${ }^{1} \mathrm{H}$-NMR studies of iron(III) porphyrins [1235].

Asymmetric synthesis has emerged as a rich and rapidly developing area of chemistry, combining elements of organic synthesis, molecular recognition, metal coordination chemistry, and catalysis. Of the various strategies for exploiting the pool of chiral compounds available, catalytic asymmetric induction offers the distinct advantage of chemical amplification of the asymmetry of the catalyst.

The discovery that iron porphyrins will catalyze alkane hydroxylation and alkene epoxidation in the presence of such oxygen donors as iodosylbenzene [1236] has provided an opportunity to use synthetic porphyrins for modeling the oxygen-transfer reaction of cytochrome P-450 [1237]. Chiral metalloporphyrins have been shown to mediate catalytic, asymmetric oxygen-transfer, to afford optically active epoxides from prochiral alkenes [1238]. Similar behavior has been reported for chiral "basket-handle" porphyrins [1239]. Regioselective epoxidation [1240] and hydroxylation [1241] have also been achieved with membrane-spanning metalloporphyrins encapsulated in synthetic vesicles. Here, the synthesis and characterization of new vaulted porphyrins with a chirotropic binaphthyl bridge has been described. The iron(III) and manganese(III) derivatives of this porphyrin have proved to be robust catalysts for alkene epoxidation, sulfoxidation, and asymmetric hydroxylation [1242].

Additional new information on ferrocene includes: synthesis and oxidation of ferrocene-capped cobalt clathochelates [1243], synthesis of a linear polymer $\omega$-ferrocenecarboxamido- $\alpha$-methoxypolyethylene oxide [1244]. The synthesis and structure of [1] ferrocenophanes containing $\mathrm{Ti}, \mathrm{Zr}$, and $\mathrm{Hf}$ in the bridge [1245], and the synthesis of a ferrocene with a pentaarsacyclopentadienyl ligand [1246]; alkoxymethylation of ferrocenylalkenes [1247], the influence of steric hindrance on the lithiation of ferrocenylalkylamines [1248], the dynamics of ferrocene in a thiourea inclusion matrix [1249], and the coadsorption of ferrocene alkanethiols on gold films [1250] have also been studied.

9.11.8 Additional Results Metal-catalyzed oxidation of organic compounds is an expanding area of organic chemistry, with many applications in industrial processes [1251,1252]. Macrocylic metal complexes, in particular metalloporphyrins, have attracted attention as mild aerobic catalysts in oxidation reactions [1253].

The synthesis and characterization of the "picnic basket" porphyrins, which have a rigid cavity of variable dimensions on one face of the porphyrin ring have been described [1254]. The picnic basket system was designed to effect catalytic, shape-selective oxygenations [1232,1255] and thus to mimic the enzyme family cytochrome P-450.

Of the various oxidation reactions catalyzed by cytochrome P-450 enzymes, benzylic hydroxylation is a particularly favorable process. Important examples include toluene [1256], the antioxidant BHT [1257], the analgesic alkaloid morphine [1258], and the carcinogen dimethylbenz[a]anthracene [1259]. For these otherwise diverse substrates, it might logically be assumed that benzylic hydroxylation [1204] is favored over other possible reactions because of resonance stabilization of benzylic intermediates and the transition states leading to their formation [1260].

The bleomycins constitute a family of antitumor antibiotics that are considered to elicit their chemotherapeutic effects via degradation of chromosomal DNA [1217]. Studies carried out in cell-free systems using isolated DNAs have indicated that DNA degradation involves metallobleomycins that are activated in the presence of dioxygen and subsequently bind to and degrade substrate DNAs [1261]. 
Bleomycin-mediated DNA degradation is sequence-selective, as a study on the interaction of bleomycin with a methylated DNA oligonucleotide indicated. The extent of DNA cleavage by Fe-bleomycin $\mathrm{A}_{2}$ can be diminished substantially in proximity to (5)-methylated cytidine residues [1262].

Iron tyrosinate proteins are now recognized as a distinct class of non-heme proteins, that includes transferrins, the purple acid phosphatases, and a number of aromatic ring-cleaving dioxygenases [1263,1264]. These proteins all contain high-spin Fe(III) characterized by a $g=4.3$ EPR signal and a strong absorption band in the $400-600 \mathrm{~nm}$ range $\left(e_{\mathrm{M}}=20000-40000 \mathrm{~m}^{-1} \mathrm{~cm}^{-1}\right)$ due to a phenolate oxygen (a tyrosine ligand) to iron(III) charge-transfer (CT) transition [1265].

The enzyme lipoxygenase plays an important role in polyunsaturated fatty acid metabolism in plants and animals. In circulating blood cells, lipoxygenase inaugurates the biosynthesis of the leukotrienes, a family of mediators of medically relevant biological activities [1266]. The enzyme has received considerable research attention from chemists in recent years. Lipoxygenase catalyzes a stereospecific autoxidation reaction and has been used in the preparation of synthetically useful chiral moieties [1267]. The enzyme also contains an unusual non-heme iron atom in an as yet unidentified structural environment [1268]. The role of the iron atom in catalysis has become the focus of studies of the mechanism of action of lipoxygenase [1269, 1270].

A new iron(III) catalyzed degradation of aliphatic aldehydes to their lower homologues, with implications for lipid peroxidation chemistry, has been described [1271].

Efforts have been directed towards developing oxide-bridged $\mathrm{Fe}$ carboxylate chemistry, particularly high nuclearity [799] $\mathrm{Fe}$ carboxylates $\mathrm{Fe}_{6}, \mathrm{Fe}_{8}, \mathrm{Fe}_{11}$, and $\mathrm{Fe}_{16} \mathrm{M}(\mathrm{M}=\mathrm{CO}, \mathrm{Mn})[1272,1273]$.

The mutual interaction of aromatic rings of aromatic amino acid residues in proteins and peptides has been discussed [1274]. Incorporation into peptides and proteins of amino acids having a covalent link between their aromatic rings would give the stabilization of the tertiary structure of a protein, with interesting biological consequences. The $1,1^{\prime}$-disubstituted ferrocenyl amino acid $\left[1,1^{\prime}\right.$-ferrocenylbis(alanine)] may be considered to be an analog of two aromatic amino acids having conformationally locked side-chains, and its synthesis (to give optically active material) has been described [1275].

Chiral recognition to the extent of 30:1 has been observed in the reaction between the homochiral iron acyl complex $\left[\left(\eta^{5}-\mathrm{C}_{5} \mathrm{H}_{5}\right) \mathrm{Fe}(\mathrm{CO})\left(\mathrm{PPh}_{3}\right) \mathrm{COCH}_{2} \mathrm{OCH}_{2} \mathrm{Ph}\right]$ and racemic 1-phenylethyl bromide [1276].

Reagents that react specifically with protein chains and deoxyribonucleic acid (DNA) are extremely useful in chemistry and biology. A few biological cleavage reagents are based on iron-EDTA complexes. The substitution and redox reactions of ethylenediaminetetraacetic acid (EDTA) and related polyamino carboxylate complexes of $\mathrm{Fe}$ (II) and $\mathrm{Fe}$ (III) have increasingly received attention for the sequence-specific cleavage of DNA [1277-1279]. In addition, a number of mechanistic studies have been reported on the Fe(II/III)/ $\mathrm{H}_{2} \mathrm{O}_{2} / \mathrm{HO}_{2}^{-}$system and for related polyamino carboxylate complexes [1280,1281].

The ability to bind and sever double helical DNA at a particular sequence of bases in the presence of a vast number of other sequences of bases is one of the central challenges in molecular biology. Restriction enzymes carry out such a reaction, but most restriction enzymes, useful as they are, recognize only four to six DNA base pairs, although a few recognize eight base pairs. Progress has been made in recognition by the pyrimidine oligonucleotide of thymine-adenine base pairs in duplex DNA [1282] and in designing of oligonuceotides capable of binding alternate strands of DNA [1283]. Coupled with this study, research on yeast chromosome advanced toward a practical method of producing sequence-specific, DNA-cleavage reagents targeted toward a large number of potential binding-sites. It has been shown [1284] that a synthesized 20-base pyrimidine oligonucleotide (EDTA-Fe) ${ }_{2}$ reagent cleaves the yeast chromosome into two fragments that are about 230,000 and 110,000 base pairs in length. Thus, the reagent binds to, and severs, the chromosome of the almost 14 million base-pairs of DNA that make up the yeast genome.

The ability of chemical reagents selectively to cleave peptides and proteins at defined sequences can greatly facilitate studies of protein structure and function. Protein-cleavage reagents permit sequence analysis of large or blocked proteins, functional analysis of protein domains, and structural analysis of receptors; the could also lead to the development of new therapeutic agents. A new EDTA reagent has been found effective in cleavage of calmodulin, a calcium receptor protein that plays an important role in cellular regulation. The reagent consists of the iron chelator EDTA covalently bound to the calmodulin antagonist trifluoroperazine -EDTA (TFE). In the presence of Fe(II) and oxygen, TFE oxidatively cleaves the protein to produce six major cleavage fragments. The cleavage reagent only cleaves calmodulin that has bound four calcium ions [1182]. 
A similar cleavage reagent targets the protein streptavidin, a protein that binds biotin. Here, EDTA is attached to biotin, which then delivers redox-active copper or iron to the binding sites of the protein. In the presence of oxygen and $\mathrm{Fe}$ (III) or $\mathrm{Cu}(\mathrm{II})$, the biotin-EDTA reagent (in which the two groups are closely linked) cleaves streptavidin in a manner that suggests that the cleavage reaction occurs close to the biotin site of the protein. Biotin completely inhibits the cleavage reaction [1183].

Purple acid phosphotases are important iron-containing, non-heme proteins that catalyze the hydrolysis of activated phosphoric esters [1285,1286]. A new synthesis of $\mathrm{Zn}$ (II)Fe(III) and $\mathrm{Fe}$ (II)Fe(III) complexes containing an ( $\eta$-phenoxo)bis( $\eta$-diphenylphosphato)-dimetal(II,III) core as a model complex for an active site of purple phosphatase has been reported [1287].

The role of conformational changes of cytochrome $C$ that occur during electron transfer with its in vivo reaction partners has attracted some attention [1288]. Here, the rate of conformational changes of cytochrome $\mathrm{C}$ during electron transfer, determined by double potential step chronoelliptometry, has been reported [1289].

Chiral ferrocene derivatives are highly useful ligands for homogeneous asymmetric catalysis [1290] and peptide synthesis [1291]. They have been prepared by using classical resolution techniques [1292] and subsequently by enzymatic kinetic resolution [1293]. An efficient method for the synthesis of $(R)$-1-ferrocenylethylamine and 1-ferrocenylethyl acetate via highly diastereoselective hydride reduction of the corresponding imine has been reported [1294].

There is broad agreement that the carbon dioxide content of the atmosphere and the earth's climate are closely linked. Carbon dioxide is the most important of the "greenhouse" gases, which also include methane and chlorofluorocarbons. An intriguing scientific hypothesis is that the iron content of some large expanses of ocean may actually determine the biological productivity of those waters. Consequently, "fertilizing" the ocean with iron might be able to control, in part, the level of carbon dioxide in the atmosphere [1295].

One of the proposed models [1296] incorporates the notion of a "biological pump," that is, photosynthetic uptake of $\mathrm{CO}_{2}$ by the chlorophyll-containing marine microorganisms known as phytoplankton, and subsequent removal of carbon to the deep ocean when the remains of the phytoplankton sink away from the surface. When the pump is functioning efficiently, atmospheric $\mathrm{CO}_{2}$ levels are low, and vice versa.

Ferritin is a protein that is widespread in nature, including bacteria, plants, and animals, and its function is usually associated with iron storage, e.g., biomineralization of iron [1199,1297].

Although the presence of metalloporphyrins in fossil fuels has been recognized for more than fifty years, it is only recently that iron porphyrins have been satisfactorily identified in coals and lignites [1298]. In recent years, there has been extensive study of the paramagnetically shifted H-NMR spectra of iron porphyrins, especially in relation to hemoprotein structure $[1299,1300]$.

9.11.9 Pertinent Books and Reviews $\mathrm{A}$ book on the chemistry and biochemistry of $N$-substituted porphyrins has been published [1301]; it reviews, and critically evaluates, the field of $N$-substituted porphyrins and their metal complexes; among the topics discussed are spectroscopic properties, and inhibition of ferrochelatase and cytochrome P-450.

A book on the spectroscopy of iron porphyrins and heme proteins has been published [1302].

Another book, on organic transformations, has appeared [1303]; the volume (1160 pages) covers a wide area of interest to the organometallic chemist, including, for example, new synthetic methods, enantioselective catalysts, and metal-promoted coupling reactions.

A useful addition to the library of the organometallic chemist is a book on reactions of coordinated ligands [1304]; it discusses reactions of coordinated $\mathrm{CO}_{2}$ and $N, N$-dialkylcarbamates, hydrolysis and condensation reactions of $O$ - and $N$-bonded ligands, reactions of coordinated phosphorus and sulfur ligands, and other topics.

New aspects of organic chemistry have been discussed in a monograph [1305].

Pertinent reviews include metallocenes as reaction intermediates [1306], main-group metallocenes (recent developments) [1307], porphyrin-quinone compounds as synthetic models of the reaction center in photosynthesis [1308], enzymatic catalysts in organic synthesis [1309], from natural cleomycins to mandesigned cleomycins [1310], molecular recognition and metal ion template synthesis [1311], transition-metal templates as guides for cycloaddition [1312], a new approach for natural-product synthesis using main-group organometallic reagents [1313], advances in catalytic asymmetric reactions promoted by transition-metal complexes [1314], stereoselectivity of intermolecular, free-radical reactions [1315], phosphaalkynes and phosphaalkenes [1316], transition-metal complexes of unsaturated carbenes [1317], heterometallic, sulfide- 
bridged clusters of transition elements [1318], and highly reactive intermediates from condensation reactions of iron, cobalt, and nickel vapors with arenes [1319].

9.11.10 Other Miscellaneous Results Additional new work included addition of halogencarbons to alkenes in the presence of $\left[\mathrm{Fe}_{2}(\mathrm{CO})_{4}\left(\eta-\mathrm{C}_{5} \mathrm{H}_{5}\right)_{2}\right][1320]$, use of $\left[\mathrm{Fe}(\mathrm{CO})_{3} \mathrm{NO}\right]^{-}$for the carbonylation of primary, secondary, and allylic halides [1321], a new synthesis of azaferrocene, $\left(\eta^{5}-\mathrm{C}_{4} \mathrm{H}_{4} \mathrm{~N}\right)\left(\eta^{5}-\mathrm{C}_{5} \mathrm{H}_{5}\right) \mathrm{Fe}$ [1322], synthesis of $\mathrm{Fe}_{2}(\mathrm{CO})_{6}\left(\eta-\mathrm{CRCR}^{1} \mathrm{COEtH}\right)$ complexes $\left(\mathrm{R}=\mathrm{R}^{1}=\mathrm{Ph} ; \mathrm{R}=\mathrm{Ph}, \mathrm{R}^{1}=\mathrm{Me}\right)$ [1323], 1,3- dipolar cycloaddition to the $\mathrm{C}=\mathrm{N}-\mathrm{Fe}$ fragment [1324], rearrangement of $\eta^{5}-\mathrm{C}_{5} \mathrm{H}_{5}(\mathrm{CO})_{2} \mathrm{Fe}-\eta^{1}$-homoallylidene to $\eta^{5}$ $\mathrm{C}_{5} \mathrm{H}_{5}(\mathrm{CO})_{2} \mathrm{Fe}-\eta^{1}$-allylidene [1325], reaction of allene episulfide with $\mathrm{Fe}_{2}(\mathrm{CO})_{9}$ [1326], reaction of [bis(dimethylgermyl)alkane] iron tetracarbonyls with carbonyl compounds [1327], and synthesis of a new organic conductor, bis(ethylenedithio)tetratiafulvalene-iron oxychloride [1328].

Other studies reported on the photochemical insertion of alkenes into the S-S bond of cluster $\left[(\mathrm{CO})_{3} \mathrm{FeS}\right]_{2}$ [1329], insertion of a methylene group into the Te-Te bond of $\mathrm{Fe}_{2}(\mathrm{CO})_{6}\left(\eta^{2}-\mathrm{Te}_{2}\right)$ [1330], the molecular structure of the binuclear complex $\mathrm{Fe}_{2}(\mathrm{CO})_{6}\left(\eta-\mathrm{PhNC}(\mathrm{O}) \mathrm{C}_{6} \mathrm{H}_{4} \mathrm{NH}\right)$ synthesized from $\mathrm{Fe}(\mathrm{CO})_{6}$ and azobenzene [1331], formation and properties of a $\mathrm{NiFe}_{3} \mathrm{~S}_{4}$ cluster in Pyrococcus furiosus ferredoxin [1332], x-ray structure of cluster $\mathrm{Au}_{2} \mathrm{Fe}_{2} \mathrm{Ir}\left(\eta^{4}-\mathrm{C}_{2} \mathrm{Ph}\right)(\mathrm{CO})_{7}\left(\mathrm{PPh}_{3}\right)_{3}$ [1333], synthesis of a "cascade-type" quest organotin(IV) coordination polymer $\left[\left(\mathrm{Me}_{3} \mathrm{Sn}\right)_{4} \mathrm{Fe}(\mathrm{CN})_{6} \cdot 2 \mathrm{H}_{2} \mathrm{O} \cdot \mathrm{C}_{4} \mathrm{H}_{8} \mathrm{O}_{2}\right] \infty$ [1334], reaction of carbido cluster $\mathrm{Fe}_{5} \mathrm{C}(\mathrm{CO})_{15}$ with metallic $\mathrm{As}$ and $\mathrm{Bi}[1335]$, and $\mathrm{x}$-ray diffraction study of a pyramidal cluster $\left[\mathrm{Fe}_{5} \mathrm{C}(\mathrm{CO})_{12}\left(\mathrm{PMe}_{3} \mathrm{Ph}\right)_{3}[1336,1337]\right.$, the crystal structure of the mixed-valence $1^{\prime}, 1^{\prime \prime \prime}$-dibenzylbiferrocenium cation [1338], substitution reactions of the solvent-coordinated acyl complexes, e.g., $\left(\eta^{5}-\mathrm{C}_{5} \mathrm{H}_{5}\right)$ $\left(\mathrm{CH}_{3} \mathrm{COCH}_{3}\right) \mathrm{FeCOMe}^{a_{+}+}$involving thioethers [1339], and $\mathrm{MO}$ theory into the problem of the $\mathrm{Fe}-\mathrm{Fe}$ bond in $\mathrm{Fe}_{2}(\mathrm{CO})_{9}[1340]$. Other selected topics include kinetic and photochemical studies of $\mathrm{FeC}_{5} \mathrm{H}_{6}^{+}$in the gas phase [1341], gas-phase reactions of $\mathrm{Fe}^{+}$with aromatic compounds [1342], binuclear iron(III) complexes with squarate as a bridging ligand [1343], synthesis of macrocyclic tetraamide five-coordinate iron(IV) complex [1344], of boron-containing macrocyclic iron(II) complexes [1345], of octahedral hydrido stannyl complexes of iron [1346], and of a $\mathrm{Fe}_{4} \mathrm{~S}_{4}$ cubane-type iron-sulfur protein analog [1347]. Other topics covered are: acetolysis of ferrocenylmethyl benzoate [1348], mixed arene ferrocenes [1349,1349a], pyrrolyl iron complexes (octamethyl-1,1'-diazaferrocene) [1350], monoacetylferrocene thiosemicarbazone complexes [1351], ferrocene-containing cryptands [1352], picket fence porphyrins [1353], chiral "single-armed" porphyrins [1354], crystal structure of $\mathrm{BiFe}(\mathrm{CN})_{6} \cdot 4 \mathrm{H}_{2} \mathrm{O}$ [1355], crystal structure of $N$-methyl-substituted $\eta$-oxo diiron(III) tetraphenylporphyrin [1356], x-ray structure of iron dimer $\left[\left(\mathrm{CH}_{2} \mathrm{COCH}_{2}\right)(\mathrm{CO})_{3} \mathrm{Fe}\right]_{2}[1357]$, crystal structure of $\left[\mathrm{Fe}_{2}(\mathrm{CO})_{6}\left(\eta-\mathrm{PPh}_{2}(\eta \mathrm{CPh}=\mathrm{CPhH})\right.\right.$ [1358], synthesis of a tripledecker $2 \pi$-ligand $\mathrm{RPFe}_{2}(\mathrm{CO})_{6}$ [from cluster $\left.\mathrm{Fe}_{3}(\mathrm{CO})_{10}\left(\eta^{3}-\mathrm{RP}\right)\right]$ [1359], reaction of $O$-fluorolithiobenzene with dicarbonyl ( $\eta^{5}$-cyclopentadienyl) iodoiron [1360], photo-induced redox reaction of $\mathrm{Fe}\left(2,2^{\prime}\right.$-bipyridine $)(\mathrm{CN})_{4}^{2-}[1361]$, and high-affinity iron-chelating agents for clinical use [1362]. Other pertinent articles treat the study of the iron-phosphorus bond (e.g., ligand effects) [1363], four-legged piano-stool structures (a theoretical study) [1364], structural study of bis(thiocyanato)bis(2,2'-bi-2-thiazoline) iron(II) complexes [1365], ET reactions of $\mathrm{Fe}$ (II) and $\mathrm{Fe}$ (III) bis(oxime-imine) complexes [1366], reaction of iron-alkene ions with chlorobenzene in the gas phase [1367], magnetic characterization of $\left[\mathrm{Fe}\left(\mathrm{C}_{5} \mathrm{Me}_{5}\right)_{2}\right]^{+}\left[\mathrm{TCNQI}_{2}\right]^{--}$(electron-transfer complexes) [1368], and MO analysis on the dimer $(\mathrm{CO})_{3} \mathrm{Fe}(\eta-\mathrm{CO})_{3} \mathrm{Fe}(\mathrm{CO})_{3}$ and related tetranuclear clusters [1369]. Other studies included that of conversion of 2,5-dihydrothiophene 1,1-dioxide into highly functionalized ( $\eta^{4}$-buta-1,3diene) tricarbonyliron ( 0 ) complexes [1370], an efficient method for studying biosynthetic oxidation by using cytochrome P-450 inhibitors [1371], oxidation of aldehydes by an iron(III) porphyrin complex-m-chloroperbenzoic acid system [1372], formation of iron acetylides and diacetylides via complexes of molecular hydrogen [1373], an electron-transfer-chain-catalyzed chelation of the dithiocarbonate ligand in $\mathrm{Fe}\left(\eta^{5}-\mathrm{C}_{5} \mathrm{Me}_{5}\right)(\mathrm{CO})_{2}$ [1374], metal complexes of macrocyclic polyamines [1375], structural studies of $\mathrm{Fe}_{4} \mathrm{~S}_{4-}$ siroheme and related heme proteins [1376], reactions of dimethylamine with multiply charged ions of cytochrome $\mathrm{C}$ [1377], observation of the $\mathrm{Fe}(\mathrm{II})-\mathrm{O}_{2}$ stretching Raman band for cytochrome oxidase compound A [1378], and some new chiral, analytical techniques [1379].

\section{Acknowledgments}

The author is thankful to Prof. Rene Grée and Prof. John A. Gladysz for preprints, Prof. Arthur J. Birch for reprints, and Dr. Lorna Sniegoski and Dr. Polly Ellerbe for proofreading. 


\section{References}

[1] Colquhoun, H. M., Horton, J., Thompson, D. J., and Twigg, M. V., New Pathways for Organie Synthesis: Practical Application for Transition Metals, Plenum Press, Ncw York (1984).

[2] Bergman, R. G., Science 223, 902 (1984); Evans, D. A., Seience 240, 420 (1988).

[3] Shrock, R. R., Scienee 219, 13 (1983); J. Organomet. Chem. 300, 249 (1986).

[4] Marko, L. J., Organomet. Chem. 305, 333 (1986).

[5] Bosnich, B., Ed., Asymmetric Catalysis, Martinus Nijhoff Publ. Dordrecht (1986).

[6] Halpern, J., Science 227, 869 (1985).

[7] Marks, T. J., Seienee 227, 881 (1985).

[8] Trost, B. M., Angew. Chem. 98, 1 (1986); Angew. Chem. Int. Ed. Engl. 25, 7 (1986); Angew. Chem. 101, 1199 (1989); Angew. Chem. Int. Ed. Engl. 28, 1173 (1989).

[9] King, R. B., Stone, F. G. A., Summitt, R. S., and Adgell, E. W., Inorg. Synth. VII, 193 (1963).

[10] Alper, H., in Organie Syntheses via Metal Carbonyls, Wender, I., Pino, P., Eds., John Wiley, New York (1977), Vol. 2 pp. 545-585.

[11] A recent Gmelin series on organoiron eompounds covers exhaustively mononuclear and polynuelear iron complexes, e.g., ( $\eta^{5}-\mathrm{cy}-$ clohexa-1,3-diene) irontriearbonyl complexes and complexes with $C_{7}-C_{9}$-membered ring systems; also mononuclear iron complexes with two-carbonyl ligand such as $\left(\eta^{5}-\mathrm{C}_{5} \mathrm{H}_{5}\right) \mathrm{Fe}(\mathrm{CO})_{2}$ have been covered; see Gmelin Handbook of Inorganic Chemistry. Fe-Organoiron Compounds, Springer-Verlag, Berlin, Part B8 (1985); Part B9 (1985); Part B10 (1986); Part B12 (1987).

[12] Kerbcr, R. C., J. Organomet. Chem. 318, 157 (1987).

[13] Hegedus, J. W., J. Organomet. Chem. 261, 283 (1984).

[14] Birch, A. J., and Jenkins, I. D., in Transition Metal Organometallics in Organic Synthesis, Alper, H., Ed., Academic Press, New York (1976), Vol 1. pp. 1-82. Bireh, A. J., and Kelly, L. F., J. Organomet. Chem. 285, 267 (1985).

[15] Twigg, M. V., Ed., Mechanisms of Inorganic and Organometallie Reactions, Plenum Press, New York (1986), Vol. 4. Sweigart, D. A., in Mechanism of Inorganic and Organometallic Reactions, Twigg, M. V., Ed., Plenum Press, New York (1985), Vol. 3, Chapter 10, pp. 263-281; J. Am. Chem. Soe. 110, 2109 (1988). For properties of a short-lived intermediate $\mathrm{Fe}(\mathrm{CO})_{4}$, see Poliakoff, M., and Weitz, E., Aec. Chem. Res. 20, 408 (1987).

[16] Therien, M. J., and Trogler, W. C., J. Am. Chem. Soc. 109, 5127 (1987) and referenees 1-18 cited therein. See also MaeKenzie, V., and Tyler, D. R., J. Chem. Soc. Chem. Commun. 1783 (1987) and referenees 1-2 therein.

[17] Lauer, J. W., J. Am. Chem. Soc. 108, 1521 (1986).

[18] Jaouen, G., in Transition Metal Organometallics in Organic Synthesis, Alper, H., Ed., Academic Press, New York (1978), Vol. 2, Chapter 2, pp. 65-120.

[19] Semmelhaek, M. F., Pure Appl. Chem. 53, 2379 (1981).

[20] Pearson, A. J., Metallo-Organic Chemistry, John Wiley \& Sons, Chichester-New York (1985).

[21] Pearson, A. J., Acc. Chem. Res. 13, 463 (1980).

[22] Parkins, A. W., and Poller, P. C., An Introduction to Organometallic Chemistry, Maemillan Publishers (1986).

[23] Mann, B. E., Chem. Soc. Rev. 15, 67 (1986).

[24] Kegley, S. E., and Pinhas, A. R., Problems and Solutions in Organometallic Chemistry, Oxford University Press (1987).

[25] Ho, T.-L., in Organic Synthesis by Oxidation with Metal Compounds, Mijs, W. J., and de Jonge, C. R. H. I., Eds., Plenum Press, Ncw York (1986), Chapter 11, pp. 569-631. For supported (silica gel) ammonium eerium(IV) nitrate as oxidizing agent, see Fiseher, A., and Henderson, G. N., Synthesis 641 (1985).

[26] Shvo, Y., and Hazum, E., J. Chem. Soc. Chem. Commun. 336 (1974). Trimethylamine N-oxidc is now a wcll established procedure to promote substitution of $\mathrm{CO}$; the oxidative decarbonylation by $\mathrm{Mc}_{3} \mathrm{NO}$ leads to synthesis of iron-free derivatives not accessible by thermal routes, see Aime, S., Botta, M., Gobetto, R., and Osella, D., Organometallics 4, 1475 (1985), and particularly reference 2 cited therein.

[27] Knox, G. R., and Thom, I. G., J. Chem. Soc. Chem. Commun. 373 (1981).

[28] Knölker, H.-J., Bauermeister, M., Bläser, D., Boese, R., and Pannek, J.-B., Angew. Chem. 101, 225 (1989); Angew. Chem. Inter. Ed. Engl. 28, 223 (1989); Knölker, H.-J., and Bauermeister, M., J. Chem. Soc. Chem. Commun. 664 (1990); ibid. 1468 (1990).

[29] Fatiadi, A. J., Synthesis 959 (1987).

[30] Grée, R., Synthesis 341 (1989).

[31] Blystone, S. L., Chem. Rev. 89, 1663 (1989).

[32] Fischer, E. O., Rev. Pure Appl. Chem. 30, 353 (1972); ibid., 24, 407 (1970); Angew. Chem. 86, 651 (1974).

[33] Fischer, E. O., and Maasböl, A., Angew. Chem. 76, 645 (1964); Angew. Chem. Int. Ed. Engl. 3, 580 (1964); Chem. Ber. 100, 2445 (1967); Fischer, E. O., and Dötz, K. H., J. Organomet. Chem. 36, C4 (1972); Fischer, E. O., and Plabst, D., Chem. Ber. 107, 3326 (1974).

[34] Pettit, R., Mauldin, C. H., Cole, T., and Kang, H., Ann. NY Acad. Sci. 295, 151 (1977); Pettit, R., Proc. Robert A. Welch Found. Conf. Chem. Res. 17, 227 (1973).

[35] Müller, J., The Organic Chemistry of Iron, von Gustorf, K. E. A., Grevels, F.-W., and Fischer, I., Eds., Academic Press, New York (1978), Vol. 1, Chaptcr 5; Müller, J., Angew. Chem. 84, 725 (1972); Angew. Chem. Int. Ed. Engl. 11, 653 (1972).

[36] King, R. B., Wu, F.-J., and Holt, E. M., J. Am. Chem. Soe. 110, 2775 (1988); King, R. B., Wu, F.-J., and Holt, E. M., J. Am. Chem. Soc. 109, 7764 (1987).

[37] Rosenblum, M., J. Organomet. Chem. 300, 191 (1986).

[38] Rosenblum, M., Acc. Chem. Res. 7, 122 (1974).

[39] Rosenblum, M., Chang, T. C. T., Foxman, B. M., Samuels, S. B., and Stockman, C., in Organic Synthesis Today and Tomorrow, Trost, B. M., and Hutchinson, C. R., Eds., Pergamon Press, Oxford, (1982) pp. 47-54. 
[40] Begum, M. K., Chu, K.-H., Coolbaugh, T. S., Rosenblum, M., and Zhu, X.-Y., J. Am. Chem. Soc. 111, 5252 (1989).

[41] Brunner, H., Synthesis 645 (1988); Adv. Organomet. Chem. 18, 151 (1980).

[42] Collman, J. P., Acc. Chem. Res. 8, 342 (1975).

[43] Gompper, R., and Bartmann, E., Angew. Chem. 97, 207 (1985); Angew. Chem. Int. Ed. Engl. 24, 209 (1985).

[44] Sarel, S., Acc. Chem. Res. 11, 204 (1978).

[45] Noyori, R., Acc. Chem. Res. 12, 61 (1979).

[46] Noyori, R., in Transition Metal Organometallics in Organic Synthesis, Alper, H., Ed., Academic Press, New York (1976), Chapter 2, pp. 83-187.

[47] Casey, C. P., Woo, L. K., Fagan, P. J., Palermo, R. E., and Adams, B. R., Organometallics 6, 447 (1987) and references therein.

[48] Shade, Y. E., and Wojcicki, A., J. Organomet. Chem. 319, 391 (1987) and references cited therein.

[49] Reger, D. L., Acc. Chem. Rcs. 21, 229 (1988) and referenes cited thcrein.

[50] Kuo, G.-H., Helquist, P., and Kerber, R. C., Organometallics 3, 806 (1984); Kremer, K. A. M., Kuo, G.-H., O'Connor, E. J., Helquist, P., and Kerber, R. C., J. Am. Chem. Soc. 104, 6119 (1982).

[51] Bodner, G. S., Smith, D. E., Hatton, W. H., Hcah, P. C., Georgiou, S., Rheingold, A. L., Gcib, S. J., Hutchinson, J. P., and Gladysz, J. A., J. Am. Chem. Soc. 109, 7688 (1987) and references cited therein.

[52] Kerber, R. C., J. Organomet. Chem. 360, 1 (1989); see also references 12, 50, 569 and 570.

[53] Wulff, W. D., in Advances in Metal-Organic Chemistry, Licbcskind, L. A., Ed., JA1 Press, Greenwich, Connecticut (1989) Vol. 1 , Chapter 6.

[54] Ojima, I., in reference 53, Chapter 2.

[55] Negishi, E., in reference 53, Chapter 5.

[56] Backvall, J.-E., in reference 53, Chapter 4.

[57] Herndon, J. W., Wu, C., and Ammon, H. L., J. Org. Chem. 5, 2873 (1988).

[58] von Gustorf, K. E. A., Grcvels, F.-W., Fischer, I., Eds., The Organic Chemistry of Iron, Academic Press, New York (1978), Vol. 1; ibid., (1981) Vol. 2.

[59] Seyferth, D., and Womack, G. B., Organometallics 5, 2360 (1986) and references therein.

[60] Davies, S. G., Chem. Britain 25, 268 (1989).

[61] Davies, S. G., Dordor-Hedgecock, I. M., Easton, R. J., Preston, S. C., Sutton, K. H., and Walker, J. C., Bull. Soc. Chim. Fr. 608 (1987).

[62] Davies, S. G., and Dordor-Hedgecock, I. M., Annu. Rep. Progr. Chem. Sec. B. 84, 211 (1987).

[63] Davies, S. G., Pure Appl. Chem. 60, 13 (1988).

[64] Liebeskind, L. S., Welkcr, M. E., and Fengl, R. M., J. Am. Chem. Soc. 108, 6328 (1986).

[65] Semmelhack, M. F., Tamura, R., Schnatter, W., and Springer, J., J. Am. Chem. Soc. 106, 5363 (1984) and refcrences therein.

[66] Brookhart, M., and Studabaker, W. B., Chem. Rev. 87, 411 (1987).

[66a] Brookhart, M., Liu, Y., Goldman, E. W., Timmers, D. A., and Williams, G. D., J. Am. Chcm. Soc. 113, 927 (1991); Brookhart, M., and Liu, Y., ibid. 113, 339 (1991). See also Brookhart, M., and Liu, Y., Advances in Metal Carbene Chemistry, Schubert, U., ed., Kluwer Academic Publishers (1989) pp. 251-270.

[67] Halpern, J., Inorg. Chem. Acta. 100, 41 (1985).

[68] Glass, R. S., McConnell, W. W., and Andruski, S. W., J. Org. Chem. 51, 5123 (1986).

[69] Takass, J. M., and Anderson, L. G., J. Am. Chem. Soc. 109, 2200 (1987).

[70] Barrett, A. G. M., and Sturgess, M. A., J. Org. Chem. 52, 3940 (1987).

[71] Sutherland, R. G., Chowdhury, R. L., Piorko, A., and Lee, C. C., J. Org. Chem. 52, 4618 (1987).

[72] Jones, W. D., and Feher, F. J., Acc. Chem. Res. 22, 91 (1989).

[73] Schwarz, H., Acc. Chem. Res. 22, 282 (1989).

[74] Dötz, K. H., Angew. Chem. 96, 573 (1984); Angew. Chem. Int. Ed. Engl. 23, 587 (1984); see also reference 137. Dötz, K. H., Erben, H.-G., and Harms, K., J. Chcm. Soc. Chem. Commun. 692 (1989) and references therein.

[75] Xu, Y.-C., Challener, C. A., Dragisich, V., Brandvold, T. A., Peterson, G. A., Wulff, W. D., and Willard, P. G., J. Am. Chem. Soc. 111,7269 (1989) and pertinent references therein; see also reference 153.

[76] Hegedus, L. S., Tetrahedron 41, 5883 (1985).

[77] Yamashita, A., Toy, A., Ghazal, N. B., and Muchmorc, C. R., J. Org. Chem. 54, 4481 (1989) and references therein.

[77a] Davies, S. G., and Goodfellow, G. L., Synlett 59 (1989) and references therein.

[77b] Solladie-Cavallo, A., in reference 53, Chapter 3.

[78] Wilkinson, G., Stone, F. G. A., and Abel, E. W., Eds., Comprehensive Organometallic Chemistry. The Synthesis, Reactions, and Structures of Organometallic Compounds, Pergamon Press, Oxford, (1982), Vols. 1-8.

[79] Davies, S. G., Organotransition Metal Chemistry: Applications to Organic Synthesis, Pergamon Press, Oxford (1982); Green, M. L. H., and Davies, S. G. Eds., Organometallic Chemistry and Organic Synthesis, The Royal Society, London, 1988.

[80] Knox, G. R., Organometallic Compounds of Iron, Chapman \& Hall, London, (1985). See also reference 29 and particularly rcferences 5, 13, 21-39 therein for an additional list of recent books on organometallics. See also Weisberger, E., and Laszlo, P., Acc. Chem. Res. 9, 209 (1976) and references therein.

[81] Omae, I., Organometallic Intramolecular-Coordination Compounds, Elsevier, Amsterdam (1986).

[82] Bernal, I., Ed., Stereochemistry of Organometallic and Inorganic Compounds, Elsevier, Amsterdam (1989).

[83] Crabtree, R. H., The Organometallic Chemistry of the Transition Metals, Wiley-Interscience, New York (1988).

[84] Yamamoto, A., Organotransition Metal Chemistry; Fundamental Concepts and Applications, Wiley-Interscience, New York (1986).

[85] Collman, J. P., Hegedus, L. S., Norton, J. R., and Finke, R. G., Principles and Applications of Organotransition Metal Chemistry, University Science Books, Mill Valley, California (1987).

[86] Scheffold, R., Modern Synthetic Methods, Wiley, New York (1983) Vol. 3. 
[87] Hartley, F. R., Ed., The Use of Organometallic Compounds in Organic Synthesis, John Wiley \& Sons, New York (1987).

[88] Semmelhack, M. F., and Le, H. T., J. Am. Chem. Soc. 107, 1455 (1985).

[89] Pearson, A. J., and Ong, C. W., J. Org. Chem. 47, 3780 (1982).

[90] Rosenblum, M., Turnbull, M. M., and Foxman, B. M., Organometallics 5, 1062 (1986).

[91] Wright, M. E., Nelson, G. O., and Glass, R. S., Organometallics 4, 245 (1985).

[92] tom Dieck, H., and Dietrieh, J., Angew. Chem. 97, 795 (1985); Angew. Chem. Int. Ed. Engl. 24, 781 (1985).

[93] Hoberg, M., Jenni, K., Krüger, C., and Raabe, E., Angew. Chem. 98, 819 (1986); Angew. Chem. Int. Ed. Engl. 25, 810 (1986).

[94] Barton, D. H. R., Gunatilaka, A. A., Nakanishi, T., Patin, H., Widdowson, D. A., and Worth, B. R., J. Chem. Soe. Perkin Trans. 1,821 (1976).

[95] Pearson, A. J., and Chen, Y.-S., J. Org. Chem. 51, 1939 (1986).

[96] Jaouen, G., Vessieres, A., Top, S., Ismail, A. A., and Butler, I. S., J. Am. Chem. Soc. 107, 4778 (1985).

[97] Boehm, M. F., and Prestwich, G. D., J. Org. Chem. 52, 1349 (1987).

[98] Araki, S., Hatano, M., and Butsugan, Y., J. Org. Chem. 51, 2126 (1986) and references therein.

[99] Gabioud, R., and Vogel, P. J. Org. Chem. 51, 2385 (1986).

[100] Xu, Y., and Zhou, B., J. Org. Chem. 52, 974 (1987).

[101] Banthrope, D. V., Fitton, H., and Lewis, J., J. Chem. Soe. Perkin Trans. 1, 2051 (1973).

[102] Evans, J., Johnson, B. F. G., and Lewis, J., J. Organomet. Chem. 102, 507 (1974).

[103] Franck-Neumann, M., and Martina, D., Tetrahedron Lett. 1759 (1975).

[104] Birch, A. J., and Pearson, A. J., J. Chem. Soc. Chem. Commun. 601 (1976); Samuelson, A. G., and Carpenter, B. K., ibid., 354 (1981).

[105] Shilov, A. E., Aetivation of Saturated Hydrocarbons by Transition Metal Complexes, D. Reidel, Dordrecht, Holland (1984).

[106] Ephritikhine, M., Nouv. J. Chim. 10, 9 (1986).

[107] Sermon, P. A., Chem. Soc. Rev. 16, 339 (1987); Derey, M. J,. Kenttamaa, H. I., Wysocki, V. H., and Cooks, R. G., Org. Mass. Spectrom. 21, 193 (1986).

[108] Dillow, G. W., Nicol, G., and Kebarle, P., J. Am. Chem. Soc. 111, 546 (1989).

[109] Birch, A. J., Shoukry, E. M. A., and Stansfield, F., J. Chem. Soc. 5376 (1961).

[110] Pearson, A. J., Chem. \& Ind. (London) 741 (1982).

[111] Pearson, A. J., Transition Met. Chem. (Weinheim) 6, 67 (1981).

[112] Pearson, A. J., Pure Appl. Chem. 55, 1767 (1983).

[113] Pearson, A. J., and Ray, T., Tetrahedron 41, 5765 (1985).

[114] Pearson, A. J., Kole, S. L., and Ray, T., J. Am. Chem. Soc. 106, 6060 (1984).

[115] Pearson, A. J., and Bansal, H. S., Tetrahedron Lett. 27, 283 (1986); Pearson, A. J., Bansal, H. S., and Lai, Y.-S., J. Chem. Soc. Chem. Commun. 519 (1987). See also Pearson, A. J., and Lai, Y.-S., J. Chem. Soc. Chem. Commun. 442 (1988).

[116] Pearson, A. J., in Organometallic Chemistry, Wilkinson, G., Stone, F.G., and Abel, E. W., Eds., Pergamon Press, Oxford (1982), Vol. 8, pp. 939-1011.

[117] Pearson, A. J., Seience 223, 895 (1984).

[118] Pearson, A. J., Richards, I. C., and Gardner, D. V., J. Org. Chem. 49, 3887 (1984).

[119] Pearson, A. J., and Perrior, T. R., J. Organomet. Chem. 285, 253 (1985).

[120] Pearson, A. J., and Ong, C. W., J. Am. Chem. Soc. 103, 6686 (1981).

[121] Pearson, A. J., and Yoon, J., J. Chem. Soc. Chem. Commun. 1467 (1986).

[122] Pearson, A. J., Blystone, S. L., Nar, H., Pinkerton, A. A., Roden, B. A., and Yoon, J., J. Am. Chem. Soc. 111, 134 (1989); Pearson, A. J., Blystone, S. L., and Roden, B. A., Tetrahedron Lett. 28, 2459 (1987).

[123] Palotai, I. M, Stephenson, G. R., and Kane-Maguire, L. A. P., J. Organomet. Chem. 319, C5 (1987).

[124] Birch, A. J., Kelly, L. F., and Weerasuria, D. V., J. Org. Chem. 53, 278 (1988).

[125] Birch, A. J., and Kelly, L. F., J. Organomet. Chem. 285, 267 (1985).

[126] Alexander, R. P., Morley, C., and Stephenson, G. R., J. Chem. Soc., Perkin Trans. 1, 2069 (1988).

[127] Howard, P. W., Stephenson, G. R., and Taylor, S. C., J. Chem. Soc. Chem. Commun. 1603 (1988).

[128] Birch, A. J., and Pearson, A. J., J. Chem. Soc. Perkin Trans. 1, 638 (1978).

[129] Pearson, A. J., and Yoon, J., Tetrahedron Lett. 26, 2399 (1985).

[130] Birch, A. J., and Williamson, D. H., J. Chem. Soc. Perkin Trans. 1, 1892 (1973).

[131] Pearson, A. J., Zettler, M., and Pinkerton, A. A., J. Chem. Soc. Chem. Commun. 264 (1987).

[132] Martin, S. F., Tetrahedron 36, 419 (1980) and references cited therein. See also Ibuka, T., Tanaka, M., Nishii, S., and Yamamoto, Y., J. Chem. Soc. Chem. Commun. 1596 (1987).

[133] Vandewalle, M., and DeClereq P., Tetrahedron 41, 1764 (1985) and references cited therein.

[134] ApSimon, J., Ed., The Total Synthesis of Natural Products, Wiley, New York (1983), Vol. 5.

[135] Pearson, A. J., and Zettler, M. W., J. Chem. Soc. Chem. Commun. 1243 (1987).

[136] Birch, A. J., and Bandara, B. M. R., Tetrahedron Lett. 21, 2981 (1980).

[137] Dötz, K. H., Fischer, H., Hofmann, P., Kreissl, F. R., Sehubert, U., and Weiss, K., Transition Metal Carbene Complexes, Verlag Chemie, Deerfield Beach, Florida (1983) pp. 1-264.

[138] Kirmse, W., Carbene Chemistry, Academic Press, New York (1971).

[139] Kress, J., and Osborn, J. A., J. Am. Chem. Soc. 109, 3953 (1987) and references therein; Marynick, D. S., and Kirkpatrick, C. M., J. Am. Chem. Soc. 107, 1993 (1985). Gregory, A. R., and Mintz, E. A., J. Am. Chem. Soc. 107, 2179 (1985).

[140] Reference 85, Chapter 3, pp. 113-119; Chapter 16, pp. 783-823.

[141] Casey, C. P., in Reactive Intermediates, Jones, Jr. M., and Moss, R. A., Eds., Wiley, New York (1981), Vol. 2, pp. $135-174$.

[142] Casey, C. P., in Transition Metal Organometallics in Organic Synthesis, Alper. H., Ed., Academic Press, New York (1976), Vol. 1, Chapter 3, pp. 189-233. 
[143] Fischer, E. O., Adv. Organomet. Chem. 14, 1 (1976). For an alternative synthesis of transition-metal carbene synthesis, see recent review by Erker, G., Angew. Chem. 101, 411 (1989); Angew. Chem. Int. Ed. Engl. 28, 397 (1989).

[144] Taylor, T. E., and Hall, M. B., J. Am. Chem. Soc. 106, 1576 (1984).

[145] Reference 85, pp. 119-137; see also chapter 16.

[146] Riley, P. E., Capshew, C. E., Pettit, R., and Davis, R. E., Inorg. Chem. 17, 408 (1978).

[147] Semmelhack, M. F., and Tamura, R., J. Am. Chem. Soc. 105, 4099 (1983) and reference 2-4 and 10-13 therein.

[148] Schrock, R. R., J. Am. Chcm. Soc. 96, 6796 (1974); Schrock, R. R., and Fellmann, J. D., ibid., 100, 3359 (1978); Schrock, R. R., Acc. Chem. Res. 12, 98 (1979).

[149] Sayatkovskii, A. I., and Babitskii, B. D., Russ. Chem. Rcv. 53, 672 (1985).

[150] Semmelhack, M. F., Ho, S., Steigerwald, M., and Lee, M. C., J. Am. Chem. Soc. 109, 4397 (1987); Semmelhack, M. F., Garcia, J. L., Cortes, D., Farina, R., Hong, R., and Carpenter, B. K., Organometallics 2, 467 (1983) and references therein.

[151] Dötz, K. H., Popall, M., and Müller, G., J. Organomet. Chem. 334, 57 (1987); Dötz, K. H., and Popall, M., Angew. Chem. 99, 1220 (1987); Angew Chem. Int. Ed. Engl. 26, 1158 (1987).

[152] Helquist, P., Abstracts of Papers, 194th National Meeting of the American Chemical Society, New Orleans, LA (1987), ORGN 75.

[153] Wulff, W. D., Tang, P.-C., Chan, K.-S., McCallum, J. S., Yang, D. C., and Gibbertson, S. R., Tetrahedron 41, 5813 (1985); Wulff, W. D., and Tang, P.-C., J. Am. Chem. Soc. 106, 434 (1984); Yamashita, A., J. Am. Chem. Soc. 107, 5823 (1985).

[154] Wulff, W. D., in Advances in Metal-Organic Chemistry, Liebeskind, L. S., Ed., JAI Press Inc., Greenwich, Connecticut (1988) Vol. 1.

[155] Ivin, K. J., Olefin Metathesis, Academic Press, London (1983); Cross, R. J., Catalysis 5, 382 (1982).

[156] Turner, H. W., and Schrock, R. R., J. Am. Chem. Soc. 104, 2331 (1982).

[157] Herrmann, W. A., Angew. Chem. 94, 118 (1982); Angew. Chem. Int. Ed. Engl. 21, 117 (1982); Muetterties, E.L., J. Organomet. Chem. 200, 177 (1980).

[158] Anderson, R. B., The Fischer-Tropsch Synthesis, Academic Press, New York (1984).

[159] Casey, C. P., Miles, W. H., and Tukada, H., J. Am. Chcm. Soc. 107, 2924 (1985).

[160] Hubbard, J. L., and MacVicar, W. K., J. Am. Chem. Soc. 108, 6422 (1986).

[161] Holmgren, J. S., and Shapely, J. R., Organometallics 4, 793 (1985).

[162] Woodcock, C., and Eisenberg, R., Organometallics 4, 4 (1985).

[163] Herrmann, W. A., Angew. Chem. 90, 855 (1978); Angew. Chcm. Int. Ed. Engl. 17, 800 (1978).

[164] Hegedus, L. S., Schultze, L. M., Toro, J., and Yijun, C., Tctrahedron 41, 5833 (1985).

[165] Dötz, K. H., and Popall, M., Tetrahedron 41, 5797 (1985).

[166] Semmelhack, M. F., Bozell, J. J., Keller, L., Sato, T., Spiess, E. J., Wulff, W., and Zask, A., Tetrahedron 41, 5803 (1985).

[167] Dötz, K. H., in Organometallics in Organic Synthesis - Aspects of a Modern Interdisciplinary Field, de Meijere, A., tom Dieck, H., Eds., Springer-Verlag, Berlin (1988).

[168] Dötz, K. H., Noack, R., and Müller, G., J. Chem. Soc. Chem. Commun. 302 (1988) and referenccs therein.

[169] Dötz, K. H., in reference 137, Chapter 6, pp. 191-246.

[170] Fischer, H., in reference 137, Chapter 1, pp. 1-68; 247-264. The X-ray crystal structure of the iron-carbenc complex has recently been reported: Mansuy, D., Battioni, J.-P., Lavallee, D. K., Fischer, J., and Weiss, R., Inorg. Chem. 27, 1052 (1988).

[171] Brandt, S., and Helquist, P., J. Am. Chem. Soc. 101, 6473 (1979).

[172] Kremer, K. A., Helquist, P., and Kerber, R. C., J. Am. Chem. Soc. 103, 1862 (1981).

[173] O'Connor, E. J., and Helquist, P., J. Am. Chem. Soc. 104, 1869 (1982).

[174] Brookhart, M., Broom, B. H., Kratzer, H. J., and Nclson, G. O., J. Am. Chem. Soc. 102, 7802 (1980).

[175] Brookhart, M., Tucker, J. R., and Husk, G. R., J. Am. Chcm. Soc. 103, 979 (1981).

[176] Reference 85, Chapter 6.

[177] Fischer, H., Schmid, J., and Markel, R., J. Chem. Soc. Chem. Commun. 572 (1985).

[178] Fischer, E. O., Beck, H.-J., Kreiter, C. G., Lynch, J., Müller, J., and Winkler, E., Chem. Ber. 105, 162 (1972).

[179] Baird, G. J., Davies, S. G., Jones, R. H., Prout, K., Warner, P., J. Chem. Soc. Chem. Commun. 745 (1984).

[180] Curtis, P. J., and Davies, S. G., J. Chem. Soc. Chem. Commun. 747 (1984).

[181] Abbott, S., Davies, S. G., and Warner, P., J. Organomet. Chem. 246, C65 (1983).

[182] Green, M. L. H., Mitchard, L. C., and Swanwick, M. G., J. Chem. Soc. A 794 (1971).

[183] Buhro, W. E., Wong, A., Merrifield, J. H., Lin, G.-Y., Constable, A. C., and Gladysz, J. A., Organometallics 2, 1852 (1983).

[184] Casey, C. P., Miles, W. H., Tukada, H., and O'Connor, J. M., J. Am. Chem. Soc. 104, 3761 (1982).

[185] Casey, C. P., and Miles, W. H., Organometallics 3, 808 (1984) and references therein.

[186] Bodnar, T., and Culter, A. R., J. Organomet. Chem. 213, C31 (1981).

[187] Semmelhack, M. F., and Park, J., J. Am. Chcm. Soc. 109, 935 (1987).

[188] Semmelhack, M. F., and Herndon, J. M., Organometallics 2, 363 (1983).

[189] Birch, A. J., J. Organomet. Chem. 285, 267 (1983).

[190] Semmelhack, M. F., and Herndon, J. W., J. Organomet. Chem. 365, C15 (1984); Semmelhack, M. F., Herndon, J. W., and Springer, J. P., J. Am. Chem. Soc. 105, 2497 (1983).

[191] Semmelhack, M. F., and Park, J., Organometallics 5, 2550 (1986).

[192] Ayscough, A. P., and Davies, S. G., J. Chem. Soc. Chem. Commun. 1648 (1986) and references therein.

[193] Brown, F. J., Prog. Inorg. Chem. 27, 1 (1980).

[194] Casey, C. P., React. Intermed. 3, 109 (1985).

[195] Collman, J. P., Hegedus, L. S. Principals and Applications of Organotransition Metal Chemistry, University Sciencc Books, Mill Valley, CA (1980) pp. 91-103. 
[196] For reviews, see Nugent, W. A., and Haymorc, B. L., Coord. Chem. Rev. 31, 123 (1980); Cenini, S., and LaMonica, G., Inorg. Chim. Acta 18, 279 (1976).

[197] Hegedus, L. S., and Kramer, A., Organometallics 3, 1263 (1984).

[198] Williams, G. D., Whittle, R. R., Geoffroy, G. L., and Rheingold, A. L., J. Am. Chem. Soc. 109, 3936 (1987).

[199] Greenberg, A., and Liebman, J., Strained Organic Molecules, Academic Press, New York (1978).

[200] Greenberg, A., and Stevenson, T. A., in Molecular Structure and Energetics, Liebman, J. F., and Greenberg, A., Eds., VCH. Publishers, Deerfield Beach, Florida (1986), Vol. 3, Chapter 5, pp. 193-266.

[201] Rappoport, Z., Ed., The Chemistry of the Cyclopropyl Group, Wiley-Interscience, New York (1987), Part 1 and 2. On use of cyclopropanes and their derivatives in organic synthesis, see Wong, H. N. C., Hon, M.-Y., Tse, C.-W., Yip, Y.-C., Tanko, J., and Hudlicky, T., Chem. Rev. 89, 165 (1989).

[202] Adams, J., Frenette, R., Bellcy, M., Chibante, F., and Springer, J. P., J. Am. Chem. Soc. 109, 5432 (1987).

[203] Burke, S. D., and Grieco, P. A., Organic Reactions, John Wiley \& Sons, New York (1979), Vol. 26, pp. $361-475$.

[204] For the related strained ring systems, e.g., the chemistry of alkylidenecycloproparenes see Halton, B., and Stang, P. J., Acc. Chem. Res. 20, 443 (1987).

[205] de Meijere, A., Chem. Britain 865 (1987).

[206] Wulff, W. D., Yang, D. C., and Murray, C. K., J. Am. Chem. Soc. 110, 2653 (1988).

[207] Korkowski, P. L., Hoye, T. R., and Rydberg, D. B., J. Am. Chem. Soc. 110, 2676 (1988) and reference 3 and 4 in this paper.

[208] Reference 85, Chapter 16, pp. 797-800.

[209] Mattson, M. N., Bays, J. P., Zakutansky, J., Stolarski, V., and Helquist, P., J. Org. Chem. 54, 2467 (1989); Helquist, P. in reference 53 , Vol. 2 , in press.

[210] O'Connor, E. J., Brandt, S., and Helquist, P., J. Am. Chem. Soc. 109, 3739 (1987). For a thorough compilation of references on methods for the preparation of cyclopropanes, sec rcference 5 in this papcr; for some examplcs of carbene complexes undergoing cyclopropanation reactions, see refercnce 9; see also pertinent references 12-16 cited therein.

[211] Rilcy, P. E., Capshew, C. E., Pettit, R., and Davies, R. E., Inorg. Chem. 17, 408.

[212] Green, M. L. H., Mitchard, L. C., and Swanwick, M. G., J. Chem. Soc. A 794 (1971).

[213] References 12-16 in reference 209.

[214] Kremer, K. A. M., Kuo, G.-H., O'Connor, E. J., Helquist, P., and Kerber, R. C., J. Am. Chem. Soc. 104,6119 (1982).

[215] Kuo, G.-H., Helquist, P., and Kerber, R. C., Organometallics 3, 806 (1984).

[216] Brookhart, M., Humphrey, M. B., Kratzer, H. J., and Nelson, G. O., J. Am. Chem. Soc. 102, 7802 (1980).

[217] Brookhart, M., and Tucker, J. R., J. Am. Chem. Soc. 103, 1862 (1981).

[218] Brookhart, M., Tucker, J. R., and Husk, G. R., J. Am. Chem. Soc. 105, 258 (1983).

[219] Brookhart, M., and Nelson, G. O., J. Am. Chem. Soc. 99, 6099 (1977).

[220] Brookhart, M., and Studabaker, W. B., Organomctallics 4, 943 (1985).

[221] Cascy, C. P., and Miles, W. H., Organometallics 3, 808 (1984) and references thcrein.

[222] Barron, A. R., and Cowley, A. H., J. Chem. Soc. Chem. Commun. 1272 (1987).

[223] Smith, L. J., and Casey, C. P., Abstracts of Papers, 195th National Meeting of American Chcmical Society, Toronto, Canada (1988), ORGN 157.

[224] Bosnich, B., and Fryzuk, M. D., in Topics in Inorganic and Organomctallic Stcreochemistry, Geoffroy, G. L., Ed., Interscience, New York (1981), Vol. 12, see Topics in Stcrcochemistry, pp. 119-154; Howell, J. A. C., and Thomas, M. J., J. Chem. Soc., Dalton Trans. 1401 (1983).

[225] Brookhart, M., Timmers, D., Tucker, J. R., Husk, G. R., Brunner, H., and Hammer, B., J. Am. Chem. Soc. 105, 6721 (1983).

[226] Brookhart, M., and Buck R. C., J. Am. Chem. Soc. 111, 559 (1989); Brookhart, M., Buck, R. C., and Danielson, E., I11, J. Am. Chem. Soc. 111, 567 (1989).

[227] Monpert, A., Martelli, J., Grée, R., and Carrié, R., Tctrahedron Lett. 22, 1961 (1981).

[228] Franck-Nenumann, M., Martina, D., and Heitz, M. P., Tetrahedron Lett. 23, 3493 (1982).

[229] Monpert, A., Martelli, J., Gréc, R., and Carrié, R., Nouv. J. Chem. 7, 345 (1983).

[230] Bishop, K. C., III, Chcm. Rev. 76, 461 (1976); Kozikowski, A. P., and Wctter, H. F., Synthesis 561 (1976).

[231] Jemmis, E. D., and Hoffmann, R., J. Am. Chem. Soc. 102, 2750 (1980).

[232] Ben-Shoshan, R., and Sarel, S., J. Chem. Soc. Chem. Commun. 883 (1969); Noyori, R., Nishimura, T., and Takaya, H., ibid., 89 (1969).

[233] Sarel, S., Ben-Shoshan, R., Kirson, B., J. Am. Chem. Soc. 87, 2517 (1965); Israel J. Chem. 10, 787 (1972).

[234] Victor, R., Ben-Shoshan, R., and Sarel, S., Tetrahedron Lett. 4253 (1970). Pentacarbonyliron [Fe(CO)s] is also known for its rich photosubstitution chemistry and its various derivatives make excellent isomerization photocatalysts, see Geoffroy, G.L., and Wrighton, M. S. Organomctallic Photochemistry, Academic Press, New York (1979); Graff, J. L., Sanner, R. D., and Wrighton, M. S., Organometallics 1, 837 (1982). For catalytic properties of $\mathrm{Fe}(\mathrm{CO})_{3}\left(\mathrm{C}_{2} \mathrm{H}_{4}\right)_{2}$ see Miller, M. E., and Grant, E. R., J. Am. Chem. Soc. 109, 7951 (1987).

[235] Moriarty, R. M., Yeh, L. L., and Ramey, K. C., J. Am. Chem. Soc. 93, 6709 (1971).

[236] Eilbracht, P., Chem. Ber. 109, 1429, 3136 (1976).

[237] Victor, R., Ben-Shoshan, R., Sarel, S., Tetrahedron Lett. 4211 (1973).

[238] Victor, R., Usieli, V., and Sarel, S., J. Organomet. Chem. 129, 387 (1977).

[239] Goldschmidt, Z., and Crammer, B., Chem. Soc. Rev. 17, 229 (1988).

[240] Sarcl, S., and Langbeheim, M., J. Chem. Soc. Chem. Commun. 73 (1979).

[241] Aumann, R., J. Am. Chem. Soc. 96, 2631 (1974).

[242] Churchill, M. R., Fettinger, J. C., McCullough, L. G., and Schrock, R. R., J. Am. Chem. Soc. 106, 3356 (1984); Schrock, R. R., Acc. Chem. Res. 12, 98 (1979). 
[243] DeSimone, D. M., Desrosiers, P. J., and Hughes, R. P., J. Am. Chem. Soc. 104, 4842 (1982).

[244] Gompper, R., and Bartmann, E., Angew. Chem. 90, 490 (1978); Angew. Chem. Int. Ed. Engl. 17, 456 (1978).

[245] Gompper, R., and Bartmann, E., Liebigs Ann. Chem. 229 (1980).

[246] Hemond, R. C., and Hughes, R. P., J. Chem. Soc. Chem. Commun. 318 (1988).

[247] Coppola, G. A., and Schustcr, H. F., Asymmeric Synthesis, Wiley-Interscience, New York (1987). For an excellent, recent review of chiral auxiliaries for asymmetric induction and of $C_{2}$ symmetry, see Whitesell, J. K., Chem. Rev. 89, 1581 (1989); see also, Kelly, T. R., Chandrakumar, N. S., and Saha, J. K., J. Org. Chem. 54, 980 (1989); Nakazaki, M., Top. Stereochem. 15, 199 (1984).

[248] Jones, J. B., in Asymmetric Synthesis, Morrison, J. D., Ed., Academic Press, New York (1985), Vol. 5, Chapter 9.

[249] Katsuki, T., and Sharpless, K. B., J. Am. Chem. Soc. 102, 5974 (1980).

[250] Enders, D., and Hoffmann, R. W., Chem. i. Unserer Zeit 19, 177 (1985).

[251] For discussions see: Kagan, H. B., in Asymmetric Synthcsis, Morrison, J. D., Ed., Academic Press, New York (1985), Vol. 5, Chapter 1.

[252] Sharpless, K. B., in reference 251, Chapter 8.

[253] Miyashita, A., Yasuda, A., Takaya, H., Toriumi, K., Ito, T., Souchi, T., and Noyori, R., J. Am. Chem. Soc. 102, 7932 (1980).

[254] Noyori, R., Pure Appl. Chem. 53, 2315 (1981).

[255] Masamune, S., Kim, B. M., Petersen, J. S., Sato, T., and Veenstra, S. J., J. Am. Chem. Soc. 107, 4549 (1985). For asymmetric reduction with organoborane reagents, see Midland, M. M., Chem. Rev. 89, 1553 (1989). For asymmetric hydroboration, see Brown, H. C., and Singaram, B., Pure Appl. Chem. 59, 879 (1987); Hayashi, T., Matsumoto, Y., and Ito, Y., J. Am. Chem. Soc., 111, 3426 (1989).

[256] Kelly, T. R., Whiting, A., and Chandrakumar, N. S., J. Am. Chem. Soc. 108, 3510 (1986).

[257] Brunner, H., J. Organomet. Chem. 300, 39 (1986). For entantiosclective homogeneous catalysis involving transition-metal-allyl intermediatcs, see reccnt revicw by Consiglio, G., and Waymouth, R. M., Chem. Rev. 89, 257 (1989).

[258] Gorenstein, D. G., Chem. Rcv. 87, 1047 (1987). Schnclder, M. P. (Ed.) Enzymes as Catalysts in Organic Synthesis, Kluwer Academic Publishers, Hingham, MA (1986).

[259] Retey, J., and Robinson, J. A., Sterospecificity in Chemistry and Enzymology, VCH Publishers, Deerfield Beach, Florida (1981), Volume 13.

[260] Gassen, H. G., Lang, A., Eds., Chemical and Enzymatic Synthesis of Gene Fragments, VCH Publishers, Deerfield Beach, Florida (1982).

[261] Birch, A. J., Prog. Bioorg. Chem. Mol. Biol. Proc. Int. Symp. Front. Bioor. Chem. Mol. Biol. (1984) pp. $471-477$.

[262] Hanessian, S., Total Synthesis of Natural Products: Thc Chiron Approach, Pergamon Press, New York (1983).

[263] Hanessian, S., Aldrichimica Acta 25, 5 (1989).

[264] Hase, T. A., Ed., Umpoled Synthons, Wiley-Interscience, New York (1987).

[265] Deslongchamps, P., Stereoelectronic Effects in Organic Chemistry, Pergamon, Oxford (1983).

[266] Deslongchamps, P., Aldrichimica Acta 17, 59 (1984).

[267] Kocovsky, P., Turecek, F., and Häjicek, J., Synthcsis of Natural Products: Problems of Stereoselectivity, CRC Press, Boca Raton, Florida (1986), Vols. 1 \& 2.

[268] Rebek, J., Askew, B., Ballester, P., and Doa, M., J. Am. Chem. Soc. 109, 4119 (1987).

[269] Scott, J. W., in Asymmetric Synthesis, Morrison, J. D., and Scott, J. W., Eds., Academic Press, Orlando (1984), Vol. 4, Chapter 1.

[270] Scheffold, R., Ed., Modern Synthetic Methods, Otto Salle Verlag, Frankfurt am Main (1980), Vol. 2, Chapters 2-4.

[271] Inch, T. D., Tetrahedron 40, 3161 (1984).

[272] Streith, J., Prinzbach, H., and Schill, F., Eds., Organic Synthesis, Blackwcll Scicntific Publications, Oxford (1985).

[273] Fuhrhop, J., and Penzlin, G. Organic Synthcsis, VCH Publishers, Deerfield Beach, Florida (1983).

[274] Carruthers, W., Some Modern Methods of Organic Synthesis, Cambridge Univcrsity Press, New York (1987).

[275] Horton, D., Hawkins, L. D., and McGarvey, G. J., Trends in Synthetic Carbohydrate Chemistry, American Chemical Society, Washington, DC (1988).

[276] Enders, D., in Selectivity-A Goal for Synthctic Efficicncy, Bartmann, W., and Trost, B. M. (Eds.) Verlag Chemie, Weinhcim (1984).

[277] Seebach, D., Beck, A. K., Schiess, M., Widler, L., and Wonnacott, A., Pure Appl. Chem. 55, 1807 (1983).

[278] Sharpless, K. B., and Verhoeven, T. R., Alrichimica Acta 12, 63 (1979).

[279] Nógrádi, M., Stereoselective Synthesis, VCH Publishers, New York (1987).

[280] Bartmann, W., and Sharpless, K. B., Eds., Stereochemistry of Organic and Bioorganic Transformations, VCH Publishcrs, New York (1987).

[281] Hartley, F. R., and Patai, S., Eds., The Use of Organometallic Compounds in Organic Synthesis, John Wiley and Sons, Chichester, England (1987).

[282] Morrison, J. D., Asymmetric Synthesis, Academic Press, New York (1983), Vol. 2, pp. 201-241.

[283] Morrison, J. D., Ed., Asymmetric Synthcsis, Academic Prcss, Orlando, Florida (1985), Vol. 4. See also Mason, S. F., Molecular Optical Activity and the Chiral Discrimination, Cambridge University Press (1982). For structure and dynamics of chiral molecules, see Quack, M., Angew. Chem. 101, 588 (1989); Angew. Chem. Int. Ed. Engl. 28, 571 (1989).

[284] Mason, S. F., Molecular Optical Activity and the Chiral Discrimination, Cambridge University Press (1982).

[285] For a chirality transfer, see Birch, A. J., Raverty, W. D., and Stephenson, G. R., Organometallics 3, 1075 (1984). For the proposed mechanism for the racemization of organoiron complexes, see Birch, A. J., and Stephenson, G. R., Tetrahedron Lett. 22, 779 (1984). 
[286] Brown, S. L., Davies, S. G., Warncr, P., Jones, R. H., and Prout, K., J. Chem. Soc. Chem. Commun. 1446 (1985).

[287] Enders, D., and Hoffman, R. W., Chem. Unserer Zeit 19, 177 (1985).

[288] For recent applications of transition metal carbonyls in organic synthesis, see Davies, J. A., and Shaver, R. J., Chcmistry of the Metal-Carbon Bond (1985), Vol. 3, pp. 295-333.

[289] Aktogu, N., Felkin, H., and Davies, S. G., J. Chem. Soc. Chem. Commun. 1303 (1984).

[290] Rosenblum, M., Bucheistcr, A., Chang, T. C. T., Cohen, M., Marsi, M., Samuels, S. B., Scheck, D., Sofen, N., and Watkins, J. C., Pure Appl. Chem. 56, 129 (1984).

[291] Marsi, M., and Rosenblum, M., J. Am. Chem. Soc. 106, 7264 (1984).

[292] Ojima, I., and Kwon, H. B., Chem. Lett. 1327 (1985).

[293] Corbridge, D. E. C., The Structural Chemistry of Phosphorus, Elsevier Publisher, New York, 1976, Tables 50 and 51; Brunner, H., and Lautensclager, H.-J., Synthesis 706 (1989).

[294] Georgiou, S., and Gladysz, J. A., Tetrahedron 42, 1109 (1986).

[295] Fernandez, J. M., and Gladysz, J. A., Inorg. Chem. 25, 2672 (1986).

[296] Grocco, G. L., and Gladysz, J. A., J. Chem. Soc. Chem. Commun. 1154 (1986).

[297] Smith, D. E., and Gladysz, J. A., Organometallics 4, 1480 (1985).

[298] Merrifield, J. H., Fernandez, J. M., Buhre, W. E., and Gladysz, J. A., Inorg. Chem. 23, 4022 (1984).

[299] Kiel, W. A., Lin, G.-Y., Constable, A. G., McCormick, F. B., Strouse, C. E., Eisenstein, O., Gladysz, J. A., J. Am. Chem. Soc. 104, 4865 (1982).

[300] Pearson, A. J., in reference 116, Vol. 8, p. 1004.

[301] Brunner, H., and Schmidt, E., J. Organomet. Chem. 36, C18 (1972).

[302] Brunner, H., Hammer, B., Bernal, I., and Draux, M., Organometallics 2, 1595 (1983).

[303] Flood, T. C., and Campbell, K. D., J. Am. Chem. Soc. 106, 2853 (1984).

[304] Evans, D. A., Nelson, J. V., and Taber, T. R., in Topics in Stereochemistry, Allinger, N. E., Eliel, E. L., and Wilen, S. H., Eds., Wiley, New York (1982), Vol. 13, p. 1.

[305] Liebeskind, L. S., and Welker, M. E., Organometallics, 2, 194 (1983).

[306] Davies, S. G., Dordor, I. M., and Warner, P., J. Chem. Soc. Chem. Commun. 957 (1984).

[307] Baird, G. J., and Davies, S. G., J. Organomet. Chem. 248, C1 (1983).

[308] Baird, G. J., Bandy, J. A., Davies, S. G., and Prout, K., J. Chcm. Soc. Chem. Commun. 1202 (1983).

[309] Davies, S. G., and Seeman, J. I. Tetrahedron Lett. 25, 1845 (1984).

[310] Brown, S. L., Davies, S. G., Foster, D. F., Seeman, J. I., and Warner, P., Tetrahedron Lett. 27, 623 (1986).

[311] Davies, S. G., Dordor, I. M., and Warner, P., J. Chem. Soc. Chem. Commun. 25, 956 (1984).

[312] Aktogu, N., Felkin, H., Baird, G. J., Davies, S. G., and Watts, O., J. Organomet. Chem. 262, 215 (1984).

[313] Thcopold, K. H., Becker, P. N., and Bergman, R. G., J. Am. Chem. Soc. 104, 5250 (1982).

[314] Liebeskind, L. S., and Welkcr, M. E., Tetrahedron Lett. 25, 4341 (1984).

[315] Davies, S. G., Dordor-Hedgecock, I. M., Warner, P., Jones, R. H., and Prout, K., J. Organomet. Chem. 285, 213 (1985).

[316] Davies, S. G., Dordor-Hedgecock, I. M., and Warner, P., Tetrahedron Lett. 26, 2125 (1985).

[317] Ambler, P. M., and Davies, S. G., Tetrahedron Lett. 26, 2129 (1985).

[318] Licbeskind, L. S., Welker, M. E., and Goedken, V., J. Am. Chem. Soc. 106, 441 (1984).

[319] Davies, S. G., and Walker, J. C., J. Chem. Soc. Chem. Commun. 209 (1985).

[320] Araki, S., Hatano, M., and Butsugan, Y., J. Org. Chem. 51, 2126 (1986).

[321] Ojima, I., and Kwon, H.-B., Abstracts of Papers, 194th National Meeting of the American Chemical Society, New Orleans, LA (1987), ORGN 247.

[322] Brunner, H., in The Organic Chemitry of Iron, von Gustorf, K. E. A., Grevels, F.-W., and Fischer, I., Eds., Academic Press, New York (1978), Vol. 1, pp. 299-343.

[323] Johnson, R. N., and Pearson, R. G., Chem. Commun. 986 (1970).

[324] Davies, S. G., Dordor, I. M., Walker, J. C., and Warner, P., Tetrahedron Lett. 25, 2709 (1984).

[325] Liebeskind, L. S., Fengl, R. W., and Welker, M. E., Tetrahedron Lett. 26, 3075 (1985).

[326] Liebeskind, L. S., and Welker, M. E., Tetrahedron Lett. 26, 3079 (1985).

[327] Broadly, K., and Davies, S. G., Tetrahedron Lett. 25, 1743 (1984); Davies, S. G., and Walker, J. C., J. Chem. Soc. Chem. Commun. 495 (1986).

[328] Davies, S. G., Dordor-Hedgecock, I. M., Sutton, K. H., Waker, J. C., Jones, R. H., and Prout, K., Tetrahedron 42, 5123 (1986); Davies, S. G., Dordor-Hcdgecock, I. M., Sutton, K. H., and Walker, J. C., Tetrahcdron Lett. 27, 3787 (1986).

[329] Liebeskind, L. S., Welkcr, M. E., and Gocdken, V., J. Am. Chcm. Soc. 106, 441 (1984).

[330] A lactam is the active functionality in penicillin and cephalosporin, two of the most important antimicrobial agents known. For recent reviews on $\beta$-lactams, see Dürckheimer, W., Blumbach, J., Lattrell, R., and Scheunemann, K. H., Angew Chem. 97,183 (1985); Angew. Chem. Int. Ed. Engl. 24, 180 (1985). See also Kametani, T., Heterocycles 17, 463 (1982); Nagahara, T., and Kametani, T., ibid., 25, 729 (1987). New strategies for the synthesis of $\beta$-lactams include a number of novcl methods using organometallic chemistry, see, for example, Chamchang, W., and Pinhas, A. J., J. Chem. Soc. Chem. Commun. 710 (1988) and references 3-5 therein. A new synthetic approach to $\beta$-lactams involving the photolytic reaction of heteroatom-stabilized ("Fisher") chromium-carbenc complexes with imines was recently developed, see Hegedus, L. S., de Weck, G., and D'Andrea, S., J. Am. Chem. Soc. 110, 2122 (1988) and references 1-4 therein; Hegcdus, L. S., and D'Andrea, S., J. Org. Chem. 53, 3113 (1988). More on stereocontrolled synthesis of $\beta$-lactams, see Labia, R., and Morin, C., J. Antibiot. 37, 1103 (1984); Wagle, D. R., Garai, Ch., Chiang, J., Monteleone, M. G., Kurys, B. E., Sgrohmeyer, T. W., Hegde, V. R., Manhas, M. S., and Bose, A. K., J. Org. Chem. 53, 4227 (1988). For an alternative procedure for synthesis of $\beta$-lactams and macrocyclic lactams of biologicalinterest, see Wasserman, H. Aldrichimica Acta, 20, 63 (1987). For asymmetric synthesis of $\beta$-lactams, see recent review by Hart, D. J., and Ha, D.-C., Chem. Rev. 89, 1447 (1989). 
[331] Berryhill, S. R., and Rosenblum, M., J. Org. Chem. 45, 1984 (1980).

[332] Berryhill, S. R., Price, T., and Rosenblum, M., J. Org. Chem. 48, 158 (1983).

[333] Weiss, E., Stark, K., Lancaster, J. E., and Murdock, H. D., Helv. Chim. Acta 46, 288 (1963).

[334] Brodie, A. M., Johnson, B. F. G., Josty, P. L., and Lewis, J., J. Chem. Soc., Dalton Trans. 2031 (1972).

[335] Nesmeyanov, A. H., Rubin, L. V., Gubenko, N. T., Rybinskaya, M. I., and Petrovskii, P. V., J. Organomet. Chem. 71, 271 (1974).

[336] Thomas, S. E., J. Chem. Soc. Chem. Commun. 226 (1987); Danks, T. N., Rakshit, D., and Thomas, S. E., J. Chem. Soc. Perkin Trans. 12091 (1988).

[337] Alcock, N. W., Danks, T. N., Richards, C. J., and Thomas, S. E., J. Chem. Soc. Chem. Commun. 21 (1989).

[338] Zhang, W.-Y., Jakiela, D. J., Maul, A., Knors, Ch., Lauther, J. W., Helquist, P., and Enders, D., J. Am. Chem. Soc. 110, 4652 (1988) and comprehensive references 9-12 therein; see also related references 1-9 and 13-16 cited therein.

[339] Brookhart, M., Yoon, J., and Noh, S. K., J. Am. Chem. Soc. 111, 4117 (1989).

[340] For a recent comprehensive review on the Wittig olefinination reaction, sec Maryanoff, B. E., and Reitz, A. B., Chem. Rev. 89, 863-927 (1989).

[341] Davies, S. G., Easton, R. J. C., Walker, J. C., and Warner, P., Tetrahedron 42, 175 (1986).

[342] For a review see Ager, D. J., Synthesis 384 (1984). See also Blackburn, B. K., Challans, S. C., and Davies, S. G., Abstracts of Papers, 194th National Meeting of the American Chemical Society, New Orleans, LA, (1987), ORGN 72.

[343] Davies, S. G., Watts, O., Aktogu, N., and Fclkin, H., J. Organomet. Chem. 243, C51 (1983).

[344] King, R. B., and Bisnette, M. B., J. Organomet. Chem. 2, 15 (1964); Quinn, S., and Shaver, A., Inorgan. Chim. Acta 38, 243 (1980).

[345] For stereoselective decarbonylation reactions of acyliron complexes upon photolysis, see Bly, R. S., Silverman, G. S., and Bly, R. K., Organomctallics 4, 374 (1985).

[346] Allenmark, S. Chromatographic Enantioseparation: Methods and Applications, Wiley, New York, (1988); Pirkle, W. H., and Pochapsky, T. C., Chem. Rev. 89, 347 (1989); Advances in Chromatography, Giddings, J. C., Grushka, E., Brown, P. R., Eds., Marcel Dekker, New York, (1987), Vol. 27, Chapter 3; Takeuchi, Y., and Marchand, A. P., Eds., Applications of NMR Spectroscopy to Problems in Stereochemistry and Conformational Analysis, VCH Publishers, New York, (1986); König, W. A., Enantiomer Separation by Capillary Gas Chromatography, W. Hüting, Heidelberg, (1987); Ward, T. J., Armstrong, D. M., in Chromatographic Science, Chromatographic Chiral Separations, Zief, M., and Carne, L. J., Eds., Vol. 40, Chapter 5, Marcel Dekker, New York, (1988) pp. 131-164. Sec also Okamoto, Y., Kawashima, M., and Hatada, K., J. Chromatogr. 363, 173 (1986); Dobashi, Y., and Hara, S., J. Org. Chem. 52, 2490 (1987). See also Chicz, R. M., and Regnier, F. E., Anal. Chcm. 61, 2059 (1989). More on optical resolution of enantiomers, see Dobashi, A., Ono, T., Hara, S., and Yamaguchi, J., Anal. Chem. 61, 1984 (1989). More on chromatographic chiral separations, see Feibush, B., and Grinberg, N., in Chromatographic Chiral Separations, Zief, M., Crane, L. J., Eds., Marcel Dekker, Inc. New York and Basel, 1988; Chapter 1; Chou, T.-Y., Gao, C.-X., Grinberg, N., and Krull, I. S., Anal. Chem. 61, 1548 (1989); Allenmark S., Chromatographic Enantioseparations, John Wiley \& Sons, Inc. New York, (1988). See also Lough, W. J., Chiral Liquid Chromatography, Blackie Publisher, Glasgow (1989).

The chromatographic chiral stationary phases make it possible to directly resolve racemic mixtures on analytical and preparative scales. On theoretical discussion on how these chiral stationary phases recognize and selectively bind one of two mirror image isomers (e.g., enantiodifferentiation), see Lipkowitz, K. B., Antell, S., and Baker, B., J. Org. Chem. 54, 5449 (1989) and references 1 and 2 therein.

A perpentylated $\beta$-cyclodextrin stationary phase permits the unproblematic enantiomer separation of chiral alkenes, see Ehlers, J., König, W. A., Lutz, S., Wenz, G., and tomDick, H., Angew. Chcm. Int. Ed. Engl: 27, 1556 (1988).

The extent of asymmetric induction can also be determined by H-NMR spectroscopy in the presencc of the chiral lanthanide shift reagent (+)tris[(heptafluorobutyryl)camphorato]europium(III)[Eu(hfbc) 3 ; see reference [385a]. For chiral separations by HPLC, see Krstulovic, A. M., Ed., Chiral Separations by HPLC: Applications to Pharmaceutical Compounds, Ellis Horwood, Chichester, 1989.

[347] Davies, S. G., Dordor-Hedgecock, I. M., Sutton, K. H., Walkcr, J. C., Bourne, C., Joncs, R. H., and Prout, K., J. Chem. Soc. Chem. Commun. 607 (1986).

[348] Fluka Chemical Corp., New York or B. P. Chemicals Ltd, London; or TCI America, Portland, OR.

[349] Seeman, J. I., and Davies, S. G., J. Am. Chem. Soc. 107, 6522 (1985).

[350] Davies, S. G., Seeman, J. I., and Williams, I. H., Tetrahedron Lett. 27, 619 (1986).

[351] Davies, S. G., Dordor-Hedgecock, I. M., Sutton, K. H., Whittaker, M., J. Organomet. Chem. 320 , C19 (1987).

[352] Blackburn, B. K., Davies, S. G., and Whittaker, M., J. Chem. Soc. Chem. Commun. 1344 (1987). More on conformational analysis for ligands bound to the chiral auxiliary $\left.\left[\eta^{5}-\mathrm{C}_{5} \mathrm{H}_{5}\right) \mathrm{Fe}(\mathrm{CO})\left(\mathrm{PPh}_{3}\right)\right]$, see Blackburn, B. K., Davies, S. G., and Whittaker, M., in Stereochemistry of Organometallic and Inorganic Compounds, Bernal, I., Ed., Elsevier Publishers, Amsterdam, New York, 1989, Chapter 2.

[353] Siglmüller, F., Herrmann, R., and Ugi, I., Tetrahedron 42, 5931 (1986).

[354] Postnov, V. N., Andrianov, V. G., Struchkov, Yu. T., Baran, A. M., and Sazonova, V. A., J. Organomet. Chem. 262, 201 (1984).

[355] Davies, S. G., and Gravatt, G. L., J. Chem. Soc. Chem. Commun. 780 (1988).

[356] Morrison, J. D., Asymmetric Synthesis, Academic Press, New York (1984), Vol. 3, p. 455.

[357] Oppolzer, W., Angew. Chem. 96, 840 (1984); Angew. Chem. Int. Ed. Engl. 23, 876 (1984).

[358] Davies, S. G., and Walker, J. C., J. Chem. Soc. Chem. Commun. 609 (1986).

[359] Lenhert, P. G., Lukehart, C. M., and Sacksteder, L-.A., J. Am. Chem. Soc. 108, 793 (1986).

[360] Herndon, J. W., J. Org. Chem. 51, 2853 (1986).

[361] Herndon, J. W., J. Am. Chem. Soc. 109, 3165 (1987).

[362] Onishchenko, A. S., Diene Synthesis, Daniel Davey, New York (1964).

[363] Ciganek, E., Org. React. 32, 1-374 (1984).

[364] More on Diels-Alder reactions, see Fatiadi, A. J., Synthesis 749 (1987), and references 8-16 therein. 
[365] Wright, M. E., Hoover, J. F., Nelson, G. O., Scott, C. P., and Glass, R. S., J. Org. Chem. 49, 3059 (1984).

[366] Glass, R. S., and McConncll, W. W., Organometallics 3, 1630 (1984).

[367] Glass, R. S., McConnell, W. W., and Andruski, S. A., J. Org. Chem. 51, 5123 (1986).

[368] Stephenson, G. R., J. Organomet. Chem. 286, C41 (1985).

[369] Alexander, R. P., and Stephenson, G. R., J. Organomet. Chem. 299, C1 (1986).

[370] Palotai, I. M., Stephenson, G. R., and Kane-Maguire, L. A. P., J. Organomet. Chem. 319, C5 (1987).

[371] Kerr, P. G., Leung, P.-H., and Wild, S. B., J. Am. Chcm. Soc. 109, 4321 (1987).

[372] Kyba, E. P., Clubb, C. N., Larson, S. B., Schueler, V. J., and Davies, R. E., J. Am. Chem. Soc. 107, 2141 (1985); Brauer, D. J., Gol, F., Hietkamp, S., Peters, H., Sommer, H., Stelzer, O., and Sheldrick, W. S., Chem. Ber. 119, 349 (1986); Giampolini, M., Nardi, N., Orioli, P. L., Mangani, S., and Zanobini, F., J. Chem. Soc., Dalton Trans. 1425 (1985).

[373] Salem, G., and Wild, S. G., J. Chcm. Soc. Chem. Commun. 1378 (1987); Crisp, G. T., Salcm, G., Stephens, F. S., and Wild, S. B., ibid., 600 (1987).

[374] Pearson, A. J., Rees, D. C., and Thornber, C. W., J. Chem. Soc. Perkin Trans. 1619 (1983); Pearson, A. J., and Rees, D. C., J. Am. Chem. Soc. 104, 1118 (1982).

[375] Pearson, A. J., Tetrahedron Lett. 22, 4033 (1981); Pearson, A. J., and Rees, D. C., Tetrahedron Lett. 21, 3937 (1980). For studies in natural products chcmistry, including stcrcoselective synthesis and structure elucidation, sec Rahman, A.-Ur, Ed., Studies in Natural Products Chemistry, Elsevier Publishers, Amsterdam, The Netherlands, Vol. 1, Part A (1988); Vol. 2, Part A (1988); Vol. 3, Part B (1989).

[376] Birch, A. J., and Kelly, L. F., J. Organomet. Chem. 285, 267 (1985); Kelly, L. F., Narula, A. S., and Birch, A. J., Tetrahedron Lett. 21, 2455 (1980); Birch, A. J., Dahler, P., Narula, A. S., and Stephenson, G. R., Tetrahedron Lett. 21, 3817 (1980).

[377] Pearson, A. J., Richards, I. C., and Gardner, D. V., J. Chem. Soc. Chem. Commun. 807 (1982).

[378] Sanchez, I. H., and Tallabas, F. R., Chem. Lett. 891 (1981).

[379] Pearson, A. J., and O'Bricn, M. K., J. Chcm. Soc. Chcm. Commun. 1445 (1987); O’Brien, M. K., Pearson, A. J., Pinkerton, A. A., Schmidt, W., and Willman, K., J. Am. Chcm. Soc. 111, 1499 (1989); Pearson, A. J., and O’Brien, M. K., J. Org. Chem. 54, 4663 (1989).

[380] McDougal, P. G., and Schmuff, R. N., Prog. Chem. Org. Naturstoffe 47, 153 (1985).

[381] Pearson, A. J., Tetrahedron Lett. 21, 3929 (1980).

[382] Pearson, A. J., and Chandler, M., Tetrahedron Lett. 21, 3933 (1980).

[383] Pearson, A. J., and Khetani, V. D., J. Chem. Soc. Chem. Commun. 1772 (1986).

[384] Chandler, M., Mincione, E., and Parsons, P. J., J. Chcm. Soc. Chem. Commun. 1233 (1985).

[385] Andrus, W. A., Diss. Abstr. Int. B 42, 1886 (1981).

[385a] Pearson, A. J., Khetani, V. D., and Roden, B. A., J. Org. Chem. 54, 5141 (1989).

[386] Eliel, E. L., Allinger, N. L., Angyal, S. J., and Morrison, G. A., Conformational Analysis, American Chemical Society, Washington, D.C. (1981), pp. 206-210 and references cited therein.

[387] Pearson, A. J., Kole, S. L., and Chen, B., J. Am. Chem. Soc. 105, 4483 (1983).

[388] Pearson, A. J., and Chen, B., J. Org. Chem. 50, 2587 (1985).

[389] Pearson, A. J., and Khan, M. N. I., J. Org. Chem. 50, 5276 (1985).

[390] Airoldi, M., Barbera, G., Degancllo, G., and Gcnnaro, G., Organometallics 6, 398 (1987).

[391] Deganello, G. Transition Metal Complexes of Cyclic Polyolcfins, Academic Press, Ncw York (1979).

[392] Jiabi, C., Guixin, B., Zuohua, P., Shiwei, Z., and Yougi, T., J. Chem. Soc. Chem. Commun. 1273 (1987).

[393] Pearson, A. J., Lai, Y.-S., Lu, W., and Pinkerton, A. A., J. Org. Chem. 54, 3882 (1989); Pearson, A. J., and Ray, T., Tetrahedron Lett. 27, 3111 (1986). For an alternative synthesis of tylosin and carbomycin, see Peterson, I., and Mansuri, M. M., Tetrahedron 41, 3569 (1985). For reviews on the preparation of macrolides, see Mukayama, T., Angew. Chem. 91, 798 (1979); Angew. Chem. Int. Ed. Engl. 18, 707 (1979); Nicolaou, K. C., Tetrahedron 33, 683 (1977); Masamune, C., Bates, G. S., and Corcoran, J. W., Angew. Chem. 89, 602 (1977); Angew. Chem. Int. Ed. Engl. 16, 585 (1977).

[394] Pearson, A. J., Chen, Y.-S., Daroux, M. L., Tanaka, A. A., and Zettler, M., J. Chem. Soc. Chem. Commun. 155 (1987). See also Giese, B., Radicals in Organic Synthesis: Formation of Carbon-Carbon Bowls, Pergamon, Oxford, 1986.

[395] Wender, I., and Pino, P., Eds., Organic Synthesis via Metal Carbonyls, Interscience, New York (1968) and (1977), Vols. 1 and 2.

[396] Tsuji, J., Organic Synthcsis by Means of Transition Mctal Complexes, Springer-Verlag, Berlin and New York (1975).

[397] Cornclis, B., in New Syntheses with Carbon Monoxide, Falbe, J., Ed., Springer-Verlag, Berlin (1980); Orchin, M., Acc. Chem. Res. 14, 259 (1981). See also Nozaki, H., Ed., Current Trends in Organic Synthesis, Pergamon, Oxford (1983). For chiral arene chromium carbonyl complexes in asymmetric synthesis, see recent overview by Solladie-Cavallo, A., in refercnce 53, Chapter 3.

[398] Noyori, R., and Hayakawa, Y., Org. React. 29, 163 (1983).

[399] Noyori, R., Hayakawa, H., Takaya, H., Murai, S., Kobayashi, R., and Sonoda, N., J. Am. Chem. Soc. 100, 1759 (1978).

[400] Hoffmann, H. M. R., Angew. Chem. 95, 29 (1983). Angew. Chem. Int. Ed. Engl. 23, 1 (1984).

[401] Takaya, H., Makino, S., Hayakawa, Y., and Noyori, R., J. Am. Chem. Soc. 100, 1765 (1978).

[402] Noyori, R., Souchi, T., and Hayakawa, Y., J. Org. Chem. 40, 2681 (1975).

[403] Noyori, R., Makino, S., Baba, Y., and Hayakawa, Y., Tetrahedron Lett. 1049 (1974).

[404] Noyori, R., Baba, Y., Maino, S., and Takaya, H., Tetrahedron Lett. 1741 (1973).

[405] Noyori, R., Ann. N.Y. Acad. Sci. 295, 225 (1977).

[406] Hayakawa, Y., Yokoyama, K., and Noyori, R., J. Am. Chem. Soc. 100, 1791 (1978); ibid., 100, 1799 (1978).

[407] Noyori, R., and Hayakawa, Y., Tetrahedron 24, 5879 (1985).

[408] Noyori, R., Sato, T., and Hayakawa, Y., J. Am. Chcm. Soc. 100, 2561 (1978); Bull. Chem. Soc. Jpn. 57, 2515 (1984).

[409] Takaya, H., Makino, S., Hayakawa, Y., and Noyori, R., J. Am. Chem. Soc. 100, 1765 (1978). 
[410] Noyori, R., Makino, S., Okita, T., and Hayakawa, Y., J. Org. Chem. 40, 806 (1975).

[411] Hannessian, S. and Pernet, A. G., Adv. Carbohydr. Chem. Biochem. 33, 111 (1976).

[412] Gero, S. D., Cleophax, J., Mercier, D., and Olesker, A., in Synthetic Methods for Carbohydrates, El Khadem, H. S., Ed., American Chemical Society, Washington, DC (1976) p. 64.

[413] Buchanan, J. G., Progr. Chem. Org. Natural Produets 44, 243 (1983).

[414] Sato, T., Watanabe, M., Kobayashi, H., and Noyori, R., Bull. Chem. Soc. Jpn. 56, 2680 (1983) and references therein.

[415] Sato, T., and Noyori, R., Bull. Chem. Soc. Jpn. 56, 2700 (1983).

[416] Hayakawa, Y., Baba, Y., Makino, S., and Noyori, R., J. Am. Chem. Soc. 100, 1786 (1978).

[417] Hayakawa, Y., and Noyori, R., Bull. Chem. Soc. Jpn. 47, 2617 (1974).

[418] Fodor, G., Progr. Phytochem. 1, 491 (1968).

[419] Takaya, H., Hayakawa, Y., Makino, S., and Noyori, R., J. Am. Chem. Soc. 100, 1778 (1978).

[420] Hayakawa, Y., Sakai, M., and Noyori, R., Chem. Lett. 509 (1975).

[421] Franck-Neumann, M., Brion, F., and Martina, D., Tetrahedron Lett. 19, 5033 (1978).

[422] Noyori, R., Nishizawa, M., Shimizu, F., Hayakawa, Y., Maruoka, K., Hashimoto, S., Yamamoto, H., and Nazaki, H., J. Am. Chem. Soc. 101, 220 (1979).

[423] Nishizawa, M., and Noyori, R., Bull. Chem. Soe. Jpn. 54, 2233 (1981).

[424] Acro, M. J., Trammell, M. H., and White, J. D., J. Org. Chem. 41, 2075 (1976).

[425] Meinwald, J., Pure Appl. Chem. 49, 1275 (1977).

[426] Ansell, M. F., Caton, M. P. L., and Mason, J. S., Tetrahedron Lett. 22, 1141 (1981).

[427] Baker, R., Keen, R. B., Morris, M. D., and Tumer, R. W., J. Chem. Soc. Chem. Commun. 987 (1984).

[428] Morin, R. B., and Gorman, M., Eds., Chemistry and Biology of $\beta$-Lactam Antibiotics, Academic Press, New York (1982), Vols. I-III.

[429] Koster, W. H., Cimarusti, C. M., and Sykes, R. B., in referenee 428, Vol. III, Chapter 7.

[430] For a brief summary on different types of $\beta$-laetam antibioties, see Christensen, B. G., Chem. Britain 25, 371 (1989).

[431] Seebaeh, D., Imwinkelried, R., and Weber, T. Modern Synthetie Methods, Vol. 4, Springer Verlag, Berlin (1986); Kocovsky, P., Tureeek, F., Ha'jeek, J., Synthesis of Natural Produets: Problems of Stereoseleetivity, CPC Press, Boca Raton, Florida (1986).

[432] Cassigy, P. J., Albers-Schönberg, G., Geogelman, T. T., Miller, T., Arison, B., Stapley, E. O., Birnbaum, J., J. Chem. Soc. Chem. Commun. 637 (1981).

[433] Imada, A., Kitano, K., Kintaka, K., Muroi, M., and Asai, M., Nature (London) 289, 590 (1981).

[434] Cimarusti, C. M., and Sykes, R. B., Med. Res. Rev. 4, 7 (1984).

[435] Rajendra, G., and Miller, M. J., J. Org. Chem. 52, 4471 (1987).

[436] Sharma, S. D., Mehra, U., Khurana, J. P. S., and Pandhi, S. B., Synthesis, 990 (1987).

[437] Cevolot, L., Chevolot, A.M., Gajhede, M., Larsen, C., Anthoni, U., and Christophersen, C., J. Am. Chem. Soe. 107, 4542 (1985).

[438] Barrett, A. G. M., and Sturgess, M. A., J. Org. Chem. 52, 3940 (1987); Barrett, A. G. M., Graboski, G. G., Sabat, M., and Taylor, S. J., J. Org. Chem. 52, 4693 (1987); Kaneko, T., Okamoto, Y., and Hatada, K., J. Chem. Soc. Chem. Commun. 1511 (1987).

[439] Horton, A. M., and Ley, S. V., J. Organomet. Chem. 285, C17 (1985).

[440] Annis, G. D., Hebblethwaite, E. M., Hodgson, S. T., Hollinshead, D. M., and Ley, S. V., J. Chem. Soc. Perkin Trans. 1, 2851 (1983).

[441] Hodgson, S. T., Hollinshead, D. M., and Ley, S. V., J. Chem. Soe. Chem. Commun. 494 (1984).

[442] Hodgson, S. T., Hollinshead, D. M., Ley, S. V., Low, C. M. R., and Williams, D. J., J. Chem. Soc. Perkin Trans. 1, 2375 (1987).

[443] Rateliffe, R. W., Christensen, R. G., and Bouffard, F. A., J. Am. Chem. Soe. 102, 6161 (1980); Shiozaki, M., Isida, N., Maruyama, H., and Hiraoka, T. Tetrahedron 39, 2399 (1983).

[444] Hodgson, S. T., Holllinshead, D. M., and Ley, S. V., Tetrahedron 41, 5871 (1985).

[445] Corey, E. J., and Chaykovsky, M., J. Am. Chem. Soc. 87, 1353 (1965).

[446] Kametani, T., Huang, S.-P., Nagahara, T., Yokohama, S., and Thara, M., J. Chem. Soc. Perkin Trans. 1, 3048 (1981).

[447] For reviews, see Samuelson, B., Angew. Chem. 94, 881 (1982); Angew. Chem. Int. Ed. Engl. 21 902 (1982); Science (Washington) 220, 568 (1983).

[448] Nunn, K., Mosset, P., Grée, R., and Saalfrank, R. W., Angew. Chem. 100, 1233 (1988); Angew. Chem. Int. Ed. Engl. 27, 1188 (1988).

[449] Monpert, A., Martelli, J., Grée, R., and Carrié, R., Tetrahedron Lett. 22, 1961 (1981); Monpert, A., Doc. Eng. Thesis, University of Rennes (1983). For other pertinent $\mathrm{Fe}(\mathrm{CO})_{3}$ complexes, see Deeming, A. J., in Comprehensive Organometallie Chemistry, Wilkinson, G. and Stone, F. G. A., Eds., Pergamon Press, Oxford (1982) Vol. 4, pp. 425-474.

[450] Leblanc, Y., Fitzsimmons, B. J., Zamboni, R., and Rokaeh, J., J. Org. Chem. 53, 265 (1988).

[451] Loabassi, M., and Grée, R., Tetrahedron Lett. 29, 611 (1988).

[452] Gigou, A., Lellouche, J.-P., Beaucourt, J.-P., Toupet, L., and Grée, R., Angew. Chem. 101, 794 (1989); Angew. Chem. Int. Ed. Engl. 28, 755 (1989).

[453] For a recent discussion of enolate ehemistry, see an exeellent review: Seebach, D., Angew. Chem. 100, 1685 (1988); Angew. Chem. Int. Ed. Engl. 27, 1624 (1988).

[454] Heathcock, C. H., Asymmetric Reaetions and Processes in Chemistry, Eliel, E. L., Otsuka, S., Eds., Ameriean Chemieal Soeiety, Washington, DC (1982); Evans, D. A., Nelson, J. V., and Taber, T. R., Topics in Stereochemistry, Allinger, N. L., Eliel, E. L., Wilen, S. H., Eds., Wiley, New York (1982), Vol. 13, p. 1; Evans, D. A., Britton, T. C., Dorow, R. L., and Dellaria, J. F., J. Am. Chem. Soc. 108, 6395 (1986); Trimble, L. A., and Vederas, J. C., J. Am. Chem. Soc. 108, 6397 (1986). For Enzymes in Asymmetrie Synthesis, see Pratt, A. J., Chem. Britain 25, 287 (1989).

[455] Bandara, B. M. R., Bireh, A. J., and Kelly, L. F., J. Org. Chem. 49, 2496 (1984). 
[456] Bireh, A. J., Progress in Bio-organie Chemistry and Moleeular Biology, Ovehinnikov, Yu, A., Ed., Elsevier Publisher, New York (1984) p. 471.

[457] Birch, A. J., Bandara, B. M. R., Chamberlain, K. Chauncy, B., Dahler, P., Day, P. I., Jenkins, I. D., Kelly, L. F., Khor, T. C., Kretschmer, G., Liepa, A. J., Narula, A. S., Raverty, W. D., Rizzardo, E., Sell, C., Stephenson, G. R., Thompson, D. J., and Williamson, D. H., Tetrahedron (Woodward Speeial Issue) 37, 289 (1981).

[458] Birch, A. J., and Williamson, D. H., J. Chem. Soc. Perkin Trans. 1892 (1973).

[459] Semmelhack, M. F., and Fewkes, E. J., Tetrahedron, Lett. 28, 1497 (1987).

[460] Bashiardes, G., and Davies, S. G., Tetrahedron Lett. 28, 5563 (1987).

[461] Bashiardes, G., and Davies, S. G., Tetrahedron Lett. 29, 6509 (1988).

[462] Beckett, R. P., and Davies, S. G., J. Chem. Soe. Chem. Commun. 160 (1988).

[463] Parshall, G. W., and Nugent, W. A., Chemtechn. 184, 314, 376 (1988).

[464] Brunner, H., Top. Stereochem. 18, 129 (1988).

[465] Brown, J. M., Chem. Brit. 25, 276 (1989).

[466] Ito, Y., Sawamura, M., and Hayashi, T., J. Am. Chem. Soc. 108, 6405 (1986).

[467] Ito, Y., Sawamura, M., and Hayashi, T., Tetrahedron Lett. 28, 6215 (1987). See also Hayashi, T., Yamamoto, A., and Ito, Y., Chem. Lett. 177 (1987).

[468] Pastor, S. D., and Togni, A., J. Am. Chem. Soc. 111, 2333 (1989); see also Pastor, S. D., Tetrahedron 44, 2883 (1988).

[469] Cushman, M., and Chen, J. K., J. Org. Chem. 52, 1517 (1987).

[470] Hayashi, T., Yamamoto, A., Hojo, M., and Ito, Y., J. Chem. Soc. Chem. Commun. 495 (1989); Hayashi, T., Yamamoto, A., Ito, Y., Nishioka, E., Miura, H., and Yanagi, K, J. Am. Chem. Soc. 111, 6301 (1989).

[471] Roustan, J. L., Meror, J. Y., and Houlihan, F., Tetrahedron Lett. 20, 3721 (1979); Ladoulis, S. G., and Nieholas, K. M., J. Organomet. Chem. 285, C13 (1985); Siverman, G. S., Striekland, S., and Nieholas, K. M., Organometallies 5, 2117 (1986). More on carbon-carbon bond formation by means of organometallics, see Negishi, E., Acc. Chem. Res. 20, 65 (1987) and referenees therein.

[472] Zhou, B., and Xu, Y., J. Org. Chem. 53, 4419 (1988).

[473] Casey, C. P., Konings, M. S., and Marder, S. R., J. Organomet. Chem. 345, 125 (1988).

[474] Casey, C. P., Crocker, M., Nieeolai, G. P., Fayan, P. J., and Konings, M. S., J. Am. Chem. Soe. 110, 6070 (1988) and referenees therein.

[475] Yaouanc, J.-J., Clement, J.-C., and des Abbayes, H., J. Chem. Soc. Chem. Commun. 1379 (1988).

[476] Marr, G., and Rockett, B. W., J. Organomct. Chem. 298, 133 (1986).

[477] Castle, P. L., and Widdowson, D. A., Tetrahedron Lett. 27, 6013 (1986).

[478] Paquette, L. A., Gugelehuk, M., and MeLaughlin, M. L., J. Org. Chem. 52, 4732 (1987).

[479] Sorai, M., Nishimori, A., Hendriekson, D. N., Dong, T.-Y., and Cohn, M. J., J. Am. Chem. Soe. 109, 4266 (1987) and reference 4 therein.

[480] Takas, J. M., Anderson, L. G., Bindu Madhavan, G. V., Creswell, M. W., Seely, F. L., and Devroy, W. F., Organometallics 5, 2395 (1986).

[481] Frühauf, H.-W., and Seils, F., J. Organomet. Chem. 323, 67 (1987); Frühauf, H.-W., Pein, I., and Seils, F., Organometallies 6, 1613 (1987).

[482] Rosenblum, M., Turnbull, M. M., and Foxman, B. M., Organometallies 5, 1062 (1986).

[483] Howell, J. A. S., Squibb, A. D., and Walton, G., J. Organomet. Chem. 319, C45 (1987).

[484] Corriu, R. J. P., Guerin, C., Henner, B. J. L., and Wong Chi Man, W. W. C., J. Organomet. Chem. 320, C1 (1987).

[485] Casey, C. P., Gohdes, M. A., and Meszaros, M. W., Organometallics 5, 196 (1986).

[486] Casey, C. P., Marder, S. R., Colborn, R. E., and Goodson, P. A., Organometallies 5, 199 (1986) and references therein.

[487] Birch, A. J., and Bandara, B. M. R., Tetrahedron Lett. 21, 2981 (1980).

[488] Gabioud, R., Vogel, P., Pinkerton, A. A., and Sehwarzenbaeh, D., Hclv. Chim. Aeta 69, 271 (1986).

[489] Birch, A. J., Raverty, W. D., and Stephenson, G. R., Tetrahedron Lett. 21, 197 (1980).

[490] See also Scheffold, R., Ed., Modern Synthetic Methods. 4. Synthesis of Enantiometrically Pure Compounds; Springer-Verlag, New York (1986); see also reference 346.

[491] Alcock, N. W., Crout, D. H. G., Henderson, C. M., and Thomas, S. E., J. Chem. Soc. Chem. Commun. 746 (1988).

[492] Sorriso, S., and Cardaci, G., J. Chem. Soc., Dalton Trans. 1041 (1975).

[493] Brodie, A., Johnson, B., Josty, P., and Lewis, J., J. Chem. Soc. Dalton Trans. 2031 (1972).

[494] Bankston, D., J. Org. Chem. 54, 2003 (1989).

[495] Cotton, F., and Troup, J., J. Am. Chem. Soc. 96, 3438 (1974); Cotton, F., and Lahuerta, P., Inorg. Chem. 14, 116 (1975).

[496] Chen, J., Lei, G., Shao, M., Xu, X., and Zhang, Z., J. Chem. Soc. Chem. Commun. 1296 (1988).

[497] Grist, N. J., Hogarth, G., Knox, S. A. R., Lloyd, B. R., Morton, D. A., Orpen, A. G., J. Chem. Soe. Chem. Commun. 673 (1988).

[498] Seyferth, D., Henderson, R. S., Song, L.-C., and Womack, G. B., J. Organomet. Chem. 292, 9 (1985).

[499] Seyferth, D., Wood, T. G., and Henderson, R. S., J. Organomet. Chem. 336, 163 (1987).

[500] Seyferth, D., Hoke, J. B., and Wheeler, D. R., J. Organomet. Chem. 341, 421 (1988).

[501] Rosenhein, L. D., and McDonald, J. W., J. Organomet. Chem. 345, 143 (1988).

[502] Amatore, C., Verpeaux, J.-N., Madonik, A., Desbois, M.-H., and Astrue, D. J. Chem. Soc. Chem. Commun. 200 (1988).

[503] Liaw, W.-F., Kim, C., Darensbourg, M. Y., Rheingold, A. L., J. Am. Chem. Soc. 111, 4049 (1988).

[504] Glavee, G. N., and Angelici, R. J., J. Am. Chem. Soc. 111, 3598 (1989).

[505] Kuroda, Y., Sasaki, Y., Shiroiwa, Y., and Tabushi, I., J. Am. Chem. Soc. 110, 4049 (1988).

[506] Berg, J. M., and Holm, R. H., Iron-Sulfur Proteins, Sprio, T. G., Ed., Wiley-Interscienee, New York (1983), Vol. IV, Chapter 1.

[507] Rius, G., and Lamotte, B., J. Am. Chem. Soc. 111, 2464 (1989) and important references 1-4 therein. 
[508] Geoffroy, G. L., and Wrighton, M. S., Organometallic Photochemistry, Academic Press, New York (1979).

[509] Meyer, T. J., and Caspar, J. V., Chem. Rev. 85, 187 (1985).

[510] reference 195 , pp. 617-632.

[511] Bock, C. R., and Von Gustrof, E. A. K., Adv. Photochem. 10, 222 (1976); Jaenicke, O., Kerber, R. C., Kirsch, P., Von Gustrof, E. A. K. and Rumin, R., J. Organomet. Chem. 187, 361 (1980).

[512] Burstein, B. E., McKee, D., and Platz, M. S., J. Am. Chem. Soc. 111, 3428 (1989).

[513] Johnson, C. E., and Trogler, W. C., J. Am. Chem. Soc. 103, 6352 (1981) and reference 2-7 therein.

[514] Van Dijk, H. K., Stufkcns, D. J., and Oskam, A., J. Am. Chem. Soc. 111, 541 (1989).

[515] Casey, C. P., and Austin, E. A., J. Am. Chem. Soc. 110, 7106 (1988) and references cited therein.

[516] Lisko, J. R., and Jones, W. M., Organometallics 4, 944 (1985).

[517] Stenstrom, Y., and Jones, W. M., Organometallics 5, 178 (1986).

[518] Stenstrom, Y., Klauck, G., Koziol, A., Palenik, G. J., and Jones, W. M., Organometallics 5, 2155 (1986).

[519] Vioget, P., Vogel, P., and Roulet, R., Angew. Chem. 94, 454 (1982); Angew. Chem. Int. Ed. Engl. 21,430 (1982).

[520] Corriu, R. J., Morcau, J. J. E., and Pataud-Sat, M., Organometallics 4, 623 (1985).

[521] McMullen, L. A., and Herndon, J. W., Abstracts of Papers, 194th National Meeting of the American Chemical Society, Ncw Orleans, LA (1987), ORGN 285.

[522] Blaha, J. P., Dewan, J. C., and Wrighton, M. S., Organometallics 5, 899 (1986).

[523] Belmont, J. A., and Wrighton, M. S., Organometallics 5, 1421 (1986).

[524] Zou, C., Wrighton, M. S., and Blaha, J. P., Organometallics 6, 1452 (1987).

[525] Knoll, K., Huttner, G., Zsolnai, L., and Orama, O., J. Organomet. Chem. 327, 379 (1987).

[526] Jaeger, T., Aime, S., and Vahrenkamp, H., Organometallics 5, 245 (1986).

[527] Kruzic, P. J., Brlere, R., and Rey, P., Organomctallics 4, 801 (1985).

[528] Gadd, G. E., Poliakoff, M., and Turner, J. J., Organometallics 6, 391 (1987).

[529] van Dijk, H. K., Stufkens, D. J., Oskam, O., Rotteveel, M., and Heijdenrijk, D., Organometallics 6, 1665 (1987).

[530] Randolph, C. L., and Wrighton, M. S., Organometallics 6, 365 (1987).

[531] Cowley, A. H., and Norman, N. C., Progr. Inorg. Chem. 34, 1 (1986).

[532] Fukuda, A., Koyama, T., Hanabusa, K., Shirai, H., Nakahara, H., and Fukuda, K., J. Chem. Soc. Chem. Commun. 1104 (1988).

[533] Cowley, A. H., and Barron, A. R., Acc. Chem. Res. 21, 81 (1988).

[534] Carrano, C. J., Cowley, A. H., Nunn, C. M., Pakulski, M., and Quashie, S. J. Chem. Soc. Chem. Commun. 170 (1988).

[535] Brauer, I. J., Kn〈ppel, P. C., and Stelzer, O., J. Chem. Soc. Chem. Commun. 551 (1988); Kagan, H. B. in Asymmetric Synthesis, Morrison, J. E., Ed., Academic Press, Orlando, Florida, Vol. 5, p. 1.

[536] Baker, M. V., and Field, L. D., J. Am. Chem. Soc. 109, 2825 (1987).

[537] Dave, T., Berger, S., Bilger, E., Kalctsch, H., Pebler, J., Knecht, J., and Dimroth, K., Organomctallics 4, 1565 (1985).

[538] Baum, G., and Massa, W., Organometallics 4, 1572 (1985).

[539] Hammud, H. H., and Moran, G. M., J. Organomet. Chem. 307, 255 (1986).

[540] Sappa, E., J. Organomet. Chem. 323, 83 (1987).

[541] Caminade, A. M., Majoral, J.-P., Sanchez, M., Organometallics 6, 1459 (1987).

[542] Coille, N. J., Darling, E. A., Hearn, A. W., and Johnston, P., J. Organomet. Chem. 328, 375 (1987).

[543] Sielisch, T., and Behrens, U., J. Organomet. Chem. 327, 85 (1987).

[544] Rahman, M. M., Liu, H. Y., Prock, A., and Giering, W. P., Organometallics 6, 650 (1987).

[545] Rockett, B. W., and Marr, G., J. Organomet. Chem. 305, 199 (1986).

[546] Schlögel, K, J. Organomet. Chem. 300, 219 (1986).

[547] Rockett, B. W., and Marr, G., J. Organomet. Chem. 318, 231 (1987); ibid., 343, 79 (1988); ibid., 343, 553 (1988).

[548] Gmelin Handbook of Inorganic Chemistry Eighth Edition Fe-Organoiron Compounds, Ferrocene, Springer Verlag, Berlin (1986), Part A8, pp. 1-400.

[549] Hillman, M., Austin, J. D., and Kvick, A., Organomctallics 4, 316 (1985).

[550] Paquette, L. A., Schrich, P. F. T., Hathaway, S. J., Hsu, L.-Y., and Gallucci, J. C., Organometallics 5, 490 (1986).

[551] Spcncer, J. T., and Grimes, R. N., Organometallics 6, 328 (1987).

[552] Hisatome, M., Yoshihashi, M., Masuzoe, K., and Yamakawa, K., Organometallics 6, 1498 (1987).

[553] Dophin, D., Ed., The Porphyrins, Academic Press, New York (1987-1979), Vols. I-VII.

[554] Gill, J. P., and Eglinton, G., Educ. Chem. (London) 24, 181 (1987) and references therein.

[555] Lippard, S. J., Angew. Chem. 100, 353 (1988); Angew. Chem. Int. Ed. Engl. 27, 344 (1988); Gray, H. B., and Lever, A. B. P., Eds., Iron Porphyrins, VCH Publishers, New York, XIII (1989); Loehr, T. M., Ed., Iron Carriers, and Iron Proteins, VCH Publishers, New York, XVII (1989).

[556] Ortiz de Montellano, P. R., Ed., Cytochrome P-450, Structure, Mechanism, and Biochemistry, Plenum Press, New York (1986).

[557] Shin, K., and Goff, H. M., J. Am. Chem. Soc. 109, 3140 (1987).

[558] Okamoto, T., Sasaki, K., and Oka, S., J. Am. Chem. Soc. 110, 1187 (1988).

[559] Shiro, Y., Takeda, M., and Morishima, I., J. Am. Chem. Soc. 110, 4030 (1988).

[560] Erler, B. S., Scholz, W. F., Lee, Y. J., Scheidt, W. R., and Reed, C. A., J. Am. Chem. Soc. 109, 2644 (1987); Arasasingham, R. D., Cornman, Ch. R., and Balch, A. L., J. Am. Chem. Soc. 111, 7800 (1989); Traylor, T. G., Fann, W.-P., and Bandyopadhyay, D., J. Am. Chem. Soc. 111, 8009 (1989).

[561] Wyslouch, A., Latos-Grazynski, L., Grzeszczuk, M., and Drabent, K., J. Chem. Soc. Chem. Commun. 1377 (1988); Lavelle, D., The Chemistry and Biochemistry of N-Substituted Porphyrins, VCH Publishers, New York (1987).

[562] Beer, P. D., and Kurek, S. S., J. Organomet. Chem. 336, C17 (1987).

[563] Kim, K., Fettinger, J., Sessler, J. L., Cyr, M., Hugdahl, J., Collman, J. P., and Ibers, J. A., J. Am. Chem. Soc. 111, 403 (1989). 
[564] Setsune, J., Ikcda, M., Iida, T., and Kitao, T., J. Am. Chem. Soc. 110, 6572 (1988).

[565] Lexa, D., Saveant, J.-M., and Wang, D. L., Organometallics 5, 1428 (1986).

[566] Reagen, W. K., and Radonovich, L. J., J. Am. Chem. Soc. 109, 5274 (1987).

[567] Cox, D. D., Benkovic, S. J., Bloom, L. M., Bradley, F. C., Nelson, M. J., Que, Jr., L., and Wallick, D. E., J. Am. Chem. Soc. 110, 2026 (1988).

[568] Whittaker, J. W., and Solomon, E. I., J. Am. Chem. Soc. 110, 5329 (1988).

[569] Kerber, R. C., J. Organomet. Chem. 344, 1 (1988).

[570] Kerber, R. C., J. Organomet. Chem. 360, 319 (1989).

[571] Hegedus, L. S., J. Organomet. Chem. 343, 147 (1988).

[572] Hegedus, L. S., J. Organomct. Chem. 360, 409 (1989).

[573] Marko, L., J. Organomet. Chem. 343, 399 (1988).

[574] Jorgensen, K. A., Chem. Rev. 89, 431 (1989).

[575] Macaudière, P., Linne, M., Tambute, A., and Caude, M., Chiral Separations by HPLC: Applications to Compounds of Pharmaceutical Interest, Wilcy/Ellis Horwood, New York (1989) pp. 399-445.

[576] Winter, M. J., in The Chemistry of the Metal-Carbon Bond, Hartley, F. R., and Patai, S., Eds., John Wiley, Chichester-New York (1985), Vol. 3, Chapter 5, pp. 259-294.

[577] Schore, N. E., Chem. Rev. 88, 1081 (1988).

[578] Kahn, B. E., and Rieke, R. D., Chem. Rev. 88, 733 (1988).

[579] de Meijere, A., and tom Dieck, H., Eds., Organo-Metallics in Organic Synthesis, Aspects of a Modern Interdisciplinary Field, Springer-Verlag, New York and Berlin (1988).

[580] Corey, E. J., and Cheng, X.-M., The Logic of Chemical Synthesis, John Wiley, New York (1989).

[581] Silverman, G. S., Strickland, S., and Nicholas, K. M., Organometallics 5, 2117 (1986). See also Roustan, J. L., Merour, J. V., and Houlihan, F. Tetrahedron Lett. 19, 3721 (1978); Pearson, A. J., Tetrahedron Lett. 16, 3617 (1975).

[582] Ladoulis, S. J., and Nicholas, K. M., J, Organomet. Chem. 286, C41 (1985).

[583] Bodnar, T. W., and Culter, A. R., Organometallics, 4, 1558 (1985).

[584] Stephenson, G. R., J. Organomet. Chem. 286, C41 (1985).

[585] Mitsudo, T., Ishihara, A., Kadukura, M., and Watanabe, Y. Organometallics 5, 238 (1986).

[586] Bogdan, P. L., Woodcock, C., and Shriver, D. F., Organometallics 6, 1377 (1987). For a recent review on transition metal clusters, see Sappa, E., Tiripicchio, A., and Braunstein, P. Chem. Rev. 83, 203 (1983); Moskovits, M., Ed., Metal Clusters, John Wiley \& Sons, New York, 1986.

[587] Sakurai, H., Hirama, K., Nakadaira, Y., and Kabuto, C., J. Am. Chem. Soc. 109, 6880 (1987).

[588] Chen, J., Lei, G., Jin, Z., Hu, L., and Wei, G., J. Chem. Soc. Chem. Commun. 731 (1988).

[589] Ueno, K., Tobita, H., Shimoi, M., and Ogino, H., J. Am. Chem. Soc. 110, 4092 (1988).

[590] Edelmann, F., and Takats, J., J. Organomet. Chem. 344, 351 (1988).

[591] Odiaka, T. I., J. Organomet. Chem. 345, 135 (1988).

[592] Chlow, T. J., and Ding, M.-F., J. Organomet. Chem. 344, 351 (1988).

[593] Laurent, P., Sabo-Etiennc, S., Larsonneur, A.-M., and des Abbayes, H., J. Chem. Soc. Chem. Commun. 929 (1988).

[594] Sun, C.-H., and Chow, T. J., J. Chem. Soc. Chem. Commun. 535 (1988).

[595] Goldstein, S., Czapski, G., Cohen, H., and Meyerstein, D., J. Am. Chem. Soc. 110, 3903 (1988).

[596] Hashiba, S., Fuchigami, T., and Nonaka, T., J. Org. Chem. 54, 2475 (1989).

[597] Sakai, S., Kozawa, H., Yoshinaga, Y., Kosugi, K., and Fukuzawa, S., J. Chem. Soc. Chem. Commun. 663 (1988).

[598] Rosenblum, M., Turnbull, M. M., and Begum, M. K., J. Organomet. Chem. 321, 67 (1987).

[599] Grosselin, J.-M., and Dixneuf, P. H., J. Organomet. Chem. 5, 1376 (1986).

[600] Roberts, R. M. G., Silver, J., Wells, A. S., and Wilkinson, S. P., J. Organomet. Chem. 327, 247 (1987).

[601] Attali, S., Dahan, F., and Mathieu, R., Organometallics 5, 1376 (1986).

[602] Sheu, C., Sobkowiak, A., Zhang, L., Ozbalik, N., Barton, D. H. R., and Sawyer, D. T., J. Am. Chem. Soc. 111, 8030 (1989).

[603] Reger, D. L., and Belmore, K. A., Organometallics 4, 305 (1985) and references therein.

[604] Ma, H., Weber, P., Ziegler, M. L., and Ernst, R. D., Organometallics 5, 2009 (1986).

[605] Cariou, M., Etienne, M., Guerchais, J. E., Kergoat, R., and Kubicki, M. M., J. Organomet. Chem. 327,393 (1987).

[606] Blyholder, G., Zhao, K.-M., and Lawless, M., Organometallics 4, 1371 (1985).

[607] Giuseppetti, M. E., and Cutler, A. R., Organometallics 6, 970 (1987).

[608] Pannell, K. H., Kapoor, R. N., Wells, M., and Giasolli, T., Organometallics 6, 663 (1987).

[609] Lee, C. C., Abd-El-Aziz, R. L., Chowdhury, U. S. G., and Piorko, A., J. Organomct. Chcm. 315, 79 (1986).

[610] Wright, M. E., Nelson, G. O., and Glass, R. S., Organometallics 4, 245 (1985).

[611] Knors, C., Kuo, G.-H., Lauher, J. W., Eigenbrot, C., Helquist, P., Organometallics 6, 988 (1987).

[612] Akita, M., Kondoh, A., Kawahara, T., and Moro-oka, Y., J. Organomet. Chem. 323, C43 (1987).

[613] Casey, C. P., Marder, S. R., and Rheingold, A. L., Organometallics 4, 761 (1985).

[614] Etienne, M., and Guerchais, J. E., J. Organomet. Chem. 314, C81 (1986).

[615] Kuhn, N., and Schumann, H., J. Organomet. Chem. 315, 93 (1986).

[616] Callan, B., and Manning, A. R., J. Organomet. Chem. 306, C61 (1986).

[617] Kumar, R., Manning, A. R., and Murray, P. T., J. Organomet. Chem. 323, 53 (1987).

[618] Raubenheimer, H. G., Kruger, G. J., and van A. Lombard, A., J. Organomet. Chem. 323, 385 (1987).

[619] Carbera, E., Daran, J.-C., Jeannin, Y., and Kristiansson, O., J. Organomet. Chem. 310, 367 (1986).

[620] Lourdichi, M., and Mathieu, R., Organometallics 5, 2067 (1986).

[621] Pannell, K. H., and Rice, J. R., J. Organomct. Chem. 341, 415 (1988). 
[622] Hu, Y.-R., Leung, T. W., Su, S.-S. H., Wojcicki, A., Calligaris, M., and Nardin, G., Organometallics 4, 1001 (1985).

[623] Wojcicki, A., in Fundamental Research in Organometallic Chemistry, Tsutsui, M., Ishii, Y., and Huang, Y., Eds., van NostrandReinhold, New York (1982) pp. 569-597.

[624] Johnson, M. D., Acc. Chem. Res. 11, 57 (1978).

[625] Peake, D. A., and Grss, M. L., Organometallics 5, 1236 (1986).

[626] Wang, D., and Squires, R. R., Organometallics 6, 905 (1987).

[627] Osella, D., Gobetto, R., Montangero, P., Zanello, P., and Cinquantini, A., Organometallics 5, 1247 (1986).

[628] Beach, D. B., Bertoncello, R., Granozzi, G., and Jolly, W. L., Organometallics 4, 311 (1985).

[629] Blyholder, G., Zhao, K.-M., and Lawless, M., Organometallics 4, 2170 (1985).

[630] Lee, C. C., Chowdhury, R. L., Piorko, A., and Sutherland, R. G., J. Organomet. Chem. 310, 391 (1986).

[631] Baker, R. T., Calabrese, J. C., Krusic, P. J., Therien, M. J., and Trogler, W. C., J. Am. Chem. Soc. 110, 8392 (1988).

[632] De Paoli, M. A., Lechat, J. R., and Inumaru, A. T., J. Organomet. Chem. 320, 91 (1987).

[633] Vogler, H., J. Organomet. Chem. 306, 99 (1986).

[634] Begley, M. J., Puntambekar, S. G., and Wright, A. H., J. Organomet. Chem. 329, C7 (1987).

[635] Chapman, S., Kane-Maquire, L. A. P., and Kanitz, R., J. Organomet. Chem. 329, C11 (1987).

[636] Begley, M. J., Puntambckar, S. G., and Wright, A. H., J. Chem. Soc. Chem. Commun. 1251 (1987).

[637] King, R. B., and Oliver, J. P., Eds., Organomctallic Chemistry Review; Annual Survey: Transition Metals in Organic Synthesis, Elscvier Science Publisher, Amstcrdam-New York (1987); King, R. B., and Eisch, J. J., Eds., Organometallic Synthesis, Vol. 4, Elsevier, Amsterdam (1988).

[638] Kreiter, C. G., in Advances in Organometallic Chemistry, Stone F. G. A., and West, R., Eds., Academic Press, Inc., Orlando, Florida (1986), Vol. 26, Chapter 6. See also Lees, A., Chem. Rev. 87, 711 (1987).

[639] Xie, C.-L., and Hendrickson, D. N., J. Am. Chem. Soc. 109, 6981 (1987).

[640] Gibson, D. H., Ong, T.-S., J. Am. Chem. Soc. 109, 7191 (1987).

[641] McMurry, T., Hosseini, M. W., Garrett, T. M., Hahn, F. E., Reyes, Z. E., and Raymond, K. N., J. Am. Chem. Soc. 109 , 7196 (1987).

[642] Borovic, A. S., Murch, B. P., Quc, J. Jr., Papacfthymiou, V., and Münck, E., J. Am. Chem. Soc. 109, 7190 (1987).

[643] Lomis, T. J., Siuda, J. F., and Shepherd, R. E., J. Chem. Soc. Chem. Commun. 290 (1988).

[644] Vincent, J. B., Huffman, J. C., and Christon, G., J. Am. Chem. Soc. 110, 6898 (1988).

[645] Murch, B. P., Bradley, F. C., Boyle, P. D., Papaefthymiou, V., and Que, L. Jr., J. Am. Chem. Soc. 109, 7993 (1987).

[646] Pascal, R. A. Jr., and Huang, S.-S., J. Am. Chem. Soc. 109, 2854 (1987).

[647] Watanabe, Y., and Ishimura, Y., J. Am. Chem. Soc. 111, 410 (1989).

[648] Corey, E. J., and Walker, J. C., J. Am. Chem. Soc. 109, 8108 (1987).

[649] Tanase, T., Kuhihara, K., Yano, S., Kobayashi, K., Sakurai, T., and Yoshikawa, S., J. Chem. Soc. Chem. Commun. 1562 (1985).

[650] Isida, K., Yashiro, M., Yano, S., Hidai, M., and Yoshikawa, S., J. Am. Chem. Soc. 110, 2015 (1988) and references therein; Selke, R., J. Organomct. Chem. 370, 241 (1989).

[651] Andrews, M. A., Organometallics 8, 2703 (1989).

[652] Selke, R., J. Organomet. Chem. 370, 241 (1989).

[653] Kunz, H. and Schanzenbach, D., Angew. Chem. 101, 1042 (1989); Angew. Chem. Int. Ed. Engl. 28,1068 (1989).

[654] Brookhart, M., Studabaker, W. B., Humphrey, M. B., and Husk, G. R., Organometallics 8, 132 (1989).

[655] Brookhart, M., and Buck, R. C., J. Organomet. Chem. 370, 111 (1989).

[656] Brookhart, M., and Liu, Y., Organometallics 8, 1569 (1989); ibid., 8, 1572 (1989).

[657] Casey, C. P., and Smith, L. J., Organomctallics 8, 2288 (1989).

[658] Brunncr, H., Fisch, K., Jones, P. G., and Salbeck, J., Angcw. Chem. 101, 1558 (1989); Angcw. Chem. Int. Ed. Engl. 28, 1521 (1989).

[659] Patin, H., Darchen, A., and Lhadi, E. K., J. Organomet. Chcm. 375, 91 (1989).

[660] Howard, P. W., Stephenson, G. R., and Taylor, S. C., J. Organomet. Chem. 370,97 (1989).

[661] Schmid, G., and Rohling, T., J. Organomet. Chem. 375, 21 (1989).

[662] Pike, R. D., Ryan, W. J.,. Carpenter, G. B., and Sweigert, D. A., J. Am. Chem. Soc. 111, 8535 (1989).

[663] Paquette, L. A., O'Doherty, G. A., Miller, B. L., Rogers, R. D., Rheingold, A. L., and Geib, S. L., Organometallics 8, 2167 (1989).

[664] Morita, N., Asao, T., Sotokawa, H., Hatano, M., and Tajiri, A., J. Organomet. Chem. 339, C1 (1988).

[665] Moinet, C., Le Bozec, H., and Dixneuf, P. H., Organometallics 8, 1493 (1989) and important references 5-11 therein.

[666] Bruce, M. I., Pure Appl. Chem. 58, 553 (1986); Bruce, M. I., and Swincer, A. G., Adv. Organomet. Chem. 22, 59 (1983).

[667] Dötz, K. H., Pure Appl. Chcm. 55, 1689 (1983).

[668] Mitsudo, T.-A., Watanabe, H., Sasaki, T., Takcgami, Y., Watanabe, Y., Kafuku, K., and Nakatsu, K., Organometallics 8, 368 (1989).

[669] Reference 195, pp. 260-289.

[670] Roger, C., Toupet, L., and Lapinte, C., J. Chem. Soc. Chem. Commun. 713 (1988).

[671] Zhao, S.-K., Knors, C., and Helquist, P., J. Am. Chem. Soc. 111, 8527 (1989).

[672] Lotz, S., Dillen, J. L. M., and van Dyk, M. M., J. Organomet. Chem. 371, 371 (1989).

[673] Crocq, V., Daran, J.-C., and Jeannin, Y., J. Organomet. Chem. 373, 85 (1989).

[674] Reddy, B. R., J. Organomet. Chem. 375, C51 (1989).

[675] Etienne, M., and Toupet, L., J. Chem. Soc. Chem. Commun. 1110 (1989).

[676] Barrett, A. G. M., Carpenter, N. E., Mortier, J., and Sabat, M., Organometallics 9, 151 (1990).

[677] Bianchini, C., Mcli, A., Pcruzzini, M., and Zanobini, F., Organomctallics 9, 241 (1990). 
[678] Schrock, R. R., in Reactions of Coordinated Ligands, Braterman, P. S., Ed., Plenum, New York, Vol. 1, Chapter 3 (1986).

[679] Fishcer, H., Hofmann, P., Krcissl, F. R., Schrock, R. R., Schubert, U., and Wciss, K., Carbyne Complexes, VCH Publishers, New York (1988).

[680] Reference 78, Chapter 40.

[681] Muller, F., van Koten, G., Vrieze, K., Duineveld, K. A. A., Heijdenrijk, D., Mak, A. N. S., and Stam, C. H., Organometallics 8, 1324 (1989); Muller, F., van Koten, G., Vrieze, K., and Hcijdenrijk, D., Organometallics 8, 33 (1989); Muller, F., van Koten, G., Vrieze, K., Heijdenrijk, D., Krijnen, B. B., and Stam, C. H., Organometallics 8, 41 (1989); Muller, F., van Koten, G., Kraakman, M. J. A., Vrieze, K. Heijdenrijk, D., and Zoutberg, M. C., Organometallics 8, 1331 (1989).

[682] Muller, F., van Koten, G., Polm, L. H., Vrieze, K., Zoutberg, M. C., Heijdenrijk, D., Kragten, E., and Stam, C. H., Organometallics 8, 1340 (1989).

[683] Matachek, J. R., Angelici, R. J., Schugart, K. A., Haller, K. J., and Fenske, R. F., Organometallics 3, 1038 (1984).

[684] Braunstein, P., Keller, E., and Vahrenkamp, H., J. Organomet. Chem. 165, 233 (1979).

[685] Maatta, E. A., and Devore, D. D., Angew. Chem. 100, 583 (1988); Angew. Chem. Int. Ed. Engl. 27,569 (1988).

[686] Richter-Addo, G. B., and Hunter, A. D., Inorg. Chem. 28, 4063 (1989).

[687] Hunter, A. D., and McLernon, J. L., Organometallics 8, 2679 (1989).

[688] Hunter, A. D., and Szigety, A. B., Organometallics 8, 2670 (1989).

[689] Stille, J. K., Smith, C., Anderson, O. P., and Miller, M. M., Organometallics 8, 1040 (1989).

[690] Seyfcrth, D., Anderson, L. L., and Davis, W. M., Organometallics 8, 1371 (1989).

[691] Seyferth, D., Ruschke, D. P., Davis, W. M., Cowle, M., and Huntcr, A. D., Organomctallics 8, 836 (1989).

[692] Ching, S., Jensen, M. P., Sabat, M., and Shriver, D. F., Organomctallics 8, 1058 (1989).

[693] Ching, S., Sabat, M., and Shriver, D. F., Organometallics 8, 1047 (1989).

[694] Schroeder, N. C., Fuchess, R., Jacobson, R. A., and Angelici, R. J., Organometallics 8, 521 (1989); Buchholz, D., Huttner, G., Imhof, W., Zsolnai, L., and Günauer, D., J. Organomet. Chem. 381, 79 (1990).

[695] Wuchcrer, E. J., Tasi, M., Hanscrt, B., Powcll, A. K., Garland, M.-T., Halet, J.-F., Saillard, J.-Y., and Vahrenkamp, H., Inorg. Chem. 28, 3564 (1989).

[696] Tasi, N., Powell, A. K., and Vahrenkamp, H., Angew. Chem. 101, 327 (1989); Angew. Chem. Int. Ed. Engl. 28, 318 (1989).

[697] Richter-Addo, G. B., and Hunter, A. D., Inorg. Chem. 28, 4063 (1989).

[698] Zoet, R., Elsevier, C. J., van Koten, G., Versloot, P., Vrieze, K., van Wijnkoop, Duineveld, C. A., Goubitz, K., Heijdenrijk, D., and Stam, C. H., Organometallics 8, 23 (1989).

[699] Housecroft, C. E., Shongwe, M. S., and Reingold, A. L., Organometallics 8, 2338 (1989).

[700] Frühauf, H.-W., Seils, F., and Stam, C. H., Organometallics 8, 2338 (1989).

[701] Ishihara, A., Mitsudo, T.-A., and Watanabe, Y., J. Organomet. Chem. 368, 199 (1989).

[702] Adams, R. D., Chen, G., Sun, S., and Wolfe, T. A., J. Am. Chem. Soc. 112, 868 (1990)

[703] Levitre, S. A., Cutler, A. R., and Forscher, T. C., Organomctallics 8, 1133 (1989).

[704] Cox, M. G., Soye, P., and Manning, A. R., J. Organomet. Chem. 369, C21 (1989).

[705] Sidebotham, R. P., Beer, P. D., Hamor, T. A., Jones, C. J., and McCleverty, J. A., J. Organomet. Chem. 371 , C31 (1989).

[706] Casey, C. P., Crocker, M., and Vosejpka, P. C., Organometallics 8, 278 (1989).

[707] Casey, C. P., Gable, K. P., and Roddick, D. M., Organometallics 9, 221 (1990).

[708] Kahn, B. E. and Rieke, R. D., Chem. Rev. 88, 733 (1988).

[709] Adams, R. D., Chcm. Rev. 89, 1703 (1989).

[710] Walcs, D. J., and Stonc, A. J., Inorg. Chcm. 28, 3120 (1989). For various geometries of clusters, see Wales, D. J., Mingos, D. M. P., Slee, T., and Zhenyang, L., Acc. Chem. Res. 23, 17 (1990).

[711] Gates, B. C., Guczi, L., and Knozinger, H., Eds., Mctal Clusters in Catalysis, Elsevier, Amsterdam (1986).

[712] Bruce, M. I., J. Organomet. Chem. 242, 147 (1983).

[713] Muetterties, E. L., and Krause, M. J., Angew. Chem. 95, 135 (1983); Angew. Chem. Int. Ed. Engl. 22, 135 (1983).

[714] Herrmann, W. A., Angew. Chem. 98, 57 (1986); Angew. Chem. Int. Ed. Engl. 25, 56 (1986).

[715] Clark, D. T., Sutin, K. A., and McGlinchey, M. J., Organometallics 8, 155 (1989).

[716] Laschi, F., and Zanello, P., Organometallics 8, 620 (1989).

[717] Lo Sterzo, C., Miller, M. M., and Stille, J. K., Organometallics 8, 2331 (1989).

[718] Bunnel, E. E., Vallc, L., Joncs, N. L., Carroll, P. J., Gonzalcz, M., Munoz, N., and Manriquer, J. M., Organometallics 7, 789 (1988).

[719] Wang, J., Crespi, A. M., Sabat, M., Harris, S., Woodcock, C., and Shriver, D. F., Inorg. Chem. 28, 697 (1989).

[720] Lentz, D., and Michacl, H., Angcw. Chem. 101, 329 (1989); Angew. Chem. Int. Ed. Engl. 28, 321 (1989).

[721] Alvarez, S., Ferrer, M., Reina, R., Rossell, O., Seco, M., and Solans, X., J. Organomet. Chem. 377, 291 (1989).

[722] Anema, S. G., Mackay, K. M., and Nicholson, B. K., J. Organomet. Chem. 372, 25 (1989).

[723] Anema, S. G., Mackay, K. M., and Nicholson, B. K., Inorg. Chem. 28, 3158 (1989).

[724] Rumin, R., Petillon, F., Manojlovic-Muir, L., and Muir, K. W., J. Organomet. Chem. 371, C9 (1989).

[725] Jenkins, H. A., Loeb, S. J., and Stephan, D. S., Inorg. Chem. 28, 1998 (1989).

[726] Braunstein, P., Guarino, N., de Mcric de Bellefon, C., and Richcrt, J.-L., Angew. Chem. 99, 77 (1987); Angew. Chem. Int. Ed. Engl. 26, 88 (1987).

[727] Carbera, E., Daran, J. C., and Jeannin, Y., Organometallics 8, 1811 (1989).

[728] Adams, R. D., Chen, G., Tanner, J. T., and Yin, J., Organometallics 8, 2493 (1989).

[729] Bandyopadhyay, A. K., Khattar, R., and Fchler, T. P., Inorg. Chem. 28, 4434 (1989).

[730] Vahrenkamp, H., J. Organomet. Chem. 370, 65 (1989).

[731] Herrmann, W. A., Angew. Chem. 98, 57 (1986); Angew. Chem. Int. Ed. Engl. 25, 56 (1986).

[732] Whitmire, K. H., J. Coord. Chcm. 17, 95 (1988). 
[733] Norman, N. C., Chem. Soc. Rev. 17, 269 (1988).

[734] Mathey, F., Angew. Chem. 99, 285 (1987); Angew. Chem. Int. Ed. Engl. 26, 275 (1987).

[735] Bohle, D. S., and Roper, W. R., Organometallics 5, 1607 (1986).

[736] Scherer, O. J., Angew. Chem. 97, 905 (1985); Angew. Chem. Int. Ed. Engl. 24, 924 (1985).

[737] Crisp, G. T., Salem, G., Wild, S. B., and Stephens, F. S., Organometallics 8, 2360 (1989).

[738] Rahman, M. M., Liu, H.-Y., Eriks, K., Prock, A., and Giering, W. P., Organometallics 8, 1 (1989).

[739] Regitz, M., and Binger, P., Angew. Chem. 100, 1541 (1988); Angew. Chem. Int. Ed. Engl. 27, 1484 (1988).

[740] Appel, R., Schuhn, W., and Nieger, M., Angew. Chem. 100, 437 (1988); Angew. Chem. Int. Ed. Engl. 27, 416 (1988).

[741] Berryhill, S. R., Clevenger, G. L., and Burdurlu, F. Y., Organometallics 4, 1509 (1985).

[742] Liebeskind, L. S., and Welker, M. E., Organometallics 2, 194 (1983).

[743] Brinkman, K., and Helquist, P., Tctrahedron Lett. 26, 2845 (1985).

[744] Abbott, S., Baird, G. J., Davies, S. G., Dordor-Hedgccock, I. M., Maberly, T. R., Walker, J. C., and Warner, P., J. Organomct. Chem. 289, C13 (1985).

[745] Nakazawa, H., Sone, M., and Miyoshi, K., Organometallics 8, 1564 (1989).

[746] Paciello, R. A., Manriquez, J. M., and Bercaw, J. E., Organometallics 9, 260 (1990).

[747] Ching, S., and Shriver, D. F., J. Am. Chem. Soc. 111, 3243 (1989).

[748] Zybill, C., Wilkinson, D. L., Leis, C., and Müller, G., Angew. Chem. 101, 206 (1989); Angew. Chem. Int. Ed. Engl. 28, 203 (1989).

[749] Schubert, U., and Knorr, M., Inorg. Chem. 28, 1765 (1989).

[750] Colomer, E., Corriu, R. J. P., and Lheureux, M., Organometallics 8, 2343 (1989).

[751] Berryhill, S. R., and Corriu, R. J. P., J. Organomet. Chcm. 370, C-1 (1989).

[752] Frank-Neumann, M., Sedrati, M., and Abdali, A., J. Organomet. Chem. 339, C-9 (1988).

[753] Bellachioma, G., Cardaci, G., Colomer, E., and Corriu, R. J. P., Inorg. Chem. 28, 519 (1989).

[754] Barrau, J., Hamida, N. B., Agrebi, A., and Satge, J., Organometallics 8, 1585 (1989).

[755] Lappert, M. F., McGeary, M. J., and Parish, R. V., J. Organomet. Chem. 373, 107 (1989).

[756] Janzen, A. F., Nquyen, T. Q., Qu, F., and Marat, K., J. Chem. Soc. Chem. Commun. 1274 (1988).

[757] Maier, G., and Born, D., Angew. Chem. 101, 1085 (1989); Angew. Chem. Int. Ed. Engl. 28, 1050 (1989).

[758] King, R. B., and Chorghade, G. S., J. Organomet. Chem. 341, 407 (1988).

[759] Ellis, J. E., and Chen, Y.-S., Organometallics 8, 1350 (1989).

[760] Suades, J., Dahan, F., and Mathleu, R., Organometallics 8, 842 (1989).

[761] Mitsudo, T., Watanabe, H., Sasaki, T., Takegami, Y., Watanabe, Y., Kafuku, K., and Nakatsu, K., Organometallics 8, 368 (1989).

[762] del Pozo, A. G., Caminade, A.-M., Dahan, F., Majoral, J.-P., and Mathieu, R., J. Chem. Soc. Chem. Commun. 574 (1989).

[763] Nakazawa, H., Kadei, Y., and Miyoshi, K, Organometallics 8, 2851 (1989).

[764] Caballero, C., Chavez, J. A., Göknur, O., Lochel, I., Nuber, B., Pfisterer, H., and Ziegler, M. L., J. Organomet. Chem. 371,329 (1989).

[765] Weber, L., Bungardt, D., Sonnenberg, U., and Boese, R., Angew. Chem. 100, 1594 (1988); Angew. Chem. Int. Ed. Engl. 27, 1537 (1988).

[766] Pohl, S., Lotz, R., Saak, W., and Haase, D., Angew. Chem. 101, 355 (1989); Angew. Chem. Int. Ed. Engl. 28, 344 (1989).

[767] Whitmire, K. H., Shieh, M., and Cassidy, J., Inorg. Chem. 28, 3164 (1989).

[768] Luo, S., and Whitmire, K. H., J. Organomet. Chem. 376, 297 (1989).

[769] Seyferth, D., Womack, G. B., Archer, C. M., and Dewan, J. C., Organometallics 8, 430 (1989).

[770] Seyferth, D., Womack, G. B., Archer, C. M., Organometallics 8, 443 (1989).

[771] Cowie, M., DeKock, R. L., Wagenmaker, T. R., Sayferth, D,. Henderson, R. S., Gallegher, M. K., Organometallics 8, 119 (1989).

[772] Sayferth, D., Ruschke, D. P., Davis, W. M., Cowie, M., and Hunter, A. D., Organometallics 8, 836 (1989).

[773] Liaw, W.-F., Kim, C., Darensbourg, M. Y., and Rheingold, A. L., J. Am. Chem. Soc. 111, 3591 (1989).

[774] Glavec, G. N., and Angelici, R. J., J. Am. Chem. Soc. 111, 3598 (1989).

[775] Li, J., Hoffmann, R., Mealli, C., and Silvestre, J., Organometallics 8, 1921 (1989).

[776] Shaver, A., Butler, I. S., and Gao, J. P., Organometallics 8, 2079 (1989).

[777] Raubenheimer, H. G., Linford, L., and van Lombard, A. A., Organometallics 8, 2062 (1989).

[778] Leboeuf, A., Leblanc, J. C., and Moîe, C., J. Organomet. Chem. 372, 391 (1989).

[779] Desbois, M.-H., and Astruc, D., Angew. Chem. 101, 459 (1989); Angew. Chcm. Int. Ed. Engl. 28, 460 (1989).

[780] Guerchais, V., Thépot, J.-Y., and Lapinte, C., J. Chem. Soc. Chem. Commun. 1554 (1989).

[781] Wu, X., Bose, K. S., Sin, E., Averill, B. A., Organometallics 8, 251 (1989).

[782] Donegan, P., and Manning, A. R., J. Organomet. Chem. 336, 115 (1987).

[783] Giuseppetti-Dery, M. E., Landrum, B. E., Shibley, J. L., and Cutler, A. R., J. Organomct. Chem. 378, 421 (1989).

[784] Fässler, Th., and Huttner, G., J. Organomet. Chem. 376, 367 (1989).

[785] Patin, H., LeRouzic, A., Lhadi, E. K., Darchen, A., Mousser, A., and Grandjen, D., J. Organomet. Chem. 375, 101 (1989).

[786] Bouzig, M., Pradére, J. P., Palvadeau, P., Vénien, J. P., and Toupet, L., J. Organomet. Chem. 369, 205 (1989).

[787] Mayr, A. J., Pannell, K. H., Carrasco-Flores, B., and Cervates-Lee, F., Organometallics 8, 2961 (1989).

[788] Fässler, Th., Buchholz, D., Huttner, G., and Zsolnai, L., J. Organomet. Chem. 369, 297 (1989).

[789] Glidewell, Ch., Chem. Britain 26, 137 (1990).

[790] Reddy, D., Lancaster, J. R., Jr., and Cornforth, D. P., Science 221, 769 (1983). 
[791] Carney, M. J., Papaefthymoiu, G. C., Frankel, R. B., and Holm, R. H., Inorg. Chem. 28, 1497 (1989).

[792] Ciurli, S., Carney, M. J., Holm, R. H., and Papaefthymiou, G. C., Inorg. Chem. 28, 2696 (1989).

[793] Coucouvanis, D., Challen, P. R., Koo, S.-M., Davis, W. M., and Dunham, W. R., Inorg. Chem. 28,4181 (1989).

[794] Ciurli, S., and Holm, R. H., Inorg. Chem. 28, 1685 (1989).

[795] Tomohiro, T., Uoto, K., and Okuno, H. Y., J. Chem. Soc. Chem. Commun. 194 (1990). See also Behr, A., Carbon Dioxide Activation by Metal Complexes, VCH, Weinheim (1988); Ichikawa, M., Polyhedron 7, 2351 (1989).

[796] Snyder, B. S., and Holm, R. H., Inorg. Chem. 29, 274 (1990); You, J.-F., Snyder, B. S., Papaefthymiou, G. C., and Holm, R. H., J. Am. Chem. Soc. 112, 1067 (1990).

[797] Roberts, M. W., Chem. Soc. Rev. 18, 451 (1989).

[798] Shen, G., Sobkowiak, A., Jeon, A., and Sayer, D. T., J. Am. Chem. Soe. 112, 879 (1990).

[799] Refcrence 555(a); Lippard, S. J., Chem. Britain 222 (1986).

[800] Brudvig, G. W., and Crabtree, R. H., Prog. Inorg. Chem. 37, 99 (1989).

[801] Vineent, J. B., and Christon, G., Adv. 1norg. Chem. 33, 197 (1989).

[802] Que, L. Jr., and Scarrow, R. C. in Metal Clusters in Proteins, Que, L., Jr., Ed., ACS Symposium Series 372, American Chemical Society, Washington, DC, pp. 158-178 (1988).

[803] Borovik, A. S., Papaefthymiou, V., Taylor, L. F., Anderson, O. P., and Que, L., Jr., J. Am. Chem. Soc. 111, 6183 (1989).

[804] Wilkins, P. C., and Wilkins, R. G., Coord. Chem. Rev. 79, 195 (1987); Pearee, L. L., Kurtz, D. M., Jr., Xia, Y.-M., and Debrunner, P. G., J. Am. Chem. Soc. 109, 7286 (1987).

[805] Reichard, P., and Ehrenberg, A., Science (Washington, DC) 221, 514 (1983).

[806] Fox, B. G., Surerus, K. K., Münck, E., and Lipscomb, J. D., J. Biol. Chem. 263, 10553 (1988).

[807] Doi, K., Antanaitis, B. C., and Aisen, P., Struk. Bonding (Berlin) 70, 1 (1988); Drüeke, S., Wieghardt, K., Nuber, G,. Weiss, J., Fleischhauer, H.-P., Gehring, S., and Haase, W., J. Am. Chem. Soc. 111, 8622 (1989).

[808] Scarrow, R. C., Pyrz, J. W., and Quc, L., Jr., J. Am. Chem. Soe. 112, 657 (1990).

[809] Feng, X., Bott, S. G., and Lippard, S. J., J. Am. Chem. Soc. 111, 8046 (1989).

[810] Turowski, P. N., Armstrong, W. H., Roth, M. E., and Lippard, S. J., J. Am. Chem. Soc. 112, 681 (1990).

[811] Tolman, W. B., Bino, A., and Lippard, S. J., J. Am. Chem. Soc. 111, 8522 (1989).

[812] Sanders-Loehr, J., in Iron Carriers and Iron Proteins, Loehr, T. M., Ed., VCH Publishers, New York - Weinheim, p. 373 (1989).

[813] Beer, R. H., Tolman, W. B., Bott, S. G., and Lippard, S. J., Inorg. Chem. 28, 4559 (1989).

[814] Norman, R. E., Yan, S., Que, L., Jr., Baekes, G., Ling, J., Sanders-Loehr, J., Zhang, J. H., and O'Connor, C. J., J. Am. Chem. Soc. 112, 1554 (1990); Yan, S., Cox, D. D., Pearce, L. L., Juarez-Careia, C., Que, L., Jr., Zhang, J. H., and O'Connor, C. J., Inorg. Chem. 28, 2507 (1989).

[815] Drüekc, S., Wieghardt, K., Nubcr, B., and Weiss, J., Inorg. Chem. 28, 1414 (1989); Drüeke, S., Wieghadt, K., Nuber, B., Weiss, J., Bominaar, E. L., Sawaryn, A., Winkler, H., and Trautwein, A. X., 1norg. Chem. 28, 4477 (1989).

[816] Spartalian, K., and Carrano, C., J. Inorg. Chem. 28, 19 (1989).

[817] Tse, P., Scopes, R. K., and Wedd, A. G., J. Am. Chem. Soc. 111, 8703 (1989).

[818] Basu, P., Choundhury, S. B., Pal, S., and Chakravorty, A., Inorg. Chem. 28, 2680 (1980).

[819] Nelsen, M. J., J. Am. Chem. Soc. 110, 2985 (1988).

[820] True, A. E., McLean, P., Nelson, M. J., Orme-Johnson, W. H., and Hoffman, B. M., J. Am. Chem. Soe. 112, 651 (1990).

[821] Nanthakumar, A., and Goff, H. M., Inorg. Chem. 28, 4559 (1989).

[822] Nishida, Y., and Yokomizo, T., 1norg. Chim. Acta 163, 9 (1989).

[823] Reference 69.

[824] Wahlgren, C. G., Addison, A. W., Burman, S, Thompson, L. K., Sinn, E., and Rowe, T. M., Inorg. Chim. Aeta 166, 59 (1989).

[825] Thorp, H. H., Sarneski, J. E., Brudvig, G. W., and Crabtree, R. H., J. Am. Chem. Soe. 111, 9249 (1989).

[826] Bodner, A., Drūeke, S., Wieghardt, K., Nuber, B., and Weiss, J., Angew. Chem. 102, 60 (1990); Angew. Chem. Int. Ed. Engl. 29, 68 (1990).

[827] Bockman, T. M., and Kochi, J. K., J. Am. Chem. Soc. 110, 1294 (1989).

[828] Bergamini, P., DiMartino, S., Maldotti, A., Sosters, S., and Traverso, O., J. Organomet. Chem. 365, 341 (1989).

[829] Fox, M. A., and Chanon, M., Eds., Photoinitiated Electron Transfer, Elsevier, Amsterdam, Parts C and D (1988).

[830] Menon, R. K., and Brown, T. L., Inorg. Chem. 28, 1370 (1989).

[831] Catheline, D., and Astruc, D., J. Organomet. Chem. 272, 417 (1984); Astruc, D., Acc. Chem. Res. 12, 377 (1986).

[832] Chrisope, D. R., and Schuster, G. B., Organometallics 8, 2737 (1989).

[833] Bursten, B. E., and Cayton, R. H., Organometallics 7, 1349 (1988); Bursten, B. E., and Cayton, R. H., Polyhedron 7, 943 (1988).

[834] Geoffroy, G. L., and Wrighton, M. S., Organometallic Photochemistry, Academic Press, New York (1979).

[835] Meyer, T. J., and Caspar, J. V., Chem. Rcv. 85, 187 (1985).

[836] Bursten, B. E., MeKec, S. D., and Platz, M. S., J. Am. Chem. Soc. 111, 3428 (1989).

[837] Santos, E. H., Stcin, E., and Vichi, E. J. S., J. Organomct. Chem. 375, 197 (1989).

[838] Leboeuf, A., Leblanc, J. C., and Möise, C., J. Organomet. Chem. 372, 391 (1989).

[839] Herrick, R. S., Frederic, A. B., and Duff, Jr., R. R., Organometallics 8, 1120 (1989).

[840] Traee, R. L., and Joncs, W. M., J. Organomet. Chem. 376, 103 (1989).

[841] Castellanic, M. P,. and Tyler, D. R., Organometallics 8, 2113 (1989).

[842] Pannell, K. H., Wang, L.-J., and Rozell, J. M., Organometallies 8, 550 (1989).

[843] van Dijk, H. K., Stufkens, D. J., and Oskam, A., J. Organomet. Chem. 340, 227 (1988).

[844] van Dijk, H. K., Kok, J. J., Stufkens, D. J., and Oskam, A., J. Organomet. Chem. 362, 163 (1989).

[845] Russell, D. H., Ed., Gas-Phase Inorganic Chemistry, Plenum Press, New York (1989); Maier, J. P., (Ed.,) lon Cluster lon Spcctroscopy and Structure, Elsevier Publishers, Amstcrdam and New York (1989). 
[846] Shilov, A. E., Activation of Saturated Hydroearbons by Transition Metal Complexes, D. Reidel, Dordrecht (1984).

[847] Dahlenburg, L., Nachr. Chem. Tech. Lab. 36, 899 (1988).

[848] Schwarz, H., Acc. Chem. Res. 22, 282 (1989).

[849] Armentrout, P. B., and Beachamp, J. L., Acc. Chem. Res. 22, 315 (1989).

[850] Eller, K., Zummack, W., and Schwarz, H., J. Am. Chem. Soc. 112, 621 (1990).

[851] Steinrück, N., and Schwarz, H., Organometallics 8, 759 (1989).

[852] Prüsse, T., and Schwarz, H., Organometallies 8, 2856 (1989).

[853] Czekay, G., Drewello, T., Eller, K., Zummack, W., and Schwarz, H., Organometallies 8, 2439 (1989).

[854] Jacobson, D. B., Gord, J. R., and Freiser, B. S., Organometallies 8, 2957 (1989).

[855] MeDonald, R. N., Reed, D. J., and Chowdhury, A. K., Organometallics 8, 1122 (1989).

[856] Bjarnason, A., and Taylor, J. W., Organometallics 8, 2020 (1989).

[857] Jacobson, D. B., J. Am. Chem. Soe. 111, 1626 (1989).

[858] Kuhlman, T., Roth, S., Roziere, J., and Siebert, W., Angew. Chem. 98, 88 (1986); Angew. Chem. Int. Ed. Engl. 25, 105 (1986).

[859] Plitzko, K.-D., and Boekelheide, V., Organometallics 7, 1573 (1988); Boekelheide, V., Pure Appl. Chem. 58, 1 (1986).

[860] Jutzi, P., Siemeling, U., Müller, A., and Bögge, H., Organometallics 8, 1744 (1989).

[861] Hopf, H., and Dannheim, J., Angew. Chem. 100, 724 (1988); Angew. Chem. Int. Ed. Engl. 27, 701 (1988).

[862] Arnold, R., Foxman, B. M., Rosenblum, M., Euler, W. B., Organometallics 7, 1253 (1988); Arnold, R., Matchett, S. A., and Rosenblum, M., Organometallies 7, 2261 (1988).

[863] Seherer, O. J., Sehwall, J., Swarowsky, H., Wolmershauser, G., Kaim, W., and Gross, R., Chem. Ber. 121, 443 (1988); Herberich, G. E., Hausmann, I., and Klaff, N., Angew. Chem. 101, 328 (1989); Angew. Chem. Int. Ed. Engl. 28, 319 (1989); Jammis, E. D., and Reddy, A. C., Organometallics 7, 1561 (1988).

[864] Jemmis, E. D., and Reddy, A. C., J. Am. Chem. Soc. 112, 722 (1990).

[865] Herberieh, G. H., Dunne, B. J., and Hessner, B., Angew. Chem. 101, 798 (1989); Angew. Chem. Int. Ed. Engl. 28, 737 (1989).

[866] Webb, R. J., Rheingold, A. L., Geib, S. J., Staley, D. L., and Hendriekson, D. N., Angew. Chem. 101, 1422 (1989); Angew. Chem. Int. Ed. Engl. 28, 1388 (1989).

[867] Hor, T. S. A., and Phang, L.-T., J. Organomet. Chem. 373, 319 (1989); J. Organomet. Chem. 381, 121 (1990).

[868] Beer, P. D., Sikanyika, H., Blackburn, C., and MeAleer, J. F., J. Chem. Soc. Chem. Commun. 1831 (1989).

[869] Herberhold, M., Leitner, P., Dörnhöfer, C., and Ott-Lastic, J., J. Organomet. Chem. 377, 281 (1989).

[870] Todres, Z. V., Yanovsky, A. I., Ermekov, D. S., and Struchkov, Yu. T., J. Organomet. Chem. 369, 377 (1989).

[871] Todres, Z. V., and Ermekov, D. S., J. Organomet. Chem. 369, 371 (1989).

[872] Wang, Yu-P., and Hwu, J.-M., J. Organomet. Chem. 371, 71 (1989).

[873] Kabouche, Z., and Dinh, N. H., J. Organomet. Chem. 375, 191 (1989).

[874] Hardeastle, K. I., Deeming, A. J., Nuel, D., and Powell, N. I., J. Organomet. Chem. 375, 217 (1989).

[875] Beer, P. D., Smythe, A. C., Tite, E. L., and Ibbotson, A., J. Organomet. Chem. 376, C11 (1989).

[876] More on ferrocene reactions, see J. Organomet. Chem. 373, C-38 (1989).

[877] Yongskulrote, W., Bramlett, J. M., Mike, C. A., Durham, B., and Allison, N. T., Organometallies 8, 556 (1989).

[878] Ruiz, J., Garland, M. T., Roman, E., and Astruc, D., J. Organomet. Chem. 377, 309 (1989).

[879] Hayashi, T., Yamamoto, A., Hojo, M., Kishi, K., Ito, Y., Nishioka, E., Miura, H., and Yanagi, K., J. Organomet. Chem. 370, 129 (1989); Hayashi, T., Yamamoto, A., Hojo, M., Ito, Y., J. Chem. Soc. Chem. Commun. 495 (1989).

[880] Gross, R., and Kaim, W., J. Organomet. Chem. 383, 347 (1987); Gross, R., and Kaim, W., Inorg. Chem. 26, 3596 (1987).

[881] Astruc, D., Acc. Chem. Res. 19, 377 (1986); Chem. Rev. 88, 1189 (1988).

[882] Hamon, J.-R., and Astruc, D., Organometallics 8, 2243 (1989).

[883] Mandon, D., and Astruc, D., Organometallies 8, 2372 (1989); J. Organomet. Chem. 369, 383 (1989).

[884] Hunter, A. D., Organometallies 8, 1118 (1989).

[885] Schäufele, H., Hu, D., Pritzkow, H., and Zenneck, U., Organometallics 8, 396 (1989).

[886] Lacoste, M., Rabaa, H., Astrue, D., LeBeuze, A., Saillard, J.-Y., Precigoux, G., Courseille, C., Ardoin, N., and Bowyer, W., Organometallies 8, 2233 (1989).

[887] Goldschmidt, Z., Hezroni, D., Gottlieb, H. E., and Antebi, S., J. Organomet. Chem. 373, 235 (1989).

[888] Desbois, M.-H., Astrue, D., Guillin, J., and Varret, F., Organometallics 8, 1848 (1989).

[889] Desbois, M.-H., and Astruc, D., Organometallics 8, 1841 (1989).

[890] Heck, J., Massa, W., J. Organomet. Chem. 376, C-15 (1989).

[891] Kuhn, N., Horn, E.-M., Boese, R., and Augart, N., Angew. Chem. 101, 354 (1989); Angew. Chem. Int. Ed. Engl. 28, 342 (1989). See also Yongxiang, M., Zhengzhi, Z., Yun, M,. and Gang, Z., Inorg. Chem. Acta 165, 185 (1989).

[892] Scherer, O., and Brück, T., Angew. Chem. 99, 59 (1987); Angew. Chem. Int. Ed. Engl. 26, 59 (1987).

[893] Moulines, F., and Astrue, D., J. Chem. Soc. Chem. Commun. 614 (1989).

[894] Heppert, J. A., Thomas-Miller, M. E., Swepston, P. N., and Extine, M. W., J. Chem. Soc. Chem. Commun. 280 (1988).

[895] Benn, R., Rufinska, A.,, Kralik, M. S., and Emst, R. D,. J. Organomet. Chem. 375, 115 (1989).

[896] Gleiter, R., Hyla-Kryspin, I., Ziegler, M. L., Sergeson, G., Green, J. C., Stahl, L., and Ernst, R. D., Organometallies 8, 298 (1989).

[897] Paquette, L. A., O'Doherty, G. A., Miller, B. L., Rogers, R. D., Rheingold, A. L., and Geib, S. L., Organometallies 8, 2167 (1989).

[898] Beer, P. D., and Kurek, S. S., J. Organomet. Chem. 366, C-6 (1989). See also Rieker, C., Ingram, G., Jaintner, P., Schottenberger, H., and Schwarzhaus, K. E., J. Organomet. Chem. 381, 127 (1990).

[899] Saraceno, R. A., Riding, G. H., Allcock, H. R., and Ewing, A. G., J. Am. Chem. Soc. 110, 7254 (1988).

[900] Beer, P. D., Chem. Soc. Rev. 18, 409 (1989). 
[901] Bruice, T. C., in Mechanistic Principles of Enzyme Activity, Liebman, J. F., and Greenberg, A., Eds., VCH, New York and Weinheim, Chapter 6 (1989).

[902] Lavallee, D. K., in Mechanistic Principles of Enzyme Activity, Licbman, J. F., and Greenberg, A., Eds., VCH, Ncw York and Weinheim, Chapter 7 (1989).

[903] Shedbalkar, V. P., Modi, S., and Mitra, S., J. Chem. Soc. Chem. Commun. 1238 (1988).

[904] Collman, J. P., Wagenknecht, P. S., Hembre, R. T., Lewis, N. S., J. Am. Chem. Soc. 112, 1294 (1990).

[905] Collman, J. P., Halbert, T. R., and Suslick, K. S., in $\mathrm{O}_{2}$ Binding and Activation by Metal Centers, Spiro, T. D., Ed., Wiley, New York (1980); Collman, J. P., Acc. Chem. Res. 10, 265 (1977).

[906] Shikama, K., Coord. Chem. Rev. 83, 73 (1988). See also Uemori, Y., and Kyuno, E., Inorg. Chem. Acta 165, 115 (1989).

[907] Drain, C. M., and Cordon, B. B., Inorg. Chem. 28, 4374 (1989); Nasri, H., Goodwin, J. A., and Scheidt, W. R., Inorg. Chem. 29, 185 (1990); Collman, J. P., Braunman, J. I., Iverson, B. L., Sessler, J. L., Morris, R. M., and Gibson, Q. H., J. Am. Chem. Soc. 105, 3052 (1983); Collman, J. P., Gagne, R. R., Reed, C. A., Halbert, T. R., Lang, G., and Robinson, W. T., J. Am. Chem. Soc. 97, 1427 (1975).

[908] Schappacher, M., Fischer, J., and Weiss, R., Inorg. Chem. 28, 389 (1989); Momenteau, M., Loock, B., Tetrean, C., Lavalette, D., Croisy, A., Schaeffer, C., Huel, C., and Lhoste, J.-M., J. Chem. Soc., Perkin Trans. 2, 249 (1987).

[909] Komatsu, T., Hasegawa, E., Nishide, H., Tsuchida, E., J. Chem. Soc. Chem. Commun. 66 (1990).

[910] Uemori, Y., and Kyuno, E., Inorg. Chem. 28, 1690 (1989).

[911] Rodriguez, R. E., and Kelly, H. C., Inorg. Chem. 28, 589 (1989).

[912] Dougherty, T. J., Proc. SPIE Int. Soc. Opt. Eng. Ser. 5 997, 2 (1988); Andreoni, A., and Cubeddu, R., Eds., Porphyrins in Tumor Therapy, Plenum Press, New York (1984).

[913] Fülling, G., Schröder, D., and Franck, B., Angew. Chem. 101, 1550 (1989); Angew. Chem. Int. Ed. Engl. 28, 1519 (1989).

[914] Nanthakumar, A., and Goff, H. M., Inorg. Chem. 28, 4559 (1989). See also Zhang, Y., Jones, J. G., and Sweigart, D. A., Inorg. Chim. Acta 166, 85 (1989); Finnegan, M. G., Lappin, A. G., and Scheidt, W. R., Inorg. Chem. 29, 181 (1990).

[915] Gueutin, C., Lexa, D., Savéant, J.-M., and Wang, D.-L., Organometallics 8, 1607 (1989).

[916] Breslow, R., Brown, A. B., MeCullough, R. D., and White, P. W., J. Am. Chem. Soc. 111, 4517 (1989); Fielding, L., More, K. M., Eaton, G. R., and Eaton, S. S., J. Am. Chem. Soc. 28, 3127 (1989).

[917] Koch, C. A., Reed, C. A., Brewer, G. A., Rath, N. P., Scheidt, W. R., Gupta, G., and Lang, G., J. Am. Chem. Soc. 111, 7645 (1989); Traylor, T. G., and Xu, F., J. Am. Chem. Soc. 112, 178 (1990); Landergren, M., and Baltzer, L., Inorg. Chem. 29, 556 (1990).

[918] Groves, J. T., and Viski, P., J. Am. Chem. Soc. 111, 8537 (1989).

[919] Sukarai, H., Mori, Y., and Shibuya, M., Inorg. Chim. Acta 162, 23 (1989).

[920] Mansuy, D., Pure Appl. Chem. 59, 759 (1987).

[921] Cook, B. R., Reinert, T. J., and Suslick, K. S., J. Am. Chem. Soc. 108, 7281 (1986).

[922] Konishi, K., Aida, T., and Inoe, S., J. Org. Chcm. 55, 816 (1990); Sukurai, H. Mori, Y., and Shibuya, M., Inorg. Chim. Acta 162, 23 (1989).

[923] Grimshaw, J., and Trocha-Grimshaw, J., J. Chem. Soc. Chem. Commun. 157 (1990) and references thercin.

[924] Adams, P. A., and Goold, R. D., J. Chem. Soc. Chem. Commun. 97 (1990).

[925] Tajima, K., Shigematsu, M., Jinno, J., Ishizu, K., and Ohya-Nishiguchi, H., J. Chem. Soc. Chem. Commun. 144 (1990).

[926] Tajima, K, Inorg. Chim. Acta 164, 115 (1989).

[927] Kerber, R C., J. Organomet. Chem. 380, 77 (1990).

[928] Noyori, R., and Kitamura, M., in Modern Synthetic Methods, Volume 5, Sheffold, R., Ed., Springer-Verlag, New York and Berlin, Chapter 3 (1989).

[929] Pearson, A. J., SYNLETT, 10 (1990).

[930] de Meijere, A., and Wessjohann, L., SYNLETT 20 (1990).

[931] Atta-ur-Rahman, Ed., Stereoselective Synthesis, Vol. 6 (Part D), Elsevier Publishers, Amsterdam-New York (1990).

[932] Tullins, T. D., Ed., Metal-DNA Chemistry ACS Symposium Series No. 402, American Chemical Society, Washington, DC (1989).

[933] King, R. B., Johnson, M. K., Kurtz, D. M., Kutal, C., Norton, M. L., and Scott, R. A., Eds., Inorganic Compounds with Unusual Properties, Advances in Chemistry Series, No. 226, American Chemical Society, Washington, DC (1990).

[934] Kerber, R. C., J. Organomet. Chem. 354, 131 (1983).

[935] Williams, G. M., Rudisill, D. E., Barnum, B. A., Hardcastle, K., Heyn, R. H., Kozak, C. J., and McMillan, J. W., J. Am. Chem. Soc. 112, 205 (1990) and references therein.

[936] Edelman, F., and Takats, J., J. Organomet. Chem. 344, 351 (1988).

[937] Williams, G. M., Fisher, R. A., and Heyn, R. H., Organometallies 5, 818 (1986).

[938] Williams, G. M., and Rudisill, D. E., Inorg. Chem. 28, 797 (1989).

[939] Morita, H., Asao, T., Sotokawa, H., Hatano, M., and Tajiri, A., J. Organomet. Chem. 339, C1 (1988).

[940] Saha, M., Bagby, B., and Nicholas, K. M., Tetrahedron Lett. 27, 915 (1986).

[941] Howell, J. A. S., Squibb, A. D., Goldschmidt, Z., Gottlick, H. E., Almadhoun, A., and Goldberg, I., Organometallies 9, 80 (1990).

[942] Brunet, J.-J., and Passelaige, E., J. Organomet. Chem. 375, 203 (1989).

[943] Birk, R., Berke, H., Hund, H.-U., Huttner, G., Zsolnai, L., Dahlenburg, L., Behrens, U., and Sielisch, T., J. Organomet. Chem. 372, 397 (1989).

[944] Barrett, A. G. M., Carpenter, N. E., Mortier, J., and Sabat, M., Organometallics 9, 151 (1989).

[945] Peng, W.-J., Gamble, A. S., Templeton, J. L., and Brookhart, M., Inorg. Chem. 29, 463 (1990). 
[946] Braunstein, P., and Nobel, D., Chem. Rcv. 89, 1927 (1989).

[947] Lentz, D., J. Organomet. Chem. 377, 305 (1989).

[948] Cheng, M.-H., Wu, Y.-J., Wang, S.-W., and Liu, R., J. Organomet. Chem. 373, 119 (1989).

[949] Buchholz, D., Huttner, G., and Zsolnai, L., J. Organomet. Chem. 381, 97 (1990).

[950] Conti, N. J., Crowther, D. J., Tivakompannarai, S., and Jones, W. M., Organometallics 9, 175 (1990).

[951] McArdle, P., MacHale, D., Mahon, M., and Cunningham, D., J. Organomet. Chem. 381, C13 (1990).

[952] Hunter, A. D., Organomctallics 8, 1118 (1989).

[953] Kobayashi, M., and Wuest, J. D., Organometallics 8, 2843 (1989).

[954] Roustan, J.-L., Abedini, M., and Baer, H. H., J. Organomet. Chem. 376, C20 (1989).

[955] Liu, H., Golovin, N., Fertal, D. A., Tracey, A. A., Eriks, K., Giering, W. P., and Prock, A., Organometallics 8, 1454 (1989).

[956] Bonamico, M., Fares, V., Flamini, A., Imperatori, P., and Poli, N,. Angew. Chem. 101, 1067 (1989); Angew. Chem. Int. Ed. Engl, 28, 1049 (1989).

[957] Coffy, T. J., Medford, G., Plotkin, J., Long, G. J., Huffman, J. C., and Shore, S. G., Organometallics 8, 2404 (1989).

[958] Mirkin, C. A., Lu, K.-L., Geoffroy, G. L., and Rheingold, A. L., J. Am. Chem. Soc. 112, 461 (1990).

[959] Sacconi, L., and Manī, F., Transition Met. Chem. 8, 179 (1982).

[960] Bianchini, C., Mealli, C., Meli, A., and Sabat, M., in Stereochemistry of Organometallic and Inorganic Compounds, Bernal, I., Ed., Elsevier, Amsterdam-New York, Vol. 1, p. 146 (1986).

[961] Bianchini, C., Comments Inorg. Chem. 8, 27 (1988).

[962] Bianchini, P., and Ramirez, J. A., Organometallics 9, 226 (1990) and important references therein 1-12.

[963] Meek, D. W., in Homogeneous Catalysis with Mctal Phosphine Complcxes, Pignolct, L. H., Ed., Plenum Press, New York, p. 257 (1983).

[964] Likam Wah, H., Postel, M., and Pierrot, M., Inorg. Chim. Acta 165, 215 (1989).

[965] Garrou, P. E., Chem. Rev. 85, 171 (1985).

[966] Hogarth, G., Knox, S. A. R., and Turner, M. L., J. Chem. Soc. Chem. Commun. 145 (1990).

[967] Durfee, L. D., and Rothwell, I. P., Chem. Rev. 88, 1059 (1988).

[968] Cardaci, G., Bellachioma, G., and Zanazzi, P., Organometallics 7, 172 (1988).

[969] Jablonski, C., Bellachioma, G., Cardaci, G., and Reichenbach, G., J. Am. Chem. Soc. 112, 1632 (1990).

[970] Walsh, P. J., Hollandcr, F. J., and Bcrgmann, R. G., J. Am. Chem. Soc. 110, 8729 (1988).

[971] Gagne, M. R., and Marks, T. J., J. Am. Chem. Soc. 111, 4108 (1989).

[972] Schaad, D. R., and Landis, C. R., J. Am. Chem. Soc. 112, 1628 (1990).

[973] Miller, J. S., Ed., Extended Linear Chain Compounds, Plcnum Publisher, New York, Vol. 1-3 (1981-1983).

[974] Simon, J., and Andre, J. J., Molecular Semiconductors, Springer Verlag, New York (1985).

[975] Carter, F., Ed., Molecular Electronic Devices, Marcel Dekker, New York (1982).

[976] Ward, M. D., and Calabrese, J. C., Organometallics 8, 593 (1989).

[977] Miller, J. S., Epstein, A. J., and Rciff, W. M., Chem. Rcv. 88, 201 (1988).

[978] Miller, J. S., Glatzhofer, D. T., O'Hare, D. M., Reiff, W. M., Chakraborty, A., and Epstein, A. J., Inorg. Chem. 28, 2930 (1989).

[979] Miller, J. S., Calabrese, J. C., Rommelmann, H., Chittapeddi, S. R., Zhang, J. H., Reiff, R. W., and Epstein, A. J., J. Am. Chem. Soc. 109, 769 (1987).

[980] Miller, J. S., Glatzhofer, D. T., Calabrese, J. C., and Epstein, A. J., J. Chem. Soc. Chem. Commun. 322 (1988).

[981] Sarel, S., Avramovic-Grisaru, S., Bauminger, E. R., Felner, I., Nowik, I., Williams, R. J. P., and Hughes, N. P., Inorg. Chem. 28, 4183 (1989).

[982] Spencer, A., in Comprehensive Coordination Chemistry, Wilkinson, G., Ed., Pergamon Press, New York, Vol. 6, p. 231 (1987).

[983] Bianchini, C., Meli, A., Peruzzi, M., Vizza, F., Zanobini, F., and Frediani, P., Organomctallics 8, 2080 (1989).

[984] Czekay, G., Eller, K., Schröder, D., and Schwarz, H., Angew. Chem. 101, 1306 (1989); Angew. Chem. Int. Ed. Engl. 28, 1277 (1989).

[985] Shackelton, T. A., and Baird, M. C., Organometallics 8, 2225 (1989).

[986] Kuroda, Y., Tanaka, N., Goto, M., and Sakai, T., Inorg. Chem. 28, 997 (1989).

[987] Maliyackcl, A. C., Waltz, W. L., Lilie, J., and Woods, R. J.. Inorg. Chem. 29, 340 (1990).

[988] McGarvey, J. J., Lawthers, I., Heremans, K., and Toftlud, H., Inorg. Chem. 29, 252 (1990).

[989] Roger, C., and Lapinte, J. Chem. Soc. Chem. Commun. 1598 (1989).

[990] Amendola, P., Antoniutti, S., Albertin, G., Bordignan, E., Inorg. Chem. 29, 318 (1990).

[991] Sabo-Etienne, S., Larsonneur, A.-M., and des Abbayes, H., J. Chem. Soc. Chem. Commun. 1671 (1989).

[992] Rossell, O., Seco, M., and Jones, P. G., Inorg. Chem. 29, 348 (1990).

[993] Sullivan, E. P., Jr., and Strauss, S. H., Inorg. Chem. 28, 3093 (1989).

[994] Bernhardt, P. V., Hambley, T., and Lawrance, G. A., J. Chem. Soc. Chem. Commun. 553 (1989).

[995] Wallis, J. M., Müller, G., Riede, J., and Schmidbaur, H., J. Organomet. Chem. 369, 165 (1989).

[996] Hanson, B. E., J. Am. Chem. Soc. 111, 6442 (1989).

[997] Hanson, B. E., and Whitmire, K. H., J. Am. Chem. Soc. 112, 974 (1990).

[998] Piper, M. R. J., Stephenson, G. R., Taylor, R. J. K., Breen, C., Brooks, J. S., and Williams, G. L., J. Chcm. Soc. Chem. Commun. 1798 (1989).

[999] Keppeler, U., Deger, S.,, Lange, A., and Hanack, M., Angew. Chem. 99, 349 (1987); Angcw. Chem. Int. Ed. Engl. 26, 344 (1987).

[1000] Lee, G. M., and Weinreb, S. M., J. Org. Chem. 55, 1281 (1990).

[1001] Pruchnik, F. P., Organometallic Chemistry of Transition Elements, Plenum Press, New York (1990).

[1002] McCormick, J. M., and Solomon, E. I., J. Am. Chem. Soc. 112, 2005 (1990). 
[1003] Byrn, M. P., Curtis, C. J., Khan, S. I., Sawin, P. A., Tsurumi, R., and Strouse, C. E., J. Am. Chem. Soc. 112, 1865 (1990). On physical mcasurements of iron porphyrins that includc magnetic circular dichroism spectroscopy, Mössbauer spect roscopy, and x-ray absorption spectroscopy, see Levcr, A. B. P. and Gray, H. B. (Eds.) Iron Porphyrins Part 3. Physical Bioorganic Chcmistry 4, VCH Publishers, New York, 1989; see also Iron Porphyrins Part 1 and Part 2 published in 1983.

[1004] Gueutin, C., Lexa, D., Momenteau, M., and Savéant, J.-M., J. Am. Chem. Soc. 112, 1874 (1990).

[1005] Huang, Y., and Freiser, B. S., J. Am. Chem. Soc. 112, 1682 (1990).

[1006] Raymond, K. N., Müllcr, G., and Matzanke, B. F., Top. Curr. Chem. 123, 49 (1984); Borgias, B. A., Hugi, A. D., and Raymond, K. N., Inorg. Chem. 28, 3538 (1989).

[1007] Matzanke, B. F., Müller-Matzanke, G., and Raymond, K. N., Physical Bioinorganic Chemistry, VCH Publishers, Deerfield Beach (1989).

[1008] Hahn, F. E., McMurry, T. J., Hugi, A., and Raymond, K. N., J. Am. Chem. Soc. 112, 1854 (1990) and references therein.

[1009] Casey, C. P., Chem. Scr. 27, 501 (1987).

[1010] Casey, C. P., Meszaros, M. W., Fagan, P. J., Bly, R. K., Marder, S. R., and Austin, E. A., J. Am. Chem. Soc. 108, 4043 (1986).

[1011] Casey, C. P., Gable, K. P., and Roddick, D. M., Organometallics 9, 221 (1990), and references therein.

[1012] Akita, M., Terada, M., Oyama, S., and Moro-oka, Y., Organometallics 9, 816 (1990).

[1013] Geoffroy, G. L., and Bassner, S. L., Adv. Organomet. Chem. 21, 1 (1988).

[1014] Xu, Y.-C., Challencr, C. A., Dragisich, V., Brandvold, T. A., Petersen, G. A., and Wulff, W. D., J. Am. Chem. Soc. 111, 7269 (1989).

[1015] Cho, S. H., and Liebeskind, L. S., J. Org. Chem. 52, 2631 (1987).

[1016] Alcock, N. W., Danks, T. N., Richards, C. J., and Thomas, S. E., J. Chem. Soc. Chem. Commun., 21 (1989).

[1017] Richards, C. J., and Thomas, S. E., J. Chem. Soc. Chem. Commun., 307 (1990).

[1018] Regitz, M., and Binger, P., Angew. Chem. 100, 1541 (1988); Angew. Chem. Int. Ed. Engl. 27,1484 (1988).

[1019] Nixon, J. F., Chcm. Rev. 88, 637 (1988).

[1020] Bingcr, P., Biedenbach, B., Schncidcr, R., and Regitz, M., Synthesis, 960 (1989).

[1021] Cutler, A,. Hanna, P. K, and Vites, J. C., Chem. Rev. 88, 1363 (1988), and references cited therein.

[1022] Bly, R. S., Silverman, G. S., and Bly, R. K., J. Am. Chem. Soc. 110, 7730 (1988). For a recent discussion on electrophilic, nucleophilic and amphiphilic metal carbene complexes, see Casey, C. P., Vosejpka, P. C., and Askham, F. R., J. Am. Chcm. Soc. 112, $3713(1990)$.

[1023] Brookhart, M., Studabaker, N. B., Hamphrey, M. B., and Husk, G. R., Organometallics 8, 132 (1989).

[1024] Guerchais, V., J. Chem. Soc. Chem. Commun. 534 (1990).

[1025] Zenneck, U., Angew. Chem. 102, 171 (1990); Angew. Chem. Int. Ed. Engl. 29, 126 (1990).

[1026] Channarcddy, S., Linti, G., and Nöth, H., Angcw. Chcm. 102, 222 (1990); Angcw. Chem. Int. Ed. Engl. 29, 199 (1990). For a recent book on inorganic photochemistry, see Ferraudi, G. J., Elements of Inorganic Photochemistry Wiley-Interscience, New York (1988).

[1027] Yanez, R., Ros, J., Solans, X., Font-Altaba, M., and Mathieu, R., Organometallics 9, 543 (1990).

[1028] Pilato, R. S., McGettigan, C., and Geoffroy, G. L., Organometallics 9, 312 (1990).

[1029] Scherhag, F., Käb, H., Bright, T. A., and Malisch, W., J. Organomet. Chem. 385, C27 (1990).

[1030] Darchen, A., Lhadi, E. K., Patin, H., Grandjean, D., and Mousser, A., J. Organomet. Chem. 385, C4 (1990).

[1031] Reuvers, J. G. A., and Takas, J., Organometallics 9, 578 (1990).

[1032] Brunct, J.-J., and Taillcfer, M., J. Organomet. Chcm. 384, 193 (1990).

[1033] Howell, J. A. S., Tirvengadum, M. C., and Walton, G., J. Organomet. Chem. 338, 217 (1988).

[1034] Pearson, A. J., Kole, S. L., and Ray, T., J. Am. Chem. Soc. 106, 6060 (1984).

[1035] Howell, J. A. S., Tirvengadum, M. C., Squibb, A. D., Walton, G., McArdle, P., and Cunningham, D., J. Organomet. Chem. 347, C5 (1988).

[1036] Howell, J. A. S., Squibb, A. D., Goldschmidt, Z., Gottlieb, H. E., Almadhoun, A., and Goldberg, I., Organometallics 9, 80 (1990).

[1037] Bosnich, A., Asymmetric Catalysis, NATO Series, Martinus Nijhoff, Dordrect (1986).

[1038] Slough, G. A., Bergmann, R. G., and Heathcock, C. H., J. Am. Chem. Soc. 111, 938 (1989).

[1039] Werner, H., and Erker, G., (Eds.), Organometallics in Organic Synthesis 2, Springer-Verlag, New York and Berlin (1989).

[1040] Togni, A., and Pastor, S. D., J. Org. Chem. 55, 1649 (1990).

[1041] Brunner, H., J. Organomet. Chem. 300, 39 (1986).

[1042] Deus, N., Hübener, G., and Herrmann, R., J. Organomet. Chem. 384, 155 (1990).

[1043] Zhang, W., Loebach, J. L., Wilson, S. R., and Jacobsen, E. N., J. Am. Chem. Soc. 112, 2801 (1990).

[1044] Davies, H. G., Green, R. H., Kelly, D. R., and Roberts, S. M, Biotransformations in Preparative Organic Chemistry: The Usc of Isolated Enzymes and Whole Cell Systems in Organic Synthesis, Academic Press, New York (1989).

[1045] Klibanov, A. M., Acc. Chem. Rcs. 23, 114 (1990).

[1046] Macfarlane, E. L. A., Roberts, S. M., and Turncr, N. J., J. Chcm. Soc. Chem. Commun. 569 (1990).

[1047] Sonnet, P. E., J. Org. Chem. 52, 3477 (1987); Hiratake, J., Inagaki, M., Noshioka, T., and Oda, H., ibid., 53, 6130 (1980).

[1048] Chen, C.-S., and Sih, C. J., Angew. Chem. 101, 711 (1989); Angew. Chem. Int. Ed. Engl. 28, 695 (1989), and references thcrcin.

[1049] Ottolina, G., Carrea, G., and Riva, S., J. Org. Chem. 55, 2366 (1990); Riva, S., Bovara, R., Ottolina, G., Secundo, F., and Carrea, G., ibid., 54, 3161 (1989).

[1050] Klibanov, A. M., CHEMTECH 16, 354 (1986).

[1051] Wang, Y.-F., Lalondc, J. J., Momogan, M., Bergbreiter, D. E., and Wong, C.-H., J. Am. Chem. Soc. 110, 7200 (1988).

[1052] Boaz, N. W., Tetrahedron Lett. 30, 2061 (1989).

[1053] Chanon, M., Acc. Chem. Res. 20, 214 (1987). 
[1054] Kochi, J. K., J. Organomet. Chem. 300, 139 (1986).

[1055] Astruc, D., Angew. Chem. 100, 662 (1988); Angew. Chem. Int. Ed. Engl. 27, 643 (1988). See also Schermann, J. P., Astruc, J. P., Desfrancois, C., and Barbe, R., in Photoinduced Electron Transfer, Fox, M. A., and Chanon, M. (Eds.), Elsevier Publishers, Amsterdam (1988), Part A, Chapter 2.

[1056] Connelly, N. G., and Geiger, W. E., Adv. Organomet. Chem. 23, 1 (1984).

[1057] Eberson, L., Electron Transfer in Organic Chemistry, Springer Verlag, Berlin (1987) p. 101.

[1058] Astruc, D., Lacoste, M., and Toupet, L., J. Chem. Soc. Chem. Commun., 558 (1990).

[1059] Verpeaux, J.-N., Desbois, M.-H., Madonik, A., Amatore, Ch., and Astruc, D., Organometallics 9, 630 (1990).

[1060] Mandon, D., and Astruc, D., Organometallics 9, 341 (1990). More on double- and triple-decker sandwich complcxcs, see Davis, J. H., Jr., Attwood, M. D., and Grimes, R. N., Organometallics 9, 1171 (1990); Attwood, M. D., Davis, J. H., Jr., and Grimes, R. N., ibid., 9, 1177 (1990).

[1061] Hisatome, M., Watanabe, J., Kawajiri, Y., Yamakawa, K., Organometallics 9, 497 (1990).

[1062] Hall, C. D., Danks, I. P., Lubienski, M. C., and Sharpe, N. W., J. Organomet. Chem 384, 139 (1990). More on metallocenecontaining cryptands, see Hall, C. D., and Sharpe, N. W., Organometallics 9, 952 (1990).

[1063] Kobayashi, N., and Opallo, M., J. Chem. Soc. Chem. Commun., 477 (1990). For recent reviews on cyclodextrin inclusion compounds of transition-metal complexes, see Stoddart, J. F., and Zarzycki, R., Recl. Trav. Chim. Pays-Bas 107, 515 (1988); Sokolov, V. I., Metallorg. Chim. 1, 25 (1988); Klingert, B., and Rihs, G., Organometallics 9, 1135 (1990).

[1064] Milberg, C.I., Rao, S.J., and Petter, R. C., Abstracts of Papers, 199th National Meeting of the American Chemical Society, Boston, Mass (1990), ORGN 188. For an cxcellent book on supramolecular chemistry, see Vögte, F., Supramolecularc Chemie, Teubner, Stuttgart (1989).

[1065] Brown, K. N., Field, L. D., Lay, P. A., Lindall, C. M., and Masters, A. F., J. Chem. Soc. Chem. Commun. 408 (1990).

[1066] Kovac, S., and Rapic, V., J. Organomet. Chem. 384, 147 (1990).

[1067] Kuhn, N., and Lampe, E.-M., J. Organomet. Chem. 385, C9 (1990).

[1068] Wang, Y.-P., and Hwu, J.-M., J. Organomet. Chem. 385, 61 (1990).

[1069] Knox, G. R., Pauson, P. L., Willison, D., Solcániova, E., and Toma, S., Organometallics 9, 301 (1990).

[1070] Zakrzewski, J., and Giannotti, C., J. Organomet. Chem. 385, C23 (1990).

[1071] Wright, M. E., Organometallics 9, 853 (1990).

[1072] Slocum, D. W., Edgecombe, A. L., Fowler, J. S., Gibbard, H. F., and Phillips, J. Organometallics 9, 307 (1990). For a synthesis of thiobenzoylferrocenes, see Barnes, J. C., Bell, W., Glidewell, C., and Howie, R. A., J. Organomet. Chem. 385, 369 (1990).

[1073] Chamizo, J. A., Ruiz-Mazön, M., Salcedo, R., and Toscano, R. A., Inorg. Chem. 29, 879 (1990).

[1074] Reference 556, Chapter 8, pp. 273-314.

[1075] Lavallee, D. K., The Chemistry and Biochemistry of N-substituted Porphyrins, VCH Publishers, New York, 1987, Chapter 7, pp. 181-207, 209-260.

[1076] Collman, J. P., Hampton, P. D., and Brauman, J. I., J. Am. Chem. Soc. 112, 2977 (1990); 112, 2986 (1990).

[1077] Hill, C. L., Adv. Oxygenated Processcs 1, 1 (1988); Bruice, T. C., Adrichimica Acta 21, 87 (1989); Jorgenson, K. A., Chem. Rev. 89, 431 (1989); Mansuy, D., and Battioni, P., in Activation and Functionalization of Alkanes, Hill, C. H. (Ed.), WileyInterscience, New York (1989), p. 195; Collman, J. P., Tanaka, H., Hembre, R. T., and Brauman, J. I., J. Am. Chem. Soc. 112, 3689 (1990); Guengerich, I. P., and Macdonald, T. L., Acc. Chem. Res. 17, 9 (1984).

[1078] Black, S. D., and Coon, M. J., Adv. Enzymol. Relat, Areas Mol. Biol. 60, 37 (1987).

[1079] Dawson, J. H., Science (Washington, DC) 240, 433 (1988); Tabushi, I., Coord. Chem. Rev. 86, 1 (1988); Groves, J. T., and Neumann, R., J. Am. Chem. Soc. 111, 2900 (1989).

[1080] Benson, D. R., Valentekovich, R., and Diederich, F., Angew. Chem. 102, 213 (1990); Angew. Chem. Int. Ed. Engl. 29, 191 (1990).

[1081] Dickerson, R. E., and Timkovich, R., in the Enzymes, 3rd ed., Boyer, J., Ed., Academic Press, New York, 1975 , Vol. 11 , p. 397.

[1082] Therien, M. J., Selman, M., Gray, H. B., Chang, I-Jy, and Winkler, J. R., J. Am. Chem. Soc. 112, 2420 (1990) and references therein; sec also Burch, A. M., Rigby, E. J., Funk, W. D., MacGillivray, R. T. A., Mauk, M. R., Mauk, A. G., and Moore, G. R., Science (Washington, DC) 247, 831 (1990) and referenees therein.

[1082a] Malmström, Bo G., Chem. Rev. 90, 1247 (1990).

[1083] Weishaupt, K. R., Gomer, C. J., and Dougherty, T. J., Cancer Res. 36, 2326 (1976).

[1084] Pandey, R. K., and Dougherty, T. J., Cancer Res. 49, 2042 (1989).

[1085] Pandey, R. K., Majchrycki, D. A., Smith, K. M., and Dougherty, T. J., SPIE Proc. 165, 1065 (1989).

[1086] Shiau, F.-Y., Pandey, R. K., Ramaprasad, S., Dougherty, T. J., and Smith, K. M., J. Org. Chem. 55, 2190 (1990).

[1087] Manka, J. S., and Lawrence, D. S., J. Am. Chem. Soc. 112, 2440 (1990).

[1088] Manka, J. S., and Lawrence, D. S., Abstracts of Papers, 199th National Meeting of the American Chemical Society, Boston, MASS (1990), ORGN 186.

[1089] Gust, D., Moore, T. A., Moore, A. L., Lee, S.-J., Bittersmann, E., Luttrull, D. K., Rehms, A. A., DeGraziano, J. M., Ma, X. C., Gao, F., Belford, R. E., and Trier, T. T., Science (Washington, DC) 248, 199 (1990).

[1090] Augusto, O., Kunze, K. L., Ortiz de Montcllano, P. R., J. Biol. Chem. 257, 6231 (1982).

[1091] Shin, K., Yu, B.-S., and Goff, H. M., Inorg. Chem. 29, 889 (1990).

[1092] Kim, K., Fettinger, J., Sessler, J. L., Cyr, M., Hugdahl, J., Collman, J. P., and Ibers, J. A., J. Am. Chem. Soc. 111, 403 (1989).

[1093] Li, X.-Y., Czernuszewicz, S., Kincaid, J. R., and Spiro, T. G., J. Am. Chem. Soc. 111, 7012 (1989).

[1094] Baltzer, L., and Landergren, M., J. Am. Chcm. Soc. 112, 2804 (1990).

[1095] Brewer, C., J. Chem. Soc. Chem. Commun. 344 (1990); Arasasingham, R. D., and Bruice, T. C., Inorg. Chem. 29, 1422 (1990).

[1096] Sessler, J. L, Cyr, M. J., Lynch, V., McGhee, E., and Ibers, J. A., J. Am. Chem. Soc. 112, 2810 (1990) and references therein.

[1097] Landergren, M., and Baltzer, L., Inorg. Chcm. 29, 556 (1990). 
[1098] Kugimiya, S., J. Chem. Soc. Chem. Commun. 432 (1990); Rodriguez, R. E., Woo, F. S., Huckaby, D. A., and Kelly, H. C., Inorg. Chem. 29, 1434 (1990).

[1099] Aoyama, Y., Asakawa, M., Yamagishi, A., Toi, H., and Ogoshi, H., J. Am. Chem. Soc. 112, 3145 (1990).

[1099a] On molecular recognition with model systems, sec an excellent review by Rebek, J., Jr., Angcw. Chem. 102, 261 (1990); Angew. Chem. Int. Ed. Engl. 29, 245 (1990); Rebek, J., Jr., Pure Appl. Chem. 61, 1517 (1989); Tadayoni, B. M., Parris, K., and Rebek, J., Jr., J. Am. Chem. Soc. 111, 4503 (1989); Ballester, P., Tadayoni, B. M., Branda, N., and Rebek, J., Jr., J. Am. Chem. Soc. 112, $3685(1990)$.

[1100] Shin, K., and Goff, H. M., J. Chem. Soc. Chem. Commun., 461 (1990).

[1101] Nanthakumar, A., and Goff, H. M., Inorg. Chem. 28, 4559 (1989).

[1102] Chen, S.-M., and Su, Y. O., J. Chem. Soc. Chem. Commun., 491 (1990).

[1103] Balch, A. L., Cornman, C. R., and Olmstead, M. M., J. Am. Chem. Soc. 112, 2963 (1990).

[1104] Arassingham, R. D., Balch, A. L., and Latos-Grazynski, L., in The Role of Oxygen in Chemistry and Biochemistry, Ando, W., and Moro-Oka, Y., (Eds.), Elsevier Publishers, New York (1988) p. 417.

[1105] Mu, X. H., and Kadish, K. M., Inorg. Chem. 29, 1031 (1990).

[1106] Rohmer, M.-M,. Inorg. Chem. 28, 4574 (1989).

[1107] Nasri, H., Goodwin, J. A., and Scheidt, W. R., Inorg. Chem. 29, 185 (1990).

[1108] Finnegan, M. G., Lappin, A. G., and Scheidt, W. R., Inorg. Chem. 29, 181 (1990).

[1109] Safo, M. K., Scheidt, W. R., and Gupta, G. P., Inorg. Chem. 29, 626 (1990).

[1110] Schappacher, M., Richard, L., Fischer, J., Weiss, R., Montiel-Montoya, R., Bill, E., and Trautwein, A. X., Inorg. Chem. 28, 4639 (1989).

[1111] Shiro, Y., Sato, F., Suzuki, T., Iizuka, T., Matsushita, T., and Oyanagi, H., J. Am. Chem. Soc. 112, 2921 (1990).

[1112] Nagata, T., Osuka, A., and Maruyama, K., J. Am. Chem. Soc. 112, 3054 (1990).

[1113] Van Berkcl, G. J., Glish, G. L., and McLuckcy, Anal. Chem. 62, 786 (1990).

[1114] Moser, H. A., and Dervan, P. B., Science (Washington, DC) 238, 645 (1987).

[1115] Mei, H. Y., and Barton, J. K., Proc. Natl. Acad. Sci. U.S.A. 85, 1339 (1988).

[1116] Cech, T. R., and Latham, J. A., Science (Washington, DC) 245, 276 (1989).

[1117] Tullins, T. D. (Ed.), Metal-DNA Chemistry, ACS Symposium Series No. 402, American Chemical Society, Washington, DC (1989).

[1118] Rana, T. M., and Mears, C. F., J. Am. Chem. Soc. 112, 2457 (1990).

[1119] Chio, S.-H., J. Biochcm. 94, 1259 (1983); Kim, K., Rhee, S. G., and Stadman, C. C., J. Biol. Chcm. 260, 5394 (1985).

[1120] Hayashi, O., (Ed.), Medical, Biochemical and Chemical Aspects of Free Radicals, Elsevier Publishers, Amsterdam and New York, Volumes 1 and 2 (1989).

[1121] Rabow, L. E., McGall, G. H., Stubbe, J.-A., and Kozarich, J. W., J. Am. Chem. Soc. 112, 3203 (1990); Rabow, L. E., Stubbe, J.-A., Kozarich, J. W., J. Am. Chcm. Soc. 112, 3196 (1990).

[1122] Baldwin, J. E. in Recent Advances in the Chemistry of $\beta$-Lactam Antibiotics, Bentlcy, P. H., and Southgate, R. (Eds.), Royal Society of Chemistry, London (1989), Chapter 1.

[1123] Que, L., Jr., in Iron Carriers and Iron Proteins, Loehr, T. M. (Ed.) VCH Publishers, New York-Weinheim (1989), Chapter 6.

[1124] Ming, L.-J., Que, L., Jr., Kriauciunas, A., Frolik, C. A., and Chen, V. J., Inorg. Chem. 29, 1111 (1990).

[1125] Chasteen, N. D., Adv. Inorg. Biochem. 5, 201 (1983).

[1126] Sola, M., Inorg. Chem. 29, 1113 (1990).

[1127] Hausinger, R. P., Microbiol. Rcv. 51, 22 (1987); Cammack, R., Adv. Inorg. Chem. 32, 297 (1988).

[1128] Eidncss, M. K., Scott, R. A., Prickril, B. C., Dcr Vartanian, D. V., LeGall, J., Moura, I., Moura, J. J. G., and Peck, H. D., Jr., Proc. Natl. Acad. Sci. U.S.A. 86, 147 (1989).

[1129] Krüger, H.-J., and Holm, R. H., J. Am. Chem. Soc. 112, 2955 (1990).

[1130] Alberts, B., Bray, D., Lewis, J., Raff, K. R., and Watson, J. D., Molecular Biology of the Ccll, Garland Publishers, New York (1983), pp. 121-127. Fox, S. W., and Dose, K., Molecular Evolution and the Origin of Life, Marcel Dekker, Inc. New York (1977); Chapters 1 and 6.

[1131] Saenger, W., Principles of Nucleic Acid Structure, Springer-Verlag, New York (1984) pp. 141-143.

[1132] Klug, A., Angew. Chem. 95, 612 (1983); Angew. Chem. Int. Ed. Engl. 22, 565 (1983); Boden, N., Chem. Britain 26, 345 (1990).

[1133] Challcn, P. R., Koo, S.-M., Dunham, W. R., and Coucouvanis, D., J. Am. Chem. Soc. 112, 2455 (1990); see also reference 793.

[1134] Holm, R. H., Chem. Soc. Rev. 10, 455 (1981).

[1135] Berg, J. M., and Holm, R. H., in Iron-Sulfur Protcins, Spiro, T. G. (Ed.), Wiley-Interscience, New York, Chapter 1 (1982).

[1136] Ciurli, S., Carrie, M., Weigel, J. A., Carney, M. J., Stack, T. D. P., Papaefthymiou, G. C., and Holm, R. H., J. Am. Chem. Soc. 112, 2654 (1990); see also rcfercnces 794, 796.

[1137] Saalfrank, R. W., Stark, A., Bremer, M., and Hummel, H.-U., Angew. Chem. 102, 292 (1990); Angew. Chem. Int. Ed. Engl. 29, 311 (1990); Beer, R. H., Tolman, W. B., Bott, S. G., and Lippard, S. J., Inorg. Chem. 28, 4557 (1989).

[1138] Wicghardt, K., Angew. Chem. 101, 1179 (1989); Angew. Chcm. Int. Ed. Engl. 28, 1153 (1989).

[1139] Beck, W. F., Sears, J., Brudvig, G. W., Kulawiec, R. J., and Crabtree, R. H., Tetrahcdron 45, 4903 (1989).

[1140] Lehn, J.-M., and Rigault, A., Angew. Chem. 100, 1121 (1988); Angew. Chem. Int. Ed. Engl. 27, 1095 (1988).

[1141] Rumin, R., Petillon, F,. Manojlovic-Muir, J,. and Muir, K. W., Organometallics 9, 944 (1990).

[1142] Touchard, D., Fillaut, J.-L., Dixneuf, P. H., Adams, R. D., and Segmüller, B. E., J. Organomet. Chem. 386, 95 (1990).

[1143] Beck, W., Knauer, W., and Robl, Ch., Angew. Chem. 102, 331 (1990); Angew. Chem. Int. Ed. Engl. 29, 318 (1990).

[1144] Scott, F., Kruger, G. J., Cronje, S., Lombard, A., Raubenhcimer, H., Bcnn, R., and Rufinska, A., Organometallics 9, 1071 (1990). 
[1145] Guerchais, V., Astruc, D., Nunn, C. M., and Cowley, A. H., Organometallics 9, 1036 (1990). For a pioneer preparation of iron-methylene complexes of the type $\left[\mathrm{Fe}\left(\mathrm{C}_{\mathrm{P}}\right)\left(\mathrm{L}_{1}\right)\left(\mathrm{L}_{2}\right)\left(\mathrm{CH}_{2}\right)\right]^{+}$see Jolly, P. W., and Pettit, R., J. Am. Chem. Soc. 88, 5044 (1966).

[1146] Wang, Y.-P., Shyu, R.-S., Hwu, J.-M., Wang, Yu, and Cheng, M.-C., J. Organomet. Chem. 386, 79 (1990).

[1147] Okuda, J., J. Organomet. Chem. 385, C39 (1990).

[1148] Mathur, P., and Reddy, V. D., J. Organomet. Chem. 385, 363 (1990).

[1149] Senechal, D., Senechal-Tocquer, M.-C., Le-Bihan, J.-Y., Gentric, D., and Caro, B., J. Organomet. Chem. 385 , C35 (1990).

[1150] Jablonski, C. R., and Wang, Y.-P., Organometallics 9, 318 (1990).

[1151] Tso, C. C., and Cutler, A. R., Inorg. Chem. 29, 471 (1990).

[1152] Sun, C.-H., Chow, T. J., and Liu, L.-K., Organometallics 9, 560 (1990).

[1153] Bly, R. S., Wu, R., and Bly, R. K., Organometallics 9, 936 (1990).

[1154] Buchanan, R. M., Mashuta, M. S., Richardson, J. F., Oberhausen, K. J., Hendrickson, D. N., Webb, R. J., and Nanny, M. A., Inorg. Chem. 29, 1299 (1990).

[1155] Boyd, S. E., Field, L. D., Hambley, T. W., and Young, D. J., Inorg. Chem. 29, 1496 (1990).

[1156] Tobita, H., Ueno, K., Shimoi, M., and Ogino, H., J. Am. Chem. Soc. 112, 3415 (1990).

[1157] Poganiuch, P., Decurtins, S., and Gütlich, P., J. Am. Chem. Soc. 112, 3270 (1990).

[1158] Meng, X., Fehlner, T. P., and Rheingold, A. L., Organometallics 9, 534 (1990).

[1159] Ribakove, E. C., and Kerber, R. C., Organometallics 9, 531 (1990).

[1160] Walker, J. D., and Poli, R., Inorg. Chem. 29, 756 (1990).

[1161] Bampos, N., and Field, L. D., Inorg. Chem. 29, 587 (1990).

[1162] Rossell, O., Seco, M., and Jones, P. G., Inorg. Chem. 29, 348 (1990).

[1163] Huang, Y., and Freiser, B. S., Inorg. Chcm. 29, 1102 (1990).

[1164] Conti, N. J., Crowther, D. J., Tivakornpannarai, S., and Jones, W. M., Organometallics 9, 175 (1990).

[1165] Guillot, G., Mulliez, E., Leduc, P., and Chottard, J.-C., Inorg. Chem. 29, 577 (1990).

[1166] Tweedy, H. E., Alcock, N. W., Matsumoto, N., Padolik, P. A., Stephenson, N. A., and Busch, D. H., Inorg. Chem. 29, 616 (1990).

[1167] Paeng, I. R., and Nakamoto, K., J. Am. Chem. Soc. 112, 3289 (1990).

[1168] Calhorda, M. J., and Vichi, E. J. S., Organometallics 9, 1060 (1990).

[1169] Murray, J. B., Nicholson, B. K., and Whitton, A. J., J. Organomet. Chem. 385, 91 (1990).

[1170] Qian, L., Singh, P., Ro, H.-K., and Hatfield, W. E., Inorg. Chem. 29, 761 (1990).

[1171] Doan, P. E., and McGarvey, B. R., Inorg. Chem. 29, 874 (1990).

[1172] Eckert, J., Blank, H., Bautista, M. T., and Morris, R. H., Inorg. Chem. 29, 747 (1990).

[1173] Altbach, M. I., Hiyama, Y., Wittebort, R. J., and Butler, L. G., Inorg. Chem. 29, 741 (1990).

[1174] Krusic, P. J., Morton, J. R., Preston, K. F., Williams, A. J., and Lee, F. L., Organometallics 9, 697 (1990).

[1175] Maliyackel, A. C., Waltz, W. L., Lilie, J., and Woods, R. J., Inorg. Chem. 29, 340 (1990).

[1176] Desbois, M.-H., Nunn, C. M., Cowley, A. H., and Astruc, D., Organometallics 9, 640 (1990).

[1177] Pannell, K. H., Cervantes, J., Parkanyi, L., and Cervantes-Lee, F., Organometallics 9, 859 (1990).

[1178] Churchill, M. R., and Fettinger, J. C., Organometallics, 9, 446 (1990).

[1179] Kulawiec, R. J., Faller, J. W., and Crabtree, R. H., Organometallics 9, 745 (1990).

[1180] Hurrell, H. C., and Abruna, H. D., Inorg. Chem. 29, 736 (1990).

[1181] Haynes, R. K., and Vonwiller, S. C., J. Chem. Soc. Chem. Commun., 449 (1990).

[1182] Schepartz, A., and Cuenoud, B., J. Am. Chem. Soc. 112, 3247 (1990).

[1183] Hoyer, D., Cho, H., and Schultz, P. G., J. Am. Chem. Soc. 112, 3249 (1990).

[1184] Braunstein, P., Matt, D., and Nobel, D., Chem. Rev. 88, 747 (1988).

[1185] Kurtz, D. M., Jr., Chem. Rev. 90, 585 (1990).

[1186] Carriedo, G. A., J. Chem. Educ. 67, 294 (1990).

[1187] Ward, R. S., Chem. Soc. Rev. 19, 1 (1990).

[1188] Behr, A., Organometallics, VCH Publisher, Weinheim (1989).

[1189] Fischer, H., Carbon Dioxide Activation by Metal Complexes, VCH Publisher, Weinheim (1988).

[1190] Hoffmann, R., Carbyne Complexes, VCH Publisher, Weinheim (1988).

[1191] Liebman, J. F., and Greenberg (Eds.), Structure and Reactivity, VCH Publisher, Weinheim (1988).

[1192] Trogler, W. C. (Ed.), Organometallic Radical Processes, Elsevier Publisher, Amsterdam-New York (1990).

[1193] Twigg, M. V. (Ed.), Mechanisms of Inorganic and Organometallic Reactions, Plenum Press, New York (1989), Vol. 6. Chemistry, London (1988).

[1194] Davidson, G., and Ebsworth, E. A. V., Spcctroscopic Propertics of Inorganic and Organometallic Compounds. The Royal Society of Chemistry, London (1988).

[1195] Copper, A., Houben, J. L., and Chien, L. C. (Eds.), The Enzyme Catalysis Process: Energetics, Mechanism, and Dynamics, Plenum Press, New York (1989), Vol. 178.

[1196] McCammon, J. A., and Harvey, S. C., Dynamics of Proteins and Nucleic Acids, Cambridge University, Cambridge and New York (1988).

[1197] Schneider, M. P. (Ed.), Enzymes as Catalysts in Organic Synthesis, Reidel, Dordrecht (1986).

[1198] Davies, H. G., Green, R. H., Kelly, D. R., and Roberts, S. M., Biotransformations in Preparative Organic Chemistry, Academic Press, New York (1989).

[1199] Mann, S., and Williams, R. J. P. (Eds.), Biomincralization: Chemical and Biochemical Perspectives, VCH Publisher, Weinheim (1989). 
[1200] Belter, P. A., Cussler, E. L., and Hu, W.-S., Bioseparations, John Wiley \& Sons, New York (1988).

[1201] Stenesh, J., Dictionary of Biochemistry and Molecular Biology, John Wilcy \& Sons, New York (1989).

[1202] Otsuka, S., and Yamanaka, T. (Eds.), Metalloprotcins. Chemical Propcrties and Biological Effects, Elsevicr Publishers, Amsterdam and New York (1988).

[1203] Bilsel, O., Rodriguez, J., Holten, D., Girolami, G. S., Milam, S. N., and Suslick, K. S., J. Am. Chem. Soc. 112, 4075 (1990).

[1204] Baciocchi, E., Crescenzi, M., and Lanzalunga, O., J. Chem. Soc. Chem. Commun. 687 (1990).

[1205] Nanthakumar, A., and Goff, H. M., J. Am. Chem. Soc. 112, 4047 (1990).

[1206] Natan, M. J., Kuila, D., Baxter, W. W., King, B. C., Hawkridge, F. M., and Hoffman, B. M., J. Am. Chem. Soc. 112, 4081 (1990).

[1207] Finn, M. G., and Sharpless, K. B., Asymmetric Synthesis, Morrison, J. D. (Ed.), Academic Press (1985), Vol. 5, Chapter 8, pp. 247-301; Holm, R. H., Chem. Rev. 87, 1401 (1987).

[1208] Bach, R. D., Coddens, B. A., McDoull, J. J. W., and Schlegel, H. B., J. Org. Chem. 55, 3325 (1990).

[1209] Heller, A., Acc. Chem. Res. 23, 128 (1990).

[1210] Lieber, C. M., Karas, J. L., Mayo, S. L., Albin, M., and Gray, H. B., Long Range Electron Transfer in Proteins XXI. Design of Enzymes and Enzyme Models. Proccedings of the Robcrt A. Welch Foundation Conferences on Chemical Research, The Welch Foundation, Houston (1987) pp. 9-24.

[1211] Cowan, J. A., and Gray, H. B., Chem. Scr. 28A, 21 (1988).

[1212] Cass, A. E. G., Davis, G., Green, M. J., and Hill, H. A. O., J. Electronal. Chem. Interfacial Electrochem. 190, 117 (1985); Yeh, P., and Kuwana, T., J. Electrochem. Soc. 123, 1334 (1976).

[1213] Cass, A. E. G., Davis, G., Francis, G. D., Hill, H. A. O., Aston, W. J., Higgins, I. J., Plotkin, E. V., Scott, L. D. L., and Turner, A. P. F., Anal. Chem. 56, 667 (1984).

[1214] Turner, A. P. F., Karube, I., and Wilson, G. S. (Eds.), Biosensors: Fundamentals and Applications, Oxford Univ. Press, Oxford (1987) pp. 723-746.

[1215] Murray, R. W., Dessy, R. E., Hcineman, W. R., Janata, J., and Seitz, W. R., (Eds.), Chcmical Sensors and Microinstrumentation ACS Symposium Series, No. 403, American Chemical Society, Washington, DC (1989).

[1216] Taniguchi, I., Redox Chemistry and Interfacial Bchavior of Biological Molccules, Dryhust, G., Niki, K. (Eds.), Plenum Publishcrs, New York (1988) pp. 113-124.

[1217] Hccht, S. M., Bleomycin: Chcmical, Biochemical and Biological Aspects, Hecht, S. M., (Ed.), Springer-Verlag, New York (1979) Chapter 1; Umezawa, H., Medicinal Chemistry Series: Anticancer Agents Based on Natural Products Models, Cassady, J. M. and Douros, S., (Eds.), Academic Press, New York (1980) Vol. XVI, p. 148 ff.

[1218] Hecht, S. M., Acc. Chem. Res. 19, 383 (1986).

[1219] Stubbe, J., and Kozarich, J. W., Chem. Rev. 87, 1107 (1987).

[1220] Kozarich, J. W., Worth, L., Frank, B. L., Christner, D. F., Vanderwall, D. E., and Stubbe, J., Science 245, 1396 (1989).

[1221] Burger, R. M., Bcrkowitz, A. R., Peisach, J., and Horwitz, S. B., J. Biol. Chem. 255, 11832 (1980).

[1222] Natrajan, A., Hecht, S. M., van der Marel, G. A., and van Boom, J. H., J. Am. Chem. Soc. 112, 3997 (1990); Barr, J. R., van Atta, R. B., Natrajan, A., and Hecht, S. M., J. Am. Chem. Soc. 112, 4058 (1990); Natrajan, A., Hecht, S. M., van der Marcl, G. A., and van Boom, J. H., J. Am. Chem. Soc. 112, 4532 (1990).

[1223] Mack, D. P., and Dervan, P. B., J. Am. Chem. Soc. 112, 4604 (1990); Mack, D. P., Iverson, B. L., and Dervan, P. B., J. Am. Chem. Soc. 110, 7572 (1988).

[1224] Lam, K.-Y., Fortier, D. G., Thomson, J. B., Sykes, A. G., J. Chem. Soc. Chem. Commun. 658 (1990).

[1225] Backes, G., Sahlin, M., Sjoberg, B.-M., Loehr, T. M., and Sandcrs-Lochr, J., Biochemistry 28, 1923 (1989).

[1226] Colbert, J. E., Katopodis, A. G., May, S. W., J. Am. Chem. Soc. 112, 3993 (1990).

[1227] Guengerich, F. P., and Macdonald, T. L., Acc. Chem. Res. 17, 9 (1984); Mansuy, D., Pure Appl. Chem. 59, 579 (1987); Dawson, J. H., and Sono, M., Chem. Rev. 87, 1255 (1987).

[1228] Hickman, D. L., Nanthakumar, A., and Goff, H. M., J. Am. Chem. Soc. 110, 6384 (1988); Sugimoto, H., Tung, H.-C., and Sawyer, D. T., J. Am. Chem. Soc. 110, 2465 (1988).

[1229] Czernuszewicz, R. S., and Macor, K. A., J. Raman Spectrosc. 19, 553 (1988); see also Macor, K. A., Czernuszewicz, R. S., and Spiro, T. G., Inorg. Chem. 29, 1996 (1990).

[1230] Kincaid, J. R., Schneider, A. J., and Paeng, K. J., J. Am. Chem. Soc. 111, 735 (1989); DeVito, V. L., and Asher, S. A., J. Am. Chem. Soc. 111, 9143 (1989).

[1231] Tetreau, C., Momenteau, M., and Lavalette, D., Inorg. Chem. 29, 1727 (1990); Ansari, A., Dilorio, E. E., Dlott, D. D., Frauenfelder, H., Iben, I. E., Langer, T., Roder, H., Sauke, T. B., and Shyamsunder, E., Biochemistry 25, 3139 (1986).

[1232] Groves, J. T., and Neumann, R., J. Am. Chem. Soc. 109, 5045 (1987); van Esch, J., Roks, M. F. M., and Nolte, R. J. M., ibid., 108, 6093 (1986).

[1233] Reddi, E., and Jori, G., Rev. Chem. Interm. 10, 241 (1988).

[1234] van Esch, J. H., Peters, A.-M. P., and Nolte, R. J. M., J. Chem. Soc. Chem. Commun. 638 (1990).

[1235] Arasasingham, R. D., Balch, A. L., Cornman, C. R., de Ropp, J. S., Eguchi, K., and LaMar, G. N., Inorg. Chem. 29, 1847 (1990).

[1236] Groves, J. T., and Nemo, T. E., J. Am. Chem. Soc. 105, 5786 (1983).

[1237] McMurry, T. J., and Groves, J. T., in reference 556, pp. 1-28.

[1238] Groves, J. T., and Myers, R. S., J. Am. Chem. Soc. 105, 5794 (1983).

[1239] Renard, J. R., Battioni, J.-P., and Mansuy, D., Nouv. J. Chim. 11, 279 (1986); Mansuy, D., Devocelle, L., Artaud, I., and Battioni, J.-P., Nouv. J. Chim. 9, 216 (1985).

[1240] Groves, J. T., and Neumann, R., J. Am. Chcm. Soc. 109, 5054 (1987).

[1241] Groves, J. T., and Neumann, R., J. Org. Chem. 53, 3891 (1988). 
[1242] Groves, J. T., and Viski, P., J. Org. Chem. 55, 3628 (1990).

[1243] Murguia, M. A., Borchardt, D., and Wherland, S., Inorg. Chem. 29, 1982 (1990).

[1244] Pinkerton, M. J., LeMest, Y., Zhang, H., Watanabe, M., and Murray, R. W., J. Am. Chem. Soc. 112, 3730 (1990).

[1245] Broussier, R., DaRold, A., Gautheron, B., Dromzee, Y., and Jeannin, Y., Inorg. Chem. 29, 1817 (1990).

[1246] Scherer, O. J., Blath, C., Wolmershäuser, G., J. Organomet. Chem. 287, C21 (1990).

[1247] Ketter, A., and Herrmann, R., J. Organomet. Chem. 386, 241 (1990).

[1248] Deus, N., Robles, D., and Herrmann, R., J. Organomet. Chem. 386, 253 (1990).

[1249] Lowery, M. D., Wittebort, R. J., Sorai, M., and Hendrickson, D. N., J. Am. Chem. Soc. 112, 4214 (1990).

[1250] Chidsey, C. E. D., Bertozzi, C. R., Putvinski, T. M., and Mujsce, A. M., J. Am. Chem. Soc. 112, 4301 (1990).

[1251] Sheldon, R. A., and Koch, J. K., Metal-Catalyzed Oxidations of Organic Compounds, Academic Press (1981).

[1252] Parshall, G. W., Homogeneous Catalysis, Wiley-Interscience, New York (1980).

[1253] Meunier, B., Bull. Soc. Chim. Fr. 578 (1986). On use of porphyrin analogue iron phthalocyanine oxidation catalyst, see Bäckvall, J.-E., Hopkins, R.B., Grennberg, H., Mader, M. M., and Awasthi, A. K., J. Am. Chem. Soc. 112, 5160 (1990).

[1254] Collman, J. P., Brauman, J. I., Hampton, P. D., Naruta, Y., and Michada, T., Bull. Chem. Soc. Jpn. 61, 47 (1988). More on the topic, see Collman, J. P., Zhang, X., Hembre, R. T., and Brauman, J. I., J. Am. Chem. Soc. 112, 5356 (1990).

[1255] Herron, N., and Tolman, C. A., J. Am. Chem. Soc. 109, 2837 (1988); Mahy, J.-P., Bedi, G., Battioni, P. and Mansuy, D., Nouv. J. Chim. 13, 651 (1989).

[1256] Ling, K.-H.J., and Hanzlik, R. P., Biochem. Biophys. Res. Commun. 160, 844 (1989).

[1257] Mizutani, T., Yamamoto, K., and Tajima, K., Toxicol. Appl. Pharmacol. 69, 283 (1983).

[1258] Krowech, G., Caldera-Munoz, P. S., Straub, K, Castognoli, N., Jr., and Correia, M. A., Chem. Biol. Interact. 58, 29 (1986).

[1259] Myers, S. R., Blake, J. W., Flesher, J. W., Biochem. Biophys. Res. Commun. 151, 1441 (1988).

[1260] Hanzlik, R. P., and Ling, K.-H. J., J. Org. Chem. 55, 3992 (1990).

[1261] Van Atta, R. B., Long, E. C., Hecht, S. M., van der Marel, G. A., and van Boom, J. H., J. Am. Chem. Soc. 111, 2722 (1989); Shcpherd, R. E., Lomis, T. J., Koepsel, R. R., Hedge, R., and Mistry, J. S., Inorg. Chim. Acta 171, 139 (1990).

[1262] Long, E. C., Hecht, S. M., van der Marel, G. A., and van Boom, J. J., J. Am. Chem. Soc. 112, 5272 (1990).

[1263] Que, L., Jr., In Biological Applications of Raman Spectroscopy, Spiro, T. G. (Ed.), Wiley, New York (1988) Vol. 3, pp. 491-521.

[1264] Harris, D. C., and Aiscn, P., In Iron Carriers and Iron Proteins, Loehr, T. (Ed.), VCH, New York (1989) pp. 239-351; Sanders-Loehr, J., ibid, pp. 373-466, Que, L., Jr., ibid, 467-524.

[1265] Carrano, C. J., Carrano, M. W., Sharma, K., Backes, G., and Sanders-Loehr, J., Inorg. Chem. 29, 1865 (1990).

[1266] Samuelsson, B., Dahlen, S.-E., Lindgren, J. A., Rouzer, C. A., and Scrhan, C. N., Science 237, 1171 (1987); Samuelsson, B., and Funk, C. D., J. Biol. Chem. 264, 19469 (1989).

[1267] Zhang, P., and Kyler, K. S., J. Am. Chem. Soc. 111, 9241 (1989).

[1268] Cox, D. D., Benkovic, S. J., Bloom, L. M., Bradley, F. C., Nelson, M. J., Que, L., and Wallick, D. E., J. Am. Chem. Soc. 110, 2026 (1988).

[1269] Corey, E. J., Pure Appl. Chem. 59, 269 (1987).

[1270] Funk, M. O., Carroll, R. T., Thompson, J. F., Sands, R. H., and Dunham, W. R., J. Am. Chem. Soc. 112, 5375 (1990).

[1271] Bigwood, T., Delve, R., and Read, G., J. Chem. Soc. Chem. Commun. 776 (1990).

[1272] Micklitz, W., and Lippard, S. J., J. Am. Chem. Soc. 111, 6856 (1989).

[1273] Batsanov, A. S., Struchkov, Y. T., and Timko, G. A., Koord. Khim. 14, 266 (1988).

[1274] Burley, S. K., Wang, A. H.-J., Votano, J. R., and Rich, A., Biochemistry 26, 5091 (1987).

[1275] Carlstöm, A.-S., and Frejd, T., J. Org. Chem. 55, 4175 (1990); Synthesis 414 (1989).

[1276] Davies, S. G., Middlemiss, D., Nayor, A., and Wills, M., J. Chem. Soc. Chem. Commun. 797 (1990).

[1277] Dervan, P. B., Science 232, 464 (1986); Dervan, P. B., in Nucleic Acids and Molecular Biology, Eckstein, F., and Lilley, D. M. J., Eds., Springer-Verlag, Heidelberg (1988), Vol. 2, pp. 49-64.

[1278] Hertzberg, R. P., and Dervan, P. B., Biochemistry 23, 3934 (1984).

[1279] Youngquist, R. S., and Dervan, P. B., J. Am. Chem. Soc. 107, 5528 (1985).

[1280] Rahhal, S., and Richter, H. W., J. Am. Chem. Soc. 110, 3126 (1988).

[1281] Rush, J. D., and Koppenol, W. H., J. Am. Chem. Soc. 110, 4957 (1988).

[1282] Griffin, L. C., and Dervan, P. B., Scicnce 245, 967 (1989).

[1283] Horne, D. A., and Dervan, P. B., J. Am. Chcm. Soc. 112, 2435 (1990).

[1284] Strobel, S. A., and Dervan, P. B., Science 249, 73 (1990).

[1285] Lauffer, R. B., Antanaitis, B. C., Aisen, P., and Que, L., Jr., J. Biol. Chem. 258, 14212 (1983).

[1286] Sage, J. T., Xia, Y.-M., Debrunner, P. G., de Jersey, K. J., and Zerner, B., J. Am. Chem. Soc. 111, 7239 (1989).

[1287] Schepers, K., Bremer, B., Krebs, B., Henkel, G., Althaus, E., Mosel, B., and Müller-Warmuth, W., Angew. Chem. 102, 582 (1990); Angew. Chem. Int. Ed. Engl. 29, 531 (1990), and references cited therein.

[1288] Peerey, L. M., and Kostic, N. M., Biochemistry 28, 1861 (1989).

[1289] Yuan, X., Sun, S., and Hawkridge, F. M., J. Am. Chem. Soc. 112, 5380 (1990).

[1290] Hyshi, T., Kanehira, K., Hagihara, T., and Kumuda, M., J. Org. Chem. 53, 113 (1988); Pastor, S. D., and Togni, A., J. Am. Chem. Soc. 111, 2333 (1989); Tetrahedron Lett. 30, 1071 (1989).

[1291] Ugi, T., Rec. Chem. Progr. 30, 289 (1969).

[1292] Marquarding, D., Klysacek, H., Gokcl, G., Hoffmann, P., and Ugi, I., J. Am. Chem. Soc. 92, 5389 (1970).

[1293 Boaz, N. W., Tetrahedron Let. 30, 2061 (1989).

[1294] David, D. M., Kane-Maguire, L. A. P., and Pync, S. G., J. Chem. Soc. Commun. 888 (1990).

[1295] Baum, R., Chem. Engin. News 68, 21 (1990). 
[1296] Martin, J. H., Gordon, R. M., and Fitzwater, S. E., Nature 345, 156 (1990).

[1297] Webb, J., Biomineralization and Biological Metal Accumulation, Westbroek, P., and DcJong, E. W., Eds., Doredrecht, The Netherlands (1983), pp. 413-422.

[1298] Bonnett, R., Burke, P. J., and Reszka, A., Fuel 66, 515 (1987).

[1299] Latos-Grazynski, L., Balch, A. L., and LaMar, G. N., Adv. Chem. Ser. 201, 661 (1982); Bartini, I., and Luchinat, C., NMR of Paramagnetic Molecules in Biological Systems, Benjamin Cummings, Menlo Park, California (1986), p. 165; Sattelee, J. J., In Mctal Ions in Biological Systems, Siegel, H., Ed., Dckker, Ncw York (1987), Vol. 21, p. 121.

[1300] Bonnett, R., Czechowski, F., and Latos-Grazynski, L., J. Chem. Soc. Chem. Commun. 849 (1990).

[1301] Lavallee, D. K., The Chemistry and Biochemistry of $N$-Substituted Porphyrins, VCH, New York (1987).

[1302] Lever, P., and Gray, H. B., Eds., Iron Porphyrins, VCH, New York (1989).

[1303] Larock, R. C., Comprehcnsive Organic Transformations, VCH, New York (1989).

[1304] Braterman, P. S., Ed., Reactions of Coordinated Ligands: Volume 2, Plenum, New York and London (1989).

[1305] Yoshida, Z., Shiba, T., and Ohshiro, Y., Eds., New Aspects of Organic Chemistry, 1. Kodansha Ltd., Tokyo, Japan (1990).

[1306] Grebenik, P., Grinter, R., and Perutz, R. N., Chem. Soc. Rev. 17, 453 (1988).

[1307] Jutzi, P., Pure Appl. Chem. 61, 1731 (1989).

[1308] Borovkov, V. V., Evstigneeva, R. P., Strekova, L. N., Filippovich, E. I., and Khairutdnikov, R. F., Russ. Chem. Rev. 58, 602 (1989).

[1309] Wong, C. H., Science (Washington, DC) 244, 1145 (1989); see also Cregge, R. J., Wagner, E. R., Freedman, J., and Margolin, A. J., J. Org. Chem. 55, 4237 (1990).

[1310] Ohno, M., Pure Appl. Chem. 61, 581 (1989).

[1311] McMurry, T. J., Raymond, K. N., and Smith, P. H., Science (Washington, DC) 244, 938 (1989).

[1312] Trost, B. M., Pure Appl. Chcm. 60, 1615 (1988).

[1313] Yamamoto, H., Maruoka, K., Furuta, K., and Naruse, Y., Pure Appl. Chem. 61, 419 (1989).

[1314] Ojima, I., Clos, N., and Bastos, C., Tetrahedron 45, 6901 (1989); see also Brown, J. M., and Davics, S. G., Naturc 342,631 (1989).

[1315] Giese, B., Angew. Chem. 101, 993 (1989); Angew. Chem. Int. Ed. Engl. 28, 969 (1989).

[1316] Markovskii, L. N., and Romanenko, V. D., Tetrahedron 45, 6019 (1989).

[1317] Antonova, A. B., and Ioganson, A. A., Russ. Chcm. Rcv. 58, 693 (1989).

[1318] Pasynski, A. A., and Eremenko, I. L., Russ. Chem. Rev. 58, 181 (1989).

[1319] Zenneck, U., Angew. Chem. 102, 171 (1990); Angew. Chem. Int. Ed. Engl. 29, 126 (1990).

[1320] Davis, R., Durrant, J. L. A., Khazal, N. M. S., and Bittcrwolf, T. E., J. Organomet. Chem. 386, 229 (1990).

[1321] Davies, S. G., Smallridge, A. J., and Ibboston, A. J., Organomet. Chem. 386, 195 (1990).

[1322] Zakrzewski, J., and Giannotti, C., J. Organomet. Chem. 388, 175 (1990).

[1323] Yanez, R., Ros, J., Solans, S., Font-Bardia, M., and Mathieu, R., J. Organomet. Chem. 388, 169 (1990).

[1324] de Lange, P. P. M., Frühauf, H.-W., van Wijnkoop, M., Vrieze, K., Wang, Y., Heijdenrijk, D., and Stam, C. H., Organometallics 9, 1691 (1990).

[1325] Bly, R. S., and Raja, M., Organomctallics 9, 1500 (1990).

[1326] Ando, W., Choi, N., and Kabe, Y., J. Am. Chem. Soc. 112, 4574 (1990).

[1327] Barrau, J., Hamida, N.-B., Agrebi, H., and Satge, J. Inorg. Chem. 29, 1674 (1990).

[1328] Bringley, J. F., Fabre, J.-M., and Averill, B. A., J. Am. Chem. Soc. 112, 4577 (1990).

[1329] Kramer, A., and Lorenz, I.-P., J. Organomet. Chem. 388, 187 (1990).

[1330] Mathur, P., and Reddy, V. D., J. Organomet. Chem. 387, 193 (1990).

[1331] Katugin, A. S., Pasynskii, A. A., Eremenko, I. L., Vaśutinskaya, E. A., Struchkov, Yu. T., and Yanovsky, A. I., J. Organomet. Chem. 386, 225 (1990).

[1332] Conover, R. C., Park, J.-B., Adams, M. W. W., and Johnson, M. K., J. Am. Chem. Soc. 112, 4562 (1990).

[1333] Bruce, M. I., Corbin, P. E., Humphrey, P. A., Koutsantonis, G. A., Liddell, M. J., and Tiekink, E. R. T., J. Chem. Soc. Chem. Commun. 674 (1990).

[1334] Adam, M., Brimah, A. K., Fischer, R. D., and Xing-Fu. L., Inorg. Chcm. 29, 1595 (1990).

[1335] Caballero, C., Nuber, B., and Zieglcr, M. J., J. Organomet. Chem. 386, 209 (1990).

[1336] Gourdon, A., and Jeannin, Y., J. Organomet. Chem. 388, 195 (1990).

[1337] For a comprehensive survey of all aspects of the chemistry of phosphorus, and metal-phosphorus coordination of compounds, see Corbridge, D. E. C., Phosphorous, An Outline of its Chemistry, Biochemistry and Technology, Elsevier, Amsterdam-New York (1990).

[1338] Webb, R. J., Geib, S. J., Staley, D. L., Rheingold, A. L., and Hendrickson, D. N., J. Am. Chem. Soc. 112, 5031 (1990).

[1339] Tracey, A. A., Eriks, K., Prock, A., and Gicrig, W. P., Organometallics 9, 1399 (1990).

[1340] Mealli, C., and Proserpio, D. M., J. Organometal. Chem. 386, 203 (1990).

[1341] Huang, Y., and Freiser, B. S., J. Am. Chem. Soc. 112, 5085 (1990).

[1342] Bjarnason, A., and Taylor, J. W., Organometallics 9, 1493 (1990).

[1343] Lloret, F., Julve, M., Faus, J., Solans, X., Journaux, and Morgenstern-Badarau, I., Inorg. Chem. 29, 2232 (1990).

[1344] Collins, T. J., Kostka, K. L., Müunck, E., and Uffelman, E. S., J. Am. Chem. Soc, 112, 5637 (1990).

[1345] Voloshin, Y. Z., Kostromina, N. A., Nazarenko, A. Y., Inorg. Chim. Acta 170, 181 (1990).

[1346] Knorr, M., Piana, H., Gilbert, S., and Schubert, U., J. Organomet. Chem. 388, 327 (1990).

[1347] Uoto, K., Tomohiro, T., and Okuno, H.-Y., Inorg. Chim. Acta 170, 123 (1990).

[1348] Asperger, S., Pavlović, D., Kukrić, Z., and Sutić, D., Inorg. Chim. Acta 171, 5 (1990).

[1349] Ruiz, J., Lacostc, M., and Astruc, D., J. Am. Chem. Soc. 112, 5471 (1990). 
[1349a] Astruc, D., Acc. Chem. Res. 24, 36 (1991).

[1350] Kuhn, N., and Horn, E.-M., Inorg. Chim. Acta 170, 155 (1990).

[1351] Garg, B. S., and Kapur, L., Inorg. Chim. Acta 170, 177 (1990).

[1352] Hall, C. D., Danks, I. P., Hammond, P. J., and Sharpc, N. W., J. Organomet. Chem. 388, 301 (1990).

[1353] Imai, H., and Kyuno, E., Inorg. Chem. 29, 2416 (1990).

[1354] Konishi, K., Miyazaki, K., Aida, T., and Inoe, S., J. Am. Chem. Soc. 112, 5639 (1990).

[1355] Petter, W., Gramlich, V., Dommann, A., Vetsch, H., and Hulliger, F., Inorg. Chim. Acta 170, 5 (1990).

[1356] Bartczak, T. J., Latos-Grazynski, L., and Wyslouch, A., Inorg. Chim. Acta 171, 205 (1990).

[1357] Frey, M., Jenny, T. A., and Stoeckl-Evans, H., Organometallics 9, 1806 (1990).

[1358] Yañez, R., Ros, J., Solans, X., and Font-Bardia, M., J. Organomet. Chem. 389, 219 (1990).

[1359] Buchholz, D., Huttner, G., and Imhof, W., J. Orgnaomet. Chem. 388, 307 (1990); Buchholz, D., Huttner, G., Imhof, W., and Orama, O., ibid., 388, 321 (1990).

[1360] Butler, I. R., Gill, U., LePage, Y., Lindsell, W. E., and Preston, P. N., Organometallies 9, 1964 (1990).

[1361] Horváth, A., and Uzonyi, Zs., Inor. Chim. Acta 170, 1 (1990).

[1362] Richardson, D. R., Vitolo, L. M. W., Hefter, G. T., May, P. M., Clare, B. M., Webb, J., and Wilairat, P., Inorg. Chim. Acta 170, 165 (1990); Vitolo, L. M. W., Hefter, G. T., Clare, B. W., and Webb, J., ibid., 170, 171 (1990).

[1363] Liu, H.-Y., Eriks, K., Prock, A., and Giering, W. P., Organometallics 9, 1758 (1990).

[1364] Poli, R., Organometallics 9, 1892 (1990).

[1365] Figg, D. C., and Herber, R. H., Inorg. Chem. 29, 2170 (1990).

[1366] Marusak, R. A., Sharp, C., and Lappin, A. G., Inorg. Chem. 29, 2298 (1990).

[1367] Huang, Y., and Freiser, B. S., Inorg. Chem. 29, 2052 (1990).

[1368] Miller, J. S., Calabrese, J. C., Harlow, R. L., Dixon, D. A., Zhang, J. H., Reiff, W. M., Chittipeddi, S., Selover, M. A., and Epstein, A. J., J. Am. Chem. Soc. 112, 5496 (1990).

[1369] Mealli, C., and Proserpio, D. M., J. Organomet. Chem. 386, 203 (1990); J. Am. Chem. Soc. 112, 5484 (1990).

[1370] Yeh, M.-C. P., J. Chem. Soc. Chem. Commun. 897 (1990).

[1371] Oikawa, H., Ichihara, A., and Sakamura, S., J. Chem. Soc. Chem. Commun. 908 (1990).

[1372] Watanabe, Y., Takehira, K., Shimizu, M., Hayakawa, T., and Orita, H., J. Chem. Soc. Chem. Commun. 927 (1990).

[1373] Field, L. D., George, A. V., Hambley, T. W., Malouf, E. Y., and Young, D. J., J. Chem. Soc. Chem. Commun. 931 (1990).

[1374] Desbois, M.-H., and Astruc, D., J. Chem. Soc. Chem. Commun. 943 (1990).

[1375] Kimura, E., J. Coord. Chem. 15, 1 (1986); Melson, G. A., Ed., Coordination Chemistry of Macrocyclic Compounds, Plenum Press, New York (1979).

[1376] Cowan, J. A., and Sola, M., Inorg. Chem. 29, 2176 (1990).

[1377] McLuckey, S. A., VanBerkel. G. J., and Glish, G. L., J. Am. Chem. Soc. 112, 5668 (1990).

[1378] Oguar, T., Takahashi, S., Shinzawa-Ito, K., Yoshikawa, S., and Kitagawa, T., J. Am. Chem. Soc. 112, 5630 (1990).

[1379] Krstulovic, A. M., Ed., Chiral Scparations by HPLC, Ellis Norwood Limited, Chichester (1989).

About the Author: Dr. Alexander J. Fatiadi is a Research Chemist associated with the NIST Center for Analytical Chemistry, Organic Analytical Research Division, Biotechniques Group. He is the recipient of the Hillebrand Prize of the Chemical Society of Washington, the Intemational Scholar Award of the University of Strasbourg, France, and has an honorary D.Sc. from the World University of Arizona. 